\title{
Individual motives for (re-)distribution
}

Citation for published version (APA):

Meyer, F. (2019). Individual motives for (re-)distribution. [Doctoral Thesis, Maastricht University]. ROA. https://doi.org/10.26481/dis.20190220fm

Document status and date:

Published: 01/01/2019

DOI:

10.26481/dis.20190220fm

Document Version:

Publisher's PDF, also known as Version of record

\section{Please check the document version of this publication:}

- A submitted manuscript is the version of the article upon submission and before peer-review. There can be important differences between the submitted version and the official published version of record.

People interested in the research are advised to contact the author for the final version of the publication, or visit the DOI to the publisher's website.

- The final author version and the galley proof are versions of the publication after peer review.

- The final published version features the final layout of the paper including the volume, issue and page numbers.

Link to publication

\footnotetext{
General rights rights.

- You may freely distribute the URL identifying the publication in the public portal. please follow below link for the End User Agreement:

www.umlib.nl/taverne-license

Take down policy

If you believe that this document breaches copyright please contact us at:

repository@maastrichtuniversity.nl

providing details and we will investigate your claim.
}

Copyright and moral rights for the publications made accessible in the public portal are retained by the authors and/or other copyright owners and it is a condition of accessing publications that users recognise and abide by the legal requirements associated with these

- Users may download and print one copy of any publication from the public portal for the purpose of private study or research.

- You may not further distribute the material or use it for any profit-making activity or commercial gain

If the publication is distributed under the terms of Article $25 \mathrm{fa}$ of the Dutch Copyright Act, indicated by the "Taverne" license above, 
Individual motives for (re-)distribution 
(C) Frauke Meyer, Maastricht 2019

All rights reserved. No part of this publication may be reproduced, stored in a retrieval system, or transmitted in any form, or by any means, electronic, mechanical, photocopying, recording, or otherwise, without the prior permission in writing, from the author.

Published by ROA

Postbus 616

6200 MD Maastricht

ISBN: 978-90-5321-572-2

Printed in the Netherlands by Canon 


\section{Individual motives for (re-)distribution}

\section{DISSERTATION}

To obtain the degree of Doctor at Maastricht University, On the authority of the Rector Magnificus,

Prof. dr. Rianne M. Letschert in accordance with the decision of the Board of Deans, to be defended in public on

Wednesday February 20, 2019, at 12:00 hours

by

\section{Frauke Meyer}


Supervisor

Prof. dr. Thomas Dohmen

\section{Co-supervisor}

Dr. Martin Strobel

\section{Assessment Committee}

Prof. dr. Arno Riedl (chairman)

Dr. Kristof Bosmans

Dr. rer. pol. Marion Ott, RWTH Aachen

Prof. dr. Bertil Tungodden, NHH Norwegian School of Economics 


\section{Acknowledgements}

I thank all people who made my dedication to this thesis possible - through their professional support in terms of discussions, advice, and facilitation of this research opportunity at Maastricht University, and their personal support in terms of encouragement, listening, and time spent on taking care of my daughter Elena, and also Fritz and Henry.

I thank my supervisors Thomas Dohmen and Martin Strobel who supported me in pursuing the research of this thesis. Thank you Thomas for opening up the opportunity for the great experiments we run, especially the one in Tbilisi, for your support in attending many international conferences, courses, and workshops, and for being able to learn from your expertise in experimental economics, and your creativity. I admire your fast understanding of the big picture with which you were able to help me with every single question I approached you with. Thank you Martin for facilitating my research stay in San Diego and for advising me on many different research projects. I also thank Gari Walkowitz, Paul Smeets, and Thomas Dohmen as co-authors of my chapters. Thank you Gari for accompanying me with your valuable advice and as a friend during my research career. You already advised me during my master thesis and inspired me for the topic of basic needs. Thank you Paul for the great possibility of our experiment with Dutch millionaires, and for your valuable guidance during the process of this chapter.

I thank my colleagues at ROA and SBE for the many fruitful discussions and the great time during my PhD. Thank you Maria Polipciuc, Inge Hooijen, Ahmed Elsayed Mohamed, Kim van Broekhoven, and Alexander Dicks for being great office mates - even if in some cases only for a short period of time. Thank you Marion Collewet for sharing an office with me during my entire $\mathrm{PhD}$ at ROA - I could not have wished for better company. Thank you for accompanying me through challenging times, for teaching me the value of sighing occasionally, for statistical advice and fun talks. Thank you Ruud Gerards for many great espresso and talks about research and life. Thank you Christian Nauerz and Marion Collewet for our motivating team work in exploring individual reasoning processes.

And finally, my family: I thank my beloved husband Diego who encouraged and supported me during the whole time and who makes me smile every day. I am grateful to our wonderful daughter Elena who brings infinite joy to my life in ways that I never knew before. I also thank my mother Barbara and my brother Gerrit who are always there for me and help me wherever they can. 



\section{Contents}

$\begin{array}{lll}\text { CHAPTER I } & \text { Introduction } & 1\end{array}$

1.1 Motivation 1

1.2 Outline 3

CHAPTER II Satisfaction of basic needs as a fundamental distributional motive 5

2.1 Introduction 5

2.2 Conceptual framework and philosophical background $\quad 7$

2.3 Experiment 11

2.3.1 Design of the experiment 11

2.3.2 Motives and identification strategy 15

$\begin{array}{ll}2.3 .3 \text { Procedures } & 16\end{array}$

2.4 Results 17

2.4.1 Main results $\quad 17$

2.4.2 Robustness $\quad 29$

2.5 Qualitative data 33

2.6 Concluding remarks $\quad 34$

2.7 Appendix 36

CHAPTER III Basic needs at stake: Evidence from a high stakes experiment in Georgia $\quad 55$

3.1 Introduction $\quad 55$

$\begin{array}{ll}3.2 \text { Experiment } & 57\end{array}$

3.2.1 Identification strategy and design $\quad 57$

$\begin{array}{ll}3.2 .2 \text { Procedures } & 62\end{array}$

3.3 Results 63

3.3.1 Main choices: Basic needs satisfaction $\quad 65$

3.3.2 Isolation choices 68

3.3.3 BNS revisited: Income gap choices $\quad 72$

3.3.4 Predictions across games: Choice $24 \quad 73$

3.3.5 Heterogeneity $\quad 75$

$\begin{array}{ll}3.4 \text { Concluding remarks } & 78\end{array}$

$\begin{array}{ll}3.5 \text { Appendix } & 78\end{array}$

$\begin{array}{lll}\text { CHAPTER IV } & \text { Need games } & 109\end{array}$

$\begin{array}{ll}4.1 \text { Introduction } & 109\end{array}$

4.2 Experiment 110

4.2.1 Design 110

4.2.2 Identification strategy $\quad 112$

$\begin{array}{ll}4.2 .3 \text { Procedures } & 113\end{array}$

$\begin{array}{ll}4.3 \text { Results } & 114\end{array}$

4.4 Concluding discussion 118

$\begin{array}{ll}4.5 \text { Appendix } & 120\end{array}$ 
CHAPTER V Redistributional attitudes, preferences, and beliefs of the wealthy

$\begin{array}{ll}5.1 \text { Introduction } & 129\end{array}$

5.2 Research design $\quad 133$

5.2.1 Outline and sample 133

5.2.2 Redistributional attitudes $\quad 134$

5.2.3 Preferences for redistribution $\quad 135$

5.2.4 Beliefs 138

5.2.5 Source of wealth 138

$\begin{array}{ll}5.3 \text { Results } & 139\end{array}$

$\begin{array}{ll}\text { 5.3.1 Sample characteristics } & 139\end{array}$

5.3.2 Redistributional attitudes of the wealthy and subjects from the general population $\quad 140$

5.3.3 The role of preferences and beliefs 141

5.3.4 Source of wealth 145

5.4 Concluding remarks $\quad 150$

5.5 Appendix 153

$\begin{array}{lll}\text { CHAPTER VI } & \text { Concluding remarks } & 181\end{array}$

$\begin{array}{ll}\text { Bibliography } & 189\end{array}$

$\begin{array}{ll}\text { Valorization addendum } & 199\end{array}$

$\begin{array}{ll}\text { Curriculum Vitae } & 201\end{array}$

$\begin{array}{ll}\text { ROA Dissertation Series } & 203\end{array}$ 


\section{CHAPTER I}

\section{Introduction}

"[...] in a political democracy it is nearly impossible to implement any theory of justice without sufficient support from the general public. This support will depend on the citizens' own values and preferences. Empirical research on the acceptance of notions of justice by different social groups is therefore essential to understand the social environment in which policy decisions are taken." Gaertner and Schokkaert (2012, p.8)

\subsection{MOTIVATION}

The distribution of benefits and burdens among its members is one of society's most important issues. Inequality is a major concern of economic scholars ${ }^{1}$, policy makers ${ }^{2}$, and international organizations ${ }^{3}$, often portrayed by the increased divergence of pre-tax income or wealth owned by those at the top and the bottom of the income/wealth distribution. The topic is also at the heart of public discourse with newspapers discussing problems of rising inequality prominently. ${ }^{4}$ The recently published first "World Inequality Report" introduces changes in inequality levels as an issue that "challenge(s) our most basic and cherished notions of justice and fairness" (Alvaredo et al., 2017b, p.22). Norton and Ariely (2011) further document that people prefer a distribution of wealth that is more equal than the actual one.

1 See, for example, the World Inequality Database collecting and providing data on income and wealth inequality on a global level (https://wid.world/) coordinated by economists Facundo Alvaredo, Lucas Chancel, Thomas Piketty, Emmanuel Saez, and Gabriel Zucman, as well as numerous papers on topics of inequality published by the latter (see, e.g., Piketty and Saez, 2003; Saez and Zucman, 2016; Alvaredo et al., 2017a) and Thomas Piketty's bestseller "Capital in the twenty first century" (2014).

2 In 2013, ex-president of the United States of America Barack Obama described growing inequality as dangerous (The Washington Post, 2013). In 2017, the Social Democratic Party of Germany (SPD) lead its electoral campaign with the slogan "Time for more justice" (English translation from the German original "Zeit für mehr Gerechtigkeit"), one proposal being higher taxes on top incomes (Böcking, 2018).

3 The OECD, for example, has published a series of major reports on the issue of inequality in the last decade (see "Growing unequal" (OECD, 2008), "Divided we stand: Why inequalities keep rising" (OECD, 2011), and "In it together: Why less inequality benefits all" (OECD, 2015).

4 See, for example, Stellinga and de Koning (2017), Hagelücken (2017), Marinić (2018), Eidelson (2018). These inequalities are viewed as unfair. The German national television has aired a three-part documentation discussing the injustice of rising inequality in Germany at prime time. "Ungleichland" was aired on the public television channel WDR in 2018 and has received a lot of public attention (see, for example, Frank, 2018; Gertz, 2018; Küppers, 2018). 
In this thesis, I investigate individual motives for (re-)distribution. To alter the distribution of market incomes and wealth, governmental redistribution from richer to poorer members of the society is an important means to establish a more desirable distribution (Durante et al., 2014). Redistribution is achieved by tax and transfer systems, as well as by the provision of public goods such as education (Guillaud et al., 2017; Felbermayr et al., 2016; Dur and Teulings, 2003; Alvaredo et al., 2017a). The Gini index of incomes in the EU is reduced on average from almost 0.5 for market incomes to slightly below 0.3 after redistribution in 2017 (Niehues, 2018). ${ }^{5}$ In the US, in 2016, the Gini index after governmental redistribution was reduced by 23 percent as compared to the Gini index of market incomes (OECD, 2018a). Government spending on redistributive purposes comprises a huge share of total public expenditures. In the EU, in 2016, 41.2 percent of total government expenditure was spent on social protection alone (Eurostat, 2018). If expenditures on health and education with a large redistributional potential are included, this percentage rises to 66.7.

Not least due to this significant degree of governmental redistribution, redistribution policy that is just in the eye of society is indispensable for social cohesion (Alvaredo et al., 2017b). Whether such policies are perceived as just depends on people's fairness considerations. Gaertner and Schokkaert (2012) assert that "in a political democracy it is nearly impossible to implement any theory of justice without sufficient support from the general public. This support will depend on the citizens' own values and preferences" (p.8). Saez and Stantcheva (2016) emphasize the crucial role of society's distributional fairness concerns for the design and evaluation of optimal taxation. Frohlich and Oppenheimer (1992) note that fairness judgments can influence, for example, the perceived fairness of tax systems as mechanisms for implementing redistributive policies. This, in turn, can have severe impacts on the acceptance of these systems and, thereby, ultimately of the political regime. Empirically, people's distributional fairness concerns have been shown to be related to, among others, the probability of engaging in tax evasion (Barth et al., 2013), their political decisions (Fisman et al., 2017) and political orientations (Almås et al., 2017). ${ }^{6}$ It is therefore important to understand people's motives for redistribution (Gaertner and Schokkaert, 2012).

5 Data for EU SILC countries for which reliable data was available. The Gini index after redistribution is the Gini index of net incomes, i.e., market incomes minus taxes and social security contributions plus transfer payments (Niehues, 2018).

6 Barth et al. (2013) show that the fairness ideal to consider income based on work effort as fair and income based on other factors as unfair can explain the probability of justifying and actually engaging in tax evasion. Results of Fisman et al. (2017) reveal that subjects who are more inclined towards equality as opposed to efficiency are more likely to have given their vote to Barack Obama in the 2012 elections, and also to be a member of the Democratic Party. Almås et al. (2017) show that preferences to reward luck and effort are related to political orientation. 


\subsection{OUTLINE}

This thesis is comprised of two parts. In the first part (Chapter II-IV), I focus on the role of concerns for the fulfillment of basic human needs as a behavioral motive for (re-) distribution. Securing basic human needs is at the heart of social policies, e.g., social security systems and social law (see for example, SGB XII, AsylbLG (Germany), and Algemene Bijstandswet (Netherlands)) in which a minimum for subsistence and social participation is secured. I argue that people's support for these policies is likely to crucially depend on their willingness to secure the fulfillment of these needs on a societal level. Yet, the economics literature has paid little attention to basic needs fulfillment as an individual behavioral motive and focused instead on motives such as inequity aversion (e.g., Fehr and Schmidt, 1999; Engelmann and Strobel, 2004, 2005; Blanco et al., 2011), and the maximin principle (e.g., Charness and Rabin, 2002; Andreoni and Miller, 2002; Engelmann and Strobel, 2004, 2005). These motives also entail a concern for less well-off people in the society, but have different implications for redistribution policy. In this thesis, I formulate and extensively investigate concerns for basic needs satisfaction as a distributional motive, while disentangling it from other distributional concerns, such as inequity aversion, maximin, efficiency, and selfishness.

In Chapter II, I investigate whether basic needs satisfaction is a distributional principle in economic decisions, by analyzing incentivized choices between alternative payoff distributions in a laboratory experiment. At the same time, I also disentangle concerns for basic needs satisfaction from other distributional motives (maximin, efficiency, generosity, envy, and selfishness). Subjects make a series of choices in fiveperson dictator games. I find that basic needs satisfaction is a prevalent and important distributional concern. In line with other studies, I also find a high prevalence of choices in line with maximin concerns and selfishness. I show that these results are also robust to running the experiment with different incentive schemes (in a purely hypothetical setting and with increased stakes). My results further suggest that in situations in which both maximin and basic needs satisfaction make similar predictions - especially when it is a decision to fulfill all basic needs - the motive of basic needs satisfaction is likely to play an important role next to maximin.

Chapter III explores whether the motive of basic needs satisfaction is a behavioral driving force in decisions with (1) a real-world context (i.e., subjects are confronted with exactly the income amounts in the experiment in their everyday lives), (2) high stakes, and, most importantly, (3) the fulfillment of basic needs being at stake. For this purpose, I run an experiment based on the one in Chapter II in which subjects of a sample from the general population in Tbilisi (Georgia) decide about the distribution of actual monthly incomes between themselves and four other subjects from the same sample. I find that concerns for the satisfaction of basic needs play an important role in the motivation of subjects in this setting. The majority of subjects choose at least once in line with the motive in choices in which they have to forego utility in terms of other distributional motives, such as maximin, efficiency, generosity, envy, and selfishness. Furthermore, I show that people do not only care for the number of persons lifted above the threshold, but also for the overall amount of unfulfilled needs. Moreover, concerns for basic needs satisfaction 
elicited in this setting are predictive of helping people in need in a different choice context at the expense of subjects' own payoff. My findings also suggest that women have stronger concerns for the fulfillment of basic needs than men, but that the prevalence of the motive is independent of subjects' age and income.

In Chapter IV, I implement a variant of the dictator game - the need game - in which receivers are at risk of being eliminated from subsequent rounds of the experiment if their final payoffs fall short of a certain threshold. If less than two receivers remain in the game, it is stopped. By this, I introduce a strategic motive to satisfy the need of the receiver to reach the threshold. I find that the prevalence of behavior in line with concerns for basic needs satisfaction increases substantially. Even subjects displaying a considerable amount of self-interest in the choice experiment of Chapter II, choose to satisfy the receiver's need, even though this entails giving up half of the amount that they can distribute. I show that these results are unlikely to be explained by risk aversion or beliefs about other dictators' giving behavior. I conclude that the salience of the importance of the threshold amount for the receiver's - and ultimately also the group's - survival might have triggered dictators' desire to fulfill receivers' needs. Finally, I propose a modified version of the need game that can serve as a workhorse experiment in order to explore the motive of basic needs satisfaction further.

In the second part of this thesis (Chapter V), I investigate redistributional attitudes, preferences, and beliefs of millionaires and people from the general population. As noted by Gaertner and Schokkaert (2012), it is important to elicit "[...] the acceptance of notions of justice by different social groups [...] to understand the social environment in which policy decisions are taken." (p.8, emphasis added). Fisman et al. (2015) emphasize the importance of the differences in distributional preferences between those with political power and the general population in explaining the relation between preferences of the general population measured by researchers and actual policies. In this thesis, I assess attitudes towards redistribution in the field of a sample of Dutch millionaires and compare them to a sample from the general population in the Netherlands. In line with the literature, I find that the wealthy have a substantially less favorable attitude towards redistribution than people from the general population as measured by their political orientation, their general attitude towards income inequality, and their attitudes towards raising taxes on income or wealth. My results suggest that these differences are not due to differences in preferences to level income differences that stem from luck, or individual effort. I assess these preferences in an experiment in which subjects make a choice that has real monetary consequences for two workers who completed the same work assignment, but does not affect their own payoff. Instead, my findings indicate that these differences are driven by disparities in beliefs in the importance of hard work for success in life. Beliefs about the role of hard work might thus determine how similar preferences for redistribution translate into different redistributional decisions or attitudes. Moreover, assessing the relation between a millionaire's source of wealth and her beliefs suggests that differences between millionaires and subjects from the general population in these beliefs stem from differences in actual experienced social mobility. 


\section{CHAPTER II \\ Satisfaction of basic needs as a fundamental distributional motive ${ }^{7}$}

\subsection{INTRODUCTION}

Public expenditures, such as transfer payments, are often justified by the moral obligation to satisfy basic needs, such as food, clothing, and shelter. ${ }^{8}$ The International Labour Organization (ILO) recommends basic social security that guarantees that "all in need have access to [...] basic income security which [...] secure[s] effective access to goods and services defined as necessary at the national level" (ILO, 2012, p.3), and asserts that "basic income security should allow life in dignity" (ILO, 2012, p.4). Clearly, other motives that drive fairness norms also give rise to redistribution policy, but might have different implications for what policy is considered just. Since fairness judgments have a bearing on the acceptability and viability of social policy, and ultimately on social cohesion, the political debate of what is socially just should be based on an understanding of the prevalence of different motives for redistribution. This is not least because transfer payments are large - in 2016 countries in the European Union spent on average 19.1 percent of their GDP on social protection (Eurostat, 2018). ${ }^{9}$ Despite its importance, knowledge about the prevalence and relative importance of motives that give rise to redistribution is limited. In particular, little is known about the prevalence of the motive for basic needs satisfaction.

The economics literature has mainly focused on motives, such as inequity aversion,

7 This chapter is based on joint work Thomas Dohmen and Gari Walkowitz. The authors would like to thank participants of the 2013 Symposium on Economic Experiments in Developing Countries, the 2014 ESA International Meeting, the 4th ACCER Workshop on Cross-Cultural Experimental Economics Research, the Bay Area Experimental Economics Workshop 2015, the DUHR seminar at Maastricht University, the PhD seminar at the University of Cologne, the internal seminar at the Rady School of Management, the seminar of Economics and Management at Paderborn University, and in particular Martin Strobel, Alexander Cappelen, and Bertil Tungodden for helpful comments and suggestions. We are grateful to Kevin Breuer, Jonas Radbruch, Patrizia Stumper, and Katharina Peeters for excellent research assistance.

8 In the Netherlands, for example, social assistance has the purpose to cover the "necessary costs of living" (in Dutch: "noodzakelijke kosten van het bestaan" (see § 1, 6(a). ABW (Algemene Bijstandswet)). The German social security code specifies that social benefits have the purpose to guarantee the basic necessities for subsistence to everybody who cannot afford these necessities on her own in order to enable recipients to lead a decent human life (see $\S \S 1,27(1)$, 27a(l) SGB (Sozialgesetzbuch) XII).

9 Taking into account expenditures on health, this percentage rises to 26.2. 
which comprises generosity and envy (e.g., Fehr and Schmidt, 1999; Engelmann and Strobel, 2004, 2005; Blanco et al., 2011), the maximin principle (e.g., Charness and Rabin, 2002; Andreoni and Miller, 2002; Engelmann and Strobel, 2004, 2005), and efficiency (e.g., Charness and Rabin, 2002; Andreoni and Miller, 2002; Engelmann and Strobel, 2004, 2005; Fisman et al., 2015).

In this paper, we assess the prevalence of concerns for basic needs satisfaction in a framework that allows us to disentangle them from the above mentioned motives. While a small set of studies considers the role of basic needs fulfillment as drivers of behavior in dictator games (Brañas-Garza, 2006; Aguiar et al., 2008; Konow, 2010; Cappelen et al., 2013b) and in vignette studies (Konow, 2001; Gaertner et al., 2001; Faravelli, 2007; Weiss et al., 2017), it is not clear whether results in these studies are driven by a concern to fulfill basic needs or by other distributional motives, such as maximin or generosity. ${ }^{10} \mathrm{We}$ believe that it is crucial to disentangle these motives because they have very different implications for public policy. If maximin is taken seriously, it would call for income transfers until income equality is achieved. ${ }^{11}$ In contrast, a concern for basic needs fulfillment implies redistribution until all basic needs are met. If the motive of basic needs satisfaction is the driving factor, policy discussions should revolve around questions about the threshold amount at which basic needs can be fulfilled, rather than about whether redistribution should take place at all.

This chapter constitutes, to the best of our knowledge, the first attempt to provide clean evidence on the existence of concerns for basic needs satisfaction, by disentangling the motive from other important distributional concerns, such as maximin, efficiency, selfishness, generosity, and envy in an incentive compatible way. We employed five-person dictator games in a series of laboratory experiments (Engelmann and Strobel 2004, 2005). Subjects chose between three different allocations of payoffs among themselves and four other persons. The allocations were constructed such that a dictator's choice of a particular alternative implies that she attaches a positive weight to a particular motive. In a first set of five choices, we systematically disentangled concerns for basic needs satisfaction from each of the other five motives. We then exposed subjects to additional choices in which we altered the trade-off between concerns for basic needs satisfaction and the other motives. By this, we reveal subjects' distributional concerns, and shed light on the relative importance of the different motives.

In order to introduce basic needs in the experimental framework, we provided context

10 This is because the transfer of money to a relatively poorer person as, for example, in Cappelen et al. (2013b) reduces inequality between the giver and the receiver and, at the same time, it increases the income of the least wealthy person in the reference group within the experiment. Further, comparing giving to a person who has her basic needs satisfied versus to a person who lacks some of her basic needs are as well not suited to elicit whether basic needs fulfillment matters in an unconfounded way (see also Chapter IV). If a person, for example, takes into account the disutility a poor person derives from the lack of basic needs, she could decide to give to the person with higher unfulfilled needs because of maximin considerations rather than because she wants to fulfill this person's needs.

11 Note that Rawls (1971), where the principle originates from, viewed those inequalities as acceptable that are in the best interest of the poorest in a society. 
by informing subjects in an introductory text about the amount of money needed to satisfy basic needs. In this text, we also alluded to the other above mentioned motives for distributing income, and provided relevant income figures. Hence, we exogenously set a threshold for basic needs satisfaction, while at the same time mentioning other distributional motives.

In line with previous literature, we find that selfishness and the maximin principle are prevalent motives, whereas only a small fraction of our subjects seems to be motivated by efficiency, generosity, or envy. Our core finding is, however, that a substantial fraction of individuals is motivated by basic needs satisfaction. 34 percent of subjects choose in line with basic needs satisfaction in at least one out of the five main choices, and 9 percent of them always choose an allocation that implies that they attach a positive weight to basic needs satisfaction. Subjects' decisions in additional choices indicate the importance of concerns for basic needs satisfaction in situations in which it makes similar predictions as maximin. Our analysis of a complementing set of choices shows that the motive for basic needs satisfaction is relatively insensitive to variation in relative prices in terms of the different motives. When subjects, for example, have to forgo a higher payoff for themselves in order to guarantee basic needs satisfaction of others, many still do so.

Conditional logit and mixed logit estimates reassert our conclusion that concerns for basic needs satisfaction, maximin, and selfishness are important drivers of subjects' choices in our experiment. The mixed logit model further confirms that there is substantial heterogeneity in the extent to which subjects' care about the motives. Finally, we show that our main results are robust across different incentive schemes.

The remainder of this chapter is organized as follows. Section 2.2 introduces the conceptual framework of concerns for basic needs satisfaction. Section 2.3 outlines the design, our identification strategy, and the experimental procedures. Section 2.4 presents the results. Section 2.5 presents additional evidence drawn from qualitative data. Section 2.6 concludes.

\subsection{CONCEPTUAL FRAMEWORK AND PHILOSOPHICAL BACKGROUND}

The principle of basic needs satisfaction plays a prominent role in normative philosophical theories of distributive justice. In order to judge a distribution on the grounds of this principle, two ingredients are needed: (i) the definition of what constitutes a need on which a moral claim can be based and (ii) the rules according to which the adequacy of distributions on the grounds of this principle can be evaluated (Miller, 1999). With respect to (i), Shue (1996) advocates that the guarantee of subsistence is a basic (moral) right. He defines subsistence as a minimum of economic security, which consists of having "available for consumption what is needed for a decent chance at a reasonably healthy and active life" (Shue, 1996, p.23) like water, air, food, clothing, shelter, and health. Besides these biological necessities, a basic needs claim can also be based upon social factors (Miller, 1999). An example is a specific type of clothes enabling a person to enter the public sphere 
without shame (A. Smith, 1976, as cited in Miller, 1999). ${ }^{12}$ The sum of all claims that qualify as basic human needs constitute the threshold of basic needs satisfaction. Which social and biological factors constitute a basic need and thereby determine the level of the threshold is defined within the society in which those claims are put forward. ${ }^{13}$

Regarding (ii), the principle of basic needs satisfaction provides a rule for judging the fairness of a distribution relative to the threshold defined by the society (Miller, 1999). This paper is concerned with examining whether people apply this rule in distributional decisions. In the following, we provide a formal definition of this principle that we call concerns for basic needs satisfaction.

We define the threshold of basic needs satisfaction $t$ as the monetary amount that is necessary to fulfill a person's basic needs. We model concerns for basic needs satisfaction as the disutility an individual $i$ derives from unmet needs by a term in an individual's utility function. We assume that a person's distributional preferences are affected by various motives, where concerns for basic needs satisfaction is one of them (see, for example, Konow, 2001). For simplicity, let us first consider the two-person case. The utility of an individual who is concerned with her own payoff and with basic needs satisfaction is modeled as follows:

$$
U_{i}(x)=\alpha_{1 i} x_{i}+\alpha_{2 i}\left[-\max \left(t-x_{j}, 0\right)\right]
$$

where $x_{i} \geq t$ is individual $i$ 's own income, $x_{j}$ is the income of person $j$, and $\alpha_{1 i}$ and $\alpha_{2 i}$ are the weights she attaches to her own payoff and to satisfying the needs of person $j$, respectively. We assume that individual $i$ 's utility is linear and monotonically increasing in $x_{i}$ and in $x_{j}$ for $x_{j}<t$. The functional form implies that people who are concerned with basic needs satisfaction derive disutility if not all needs of person $j$ are satisfied.

Figure 1 depicts the utility of individual $i$ as a function of person $j$ 's income for a given $x_{i} \geq t$ relative to the threshold of basic needs satisfaction for $n=2$ and $x_{i} \geq t$. If the other person has an income lower than the threshold (i.e., $x_{j}<t$ ), individual $i$ 's utility diminishes proportional to the difference between $t$ and $x_{j}$. Thereby, the more weight she puts on the motive of basic needs satisfaction relative to the amount of her own income, the larger is the reduction in utility per unit of unfulfilled basic needs of person $j$. If person $j$ 's income is higher than the threshold, individual $i$ can reap the full benefits of her own income without experiencing any disutility.

12 These social needs are determined by a social norm of what comprises a decent human life in order to avoid social harm.

13 In the experiment, however, we implement an exogenous threshold to avoid endogeneity problems in the analysis of our choice data. Thus, we assume throughout this paper that individuals have no influence on the level of the threshold. 
Figure 1: Concerns for basic needs satisfaction (two-person case)

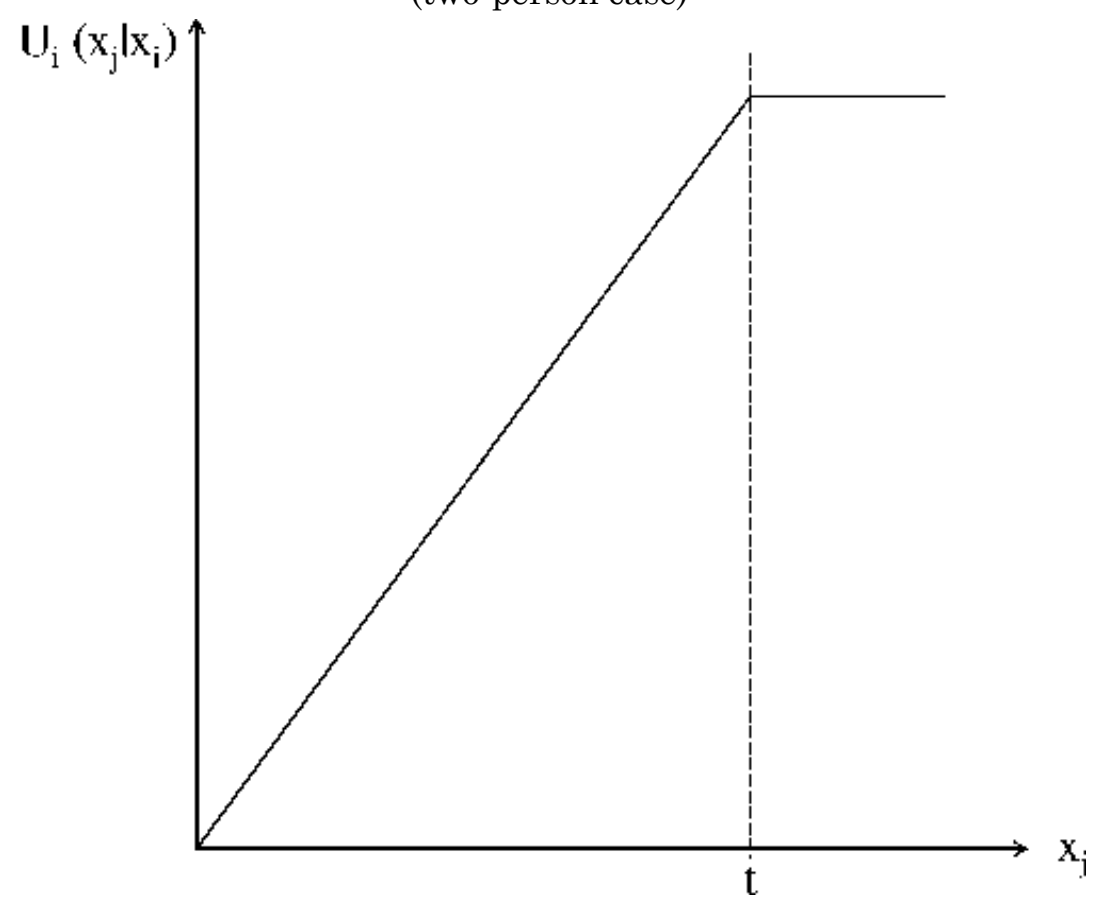

Notes: Utility of individual $i$ as a function of person $j$ 's income $\left(x_{j}\right)$ for a given income of individual $i\left(x_{i} \geq t\right.$, where $t$ is the threshold of basic needs satisfaction) relative to $t$ in the two-person case.

In the case in which the reference group of an individual is comprised of multiple persons, we assume that utility is given by:

$$
U_{i}(x)=\alpha_{1 i} x_{i}+\alpha_{2 i}\left[-\sum_{j=1}^{n} \max \left(t-x_{j}, 0\right)\right],
$$

where $x_{j}$ is the income of person $j \in\{1, \ldots, n\}$. A person concerned with basic needs satisfaction derives disutility if not all needs of all $n$ members of a society are satisfied. If one or more persons have an income lower than the threshold, individual $i$ 's utility diminishes proportional to the sum of the positive differences between $x_{j}$ and $t$. If, for example, two persons with the respective incomes $x_{1}$ and $x_{2}$ are in need, her utility is diminished by $\alpha_{2 i}\left[\left(t-x_{1}\right)+\left(t-x_{2}\right)\right] .{ }^{14}$ Thus, in a situation in which there are enough resources to satisfy

14 Note that this formulation implies that as the number of needy persons in an individual's reference group approaches infinity, her disutility approaches negative infinity. A single person's income is unlikely sufficiently high to fulfill the needs of all persons and her utility would approach minus infinity. It is, however, reasonable to assume that a person's reference group is not infinitely large. Even if the amount of unfulfilled basic needs of people in a person's reference group is sufficiently large in order to cause her utility to become negative, it is likely that the number of people willing to satisfy basic needs increases as well. This would again decrease the amount of unfulfilled basic needs in a person's reference group. In our experiment, we limit the group of people to five persons, which prevents the above mentioned limitations. 
basic needs of every member, an income distribution in which there are no unfulfilled basic needs would result in the lowest disutility. If, however, resources are not sufficient to grant every person a sufficiently high income, then minimizing the sum of the differences between the income of each member and the threshold (i.e., $\sum_{j=1}^{n} \max \left(t-x_{j}, 0\right)$ ) yields the lowest disutility. In this paper, we primarily investigate situations in which it is not possible to fulfill all basic needs in order to disentangle concerns for basic needs satisfaction from maximin. Note that the fact that the motive is modeled as a disutility in case of unfulfilled needs is in line with the notion of minimizing the injustice in cases of resource scarcity, as perfect justice cannot be achieved in these cases (Miller, 1999).

The moral reasoning behind the principle of basic needs satisfaction as defined above is that the higher the overall unfulfilled basic needs in a society, the less preferable the distribution of the resources among its members is considered. This means that the fairness judgment based on this principle is independent of the distribution of the unfulfilled basic needs. In terms of the utility function specified above, this means that the disutility individual $i$ derives from the deprivation of basic needs only depends on the sum of positive differences between the threshold and people's endowments. It is, for example, equally bad if a single person lacks 100 Euros to fulfill her basic needs as if ten persons each lack 10 Euros - ceteris paribus. This first property of the principle reflects the moral claim that everybody has an equal right to fulfill her basic human needs (Shue, 1996). Thus, there exists no criterion based on which basic needs of one person have priority over those of another person. In other words, the principle of basic needs satisfaction does not prescribe that people with distinct amounts of needs should be treated differently. This would be the case if we added, for example, the criterion that we should first fulfill basic needs of the least well-off person. Hence, our definition distinguishes the motive of basic needs satisfaction conceptually from other fairness principles that are concerned with people at the lower end of the income distribution, for instance, with the least well-off in a society (maximin) or those who are worse off than oneself (generosity). A second important property of the principle is that once all basic needs of all members of a society are satisfied, the motive does not make any further claim on how additional resources should be distributed. This is because the principle is defined relative to a threshold value. Both of these properties are crucial for identifying basic needs satisfaction as a distinct distributional motive.

Besides basic needs and selfishness, we also consider four other distributional fairness motives: maximin (the desire to maximize the minimum income) (Charness and Rabin, 2002; Andreoni and Miller, 2002), efficiency (the desire to maximize total incomes) (Charness and Rabin, 2002; Andreoni and Miller, 2002), generosity (aversion to advantageous inequality), and envy (aversion to disadvantageous inequality) (Fehr and Schmidt, 1999). ${ }^{15}$ We assume that a person can be motivated by these six motives:

15 Note that we consider the different components of inequity aversion by Fehr and Schmidt (1999) separately. Results from Dannenberg et al. (2007) indicate that subjects' envy and guilt parameters are unrelated. This implies that they should be treated as two distinct distributional motives. 


$$
\begin{aligned}
U_{i}(x)= & \alpha_{1 i} x_{i}+\alpha_{2 i}\left[-\sum_{j=1}^{n} \max \left(t-x_{j}, 0\right)\right]+\alpha_{3 i} \min _{j \in\{1, \ldots, n\}}\left(x_{j}\right)+\alpha_{4 i} \sum_{j=1}^{n} x_{j} \\
& +\alpha_{5 i}\left[-\sum_{j=1}^{n} \max \left(x_{i}-x_{j}, 0\right)\right]+\alpha_{6 i}\left[-\sum_{j=1}^{n} \max \left(x_{j}-x_{i}, 0\right)\right] \\
& = \\
& \alpha_{1 i} S L F+\alpha_{2 i} B N S+\alpha_{3 i} M X M+\alpha_{4 i} E F F+\alpha_{5 i} G E N+\alpha_{6 i} E N V,
\end{aligned}
$$

The weight individual $i$ attaches to the different motives are $\alpha_{1 i}$ for selfishness (SLF), $\alpha_{2 i}$ for basic needs satisfaction (BNS), $\alpha_{3 i}$ for maximin (MXM), $\alpha_{4 i}$ for efficiency (EFF), $\alpha_{5 i}$ for generosity (GEN), and $\alpha_{6 i}$ for envy (ENV). If a person, for example, deems her own income more important than the total income of the reference group, then $\alpha_{1}>\alpha_{4}$. In this paper, we abstract from the scaling parameter $\left(\frac{1}{1-n}\right)$ for generosity and envy, since we only consider one specific group size. ${ }^{16}$

We are aware that the above formulation is one of many possibilities to formalize the notion of concerns for basic needs satisfaction. We chose this formulation because it is simple and it clearly disentangles basic needs fulfillment from other distributional concerns. ${ }^{17}$ The goal of this paper is to provide evidence of the existence of the motive, i.e., to show that people care for the fulfillment of basic needs. Note that choices in line with basic needs satisfaction in the experiment can also be explained by alternative formulations of the motive; for example, by a desire to minimize the number of persons below the threshold (see also Section 2.5). In Chapter III, we further explore these two peculiarities of the motive.

\subsection{EXPERIMENT}

\subsubsection{Design of the experiment}

We employed five-player dictator games in each of which the dictator had to choose between three different payoff distributions among herself and four other subjects (for an example, see Table 1). ${ }^{18}$ The design builds on Engelmann and Strobel (2004, 2005), who

16 The term has the purpose to make "the relative impact of inequality aversion on player i's total payoff [...] independent of the number of players" (Fehr and Schmidt, 1999, p.824). Since we only consider groups of five persons in our experiment and we also don't implement a scaling term for the other motives under consideration, e.g., basic needs satisfaction and efficiency, we disregard the term for the purpose of this paper.

17 A concave function, for instance, could imply the prioritization of persons with greater needs and thus could be confounded with maximin concerns. A convex function, in contrast, could lead to triage (Miller, 1999).

18 The dictator game is especially suited to elicit distributional concerns. Since it does not contain any dynamic elements, possible strategic considerations of dictators such as reciprocity or reputation are eliminated (Ruffle, 1998). 
use multiple-person dictator games to elicit subjects' distributional motives. The main idea of the experiment is to identify motives from observed dictator choices. In order to disentangle concerns for MXM, GEN, and BNS, we need at least three persons with a payoff lower than the dictator's payoff. In order to disentangle MXM from BNS, the income of the worst-off person (Person 5) was always less than the basic needs threshold. We modified the income of the second worst-off person (Person 4) in order to vary the amount of basic needs fulfillment across options independent from the minimum payoff. We varied the income of the third worst-off person (Person 3) in a way that allows us to distinguish concerns for GEN from MXM and/or BNS.

In our experiment, we exogenously set a threshold for basic needs satisfaction. Immediately before making their choices in the experiment, subjects received a flyer with written text (see Appendix C). The experimenters made sure that all subjects read the text, which remained on subjects' desk during the entire experiment. The text informed that the monthly necessary amount to fulfill a person's basic needs is 630 Euros in Germany. We chose this amount based on the poverty threshold at the time of the experiment. It is defined as 40 percent of the monthly median net equivalent income. This poverty line is a generally accepted threshold for basic needs satisfaction in Germany (Statistisches Bundesamt, 2012a, b). ${ }^{19}$ To avoid a bias towards salience of basic needs fulfillment, we further informed participants about other motives related to income distribution in a society that we consider in our study, i.e., MXM, EFF, GEN, and ENV. In order to not make the amount of 630 Euros salient in the text, we also mentioned other numbers, such as the median income, which was 1570 Euros at the time of the experiment. The amounts displayed to subjects in the choices were in the same order of magnitude as the amounts in the information text. In this way, we put the choice scenarios in a context in which subjects can judge the income distributions with respect to the above mentioned distributional motives.

Table 1 shows the five main choices in our experiment in which we systematically disentangle concerns for BNS from each of the other five motives. Rows three to seven depict the payoffs of Person 1-5 for each option and choice. For instance, if a dictator in choice 1 chooses Option C, Person 1 gets 2910 Monetary Units (MU), the dictator (Person 2) gets 1620 MU, Person 3 gets 1040 MU, Person 4 gets 730 MU, and Person 5 gets 180 MU. Person 1-5 each had a fixed income position in all choices, where persons were ordered with respect to their income with Person 1 being the richest and Person 5 the poorest. The dictator as Person 2 was the second richest with an income amount close to the median income in Germany.

Next, subjects were exposed to five additional choices and subsequently to up to ten

19 It might be argued that our subjects perceived the threshold of 630 Euros as too high. Since they were mainly students, they themselves might have less than this amount at their disposal per month. This is, however, not true. A German student has on average a disposable monthly income of 864 Euros (Greiner, 2013). Moreover, in the case of Cologne, which has one of the highest rental costs in Germany, students need on average 893 Euros per month (Zeit Online, 2015). Thus, it is reasonable to assume that subjects in our study viewed the threshold as sufficiently low as to only cover basic human needs. 
trade-off choices, which we will elaborate on in Section 2.3.2 (for an overview see Figure 7 in Appendix A). Each subject made all choices in the role of the dictator (Person 2). The order in which subjects were exposed to the choices as well as the order in which the three allocation options were displayed to subjects within each choice was completely randomized both within the five main choices as well as within the five additional choices. ${ }^{20}$ For payment, subjects were randomly assigned into groups of five persons. Subjects were further randomly assigned the role of Person 1, 2, 3, 4, or 5 in their respective group. For each group, one choice was randomly chosen and paid out. The decision of each group's dictator in this choice then determined the payoffs of all five group members. ${ }^{21}$ The payment (in Euro) a subject received was the respective amount in the respective choice divided by 150 .

Our design allows us to disentangle the different distributional motives in a context in which fairness principles and selfishness concerns conflict with each other. This is a crucial ingredient to the external validity of our results and to the ability to capture behavior outside the experiment. In naturally occurring decision environments, selfish incentives are typically present and conflict with people's desire to achieve or maintain a fair distribution of benefits and burdens. The fact that dictators' decisions have consequences for the payoff of themselves and other subjects provides an incentive to evaluate the choices carefully and truthfully (V. L. Smith, 1976).

20 The randomization was carried out by the computer for each subject. In this way, we control for possible order effects and confounding effects that may occur when subjects systematically prefer an alternative due to its position, e.g., the left option.

21 A subject's payoff hence depended on her randomly determined group, her role, and on the decision of the subject that had been assigned the role of Person 2 (which could be herself or another subject) in her group. The fact that subjects faced role uncertainty at the moment of their decision could have potentially biased them towards making less selfish and more prosocial and efficiency enhancing decisions (Iriberri and Rey-Biel, 2011). Assigning subjects to the different roles upfront would have meant that we needed to pay five subjects (one dictator and four receivers) in order to collect one observation. Since this would have been too expensive, we chose the outlined design. Furthermore, note that a subject's choice only affected her own payoff in the role of Person 2 and only if she was assigned this role. This precludes the possibility that subjects' risk preferences could influence her choices (Schildberg-Hörisch, 2010). 


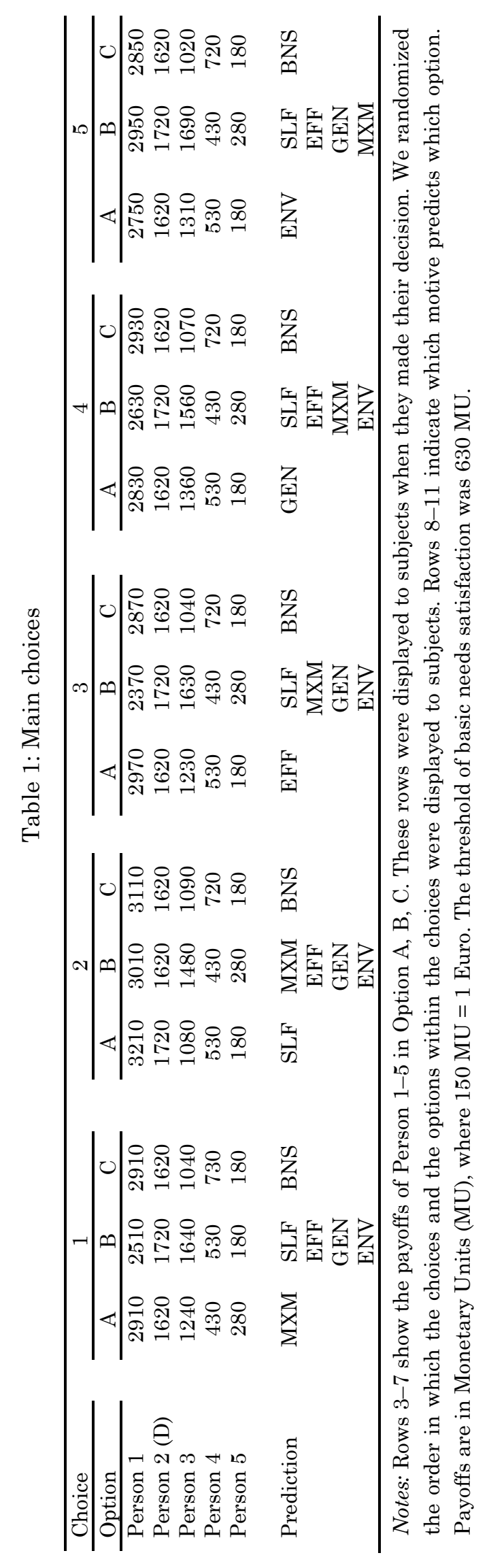




\subsubsection{Motives and identification strategy}

We assume that people can be motivated by various distributional principles that they trade off against each other (see, for example, Konow, 2001). We consider six different motives that people can take into account when comparing the different allocations in our choices. Let $x_{j}$ be the payoff of person $j \in\{1, \ldots, 5\}$ in an allocation, and assume utility is linear in $x$. Then, given the basic needs threshold of $630 \mathrm{MU}$ as defined in Section 2.3.1, given that Person 1-5 have a fixed position in the income distribution in all choices with Person 2 as the dictator, and given that Person 1 and 2 never have an income lower than the threshold amount, the utility function in equation (3) for a dictator simplifies to:

$$
\begin{gathered}
U_{2}(x)=\alpha_{1} x_{2}+\alpha_{2}\left[-\sum_{j=3}^{5} \max \left(t-x_{j}, 0\right)\right]+\alpha_{3} x_{5}+\alpha_{4} \sum_{j=1}^{n} x_{j} \\
+\alpha_{5}\left[-\sum_{j=3}^{5}\left(x_{2}-x_{j}\right)\right]+\alpha_{6}\left[-\left(x_{1}-x_{2}\right)\right] .
\end{gathered}
$$

On the basis of this utility function, we can calculate the utility in terms of the different motives for each allocation. ${ }^{22}$ We say that a motive predicts an option if the utility in terms of this motive is higher than in the remaining options. The last four rows of Table 1 indicate which option is predicted by which motive. If an option is predicted by only one motive, then choosing this option is only compatible with attaching a positive weight to the motive which alone predicts this option, since this option is worse in terms of the utility of all other motives. From here onwards we say that a motive alone predicts an option if no other motive predicts this option. This is the core of our identification strategy.

In choice 1, for example, BNS predicts Option C, since the sum of the positive differences between the threshold $(t=630)$ and each person's income is smaller in Option $\mathrm{C}$ than in A or B. In other words, the sum of unfulfilled basic needs is smallest in C, where Person 5 lacks $450 \mathrm{MU}$ to have an amount that would allow her to fulfill her basic needs (i.e., to have an amount at least as big as the threshold). All the other persons have an amount above 630 MU. By contrast, in Option B, Person 4 lacks 200 MU and Person 5 lacks 350 MU. Thus, the overall unfulfilled basic needs amount to 550 MU. Similarly, the sum of unfulfilled basic needs is also $550 \mathrm{MU}$ in Option A. Since BNS is the only motive predicting Option $\mathrm{C}$ (i.e., BNS alone predicts Option C), a dictator choosing this allocation must care to some extent for the fulfillment of basic needs, i.e., she has a positive $\alpha_{2}$. Likewise, in choice 2, for example, SLF predicts Option A, since the dictator's payoff is higher than in Option B or C. If a dictator chooses Option A in choice 2, we can deduce that she cares to some extent for her own payoff, i.e., she has a positive $\alpha_{1}$.

In our five main choices, we systematically vary the utilities in terms of the different motives in the three different allocations such that it allows us to assess to which motive(s)

22 For a complete overview of the utilities in terms of the different motives per option, see Table 4 in Appendix D. 
the dictator attaches a positive weight, where the focus of this paper is on concerns for BNS. In particular, in all choices, BNS alone predicts Option C. Hence, in all choices, a dictator choosing Option $\mathrm{C}$ must attach a positive weight to BNS. Furthermore, in each choice, one of the other five motives is the only motive predicting Option A. The remaining four motives predict Option B. In this way, these five choices allow us to assess whether BNS plays a role in dictators' choices and is thus a distinct distributional motive. Note, however, that if a dictator chooses an allocation that is not predicted by BNS, it does not imply that she deems this motive completely unimportant. Our assessment of the prevalence of concerns for BNS is thus a lower bound estimate. Moreover, the five main choices reveal which other motives play a role in subjects' decisions if they choose the option not predicted by BNS. Our within subject design further allows us to elicit individual decision patterns (e.g., how often subjects choose in line with a specific motive).

In addition to the main choices, we employed five additional choices (see Table 5 in Appendix E). In two of these choices, both BNS and MXM predict the same option (choice 6 and 7). We shed light on the role the different motives play in situations in which they make similar predictions by comparing decision patterns in the five main choices with decisions in these two additional choices. Finally, we exposed subjects to up to ten additional trade-offs, depending on their decisions in the main choices. In these choices, we vary the relative prices of the motives in order to shed light on the relative importance of different motives.

All choices have features that preclude possible confounding effects. Firstly, we avoid income amounts that might make an option salient for reasons unrelated to the motives. For example, we make sure that the income for any given person remains within an interval with the same first digit of a four-digit number. In other words, the payoff of one person, for instance, does not jump from 2900 to $3100 \mathrm{MU}$ from one allocation to the other. This difference might be more salient than the difference between, for example, 2700 and $2900 \mathrm{MU}$ and thereby introduce confounding effects. Second, the amounts are not exactly the same as those stated in the information text to avoid that these are especially salient to subjects. Third, we limit the complexity of the scenarios by ordering the persons from highest to lowest income, as well as by using numbers rounded to multiples of $10 \mathrm{MU}$ and by changing incomes of a person by multiples of $100 \mathrm{MU}$ when possible. ${ }^{23}$

\subsubsection{Procedures}

The experiment took place at the University of Cologne in the Cologne Laboratory for Economic Research (CLER). The experiment involved a total of 90 subjects who were recruited through ORSEE (Greiner, 2015). The experiment was programmed in ztree (Fischbacher, 2007). It was common knowledge that subjects remain anonymous towards other participants and the experimenter throughout the whole experiment. ${ }^{24}$ The

23 By ordering the persons from highest to lowest income, we keep the relative position of the persons with respect to their income constant. Using round numbers makes calculations with and comparisons of the amounts simple. In this way, we restrain the cognitive load during the choices, which facilitates the comparison of the allocations.

24 Anonymity of subjects makes potential social image concerns less likely, since they do not have 
experiment consisted of three parts and a questionnaire (see Figure 6 in Appendix A). Sessions lasted about 1.5 hours and subjects earned on average 9 Euros in addition to a fixed show-up fee of 2.50 Euros and a compensation of 2 Euros for filling in a questionnaire at the end of the experiment. In this paper, we focus on the first part of the experiment, in which subjects made decisions in up to 20 dictator choices (see Figure 7 in Appendix A). Subjects made on average 13 choices.

\section{$2.4 \quad$ RESULTS}

\subsubsection{Main results}

We start by providing descriptive evidence, before we estimate conditional logit and mixed logit models in order to evaluate the impact of motives on the probability that an option is chosen.

\section{Main choices}

The dark grey bars in Figure 2 represent the fraction of subjects choosing in line with BNS (Option C) in each of the main dictator choices displayed in Table 1. We find that in every choice, BNS is a prevalent motive with 11 to 21 percent of subjects choosing in line with the motive. As mentioned above, these are lower bound estimates of the prevalence of concerns for BNS, since the choice of a different allocation does not necessarily imply that subjects attach no weight to the motive. Figure 2 further reveals that SLF and MXM are important for subjects' choices with 37 percent of dictators choosing in line with each of these motives (light grey bar in choice 1 and 2, respectively).

to worry about what other people might think of their decisions (Hoffman et al., 1996). 
Figure 2: Choice fractions main choices

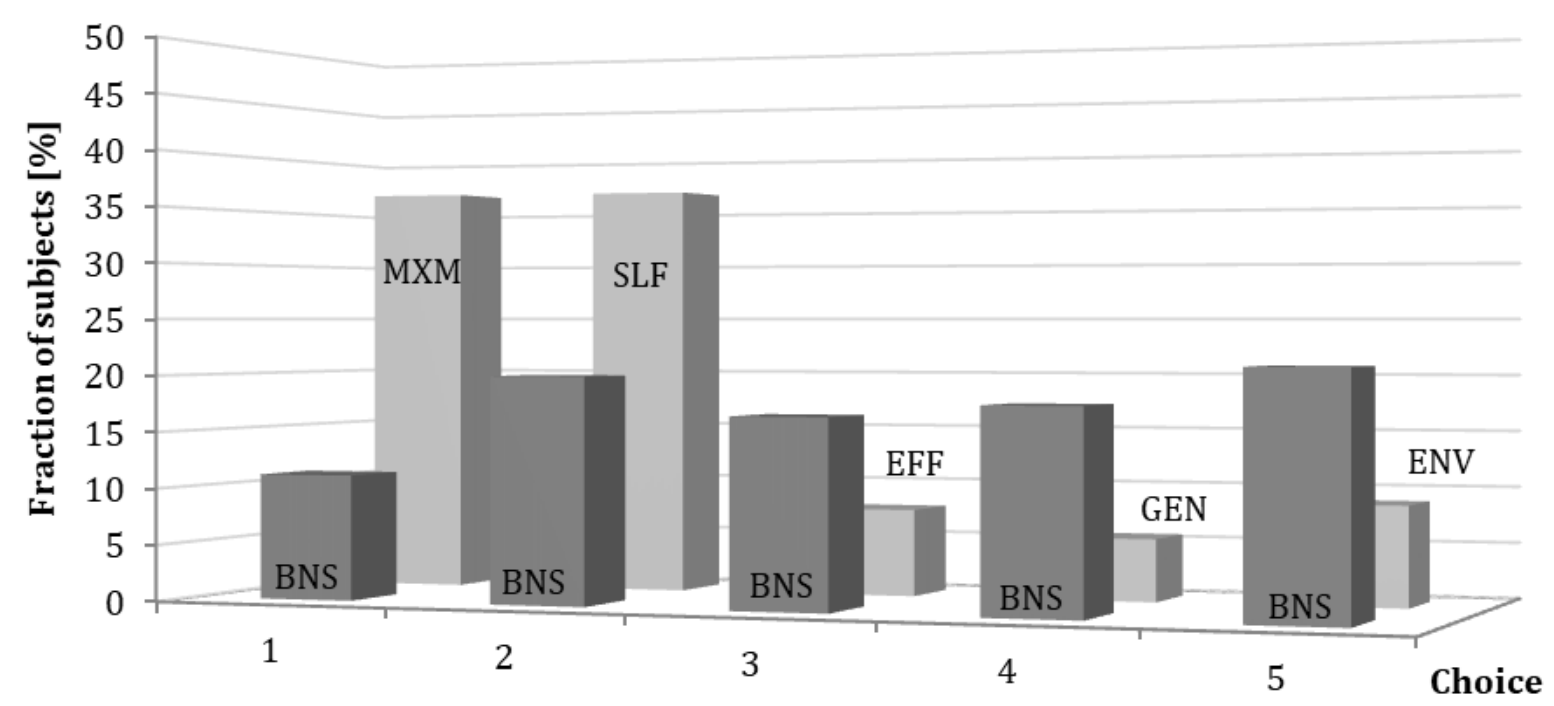

Notes: Fraction of subjects choosing Option $\mathrm{C}$ and thus attaching a positive weight to BNS (dark grey bars) and fraction of subjects choosing Option A and thus attaching a positive weight to the respective motive predicting this option (light grey bars) in the main choices (choice 1-5). The remaining subjects choose Option B (the option predicted by the four remaining motives), which is not depicted here.

We now look at individual choice patterns and turn to the question of how many subjects are concerned with BNS. Figure 3 depicts the reverse cumulative distribution of the number of times a subject chooses in line with a motive conditional on choosing in line with this motive when it alone predicts an allocation. ${ }^{25}$ The reverse cumulative distribution indicates the fraction of subjects choosing more than $x$ times in line with a motive. 34 percent of subjects choose at least once in line with BNS. For these subjects, we can conclude that they attach a positive weight to concerns for BNS, i.e., the motives enters positively into their utility function. We can further observe that about 37 percent choose in line with MXM and SLF at least once.

25 If a subject chooses in line with a motive when it alone predicts an option, this indicates that this motive is at least somewhat important to her. It is therefore a more reliable indicator of her preference than when she chooses an option that is predicted by multiple motives. For all motives except BNS, a person who chooses $x$ times in line with a certain motive chooses by construction of the main choices also $(x-1)$ times in line with all other motives except BNS. Hence, in order to look at individual choice frequencies of these motives in a meaningful way, we condition them on choosing in line with the motive when it alone predicts an option. 
Figure 3: Reverse cumulative distribution

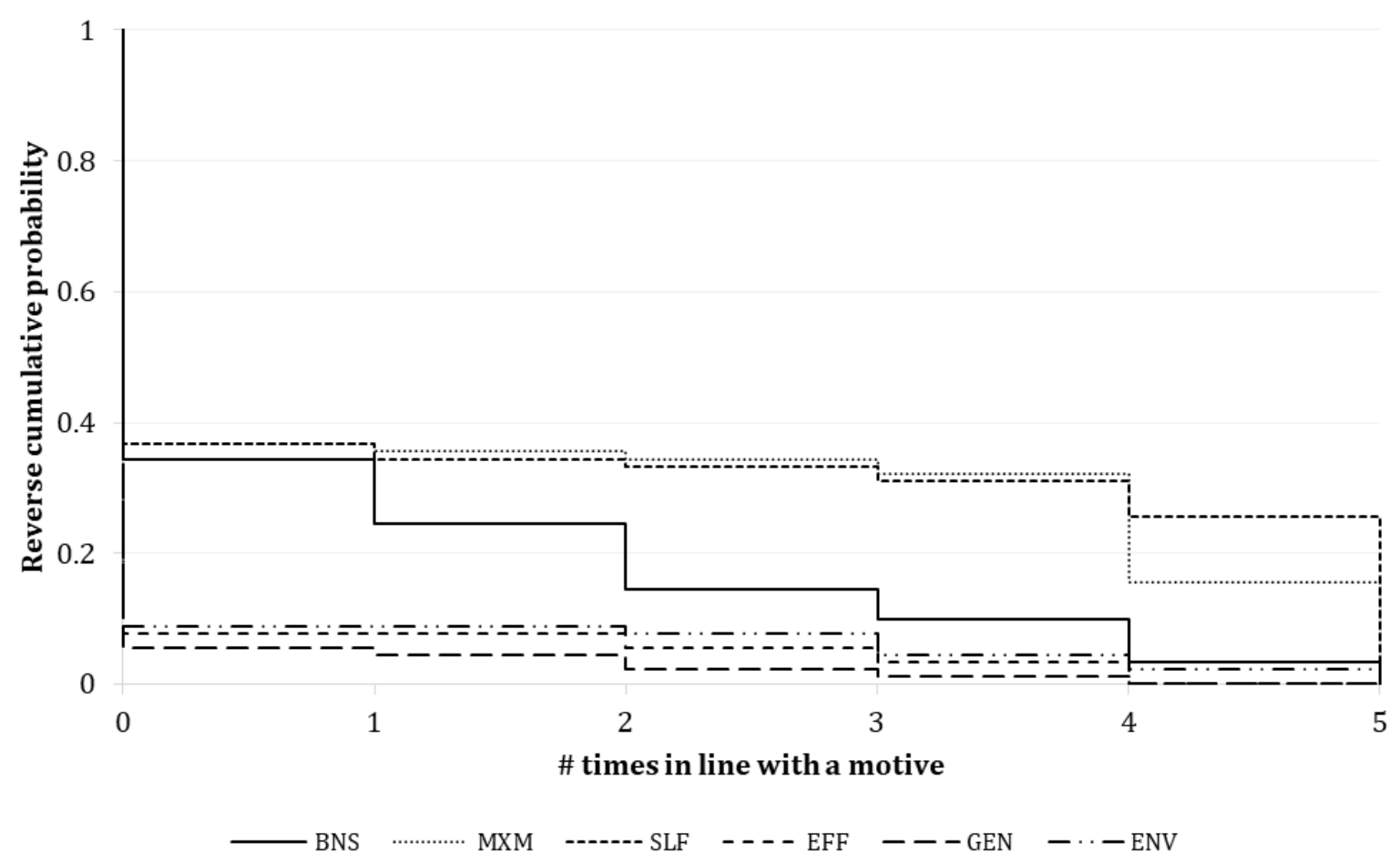

Notes: The reverse cumulative distribution indicates the fraction of subjects choosing more than $x$ times in line with a motive, conditional on choosing in line with this motive when it alone predicts an allocation. This means that for MXM, SLF, EFF, GEN, and ENV the motive has to be chosen when the respective motive alone predicts an option (in case of MXM this is, for example, Option A in choice 1) in order to qualify as choosing $x$ times in line with this motive.

Observing subjects choosing repeatedly in line with a motive raises confidence that this motive is indeed important to them. In particular, Figure 3 reveals that 10 percent of subjects choose in line with BNS at least four out of five times, while a third of these subjects always choose in line with the motive. These observed choice frequencies cannot be explained by random choice behavior. Given that subjects choose among three possible alternatives in five choices, there are exactly 243 different possible choice patterns (permutations of chosen alternatives). Under the assumption of purely random choice behavior, each option is equally likely chosen in a particular choice. There is exactly one choice pattern that implies being in line with a given motive five times. In case of BNS, this choice pattern is always choosing Option C. Thus, the resulting probability to choose five times in line with a given motive under random choice is $\frac{1}{243}$. Further, there are exactly 10 choice patterns that imply being in line with BNS exactly four times. The expected probability that subjects choose at least four times in line with BNS under random choice is therefore $\frac{10}{243}+\frac{1}{243}=\frac{11}{243}$. Two-sided binomial probability tests reject the null hypothesis that the share of dictators choosing five (at least four) times in line with BNS is equal to the share that we would expect if subjects were choosing completely at random $(p=.0119(p=.0063))$. 
Further, 32 (31) percent of subjects choose at least four times in line with MXM (SLF), while 16 (26) percent of these subjects always choose in line with the motive. Again, twosided binomial probability tests reject the null hypothesis that the share of dictators choosing five (at least four) times in line with MXM (SLF) is equal to the share that we would expect if subjects were choosing completely at random $\left(p<.0001\right.$ for all four tests). ${ }^{26}$

Overall, these results indicate that BNS, alongside MXM considerations and SLF, is an important separate distributional concern. Moreover, the fact that a large majority of our subjects chooses repeatedly in line with one of the motives under consideration lends support to the internal validity of our experiment. ${ }^{27}$ Furthermore, the individual choice data uncovers that there seems to be substantial heterogeneity in the importance subjects attach to each motive. We will elaborate further on this later in this section.

\section{Implications for the prevalence of concerns for BNS}

When interpreting differences in the fractions of subjects who repeatedly choose in line with BNS and another motive, two things should be kept in mind. First, each choice in line with BNS requires that an allocation is chosen that is not predicted by any of the other motives, i.e., that is worse in terms of the five other motives. Hence, a dictator choosing, for instance, four times in line with BNS automatically chooses four times an allocation that is neither optimal in terms of her own payoff, nor in terms of MXM, EFF, GEN, or ENV. By contrast, all the other motives, including SLF and MXM, are the single motive predicting an allocation only once out of the five main dictator choices. In the four respective other choices, these motives predict an option that is also predicted by three other motives. For example, a dictator who chooses five times in line with MXM has to choose only one allocation that is only predicted by MXM (in choice 1 when the motive predicts Option A). The remaining times MXM predicts Option B, which is also predicted

26 For MXM and SLF there is also exactly one choice pattern that implies being in line with a given motive five times resulting in a probability of $\frac{1}{243}$ to choose five times in line with a given motive under random choice. In case of MXM, for example, this choice pattern is choosing Option A in choice 1 and Option B in the remaining choices. Furthermore, the expected probability that a subject chooses at least four times in line with either MXM or SLF (conditional on choosing in line with this motive when it alone predicts an allocation) under random choice behavior is $\frac{5}{243}$.

27 Almost half of our sample always chooses in line with a single motive in the five main dictator choices. This percentage rises up to 72 percent if we also take into account those subjects who choose four times in line with one motive. Hence, a large amount of our subjects puts a strong weight on one of the motives under consideration. Of these subjects, those choosing repeatedly in line with a non-selfish motive are the majority. This suggests that our design indeed captures motivations that are important to our subjects in the presented distributional choices. It is important to keep in mind that those who do not choose repeatedly in line with a single motive might still be motivated by a mix of the motives under consideration (as elaborated in Section 2.3.2). In other words, we do not label subjects who do not choose in line with one motive in most of the choices as inconsistent or irrational. 
by three of the other motives (in choice 2-5). The same holds for the other motives. ${ }^{28,29}$ Hence, we can say that it is more restrictive to repeatedly choose in line with BNS than with any of the other four motives under consideration.

Second, it is more difficult to compare the allocations based on BNS than based on MXM or SLF. The former involves assessing the differences between the incomes and the threshold and comparing the overall differences. On the contrary, choosing the highest possible outcome for themselves (SLF) or for the least well-off person (MXM) is relatively straightforward. Subjects simply have to compare three income amounts (of Person 2 for SLF and Person 5 for MXM). Hence, applying BNS is potentially more susceptible to mistakes. To evaluate whether this is indeed the case, we compare response times of subjects who choose five (at least four) times in line with MXM, SLF, or BNS in the five main dictator choices. We find that SLF types are on average faster than BNS types $(t(24)=-2.6238, p=.0149)$ for those subjects choosing five times in line with one of the motives. We find similar differences in response times for individuals who choose one of the motives at least four times $(t(30)=-4.6609, p=.0001) .{ }^{30}$ On the contrary, we don't find a significant difference in decision times between MXM and BNS types for those who choose five times $(t(15)=-.6709, p=.5125)$ or at least four times $(t(36)=-.8466, p=$ .4028 ) in line with a motive. ${ }^{31}$ This lends support to the conjecture that applying the principle of $\mathrm{BNS}$ as a basis for decisions in the scenarios is more demanding (and thus more susceptible to mistakes) than applying SLF, while this is not the case when comparing BNS to MXM. ${ }^{32}$

Additionally, any assessment of the relative prevalence of the different motives under consideration depends on the specified utility function (see equation (5)), as well as scaling differences between the motives. Furthermore, as pointed out earlier, the fraction of subjects attaching a positive weight to concerns for BNS in each choice is a rather conservative assessment, since choosing a different allocation does not imply that subjects do not care for the motive at all. ${ }^{33}$ Overall, we can conclude that the prevalence of concerns

28 This means that for dictators who are motivated by more than one motive and whose most important motive is either MXM, SLF, EFF, GEN, or ENV, Option B is very likely to be more attractive as soon as it is predicted by her most preferred motive and other motives to which she attaches importance. Hence, these dictators are likely to choose Option B and thereby consistently with their most preferred motive.

29 In fact, even with this restriction, it is possible for subjects to classify as choosing in line four times with two of the motives (excluding BNS). This is the case if they choose two times Option A and three times Option B. In our sample, five subjects classify as choosing four times in line with MXM, as well as with SLF. These subjects choose Option A in both choice 1 and 2 , and Option B in choice $3-5$.

30 Subjects choosing in line with SLF five (at least four) times take on average 54 (61) seconds, while BNS types take 90 (104) seconds.

31 Subjects choosing in line with MXM five (at least four) times take on average 79 (91) seconds.

32 One explanation for this is that (some) subjects choosing in line with BNS do not compare the sum of unfulfilled basic needs. Instead they compare the number of persons below the threshold, which is likely to take less time. In Section 2.5, we explore this further by means of questionnaire data, while in Chapter III, we assess this via additional allocation choices.

33 This also holds for the other motives under consideration. 
for BNS, MXM, and SLF should be, if anything, compared only with care and while keeping in mind the above mentioned design features. Most importantly, the results presented in this paper are not meant to provide an exact estimate of the prevalence of concerns for basic needs satisfaction. It should rather be understood as evidence for the existence of the motive as an important distinct distributional concern.

\section{Additional choices}

In a lot of settings, predictions of concerns for MXM and BNS go in a similar direction. Concerns for BNS might, for example, also play a role in studies that have elicited MXM concerns. A reason for why we find a lower prevalence of MXM concerns than Engelmann and Strobel (2004, 2005), for instance, could be that in their setting a part of the subjects who choose in line with MXM concerns actually did so because this option has the highest prospect of fulfilling basic needs. ${ }^{34}$ To shed more light on the role the different motives play in situations in which they make similar predictions we now look at two additional choices. ${ }^{35}$ Choice 6 is similar to choice 1 with the difference that in choice 6 , BNS predicts the same option as MXM. In this option predicted by BNS and MXM, Persons 4 and 5 also get an income above the threshold, so that there are no unfulfilled basic needs in this option. The remaining four motives predict a different option. Likewise, in choice 7, which is similar to choice 2, MXM and BNS predict the same option together with all other motives but SLF. Again, in this option, all persons have an income of at least the threshold, while the option predicted by SLF leaves three persons with an income below the threshold.

We find that in choice 6, 41 percent of subjects choose Option A that is predicted by MXM and at the same time by BNS. In choice 7, the option predicted by MXM and BNS becomes even more appealing to our subjects. We find that 62 percent opted for this option. Of those subjects, the fraction who displayed a strong preference for MXM in the main choices (i.e., who chose at least four times in line with a motive) is 27 percent in choice 6 and 23 percent in choice 7. For BNS, these fractions are 24 percent in choice 6 and 14

34 Engelmann and Strobel (2004, 2005) elicit subjects' distributional motives in three and five person dictator games similar to our choice design. One possible explanation is that without information on a threshold for basic needs fulfillment, the absolute smallest monetary amount has the highest chance of being below any threshold. They find that on average 48 to 73 percent of subjects choose in line with MXM when it alone predicts an allocation. A reason for why this share is much higher than in our experiment could thus be that decisions in their setting were partly driven by concerns for BNS. In our setting subjects do have the information they need in order to judge the allocations based on basic needs fulfillment. Hence, subjects to whom BNS is sufficiently important will choose the option predicted by BNS. The combined share of subjects choosing either in line with BNS or MXM when both motives predict a different allocation in choice 1 is 48 percent in our study. This matches the shares found in Engelmann and Strobel $(2004,2005)$ more closely than the 37 percent who choose in line only with MXM in choice 1. This could indicate that concerns for BNS play a role in settings that have so far been interpreted as being purely driven by MXM concerns.

35 Table 5 in Appendix E shows the incomes allocated to Person 1-5 in, the motive predicting, and the fraction of subjects choosing the respective allocation. 
percent in choice 7. This suggests that both MXM and BNS are important in explaining why subjects choose the option in which there are no unfulfilled basic needs in choice 6 and 7. Even though we find a lower share of strong BNS than MXM types (i.e., subjects choosing at least four times in line with a given motive) in the main choices, these types make up a comparable share of the subjects choosing the option predicted by the two motives in choice 6 . This is because all strong BNS types choose this option, while only a bit more than half of the strong MXM types do so. Choice 7 presents a similar, although less pronounced picture. 72 of strong MXM types choose the option predicted by the two motives, while this share amounts to 83 percent for strong BNS types. Thus, having a strong preference for BNS seems to be more predictive for choosing the option predicted by the two motives in both choices than putting a lot of weight on MXM. This gives an indication that in situations in which both motives make predictions in a similar direction - especially when it is a decision to fulfill all basic needs - the motive of BNS is likely to play an important role next to MXM. This suggests that if basic needs satisfaction is ignored as a motive, we would ascribe behavior driven by this motive to maximin. Hence, in these situations, the prevalence of maximin would be overestimated if basic needs satisfaction is ignored as a behavioral motive. Thus, given that the motive has received less attention in the economic literature, it should be taken more seriously in future empirical and theoretical considerations.

\section{Trade-offs}

In the main choices, we observed the share of subjects who attach a positive weight to the different motives given specific relative prices in terms of each motive. In these choices, a subject has to give up $100 \mathrm{MU}$ in terms of a motive that alone predicts an option in order to gain $100 \mathrm{MU}$ in terms of another motive that alone predicts a different option when choosing in line with the latter. For example, in each of the five main choices, the option that is predicted by BNS is 100 MU better in terms of BNS and at the same time also 100 MU worse in terms of MXM. We saw that MXM, BNS, and SLF are important for subjects in these choices. Due to the fact that only some subjects choose in line with EFF, GEN, or ENV in choices 3, 4, and 5, we only look at the trade-off choices MXM vs. BNS and SLF vs. BNS here. To get a glance at the relative importance of these motives, we exposed subjects to up to 10 additional choices in which we systematically varied the relative prices of BNS in terms of the MXM and SLF, respectively. Specifically, we test if subjects are willing to give up 150, 200, and 250 MU depending on previous choices. Figure 8 and 9 in Appendix E shows the logic with which subjects were exposed to the different choices. For instance, subjects who choose MXM in choice 1 were first exposed to choice $1 \mathrm{HH}$. Of those subjects who choose MXM (BNS) in choice $1 \mathrm{HH}$ were then exposed to choice $1 \mathrm{HHH}(1 \mathrm{H})$. In this way, we narrow down the minimum amount of MU in terms of one motive a subject is willing to sacrifice in order to gain $100 \mathrm{MU}$ in terms of the motive she had chosen in the respective main choice. Subjects who chose Option B in a respective choice were not exposed to further trade-off choices belonging to this choice.

It is reasonable to assume that the higher the amount of MU in terms of one motive a subject is willing to forego in order to gain $100 \mathrm{MU}$ in terms of another motive, the more weight she attaches to the latter relative to the former. In choice $-\mathrm{H}(-\mathrm{HH},-\mathrm{HHH})$, subjects 
have to sacrifice $150(200,250)$ MU in terms of BNS when choosing Option A in order to gain $100 \mathrm{MU}$ in terms of the motive predicting Option A. Similarly, in choice -L (-LL, LLL), subjects have to sacrifice $150(200,250)$ MU in terms of the motive predicting Option A when choosing in line with BNS in order to gain $100 \mathrm{MU}$ in terms of BNS. For example, in choice $1 \mathrm{HH}$, subjects have to accept unfulfilled basic needs of $200 \mathrm{MU}$ if they choose Option A. Hence, a subject who chooses this option is likely to put a relatively high weight on MXM as compared to BNS.

We find that of those subjects who choose MXM in choice 1, 39 percent stick to MXM in choice $1 \mathrm{HH}$, while 15 percent switch to BNS. ${ }^{36}$ Again, of those who stuck to MXM in choice 1HH, 62 percent also choose in line with MXM if this entails $250 \mathrm{MU}$ more unfulfilled basic needs compared to the option predicted by BNS (choice 1HHH). This means that for 9 percent of our sample MXM is relatively more important compared to BNS. Of those subjects who switched to BNS in choice $1 \mathrm{HH}, 40$ percent stay with BNS even if the price in terms of BNS is decreased again in choice $1 \mathrm{H}$. For these subjects MXM is important, but BNS also seems to play a role. Further, of those subjects who choose the option predicted by BNS in choice 1, 30 percent stick to this option in choice 1LL and 50 percent of subjects choose option B, which is also predicted by BNS. Thus, for at least 30 percent of our subject BNS is relatively important compared to MXM. ${ }^{37}$ Regarding the trade-off choices of BNS and SLF, we find that of those subjects who are selfish in choice 2 , the majority (61 percent) stay selfish in choice $2 \mathrm{HH}$, while 18 percent switch to BNS. Of those who are selfish in choice $2 \mathrm{HH}$, in turn, 85 percent choose the selfish option even in choice $2 \mathrm{HHH}$, which entails $250 \mathrm{MU}$ more unfulfilled basic needs as compared to the option predicted by BNS. Hence, for 19 percent of our sample SLF is a relatively important motive compared to BNS. Of those subjects who switched to BNS in choice $2 \mathrm{HH}, 50$ percent stay with BNS in choice $2 \mathrm{H}$. For those subjects, SLF seems to be important but they also care about BNS to a certain extent. Of those subjects who choose in line with BNS in choice 2, 44 percent stick to BNS in choice $2 \mathrm{LL}$, while 28 percent switch to SLF. Of those who choose the BNS option in choice 2LL, 88 percent stick to BNS even though this means giving up $250 \mathrm{MU}$ of their own payoff in choice 2LLL. Hence, for 8 percent of our sample BNS is relatively important as compared to SLF.

To summarize, a non-negligible fraction of our subjects is willing to give up a substantial amount of their own payoff or of the poorest person's payoff in order to fulfill basic needs. In particular, to decrease the amount of unfulfilled basic needs by $100 \mathrm{MU}$, these subjects are willing to give up more than double this amount in terms of SLF or MXM. This confirms our earlier conjecture that BNS is a motive that plays a potentially important role in distributional decisions.

36 Figure 8 and 9 in Appendix E show the fraction of subjects choosing each allocation in each choice.

37 Choice 1L and 1LLL are hard to interpret and therefore excluded from the analysis, since both the choice of Option B and C in ILL was predicted by BNS, but only subjects who chose C were given choice 1LLL. 


\section{Estimation results: Choice models}

We further asses the importance of the motives in subjects' decisions by estimating a conditional logit model (McFadden, 1974) and a mixed logit model in order to account for heterogeneity in subjects' tastes (Train, 2009). In these models, the characteristics of each option (i.e., the monetary values of the utility terms) enter as explanatory variables. This allows us to estimate the impact of each term of the utility function on the probability that an option is chosen.

For the conditional logit model, let

$$
\begin{gathered}
V_{i k m}=\alpha^{S L F} S L F_{i k m}+\alpha^{B N S} B N S_{i k m}+\alpha^{M X M} M X M_{i k m} \\
+\alpha^{E F F} E F F_{i k m}+\alpha^{G E N} G E N_{i k m}+\alpha^{E N V} E N V_{i k m}
\end{gathered}
$$

with the utility terms $\left(S L F_{i k m}, B N S_{i k m}, M X M_{i k m}, E F F_{i k m}, G E N_{i k m}, E N V_{i k m}\right)$ of each motive in alternative $k \in\{A, B, C\}$ in choice $m \in\{1, \ldots, 5\}$ as given in Section 2.3.2 and the population parameters $\alpha^{w}, w \in\{S L F, B N S, M X M, E F F, G E N, E N V\}$. Hence, according to the conditional logit model, the probability that person $i$ chooses allocation $k$ in choice $m$ is given by:

$$
P_{i k m}=\frac{\exp \left(V_{i k m}\right)}{\exp \left(V_{i A m}\right)+\exp \left(V_{i B m}\right)+\exp \left(V_{i C m}\right)}
$$

(we largely follow Engelmann and Strobel, 2004, 2005). We estimate the model with choice data from the five main choices. ${ }^{38}$ To account for the dependence of individual decisions across choices, we allow for individual specific errors. Due to multicollinearity between SLF, EFF, GEN, and ENV, we estimate four different models, in each of which we exclude one of these variables and focus on assessing the impact of BNS and MXM. ${ }^{39}$ Table 2 displays the odds ratios of the different specifications of the conditional logit model. ${ }^{40}$ The estimation reveals that BNS and MXM have a significant and positive impact in all specifications. In particular, the odds of an allocation $\left(P_{i k m} /\left(1-P_{i k m}\right)\right)$ increase by 0.5 percent when the overall unfulfilled basic needs decrease by $1 \mathrm{MU}$ (BNS) and by 1 percent if the income of Person 5 is increased by $1 \mathrm{MU}$ (MXM). Due to the above mentioned collinearity, the odds ratios of the other motives can only be evaluated with caution. The respective linear combination of the excluded motive is significant in each model. ${ }^{41}$ This

38 In Appendix F, we show that our results are robust to estimating our model with the five main choices plus the five additional choices (see Table 6).

39 The multicollinearity is due to the construction of the utility terms $(S L F=(E F F+E N V-$ GEN)/5).

40 The odds ratios indicate by what factor the odds of an option $\left(P_{i k m} /\left(1-P_{i k m}\right)\right)$ are multiplied in case the value of this option in terms of a motive is augmented by one unit (see Engelmann and Strobel, 2004). Odds ratios greater than 1 indicate a positive influence of the independent variable, odds ratios smaller than 1 a negative influence of a motive.

41 Model $1(G E N-E F F+5 * S L F): \chi^{2}(1)=50.38, p<.0001$; Model $2(E F F+E N V-5 * S L F)$ : $\chi^{2}(1)=12.76, p=.0004$; Model $3(G E N-E N V+5 * S L F): \chi^{2}(1)=19.23, p<.0001$; Model 4 
suggests that the motives are jointly significant and that together they have a positive impact. Coming back to our descriptive evidence, we saw that in choice 2 , a large fraction of subjects chooses the option that indicates that they attach a positive weight to SLF. Hence, it stands to reason that of these four motives, especially SLF is important to some subjects.

Overall, this confirms our descriptive results that BNS, MXM, and SLF seem to be important drivers of subjects' choices in our experiment.

Table 2: Conditional logit models: Odds ratios

\begin{tabular}{ccccc}
\hline & $\begin{array}{c}(1) \\
\text { ENV } \\
\text { excluded }\end{array}$ & $\begin{array}{c}\text { GEN } \\
\text { excluded }\end{array}$ & $\begin{array}{c}\text { EFF } \\
\text { excluded }\end{array}$ & $\begin{array}{c}(4) \\
\text { SLF } \\
\text { excluded }\end{array}$ \\
\hline$\alpha^{S L F}$ & $1.013^{* * *}$ & $1.009^{* * *}$ & $1.009^{* * *}$ & \\
& $(0.0018)$ & $(0.0021)$ & $(0.0020)$ & \\
$\alpha^{B N S}$ & $1.005^{*}$ & $1.005^{*}$ & $1.005^{*}$ & $1.005^{*}$ \\
& $(0.0022)$ & $(0.0022)$ & $(0.0022)$ & $(0.0022)$ \\
$\alpha^{M X M}$ & $1.010^{* * *}$ & $1.010^{* * *}$ & $1.010^{* * *}$ & $1.010^{* * *}$ \\
& $(0.0016)$ & $(0.0016)$ & $(0.0016)$ & $(0.0016)$ \\
$\alpha^{E F F}$ & $0.999^{*}$ & 1.000 & & $1.002^{* * *}$ \\
& $(0.0004)$ & $(0.0004)$ & & $(0.0004)$ \\
$\alpha^{G E N}$ & $1.001^{*}$ & & 1.000 & $0.998^{* * *}$ \\
& $(0.0003)$ & & $(0.0004)$ & $(0.0004)$ \\
$\alpha^{E N V}$ & & $1.001^{*}$ & $1.001^{*}$ & $1.003^{*}$ \\
& & $(0.0003)$ & $(0.0004)$ & $(0.0004)$ \\
\hline
\end{tabular}

Notes: Odds ratios of the conditional logit models of subjects' decisions in the five main choices. Pseudo R-Squared: 0.288, Chisquared: $112.8657 .{ }^{*} p<.10,{ }^{* *} p<.05,{ }^{* * *} p<.01$. Individual specific standard errors in parenthesis.

The conditional logit model estimates the value that the average subject attaches to each motive. The choice patterns, however, suggest that the importance placed on the motives varies quite a lot across subjects. For example, 16 percent of subjects always choose in line with MXM and 26 percent always in line with SLF (see Figure 3). These two groups of subjects are likely to have very different tastes, since they seem to place a big weight on two different motives. To account for these differences we estimate a mixed logit model, which allows for taste heterogeneity.

$$
U_{i m k}=\alpha_{i}^{S L F} x_{i k m}+\alpha_{i}^{B N S}\left[-\sum_{j=1}^{n} \max \left(t-x_{j k m}, 0\right)\right]+\alpha_{i}^{M X M} \min (x)+\alpha_{i}^{E F F} \sum_{j=1}^{n} x_{j k m},
$$

$$
((E F F+E N V-G E N) / 5): \chi^{2}(1)=42.30, p<.0001 .
$$




$$
\begin{gathered}
+\alpha_{i}^{G E N}\left[-\sum_{j=1}^{n} \max \left(x_{i k m}-x_{j k m}, 0\right)\right]+\alpha_{i}^{E N V}\left[-\sum_{j=1}^{n} \max \left(x_{j k m}-x_{i k m}, 0\right)\right]+\varepsilon_{i k m} \\
=\alpha_{i}^{w} c_{i k m}^{w}+\varepsilon_{i k m}
\end{gathered}
$$

Let be the utility a subject $i$ derives from choosing an alternative $k \in\{A, B, C\}$ in choice $m \in$ $\{1, \ldots, 10\}$, where the coefficients $\alpha_{i}^{w}$ vary over dictators, $c_{i k m}^{w}$ is a vector of distributional concerns, $w \in\{S L F, B N S, M X M, E F F, G E N, E N V\}$, and $\varepsilon_{i k m}$ is a random term that is independently and identically extreme value distributed. The coefficient vector has density $g(\alpha \mid \theta)$ with distribution parameters $\theta$. The mixed logit choice probability (i.e., the probability of the dictator's choice sequence conditional on the parameters of the population distribution) is:

$$
P_{i}(\theta)=\int S_{i}(\alpha) g(\alpha \mid \theta) d \alpha
$$

where $S_{i}\left(\alpha_{i}\right)=\prod_{m=1}^{M} L_{i k(i, m) m}\left(\alpha_{i}\right)$ is the probability of the observed choice sequence conditional on knowing $\alpha_{i}^{w}$, in which $k(i, m)$ specifies alternative $k$ chosen by dictator $i$ in choice $m$, and with $L_{i k(i, m) m}\left(\alpha_{i}\right)=\frac{\exp \left(\alpha_{i}^{w} c_{i k(i, m) m}^{w}\right)}{\sum_{m=1}^{M} \exp \left(\alpha_{i}^{w} c_{i k m}^{w}\right)}$. The mixed logit model estimates the population parameters $\theta$ based on the simulated log likelihood $S L L(\theta)=\ln \left\{\frac{1}{R} \sum_{r=1}^{R} S_{i}\left(\alpha^{r}\right)\right\}$ for each observation. For this maximum simulated likelihood estimation, $R$ is the number of draws of $\alpha$ taken from $g(\alpha \mid \theta)$ (see Train, 2009; Hole, 2007).

Table 3 displays the means and standard deviations of the mixed logit estimates. Again, due to multicollinearity between the motives SLF, EFF, GEN, and ENV, we estimate four different models, in each of which we leave out one of the motives. The estimations are conducted with $R=5000$ Halton draws and assuming that the coefficients are normally distributed in our sample. ${ }^{42}$ We estimate the models using subjects' decisions in the five main choices plus the five additional choices in order to maximize the number of observations. We use individual specific standard errors to account for dependencies of choices across decisions of the same subject. The comparison of the estimated means with the sample means of the conditional distributions reveals that this is indeed a reasonable assumption and that the model is correctly specified (Train, 2009).

42 For model (4), we use 6000 Halton draws. We chose these numbers because from this number onwards the coefficients remain stable (i.e., when estimating model (1), (2), and (3) with, e.g., $6000,7000,9000,10,000$ draws and model (4) with 7000,9000 or 10,000 draws, the coefficients remain approximately the same (Hensher and Greene, 2001). 
Table 3: Mixed logit models

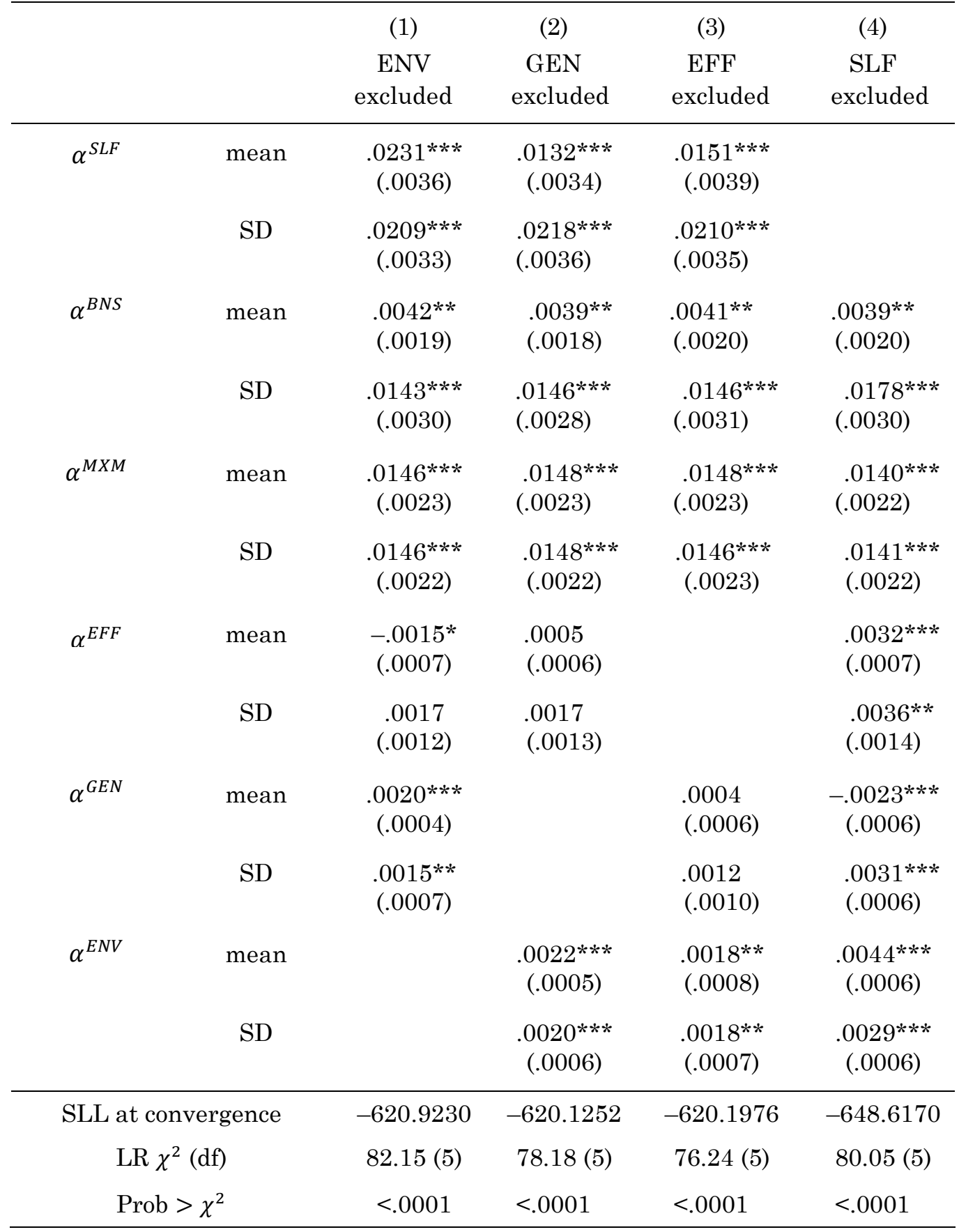

Notes: The dependent variable is the option subjects choose in the five main and the five additional choices. The independent variables are the utilities of the options in terms of each motive. Individual specific standard errors in parenthesis. SLL=Simulated log likelihood. SD= Standard deviation. LR $\chi^{2}$ is the likelihood ratio test for the joint significance of the standard deviations (degrees of freedom in parenthesis) (Hole, 2007). $N=2700 .{ }^{*} p<.10,{ }^{* *} p<.05,{ }^{* * *} p<.01$.

We find that in all models, the estimated coefficients of BNS, MXM, SLF, and ENV are significant and positive. This means that the average subject seems to attach a positive weight to these motives. Moreover, the estimated standard deviations reveal that there is significant heterogeneity in subjects' tastes. This indicates that allowing for differences in 
tastes in the mixed logit model is indeed a more suitable specification than assuming taste homogeneity as in the conditional logit model. The relation between a coefficient's mean and its standard deviation provides information about the proportion of subjects who place a positive weight on the motive (Hole, 2007). For MXM, this share is about 84 percent in all models, while for SLF the share is between 73 and 87 percent. For BNS, about 60 percent of subjects place a positive weight on the motive. For EFF, this share is between 19 and 81 percent, for GEN between 23 and 93 percent, and for ENV between 84 and 94 percent depending on the model. Note that, however, these numbers do not take into account how far away the different coefficients are from zero.

To summarize, the estimation results, both of the conditional and the mixed logit model, confirm the conclusions drawn from the descriptive results. Subjects seem to care for their own income, the income of the least well-off person, and the fulfillment of basic needs. Further, to some extent, they also seem to dislike situations, in which another person has more than themselves.

\subsubsection{Robustness}

We provide results from two additional experiments to evaluate the robustness of our results under different incentives.

\section{Hypothetical choices}

In our experiment, subjects' choices determine their own payoff and the payoff of other participants. However, the actual payments are smaller than the nominal amounts displayed in the choices and those that were referred to in the introductory text. Hence, it might be the case, for example, that individuals do not perceive that persons 4 and 5 are in need based on the income amounts in the societal frame. We are positive that the societal frame is salient to subjects when they make their decisions. Further, evaluating subjects' answers to two open-ended questions at the end of the experiment suggests that subjects actually did decide in the societal frame. ${ }^{43}$ This makes us confident that subjects in general evaluated the choices with regards to monthly incomes. Nevertheless, we also tested whether our results hold when subjects' choices are hypothetical in an additional experiment with 90 different subjects from the same subject pool. ${ }^{44}$ In a hypothetical setting, there only exists the societal frame in which the allocations can be compared. Subjects received the same set of choices and the same information text before making their decisions.

We find that the prevalence of the different motives is largely robust to removing the incentives based on dictators' decisions, with the exception that individuals behave less

43 In the two open-ended questions, we asked subjects to describe how they took their decisions (see Section 2.5). In their answers, they, for example, used terms such as 'income' to refer to the monetary amounts in the choices, which suggests that they were thinking about the income amounts displayed to them in the choices as opposed to mere experimental 'payoffs'.

44 The experiment took place at the University of Cologne. The experimenters were the same two persons and the subjects were again recruited through ORSEE. Subjects received a fixed payoff of 10 Euros, independent of their own or other subjects' decisions. 
selfishly. In the main choices in the hypothetical setting, 10-17 percent (with an average of 13 percent) of subjects choose in line with BNS in the five main choices (see Figure 4). A series of Chi-squared tests show that the differences in the fractions of subjects who choose in line with BNS between the hypothetical and the incentivized experiment are not statistically significant in any of the choices. ${ }^{45}$ The fraction of subjects choosing in line with a different other-regarding motive when it alone predicts an allocation is also comparable to the incentivized experiment. In the hypothetical experiment, however, fewer subjects choose the option that is only predicted by SLF in choice $2{ }^{46}$ That people behave less selfishly in a hypothetical setting might be due to lower costs (Forsythe et al., 1994), which might be explained by social image concerns (Bénabou and Tirole, 2006). Individual choice patterns reveal that 31 percent of subjects choose at least once in line with BNS. For these subjects, we can thus conclude that they attach a positive weight to concerns for BNS. About seven percent of subjects choose in line with the motive at least four out of five times. These findings are again comparable to the results of our main experiment. To summarize, this illustrates that the fulfillment of basic needs is an important driver of subjects' choices and that these results also hold in a setting in which the allocations can be compared regarding all motives on a purely hypothetical basis.

45 Chi-squared tests of the null-hypothesis that the fraction of subjects choosing the option that only BNS predicts is the same in the hypothetical and the incentivized experiment: Choice 1 $(\mathrm{MXM}): \chi^{2}(1)=.0539, p=.816$, choice $2(\mathrm{SLF}): \chi^{2}(1)=3340, p=.563$, choice 3 (EFF): $\chi^{2}(1)=.7193, p=.396$, choice $4(\mathrm{GEN}): \chi^{2}(1)=2.2716, p=.131$, choice $5(\mathrm{GEN}): \chi^{2}(1)=$ $1.9095, p=.167$.

46 Chi-squared tests of the null-hypothesis that the fraction of subjects choosing the option that one motive alone predicts (Option A) is the same in the hypothetical and the incentivized experiment: Choice $1(\mathrm{MXM}): \chi^{2}(1)=.8333, p=.361$, choice $2(\mathrm{SLF}): \chi^{2}(1)=5.3005, p=.021$, choice $3(\mathrm{EFF}): \chi^{2}(1)=.0000, p>.999$, choice $4(\mathrm{GEN}): \chi^{2}(1)=.1170, p=.732$, choice 5 $(\mathrm{GEN}): \chi^{2}(1)=.2469, p=.619$. 
Figure 4: Choice fractions main choices (Hypothetical experiment)

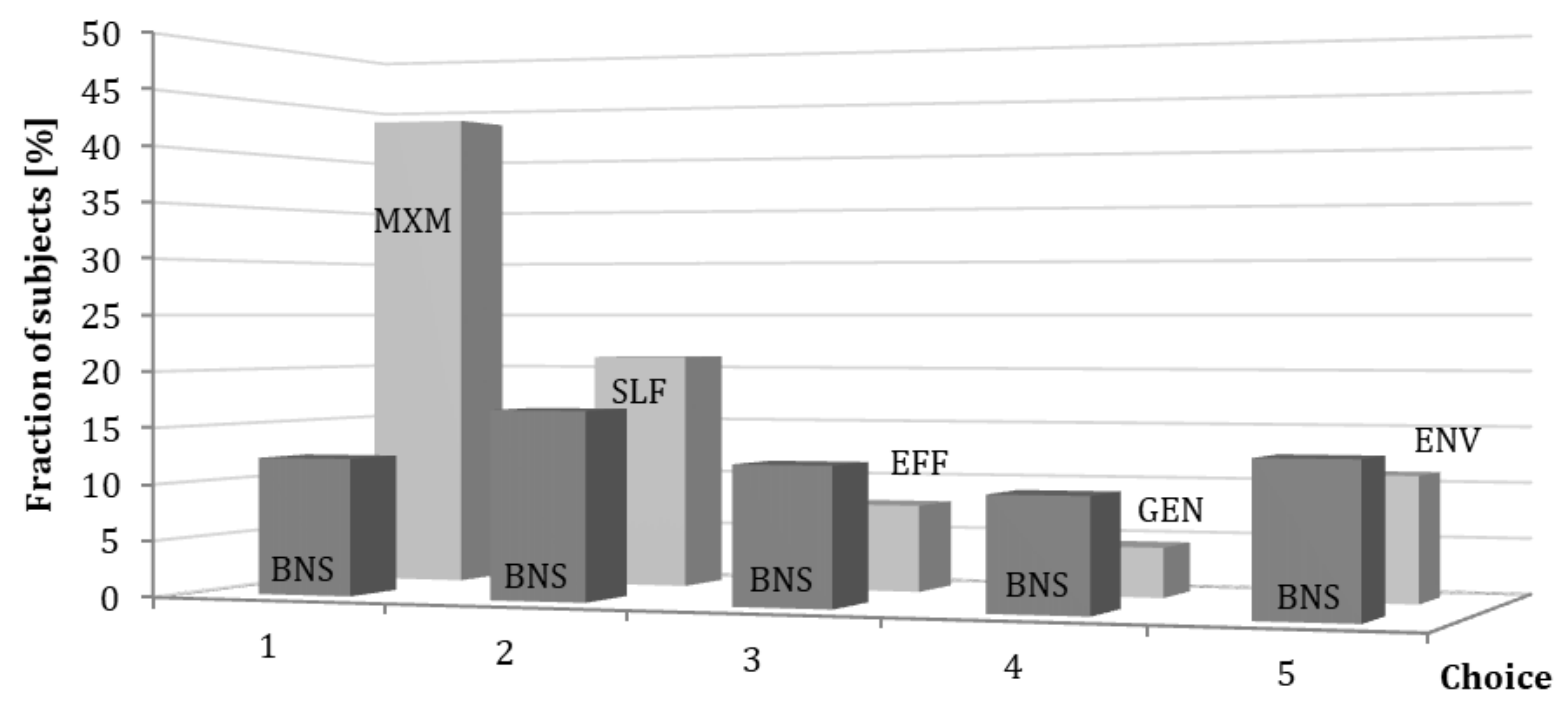

Notes: Fraction of subjects choosing Option $\mathrm{C}$ and thus attaching a positive weight to BNS (dark grey bars) and fraction of subjects choosing Option A and thus attaching a positive weight to the respective motive predicting this option (light grey bars) in the main choices (choice 1-5) of the hypothetical setting. The remaining subjects choose Option B (the option predicted by the four remaining motives), which is not depicted here.

\section{Increased stake sizes}

Another potential critique to the validity of our results is that stake sizes were small. Subjects' expected hourly earnings for the 20 choices in the first part of the experiment were 11.71 Euros. ${ }^{47}$ Despite the fact that this is in the range of common incentive sizes in laboratory experiments, it is not clear to what extent our results hold in case of higher incentives (Engel, 2011). To investigate this question, we use data from an experiment conducted with a sample of 45 students at the International School of Economies in Tbilisi (Georgia). The experiment was a pilot study for the choice experiment in Tbilisi, which will be the focus of Chapter III. Subjects were exposed to the first ten choices of the main experiment with the amounts (including the threshold for basic needs satisfaction) adjusted to the Georgian context. In this experiment, subjects could expect to earn 18.21 GEL per hour. This amount constitutes about 5.4 percent of the median monthly income in Georgia, which illustrates that incentives were quite substantial in this experiment. ${ }^{48}$ As a comparison, the hourly expected earnings in our study in Cologne make up only 0.75 percent of the median monthly income in Germany. ${ }^{49}$ The experiment was conducted on a

47 The expected earnings for 10-20 choices in the first part of the experiment that lasted about 45 minutes are 8.78 Euros. This number was calculated as the average payoff of all possible choices in the experiment given that roles are assigned at random, one choice is selected at random for payoff, and under the assumption that each option is chosen with equal probability.

48 Figure based on the median net equivalent income per month in Georgia in 2013 of 337 GEL (Geostat, 2015a).

49 Figure based on the median net equivalent income per month in Germany in 2010 of 1570 Euros (Statistisches Bundesamt, 2012b). 
pen and paper basis and in English. The rest of the experimental setup was identical to the experiment in Cologne.

Figure 5: Choice fractions main choices (Tbilisi)

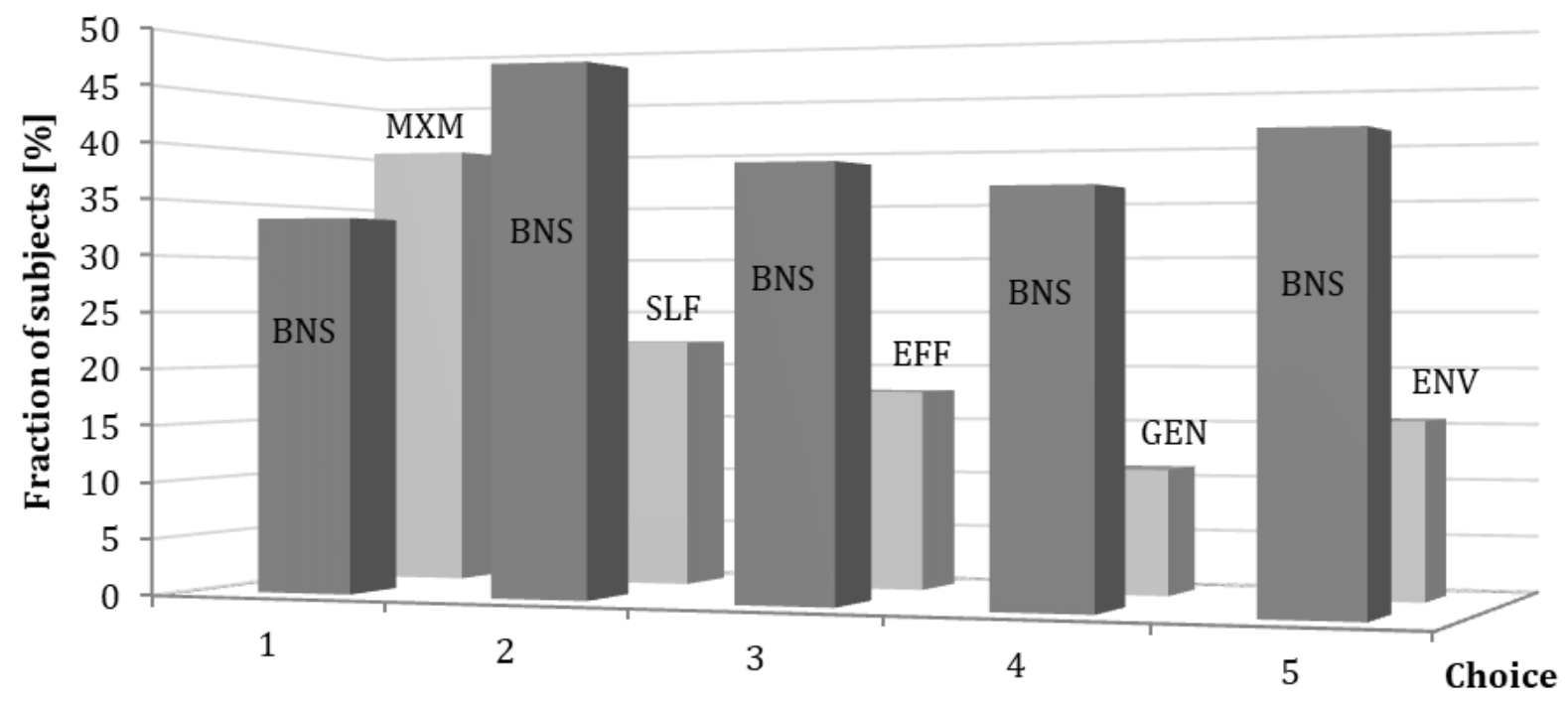

Notes: Fraction of subjects choosing Option $\mathrm{C}$ and thus attaching a positive weight to BNS (dark grey bars) and fraction of subjects choosing Option A and thus attaching a positive weight to the respective motive predicting this option (light grey bars) in the main choices (choice 1-5) in Tbilisi. The remaining subjects choose Option B (the option predicted by the four remaining motives), which is not depicted here.

Our results again indicate that BNS plays a role in subjects' decisions between the different allocations. In total, 33-47 percent (with an average of 39 percent) of subjects choose in line with the motive in the five main choices. A series of Chi-squared tests confirms that, if anything, subjects in Tbilisi place a higher weight on satisfying basic needs than our subjects in Cologne. ${ }^{50}$ Subjects in Tbilisi also seem to place a slightly lower weight on SLF, but a slightly higher weight on EFF. ${ }^{51}$ The remaining motives appear to be equally important in the two samples. ${ }^{52}$ Furthermore, the individual choice patterns indicate that BNS is a relatively important motive among subjects. 69 percent of subjects choose at least once the option that is only comparable with placing a positive weight on

50 Chi-squared tests of the null-hypothesis that the fraction of subjects choosing in line with BNS is the same in the main experiment and in Tbilisi: Choice 1: $\chi^{2}(1)=9.8182, p=.002$, choice 2 : $\chi^{2}(1)=10.3846, p=.001$, choice $3: \chi^{2}(1)=7.3931, p=.007$, choice $4: \chi^{2}(1)=5.2427, p=$ .022 , choice $5: \chi^{2}(1)=5.3799, p=.020$.

51 Chi-squared tests of the null-hypothesis that the fraction of subjects choosing in line with SLF $(\mathrm{EFF})$ is the same in the main experiment and in Tbilisi: Choice 2 (SLF): $\chi^{2}(1)=2.8836, p=$ .089 , choice $3(\mathrm{EFF}): \chi^{2}(1)=3.0375, p=.081$.

52 Chi-squared tests of the null-hypothesis that the fraction of subjects choosing in line with MXM (GEN, ENV) is the same in the main experiment and in Tbilisi: Choice $1(\mathrm{MXM}): \chi^{2}(1)=.1418$, $p=.706$, choice $4(\mathrm{GEN}): \chi^{2}(1)=1.3500, p=.245 \times 2(1)=1.3500, \mathrm{p}=0.245$, choice 5 (ENV): $\chi^{2}(1)=1.3500, p=.245$. 
the motive in the main choices. 24 percent do so at least four out of five times, while 18 percent always choose in line with the motive. To summarize, this study shows that our findings on the importance of BNS are robust to increased stake sizes. If anything, we even find a higher prevalence of the motive, indicating that subjects in Tbilisi attach a relatively high importance to it compared to subjects in Cologne.

Note that the fact that we find a substantially higher amount of choices in line with BNS could be due to the fact that subjects were more likely to know each other. The university in which the experiment was conducted is a small institution in which students are quite familiar with each other. On the contrary, at the University of Cologne with more than 50,000 students it is a lot less likely that subjects knew each other (Universität zu Köln, 2016). Decisions in both experiments were anonymous. Nevertheless, the fact that subjects in Tbilisi knew that their choice would potentially not affect a total stranger could have influenced their decision. Interestingly, from the other-regarding motives targeted towards poorer persons than the decision maker, MXM, GEN, and BNS, only BNS was substantially higher than in the main experiment. One interpretation of this is that BNS becomes more important as anonymity decreases. However, since there are also other important differences between the two samples, this remains an open question for future research.

\subsection{QUALITATIVE DATA}

It could be argued that subjects choose allocations because of different reasons than the distributional motives under consideration. The individual choice patterns indicate that a majority of subjects is indeed motivated by these motives. However, to further shed light on subjects' reasoning process, we asked subjects in the hypothetical experiment two openended questions in the post experimental questionnaire. ${ }^{53}$ The questions were phrased as follows: "What did you consider when making your decision?" and "What criteria did you apply to make your decision?". ${ }^{54}$ The answers to each of the two questions were coded with the help of three different student assistants of the University of Cologne independently from each other. They followed a strict coding protocol (see Table 7 in Appendix G). The protocol contained a detailed description of the coding categories corresponding to the six different motives. The coders were instructed to assign the respective code to an answer if it was consistent with a certain motive. ${ }^{55}$

53 The hypothetical experiment is well suited to analyze self-reflection data, since confounding effects, such as rationalization and justification of choices is less likely to occur.

54 English translation of the German original questions: "Worauf haben Sie bei Ihrer Entscheidung geachtet?” and „Nach welchen Kriterien haben Sie Ihre Entscheidung getroffen?".

55 First, two student assistants coded all answers. We then compared the two codings. If they matched, this answer was qualified as consistent with the respective motive(s). If any of the assigned codes differed, a third student assistant coded those answers again, independently from the first two coders. We then compared the codes of the three coders. An answer was rated as consistent with a motive when two of the three coders had assigned the same code to 
For the analysis, we pooled the data of the two questions. 81 percent of subjects were assigned at least one code, while 28 percent argue in line with two or three of the motives. If subjects indeed choose an allocation because of the respective motive that predicts it, then those who choose repeatedly in line with a motive should mention the respective motive more often than other subjects. A series of Fisher's exact tests confirms that this is the case for BNS, MXM, and SLF types. For ENV, GEN, and EFF types, this is, however, not the case. ${ }^{56}$ At the same time, BNS, MXM, and SLF types don't mention any of the other motives more often than other subjects. This suggests that in general subjects who appear to attach a high importance to concerns for MXM, SLF, or BNS according to their choice patterns, also seem to do so in their explanations for their decisions. Hence, those subjects indeed seem to be primarily guided by considerations in line with the motives according to which we classified them based on their decisions in the five main choices. In case subjects classified as BNS types, the answers to the open-ended questions revealed, however, that some subjects aim at minimizing the sum of unfulfilled needs, while others want to minimize the number of persons falling below the threshold. In our choices, these two variations of basic needs fulfillment cannot be disentangled on the basis of choice data, since the minimum number of persons falling below the threshold always coincides with the minimum amount of unfulfilled basic needs. In Chapter III of this thesis, we further investigate by which of these variations subjects' choices are driven.

Altogether, this is further evidence for the fact that BNS is a conceptually different distributional motive from MXM. The analysis of the two open-ended questions reveals that subjects' motives elicited by their allocation choices do, at least in the case of MXM, SLF, and BNS, reflect their (stated) reasons for choosing those allocations. Thus, these findings also lend additional support "to the behavioral relevance of social preferences models" (Jiang et al., 2016, p.164).

\subsection{CONCLUDING REMARKS}

Our findings show that a non-negligible fraction of subjects cares for the satisfaction of basic needs. In our experiment, the motive can explain choices that cannot be explained by other established motives related to caring about the incomes of relatively poorer people in a society; maximin and generosity. Hence, we have established concerns for basic needs satisfaction as an important distinct distributional motive. Further, subjects are willing to sacrifice some of their own income, efficiency, and utility in terms of envy in order to satisfy additional basic needs. Altogether, this suggests that this motive is a potentially

this answer. Answers in which subjects wrote that they wanted as many persons as possible to have an income above the threshold of 630 Euros were coded as consistent with BNS. In our choices, the minimum number of persons falling below the threshold always coincides with the minimum amount of unfulfilled basic needs.

56 P-values of two-sided Fisher's exact tests of the null-hypothesis that those subjects choosing five (at least four) times in line with a motive mention the respective motive equally often as other subjects: BNS: $p=.043$ (.001), MXM: $p=.009$ (.002), SLF: $p=.002(.002)$, EFF: $p=$ $N / A(>.999)$, GEN: $p>.999$ (.999), ENV: $p<.999(=.191)$. 
important consideration in the distribution of incomes.

Note that we assume that the desire to fulfill basic needs is a preference motive. An alternative approach is that subjects have a preference for complying with social norms, where basic needs satisfaction is one of them. In the information text, different social norms are triggered. Choices in the experiment would then reveal to which social norm subjects adhere in distributional decisions (Kimbrough and Vostroknutov, 2015).

A limitation of our study is that, while subjects' decisions are incentivized, the deprivation of basic needs remains hypothetical. Nevertheless, the unincentivized assessment of fairness motives can yield valuable results (Gaertner and Schokkaert, 2012). In the following chapters, we will explore concerns for basic needs satisfaction in two different settings in which we incentivize the fulfillment of basic needs. In Chapter III, we run fiveplayer dictator games similar to the ones in the main experiment of the current chapter with a sample from the general population in Tbilisi (Georgia). By taking into account subjects' current monthly income, dictators in the experiment decide about the final allocation of actual monthly incomes for themselves and four other persons. In Georgia, the social security system does not guarantee the fulfillment of basic human needs to everyone. Thus, if a dictator chooses an allocation in which all persons have an income above the national poverty line over an allocation in which, for example, two persons have an income below this threshold, she actively ensures that these persons have their basic needs satisfied in this month. In Chapter IV, we implement a variant of the dictator game in which receivers are at risk of being eliminated from subsequent rounds of the experiment if their final payoffs fall short of a certain threshold. By allocating money to the receiver, the dictator can help the receiver reach the threshold and thereby fulfill this person's needs. Moreover, the dictator also has a strategic motive to help the receiver, since if less than two receivers remain in the game, it is stopped. 
2.7 APPENDIX 


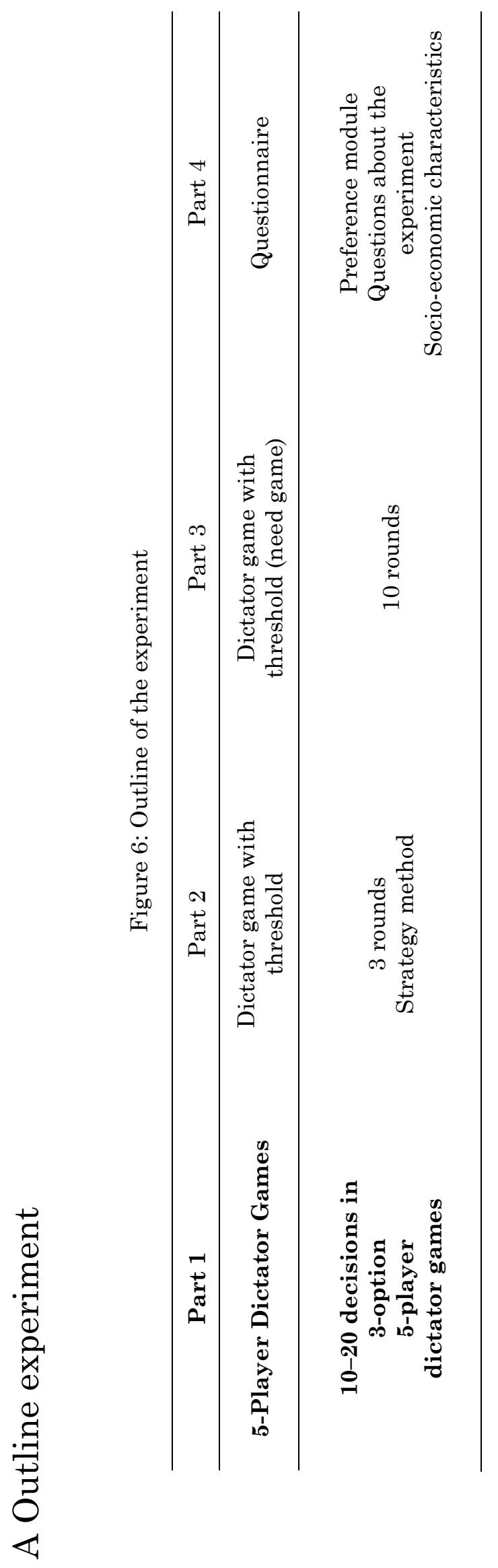




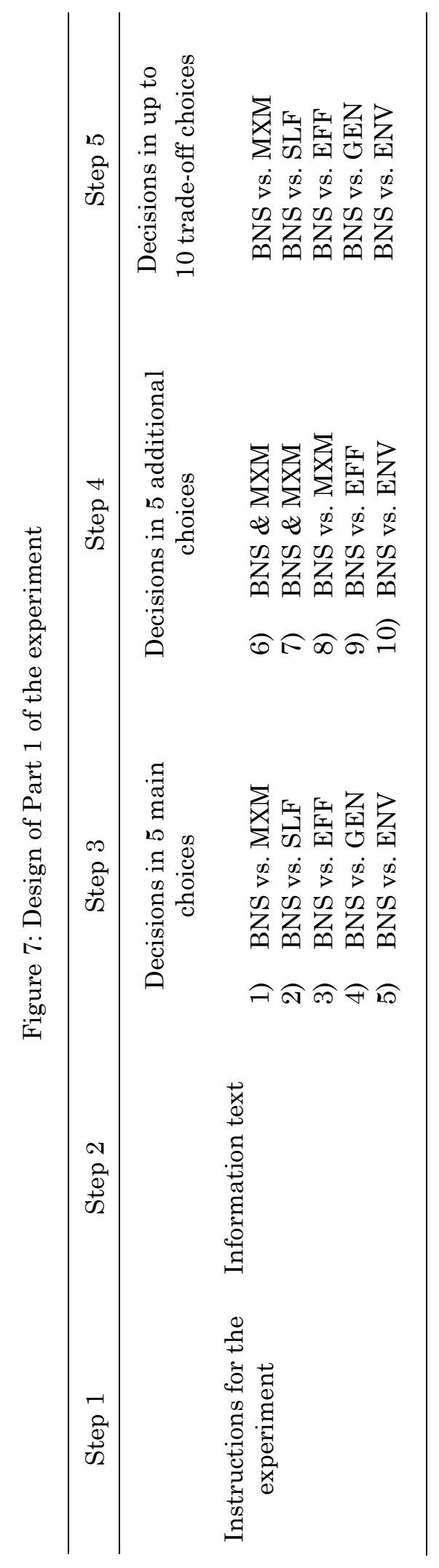




\section{B Instructions}

\section{B.l Main experiment: German original text}

\section{Instruktionen für das Experiment}

Sie nehmen nun an einem wirtschaftswissenschaftlichen Entscheidungsexperiment teil. Für Ihr Erscheinen erhalten Sie eine Aufwandsentschädigung in Höhe von 2,50 €. Im Verlauf des Experiments können Sie Geld in Form von „Talern“ hinzuverdienen. Am Ende des Experiments bekommen Sie alle im Experiment verdienten Taler in Euro umgerechnet ausgezahlt, wobei gilt:

15 Taler $=10$ Eurocent

Die Höhe Ihres Verdienstes hängt von Ihren Entscheidungen und von den Entscheidungen anderer Teilnehmer ab. Sie erfahren zu keinem Zeitpunkt die Identität der anderen Teilnehmer. Genauso erfahren die anderen Entscheider zu keinem Zeitpunkt Ihre Identität.

Alle Daten und Antworten werden anonym ausgewertet. Um Anonymität zu gewährleisten, haben Sie eine persönliche Kabinennummer gezogen.

Für die gesamte Dauer des Experiments ist es sehr wichtig, dass Sie nicht mit anderen Experimentsteilnehmern sprechen, Bitte legen Sie außerdem Ihre Handys, MP3-Player, Bücher, o.̈̈. an die Seite.

Bitte lesen Sie sich die Instruktionen für das Experiment sorgfältig durch. Wenn Sie während des Experiments etwas nicht verstehen sollten, schauen Sie bitte noch einmal in die Instruktionen. Falls Sie dann noch Fragen haben, geben Sie uns bitte ein Handzeichen, Wir werden dann zu Ihnen an die Kabinen kommen und Ihre Fragen persönlich beantworten.

Das Experiment besteht aus mehreren Teilen. Am Ende bitten wir Sie, noch einige Fragen zu beantworten.

\section{Erster Teil des Experiments}


Im ersten Teil des Experiments geht es um verschiedene Möglichkeiten, wie Einkommen zwischen den Mitgliedern einer Gesellschaft verteilt werden können. Dazu treffen Sie Entscheidungen über die Aufteilung von Geldbeträgen in mehreren Entscheidungssituationen. In jeder Entscheidungssituation haben Sie die Wahl zwischen 3 verschiedenen Aufteilungsmöglichkeiten. Jede dieser Aufteilungsmöglichkeiten beinhaltet die Zuteilung eines Betrages für Sie selbst und 4 andere Personen. Auf der Rückseite ünden Sie hierzu ein Beispiel für eine exemplarische Entscheidungssituation:

\begin{tabular}{|c|c|c|c|}
\hline Option & A & B & C \\
\hline Person 1 (Andere Person) & (Betrag 1A) & (Betrag 1B) & (Betrag IC) \\
\hline Person 2 (Sie, Sie selber) & (Betrag 2A) & (Betrag 2B) & (Betrag 2C) \\
\hline Person 3 (Andere Person) & (Betrag 3A) & (Betrag 3B) & (Betrag 3C) \\
\hline Person 4 (Andere Person) & (Betrag 4A) & (Betrag 4B) & (Betrag 4C) \\
\hline Person 5 (Andere Person) & (Betrag 5A) & (Betrag 5B) & (Betrag 5C) \\
\hline Ihre Wahl: & & & \\
\hline
\end{tabular}

Die Spalten A, B und C beschreiben die 3 Aufteilungsmöglichkeiten (Option A, B, C). zwischen denen Sie wählen können. Sie entscheiden immer aus der Perspektive von Person 2. In den Spalten von Option A, B, oder C sehen Sie die Beträge, die die Personen 1, 2, 3, 4 und 5 erhalten, wenn Sie sich für die jeweilige Option entscheiden. Wenn Sie Option A wählen, erhält Person 1 den Betrag 1A, Sie würden in der Rolle von Person 2 den Betrag 2A erhalten, Person 3 erhält den Betrag 3A, Person 4 bekommt den Betrag 4A, und Person 5 den Betrag 5A. Wenn Sie Option B wählen, erhält Person 1 den Betrag 1B, Sie als Person 2 den Betrag 2B, Person 3 den Betrag 3B, Person 4 den Betrag 4B, Person 5 den Betrag 5B. Wenn Sie Option C wählen, erhält Person 1 dementsprechend den Betrag 1C, Sie als Person 2 den Betrag 2C, Person 3 den Betrag 3C, Person 4 den Betrag 4C, Person 5 den Betrag 5C.

\section{So bestimmen sich die Auszahlungen:}

Nachdem alle Teilnehmer ihre Entscheidungen für alle Entscheidungssituationen getroffen haben, werden die Teilnehmer zufällig in Gruppen von jeweils 5 Teilnehmern eingeteilt. Dann wird zufällig ein Teilnehmer in jeder 5er-Gruppe ausgelost, dessen Entscheidung auszahlungsrelevant für die jeweilige Gruppe ist. Dieser Teilnehmer ist Person 2. Den anderen 4 Teilnehmern einer Gruppe wird zufällig die Rolle der Personen 1, 3, 4, oder 5 zugeordnet. Zuletzt wird zufällig für alle Teilnehmer eine bestimmte Entscheidungssituation für die Auszahlung ausgewählt. Die Beträge werden dann entsprechend der jeweiligen Entscheidung der ausgewählten Person 2 einer Gruppe in dieser bestimmten Entscheidungssituation am Ende des Experiments an die Personen 1, 2, 3, 4, und 5 ausgezahlt.

Beispiel 1: Ihnen wurde in Ihrer 5er-Gruppe die Rolle der Person 4 zugeordnet. Sie erhalten dann den Geldbetrag, den Person 4 gemäß der Entscheidung der ausgelosten 
Person 2 in Ihrer Gruppe in der ausgewählten Entscheidungssituation erhält - wenn Person 2 in Ihrer Gruppe sich in der auszahlungsrelevanten Entscheidungssituation für Option B entschieden hat, dann erhalten Sie den Betrag 4B. Die anderen Teilnehmer erhalten gemäß ihrer Rolle die Beträge 1B, 2B, 3B, oder 5B.

Beispiel 2: Ihnen wurde in Ihrer 5er-Gruppe die Rolle der Person 2 zugeordnet. Die Auszahlungsbeträge für alle Teilnehmer der Gruppe ergeben sich somit aus Ihrer Entscheidung in der ausgewählten Entscheidungssituation. Sie erhalten dann den Betrag, den Person 2 gemäß Ihrer eigenen Entscheidung in der ausgewählten Entscheidungssituation erhält. Alle anderen Teilnehmer in Ihrer Gruppe erhalten gemäß ihrer zugelosten Rolle die Beträge, die sich aus Ihrer Entscheidung in der ausgewählten Entscheidungssituation ergeben: Wenn Sie sich in der auszahlungsrelevanten Entscheidungssituation für Option C entschieden haben, dann erhalten Sie den Betrag 2C, Die anderen Teilnehmer erhalten gemäß ihrer Rolle die Beträge $1 \mathrm{C}, 3 \mathrm{C}, 4 \mathrm{C}$ oder $5 \mathrm{C}$.

\section{B.2 Main experiment: English translation ${ }^{57}$}

\section{Instructions for the Experiment}

You are now taking part in an experiment involving economic decision-making. You will receive $2.50 €$ as a show-up fee. During the experiment, you will be able to earn money in the form of "coins". At the end of the experiment, all the coins you earned will be converted into Euros and paid out at the following rate:

\section{5 coins $=10$ Eurocent}

The amount you earn depends on your decisions or those of the other participants. At no time will the identity of the other participants be revealed. Neither will the other participants find out who you are.

All data and answers will be evaluated anonymously. You have drawn a personal cubicle number to guarantee your anonymity.

It is very important that you refrain from talking to the other participants at any time during the experiment. Please also put away your mobile phones, MP3 players, books etc.

57 English translation of the German original text. This translation is identical to the instructions used in the study with the student sample in Tbilisi with the following exceptions: (1) The sentence "You will receive 2,50 € as a show-up fee" was deleted, since there was no show-up fee; (2) The sentence "At the end of the experiment, all the coins you earned will be converted into Euros and paid out at the following rate: 15 coins = 10 Eurocent" was changed to "At the end of the experiment, all the coins you earned will be converted into GEL and paid out at the following rate: 20 coins $=1$ GEL". 
Read the instructions for the experiment carefully. If you don't understand anything during the experiment, take another look at the instructions. If you still have any questions, please give us a hand signal. We will then come to your cubicle and answer your questions in person.

The experiment consists of several parts. At the end, we would like you to answer a few more questions.

\section{First part of the experiment}

The first part of the experiment addresses various ways in which income can be distributed between the members of a society. For this, you will make decisions about distributing monies in several situations. In each situation, you will have a choice of 3 different distribution schemes. Each of these schemes involves the division of an amount between yourself and 4 other people. You will find an example of such a situation on the back:

\begin{tabular}{|c|c|c|c|}
\hline Option & A & B & C \\
\hline Person 1 (another person) & (Amount 1A) & (Amount IB) & (Amount 1C) \\
\hline Person 2 (you, yourself) & (Amount 2A) & (Amount 2B) & (Amount 2C) \\
\hline Person 3 (another person) & (Amount 3A) & (Amount 3B) & (Amount 3C) \\
\hline Person 4 (another person) & (Amount 4A) & (Amount 4B) & (Amount 4C) \\
\hline Person 5 (another person) & (Amount 5A) & (Amount 5B) & (Amount 5C) \\
\hline Your choice: & & & \\
\hline
\end{tabular}

Columns A, B, and C describe the 3 distribution schemes (options A, B, and C) from which you have to choose. You should always make your decisions from the perspective of person 2. The columns for options $\mathrm{A}, \mathrm{B}$, and $\mathrm{C}$ show the amounts which persons $1,2,3,4$, and 5 will receive if you choose the respective option. If you choose option A, person 1 will receive amount $1 \mathrm{~A}$. In the role of person 2, you will receive amount $2 \mathrm{~A}$, Person 3 will receive amount $3 \mathrm{~A}$, person 4 amount $4 \mathrm{~A}$, and person 5 amount $5 \mathrm{~A}$. If you choose option $\mathrm{B}$, person 1 will receive amount $1 \mathrm{~B}$, you as person 2 will receive amount $2 \mathrm{~B}$, person 3 amount $3 \mathrm{~B}$, person 4 amount $4 \mathrm{~B}$, and person 5 amount $5 \mathrm{~B}$. If you choose option $\mathrm{C}$, person 1 will receive amount $1 \mathrm{C}$, you as person 2 will receive amount $2 \mathrm{C}$, person 3 amount $3 \mathrm{C}$, person 4 amount $4 \mathrm{C}$, and person 5 amount $5 \mathrm{C}$.

\section{How the payments are determined:}

After all the participants have made their decisions for all situations, they will be randomly divided into groups of 5 . One participant in each group of 5 will then be drawn by lot. His decision will determine the payment received by his group. This participant is person 2 . The other 4 participants in the group will be randomly allocated the roles of persons 1, 3, 4 or 5. Finally, a specific decision situation will be chosen at random to establish the amounts to be paid. These amounts will then be paid out to persons $1,2,3$, 
4 , and 5 at the end of the experiment according to the decision made by person 2 in the situation chosen.

Example 1: You have been allocated the role of person 4 in your group of 5. You will then receive the amount due to person 4 according to the decision made by the group member chosen as person 2 in the situation selected - if person 2 decided on option $\mathrm{B}$, you will receive amount $4 \mathrm{~B}$. The other participants will receive amounts $1 \mathrm{~B}, 2 \mathrm{~B}, 3 \mathrm{~B}$, or $5 \mathrm{~B}$.

Example 2: You have been allocated the role of person 2 in your group of 5 . The amounts paid to each group member will therefore be based on the decision you made in the situation chosen. You will receive the amount due to person 2 according to the decision you made in the respective situation. Depending on the roles they have been allocated, the other group members will receive the payment due to them according to your decision in the selected situation. If you decided on option $\mathrm{C}$, you will receive amount $2 \mathrm{C}$. The other participants will receive amounts $1 \mathrm{C}, 3 \mathrm{C}, 4 \mathrm{C}$, or $5 \mathrm{C}$ depending on their roles.

\section{B.3 Hypothetical experiment: German original text}

\section{Instruktionen für das Experiment}

Sie nehmen nun an einem wirtschaftswissenschaftlichen Entscheidungsexperiment teil.

Für Ihre Teilnahme erhalten Sie eine Aufwandsentschädigung in Höhe von $10 €$.

Sie erfahren zu keinem Zeitpunkt die Identität der anderen Teilnehmer. Genauso erfahren die anderen Entscheider zu keinem Zeitpunkt Ihre Identität.

Alle Daten und Antworten werden anonym ausgewertet. Um Anonymität zu gewährleisten, haben Sie eine persönliche Kabinennummer gezogen.

Für die gesamte Dauer des Experiments ist es sehr wichtig, dass Sie nicht mit anderen Experimentsteilnehmern sprechen. Bitte legen Sie außerdem Ihre Handys, MP3-Player, Bücher, o.̈̈. an die Seite.

Bitte lesen Sie sich die Instruktionen für das Experiment sorgfältig durch. Wenn Sie während des Experiments etwas nicht verstehen sollten, schauen Sie bitte noch einmal in die Instruktionen. Falls Sie dann noch Fragen haben, geben Sie uns bitte ein Handzeichen. Wir werden dann zu Ihnen an die Kabinen kommen und Ihre Fragen persönlich beantworten.

Das Experiment besteht aus mehreren Teilen. Am Ende bitten wir Sie, noch einige Fragen zu beantworten.

\section{Erster Teil des Experiments}

Im ersten Teil des Experiments geht es um verschiedene Möglichkeiten, wie Einkommen 
zwischen den Mitgliedern einer Gesellschaft verteilt werden können. Dazu treffen Sie hypothetische Entscheidungen über die Aufteilung von Geldbeträgen in mehreren Entscheidungssituationen. In jeder Entscheidungssituation haben Sie die Wahl zwischen 3 verschiedenen Aufteilungsmöglichkeiten, Jede dieser Aufteilungsmöglichkeiten beinhaltet die Zuteilung eines Betrages für Sie selbst und 4 andere Personen, Im Folgenden ünden Sie hierzu ein Beispiel für eine exemplarische Entscheidungssituation:

\begin{tabular}{|c|c|c|c|}
\hline Option & A & B & C \\
\hline Person 1 (Andere Person) & (Betrag 1A) & (Betrag 1B) & (Betrag IC) \\
\hline Person 2 (Sie, Sie selber) & (Betrag 2A) & (Betrag 2B) & (Betrag 2C) \\
\hline Person 3 (Andere Person) & (Betrag 3A) & (Betrag 3B) & (Betrag 3C) \\
\hline Person 4 (Andere Person) & (Betrag 4A) & (Betrag 4B) & (Betrag 4C) \\
\hline Person 5 (Andere Person) & (Betrag 5A) & (Betrag 5B) & (Betrag 5C) \\
\hline Ihre Wahl: & & & \\
\hline
\end{tabular}

Die Spalten A, B und C beschreiben die 3 Aufteilungsmöglichkeiten (Option A, B, C). zwischen denen Sie wählen können. Sie entscheiden immer aus der Perspektive von Person 2, In den Spalten von Option A, B, oder C sehen Sie die Beträge, die die Personen 1, 2, 3, 4 und 5 erhalten, wenn Sie sich für die jeweilige Option entscheiden. Wenn Sie Option A wählen, erhält Person 1 den Betrag 1A, Sie würden in der Rolle von Person 2 den Betrag 2A erhalten, Person 3 erhält den Betrag 3A, Person 4 bekommt den Betrag 4A, und Person 5 den Betrag 5A. Wenn Sie Option B wählen, erhält Person 1 den Betrag 1B, Sie als Person 2 den Betrag 2B, Person 3 den Betrag 3B, Person 4 den Betrag 4B, Person 5 den Betrag 5B. Wenn Sie Option C wählen, erhält Person 1 dementsprechend den Betrag 1C, Sie als Person 2 den Betrag 2C, Person 3 den Betrag 3C, Person 4 den Betrag 4C, Person 5 den Betrag 5C.

\section{B.4 Hypothetical experiment: English translation}

\section{Instructions for the Experiment}

You are now taking part in an experiment involving economic decision-making.

\section{You will receive $10 €$ as a show-up fee.}

At no time will the identity of the other participants be revealed. Neither will the other participants find out who you are.

All data and answers will be evaluated anonymously. You have drawn a personal cubicle 
number to guarantee your anonymity.

It is very important that you refrain from talking to the other participants at any time during the experiment. Please also put away your mobile phones, MP3 players, books etc.

Read the instructions for the experiment carefully. If you don't understand anything during the experiment, take another look at the instructions. If you still have any questions, please give us a hand signal. We will then come to your cubicle and answer your questions in person.

The experiment consists of several parts. At the end, we would like you to answer a few more questions.

\section{First part of the experiment}

The first part of the experiment addresses various ways in which income can be distributed between the members of a society. For this, you will make hypothetical decisions about distributing monies in several situations. In each situation, you will have a choice of 3 different distribution schemes. Each of these schemes involves the division of an amount between yourself and 4 other people. You will find an example of such a situation on the back:

\begin{tabular}{|c|c|c|c|}
\hline Option & A & B & C \\
\hline Person 1 (another person) & (Amount 1A) & (Amount IB) & (Amount 1C) \\
\hline Person 2 (you, yourself) & (Amount 2A) & (Amount 2B) & (Amount 2C) \\
\hline Person 3 (another person) & (Amount 3A) & (Amount 3B) & (Amount 3C) \\
\hline Person 4 (another person) & (Amount 4A) & (Amount 4B) & (Amount 4C) \\
\hline Person 5 (another person) & (Amount 5A) & (Amount 5B) & (Amount 5C) \\
\hline Your choice: & & & \\
\hline
\end{tabular}

Columns A, B, and C describe the 3 distribution schemes (options A, B, and C) from which you have to choose. You should always make your decisions from the perspective of person 2. The columns for options $\mathrm{A}, \mathrm{B}$, and $\mathrm{C}$ show the amounts which persons $1,2,3,4$, and 5 will receive if you choose the respective option. If you choose option A, person 1 will receive amount $1 \mathrm{~A}$, In the role of person 2 , you will receive amount $2 \mathrm{~A}$, Person 3 will receive amount $3 \mathrm{~A}$, person 4 amount $4 \mathrm{~A}$, and person 5 amount $5 \mathrm{~A}$. If you choose option $\mathrm{B}$, person 1 will receive amount $1 \mathrm{~B}$, you as person 2 will receive amount $2 \mathrm{~B}$, person 3 amount $3 \mathrm{~B}$, person 4 amount $4 \mathrm{~B}$, and person 5 amount $5 \mathrm{~B}$. If you choose option $\mathrm{C}$, person 1 will receive amount $1 \mathrm{C}$, you as person 2 will receive amount $2 \mathrm{C}$, person 3 amount $3 \mathrm{C}$, person 4 amount $4 \mathrm{C}$, and person 5 amount $5 \mathrm{C}$. 


\section{Information text}

\section{C.l Main experiment: German original text ${ }^{58}$}

\section{Wichtige Information zum Experiment}

Eine wichtige gesellschaftliche Frage betrifft die Höhe der individuellen Einkommen. Die Mitglieder einer Gesellschaft haben die Möglichkeit, diese zu beeinflussen. Das kann beispielsweise dadurch geschehen, dass man dem Ärmsten ein zusätzliches Einkommen gibt. Auf der anderen Seite kann auch die Höhe des gesellschaftlichen Gesamteinkommens eine Rolle spielen. Außerdem kann eine Gesellschaft die Unterschiedlichkeit der individuellen Einkommen berücksichtigen, beispielsweise im Vergleich zum mittleren Nettoeinkommen. In Deutschland liegt das mittlere Nettoeinkommen für eine alleinstehende Person pro Monat bei 1570 Euro. Es gibt dabei Menschen, die mehr oder auch weniger als diesen Betrag zur Verfügung haben. Laut Experten des Statistischen Bundesamtes liegt die Armutsgrenze in Deutschland bei 40 Prozent des mittleren Nettoeinkommens, also bei 630 Euro. Es wurde ermittelt, dass es Menschen mit einem Einkommen unterhalb dieser Grenze nicht möglich ist, die zum Leben notwendigen Ressourcen zu erwerben.

\section{C.2 Main experiment: English translation}

\section{Important information about the experiment}

One important social issue is the amount of individual income. The members of a society are able to influence this, for example by paying extra income to the poorest. However, the income available to the society as a whole can also play a part. Moreover, the society can also take differences in individual income into account, for example when compared to the average net income. In Germany, the average monthly net income for a single person is 1570 Euros. There are people who have more or less money at their disposal. According to experts at the federal statistical office, the poverty line is 40 percent of the median net income, i.e., 630 Euros. It was found that people whose income is lower than this amount are unable to acquire the resources required to subsist.

\section{C.3 Lab study Tbilisi: English original text}

\section{Important information about the experiment}

One important social issue is the amount of individual income. The members of a society are able to influence this, for example by paying extra income to the poorest. However, the

58 This text was used in the incentivized, as well as in the hypothetical experiment in Cologne. 
income available to the society as a whole can also play a part. Moreover, the society can also take differences in individual income into account, for example when compared to the average net income. In Georgia, the average monthly net income for a single person is 274 GEL. There are people who have more or less money at their disposal. According to experts at the National Statistics Office, the subsistence minimum is 130 GEL. It was found that people whose income is lower than this amount are unable to acquire the resources required to subsist. 


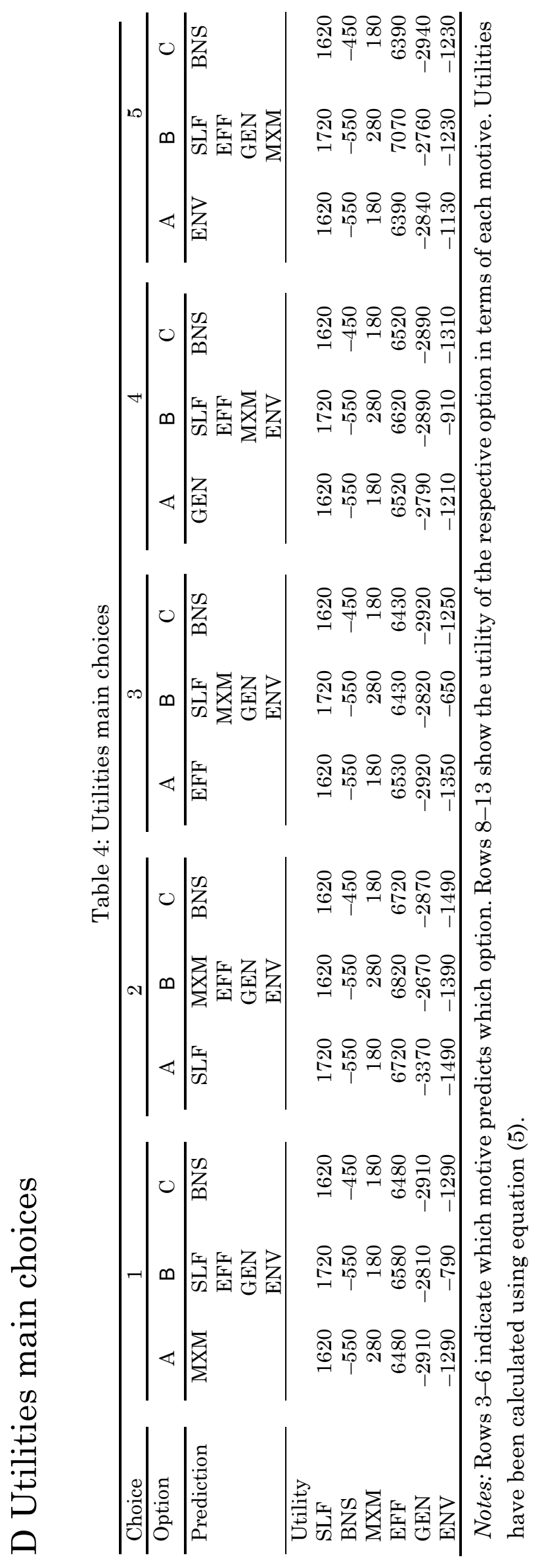




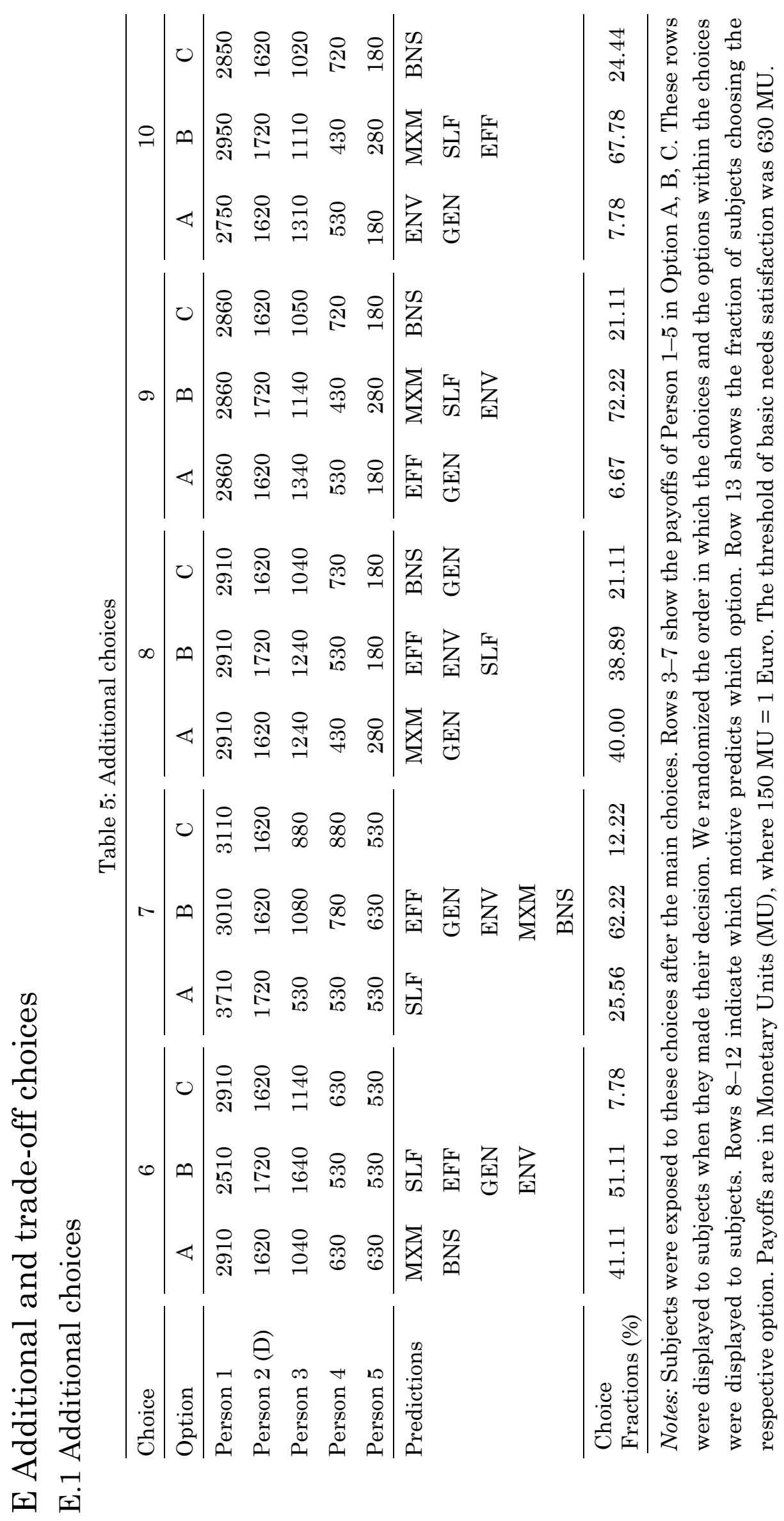




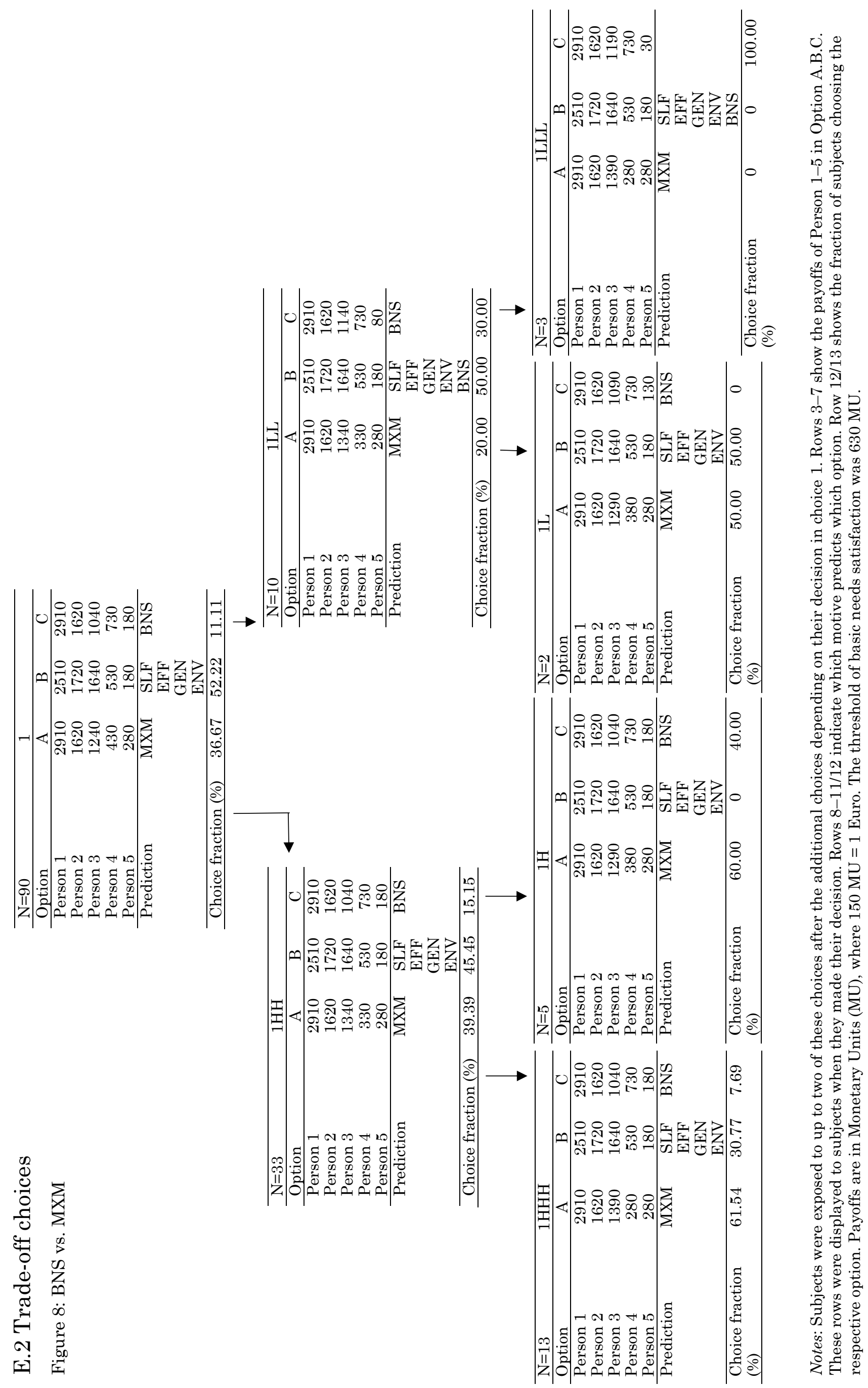




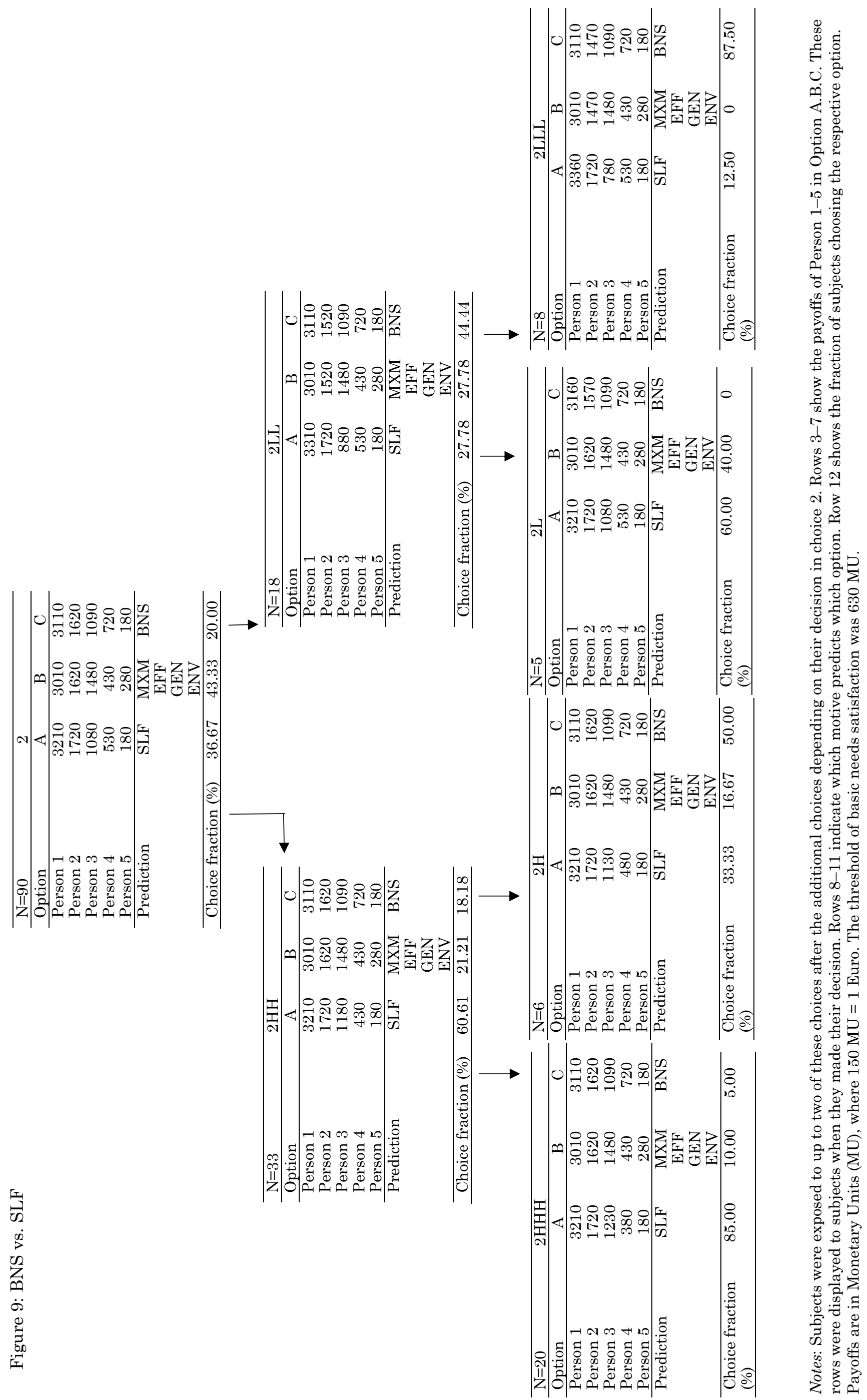




\section{F Robustness: Conditional logit}

Table 6: Conditional logit models: Odds ratios (robustness)

\begin{tabular}{ccccc}
\hline & $\begin{array}{c}(1) \\
\text { ENV } \\
\text { excluded }\end{array}$ & $\begin{array}{c}(2) \\
\text { GEN } \\
\text { excluded }\end{array}$ & $\begin{array}{c}\text { EFF } \\
\text { excluded }\end{array}$ & $\begin{array}{c}\text { SLF } \\
\text { excluded }\end{array}$ \\
\hline$\alpha^{S L F}$ & $1.013^{* * *}$ & $1.009^{* * *}$ & $1.009^{* * *}$ & \\
& $(0.0015)$ & $(0.0018)$ & $(0.0018)$ & \\
$\alpha^{B N S}$ & $1.003^{* *}$ & $1.003^{* *}$ & $1.003^{* *}$ & $1.003^{* *}$ \\
& $(0.0011)$ & $(0.0011)$ & $(0.0011)$ & $(0.0011)$ \\
$\alpha^{M X M}$ & $1.008^{* * *}$ & $1.008^{* * *}$ & $1.008^{* * *}$ & $1.008^{* * *}$ \\
& $(0.0012)$ & $(0.0012)$ & $(0.0012)$ & $(0.0012)$ \\
$\alpha^{E F F}$ & $0.999^{* *}$ & 1.000 & & $1.002^{* * *}$ \\
& $(0.0003)$ & $(0.0003)$ & & $(0.0004)$ \\
$\alpha^{G E N}$ & $1.001^{* * *}$ & & 1.000 & $0.998^{* * *}$ \\
& $(0.0002)$ & & $(0.0003)$ & $(0.0003)$ \\
$\alpha^{E N V}$ & & $1.001^{* * *}$ & $1.001^{* *}$ & $1.003^{* * *}$ \\
& & $(0.0002)$ & $(0.0003)$ & $(0.0003)$ \\
\hline
\end{tabular}

Notes: Odds ratios of the conditional logit models of subjects' decisions in the five main plus the five additional choices. Pseudo RSquared: 0.228, Chi-squared: 211.5989. ${ }^{*} p<.10,{ }^{* *} p<.05$, ${ }^{* * *} p<$ .01 . Individual specific standard errors in parenthesis. 


\section{G Coding protocol}

Table 7: Coding protocol

\begin{tabular}{|c|c|c|}
\hline Motive & Description (German original) & Description (English translation) \\
\hline SLF & $\begin{array}{l}\text { Eigenen Betrag maximieren (hier: } \\
\text { Betrag von Person 2). }\end{array}$ & $\begin{array}{l}\text { Maximize own amount (here: } \\
\text { amount of Person 2). }\end{array}$ \\
\hline $\mathrm{BNS}$ & $\begin{array}{l}\text { Summe der unerfüllten basic needs } \\
\text { minimieren (unerfüllte basic needs } \\
=\text { Betrag der zum Erreichen der } \\
630 \text { fehlt). Möglichst viele } \\
\text { Personen haben einen Betrag } \\
\text { größer als } 630 .\end{array}$ & $\begin{array}{l}\text { Minimize sum of unfulfilled basic } \\
\text { needs (unfulfilled basic needs }= \\
\text { amount that is missing to reach the } \\
\text { threshold of } 630 \text { ). Maximize the } \\
\text { number of persons having an } \\
\text { amount higher than } 630 \text {. }\end{array}$ \\
\hline MXM & $\begin{array}{l}\text { Betrag der absolut ärmsten Person } \\
\text { (hier: Person 5) maximieren. }\end{array}$ & $\begin{array}{l}\text { Maximize amount of poorest person } \\
\text { (here: Person 5). }\end{array}$ \\
\hline $\mathrm{EFF}$ & Gesamteinkommen maximieren. & Maximize total income. \\
\hline GEN & $\begin{array}{l}\text { Summe der Abstände zwischen } \\
\text { eigenem Betrag und den Beträgen } \\
\text { der Personen } 3,4 \text { und } 5 \\
\text { minimieren. }\end{array}$ & $\begin{array}{l}\text { Minimize sum of differences between } \\
\text { own amount and the amount of } \\
\text { Person } 3,4 \text {, and } 5 \text {. }\end{array}$ \\
\hline ENV & $\begin{array}{l}\text { Abstand zwischen eigenem Betrag } \\
\text { und dem Betrag von Person } 1 \\
\text { minimieren. }\end{array}$ & $\begin{array}{l}\text { Minimize difference between own } \\
\text { amount and the amount of Person } 1 .\end{array}$ \\
\hline
\end{tabular}

Notes: Coding protocol for the open-ended questions in the post-experimental questionnaire. 



\section{CHAPTER III \\ Basic needs at stake: Evidence from a high stakes experiment in Georgia 59}

\subsection{INTRODUCTION}

The results in Chapter II of this thesis suggest that concerns for the fulfillment of basic needs are an important driver of subjects' decisions in situations in which subjects are provided with a social context for the choice situation. However, in the setting of Chapter II, subjects did not necessarily have incomes below the basic needs threshold in their everyday life. Hence, it remains an open question how the motive fares in a situation in which receivers cannot satisfy their basic needs in their everyday life. In this paper, we investigate whether the motive of basic needs satisfaction is an important behavioral driving force in such contexts. We also disentangle the motive from other distributional concerns, such as selfishness, maximin, efficiency, generosity, and envy and assess their importance. We run a high stake experiment with a sample from the general population in Tbilisi (Georgia) in which subjects decide about the distribution of actual monthly incomes. ${ }^{60}$ In contrast to Chapter II, we test the importance of these motives in decisions with (1) a real-world context (i.e., subjects are confronted with exactly the income amounts in the experiment in their everyday lives), (2) high stakes, and, most importantly, (3) the fulfillment of basic needs being at stake. ${ }^{61}$ We take a closer look at the nature of the principle of basic needs satisfaction, investigate its predictive power in a different decision

59 This chapter is based on joint work Thomas Dohmen and Gari Walkowitz. The authors would like to thank participants of the ACCER 2014 Workshop on Exploring Culture and Behaviour by Economic and Psychological Experiments, the Spring School in Behavioral Economics 2015 in San Diego, the Morality, Incentives and Unethical Behavior Conference 2015, the seminar of Economics and Management at Paderborn University, and in particular Hartmut Lehmann, Karine Torosyan, Norberto Pignatti for helpful comments and suggestions. We are grateful to the VolkswagenStiftung for financial support via the project "Understanding Informal Employment in Transition: The Case of Georgia" (Hartmut Lehmann). We thank Ekaterine Mamistvalovi, Archil Dvalishvili, Salome Deisadze, Nino Khukhunaishvili, Akaki Mosakhlishvili, and Nino Alibegashvili for excellent research assistance, and Mikheil Sarjveladze for assistance in the German-Georgian translation of the experiment material. We further thank Karine Torosyan, Norberto Pignatti, Tako Jugheli, and staff members of PMCG for organizing the conduction of the experiments in Tbilisi.

60 Tbilisi is the capital and largest city of Georgia with about a third of the population living in Tbilisi (Geostat, 2016a).

61 Mueller (2012) uses high stakes to study distributive norms, but she does not consider concerns for basic needs satisfaction. 
context, and explore how it is influenced by core individual characteristics, such as gender, age, and income.

Like in Chapter II, we employed a series of five-person dictator games in which the dictator chose between three different distributions of incomes among herself and four other subjects. We provided subjects with information about the monthly amount of money necessary to fulfill basic needs in Tbilisi and about the actual current monthly income (personal income) of the four other subjects they are matched with in the experiment. The payoff a subject received in an allocation chosen by the dictator was the difference between the amount allocated to them by the dictator and her personal income. In this way, the choices a dictator made were about final distributions of actual incomes among five genuine persons for the month of the experiment. Of the four subjects a dictator was matched with, the personal incomes of two subjects were below the threshold of basic needs satisfaction. Hence, choosing an allocation in which the income amount of one or two of these persons is higher than the threshold entailed satisfying their basic needs. Thus, subjects could judge the allocations based on the deprivation of basic needs in subjects' everyday lives. The allocation choices were designed in such a way that we can disentangle the motive from other relevant distributional concerns, such as maximin, efficiency, generosity, envy, and selfishness.

Georgia is especially suitable for the purpose of our study, since it is possible to incentivize the fulfillment of basic human needs in this context. In Georgia, a substantial share (10.1 percent in 2015) of the population is living with an income below the nationally defined subsistence level (Geostat, 2016b). Further, the poorly developed social security system does not sufficiently reach the people in need. ${ }^{62}$ This means that these people are actually deprived of their basic needs and thus we can incentivize the fulfillment of these needs in our experiment. A second advantage is that in Georgia the education level including this of the less wealthy is relatively high compared to other developing countries in which we would find a poorly developed social security system. ${ }^{63}$ This facilitates conducting an experiment that is relatively complex.

We find that concerns for the satisfaction of basic needs seem to play an important role in the motivation of subjects in this setting. Comparable to the results from the lab study in Cologne (see Chapter II), on average 22 percent of subjects choose in line with the motive in choices in which they have to forego utility in terms of all other motives. Looking at individual choice patterns, we see that the majority of subjects choose at least once in line with the motive. Furthermore, we find that subjects' behavior can indeed be explained by a desire to minimize overall unfulfilled basic needs, as compared to solely minimizing the number of people in need as an alternative explanation. Moreover, concerns for basic needs satisfaction elicited in this setting are predictive of helping people in need in a different choice context at the expense of subjects' own payoff. Finally, our findings suggest

62 UNICEF Georgia and the University of York (2010) estimate that only 20 percent of officially poor households receive targeted social assistance - Georgia's main program for social security -, while more than a third of poor households do not receive any social assistance at all.

63 For example, the adult literacy rate in Georgia is 99.75 percent as compared to 83.44 percent in all middle income countries and 57.50 percent in low income countries (Worldbank, 2016). 
that women are more likely to have stronger concerns for the fulfillment of basic needs than men, but that the motive is independent of subjects' age and income.

The remainder of this chapter is organized as follows. Section 3.2 provides an overview of the experimental design and procedures. Section 3.3 presents the results. Section 3.4 concludes.

\subsection{EXPERIMENT}

\subsubsection{Identification strategy and design}

\section{Example of a choice and identification strategy}

We use the definitions of the different distributional motives, the assumptions about an individual's utility function, and the identification strategy introduced in Chapter II of this thesis. Accordingly, we assume that an individual $i$ can be motivated by a combination of six different motives - basic needs satisfaction (BNS), maximin (MXM), selfishness (SLF), efficiency (EFF), generosity (GEN), and envy (ENV) - that she trades off against each other. For a detailed description and the exact formulation of the utility function, see Chapter II, Section 2.3.2.

Table 1: Example of a choice

\begin{tabular}{cccc}
\hline Option & 1 & 2 & 3 \\
\hline Person A & 682 & 622 & 632 \\
Dictator & 334 & 334 & 355 \\
Person B & 203 & 326 & 307 \\
Person C & 159 & 119 & 98 \\
Person D & 72 & 72 & 93 \\
\hline Prediction & BNS & GEN & SLF \\
& & & MXM \\
& & & EFF \\
& & & ENV \\
\hline
\end{tabular}

Notes: Rows 2-6 show the income amounts (in Georgian Lari (GEL)) of the dictator and Person A-D in Option 1, 2, and 3. These rows were displayed to subjects when they made their decision. Rows $7-10$ indicate which motive predicts which option.

Like in Chapter II, subjects made a series of choices in five-player dictator games in each of which the dictator had to choose between three different distributions of income amounts among herself and four other subjects. Table 1 depicts an example of a choice. Rows 2-6 depict the amounts of the dictator and Person A-D for each option and choice. For instance, if a dictator chooses Option 1 in the example, Person A has an income amount of 682 Georgian Lari (GEL), the dictator an amount of 334 GEL, Person B an amount of 
203 GEL, Person C an amount of 159 GEL, and Person D an amount of 72 GEL. We say that a motive predicts an option if the utility in terms of this motive is higher than in the remaining options. The last four rows of Table 1 indicate which option is predicted by which motive. If an option is predicted by only one motive, then choosing this option is only compatible with attaching a positive weight to the motive that alone predicts this option, since this option is worse in terms of the utility of all other motives.

\section{Incentivizing basic needs satisfaction}

Basic needs fulfillment was incentivized as follows. Dictators decided about the actual monthly income of receivers (Person A, B, C, and D) and themselves in the month of the experiment. These incomes were determined by the allocation in the dictator's preferred income distribution. We supplemented subjects' actual current monthly personal income so that it amounted to the income amount depicted in the respective allocation. Receivers, as well as the dictator, were people living in Tbilisi who had participated in a pre-survey. In this pre-survey, we had required information about these people's incomes.

Table 2: Income categories

\begin{tabular}{lcccccc}
\hline Category & Dictator & Person A & Person B & Person C & Person D & N (dictators) \\
\hline I & $220-329$ & $590-617$ & $171-197$ & $69-95$ & $32-68$ & 31 \\
II & $330-439$ & $696-723$ & $171-197$ & $69-95$ & $32-68$ & 27 \\
III & $440-549$ & $799-826$ & $171-197$ & $69-95$ & $32-68$ & 26 \\
IV & $550-659$ & $975-1002$ & $171-197$ & $69-95$ & $32-68$ & 20 \\
V & $660-769$ & $1071-1112$ & $171-197$ & $69-95$ & $32-68$ & 9 \\
\hline Notes: Personal income (in GEL) of dictators and receivers assigned to the role \\
of Person A, B, C, and D in GEL in the respective income category (I-V) of the \\
dictator.
\end{tabular}

In particular, subjects were assigned to the group of dictators or of Persons A, B, C, or $\mathrm{D}$ (receivers) based on their personal income (see Table 2). ${ }^{64}$ We had five different income categories of dictators and of receivers in the role of Person A. ${ }^{65}$ For this reason, there were five different versions of the instructions, control questions, and decision booklets in which the respective personal incomes of subjects and the income amounts in the choices were adjusted accordingly. Before making their choices, dictators received information about the personal income of receivers they were matched with in the experiment. A dictator in income category I, for instance, was informed that she is matched to a receiver in the role of Person A whose personal income is between 590-617 GEL, Person B with 171-197 GEL,

64 Receivers were drawn from the same subject pool as dictators. From the pool from which subjects for this experiment were drawn, subjects for two other experiments were selected as well. All subjects from this pool took the survey questionnaire. Most of these subjects also participated in one of the experiments. Each subject participated only in one of the experiments (see Section 3.2.2 and Figure 7 in Appendix A).

65 We had five income categories in order to keep the income ranges of Person A and the dictator stated in the instructions small. 
Person C with 69-95 GEL, and Person D with 32-68 GEL. The personal income was calculated on the basis of income information subjects provided in the pre-survey (see Section 3.2.2). In particular, the personal income was computed as their monthly disposable equalized income. ${ }^{66}$ Since receivers did not make choices, they were not present in the experiment. ${ }^{67}$

Additionally, subjects received information about the threshold of basic needs satisfaction. For this purpose, dictators received an information text after reading the instructions and immediately before making their decisions on a piece of paper (see Appendix C). ${ }^{68}$ The text was similar to the one provided to subjects in the experiment of Chapter II, but was adjusted to the Georgian context. The experimenters made sure that all subjects had read the text, which remained on subjects' desk while they made their decisions. In this text, they learned that the monthly necessary amount to fulfill a person's basic needs is 140 GEL in Georgia. This amount was based on the nationally defined subsistence minimum for a single member household at the time of the experiment, which is calculated by the National Statistics Office of Georgia. The amount contains a minimum food basket (70 percent) and 30 percent of non-monetary items (Geostat, 2015b, 2016c).

The personal incomes of two groups of receivers (Person $\mathrm{C}$ and $\mathrm{D}$ ) were below this threshold of basic needs satisfaction. Hence, if in an allocation, these persons' incomes were higher than $140 \mathrm{GEL}$, then their basic needs would be fulfilled for this month. If they were lower than this amount, they would be deprived of some of their basic necessities. Consequently, the choice of an option in which, for example, the income of Person $\mathrm{C}$ is higher than the threshold implied satisfying this person's needs. Likewise, choosing an allocation in which her income is higher as compared to a different allocation, but not higher than the threshold entailed satisfying some of her needs.

To summarize, the payoff a subject received in an allocation of a choice was the income amount in this allocation minus her personal income. The choices a dictator made were thus about actual distributions of monthly income. Knowing the amount of the threshold of basic needs satisfaction and the personal incomes of the persons they were matched with, dictators could satisfy basic needs of Person C and D in the experiment; genuine persons who were actually living with an income below the basic needs threshold in their real life. Dictators could thus - on top of other threshold-independent distributional considerations such as, maximin, efficiency, generosity, envy, or selfishness - judge the allocations based on the persons' deprivation of basic needs.

\section{Choices}

Subjects first made decisions in 16 isolation choices (see Table 7 in Appendix D). In these

66 Subjects provided their family income and the household size. Based on this, we calculated subjects' monthly disposable equalized income. We used the "OECD modified equivalence" scale in order to account for household composition (a value of 1 is assigned to the household head, 0.5 to each additional adult, 0.3 to each child) (see OECD, 2013).

67 Receivers answered the survey questionnaire or additionally participated in another experiments.

68 For the complete instructions, see Appendix B. 
choices, we systematically varied the utilities in terms of the different motives in the three different allocations such that it allows us to assess to which motive(s) the dictator attaches a positive weight (see beginning of this section). In particular, one motive alone predicted Option 1 and another motive alone predicted Option 3. The remaining four motives predicted Option 2. In this way, each motive was the only motive predicting an option five times. ${ }^{69}$ Choice $1-5$, in which BNS alone predicts an option, are comparable to the five main choices in the experiment of Chapter II adjusted to the Georgian context.

Subjects additionally made decisions in five income gap choices in which we explicitly tested one assumption of our model of concerns for basic needs satisfaction of Chapter II. In particular, we tested whether subjects indeed care about the sum of unfulfilled needs (i.e., the income gap) or, alternatively, about the number of persons below the basic needs threshold (i.e., headcount considerations). ${ }^{70}$ In the main choices, in order to be able to disentangle BNS from MXM, the option predicted by BNS had the smallest amount of unfulfilled basic needs, and, at the same time, the smallest number of persons with an income below the threshold. Hence, it is not clear which of the criteria induced subjects to choose this option. In the income gap choices, however, we kept the number of persons with an income below the threshold constant across options (see Table 8 in Appendix D). ${ }^{71}$ Hence, by comparing decisions in the main choices to those in the income gap choices, we shed light on which of the two criteria subjects use when choosing in line with concerns for BNS. In particular, if subjects are concerned with minimizing the income gap, then choice fractions in the income gap choices should not be different from those in the main choices. If, on the contrary, subjects care mainly for minimizing the number of persons below the threshold, then the fraction of subjects choosing in line with the BNS option should be smaller in the income gap choices.

Finally, we assess whether choosing in line with BNS in our discrete dictator games is predictive of choices entailing the fulfillment of basic needs of another person in a situation in which they could freely distribute an amount of money between different persons. For this purpose, dictators made a continuous dictator game choice (choice 24) after the 23 discrete choices. ${ }^{72}$ In this decision, subjects were asked to distribute 200 GEL between

69 It is not possible to have the motives SLF and GEN alone predict a different option at the same time. Thus, we employed one choice in which SLF alone predicted an option and GEN and EFF predicted a different option (choice 11) and a second choice in which GEN alone predicted an option and SLF and EFF predicted a different option (choice 12).

70 The terms income gap and headcount are borrowed from the poverty measurement literature, where both are measures of the extent of poverty. The income gap is defined as the difference between the poverty threshold and the mean income of the poor (Chakravarty, 2009). Our definition of concerns for BNS takes into account the sum of the differences between the poverty threshold and the income of the poor.

71 In order to not confuse MXM and BNS considerations, in these choices we kept the income of the poorest person (Person D) always the same (72 GEL). Thus, MXM does not make any prediction in these choices. Apart from that, the choices are similar to the main choices (choice $1-5)$.

72 Additionally, subjects were also exposed to two additional choices (choice 17 and 18) (see Table 8 in Appendix D). 
themselves and four other persons they were matched with. They could allocate an amount between 0 and 200 GEL to Person A, B, C, and D, where the total had to equal 200 GEL. The amount they did not allocate to any other person, they kept for themselves. For this decision, dictators were informed about the exact monthly income of the receivers (Person A-D) they would be matched with in case this choice was drawn for payoff (see Table 9 in Appendix E). In this way, dictators could make sure that Person $\mathrm{C}$ and $\mathrm{D}$ received enough to lift their income for this month above the threshold. To achieve this, they had to allocate at least 57 GEL to Person C and at least 90 GEL to Person D. We relate giving behavior in choice 24 to choices in the isolation choices. By this, we assess whether concerns for BNS are predictive for helping people in need in a different choice setting at the expense of subjects' own payoff.

The experiment consisted of three parts (see Figure 8 in Appendix A). This paper is about Part 1 of the experiment. In Part 1A, subjects made the 23 three-option five-player dictator game decisions, which have been explained above (see also Figure 9 in Appendix A). To make sure that subjects understood the instructions, they received a set of control questions after they had read the instructions (see Appendix F). ${ }^{73}$ The experiment assistants corrected the control questions of each subject individually. In case a subject made a mistake, the assistant explained the relevant part of the instructions again and made sure the subject understood everything. If a subject answered control question 1 incorrectly, they received an additional control question similar to question 1 . This question was then again corrected individually by the assistants. The experimental assistants were instructed to make a note in case a subject did not understand the instructions even after several rounds of explanation. This subject would then be excluded from the analysis. ${ }^{74}$ After the control questions, subjects received the information text. After everyone had read the text, they received the decision booklet with the 23 decisions. Each decision was depicted on a separate page, and pages were printed one-sided. Subjects were instructed to make decisions sequentially, without looking at previous decisions. ${ }^{75}$ On the last pages of the booklet, subjects were confronted with the continuous dictator game decision (choice 24) including the corresponding instructions (Part 1B). Finally, they filled in a post experimental questionnaire in which they were asked questions related to the experiment (Part 1C).

73 This is especially important in this setting, given that subjects were unfamiliar with taking part in economic experiments.

74 This was not the case for any of the subjects. In total, 21 of the 113 subjects received the additional control question.

75 Due to the fact that the experiment was paper-pencil based, and that the administration of the five different sets of decision booklets was already organizationally demanding, the order of the 23 choices, as well as the presentation of choice alternatives, was the same for all subjects. Within the isolation choices as well as within the additional and income gap choices, the order of choices was determined randomly before the experiment. The presentation of choice alternatives was balanced for each motive across the 23 choices, such that each motive was presented to subjects on Option 1, 2, and 3 five to six times. In this way, we control for possible confounding effects if subjects for some reason systematically have a preference for, for example, the middle option (Option 2). 


\section{Incentives}

Subjects were paid for one of their decisions in Part 1 or 3 of the experiment. Part 2 was not incentivized. After completing all three parts, the decision that determined payoffs was randomly determined for each subject. Subjects first drew a card from a bag to either select Part 1 with probability 0.2 or Part 3 with probability $0.8{ }^{76}$ Subjects next determined the decision in the respective part that was paid out, again by physically drawing a card from a bag (see Figure 11 in Appendix B). ${ }^{77}$ Dictators who received payment for a decision in Part 1 of the experiment were matched with four receivers (one subject for each role) corresponding to their respective income categories. These receivers got their payment at the end of the session in which they filled in the survey questionnaire. In case this session was before or on the same day of the session of the respective dictator, they could collect their payment later.

\subsubsection{Procedures}

The experiment took place in centralized sessions at the University of Georgia and the International School of Economies in Tbilisi (Georgia) between November 2015 and May 2016, and involved a total of 113 dictators. Each session lasted about 2 hours. The experiment was paper-pencil based and conducted in Georgian. Instructions were translated from German into Georgian by translation and back-translation. The backtranslation makes sure that the translation is as accurate as possible and that the meaning of the original text is not altered (Brislin, 1970). All contact to subjects was administered by a team of helpers and experiment assistants in Georgian. Assistants were Georgian natives with Georgian as their mother tongue. ${ }^{78}$ The team of experiment assistants was led by an experimental supervisor (also Georgian) who was responsible for coordinating all activities related to the execution of the experiment. Assistants and the supervisor were instructed in the conduction of the experiment by the authors. The training sessions took place in October 2015 in Tbilisi. At the end of this training a trial session of the experiment was conducted to make sure the procedures run smoothly and were absolutely clear to the experimenters.

Subjects in the experiment were recruited from two different samples of the general population in Tbilisi (Georgia). The first sample contains respondents of a survey who had been recruited via the random walk method in 2013. The second sample consists of subjects directly recruited by the Georgian helper team. The study includes five steps (see Figure 7 in Appendix A). In the first step, subjects were approached by helpers in home visits. During these visits, helpers conducted a pre-survey in which they asked respondents - among other things - about their monthly disposable household income and

76 The different payment probabilities were designed to balance the different stake sizes in Part 1 and 3 .

77 In Part 3, this consisted again of a series of draws. We do not explain this here in detail, since Part 3 is not the focus of this paper.

78 We also recruited Armenian assistants who were not fluent in Georgian. They took over administrative tasks before, during, and after the experimental sessions without direct contact to the participants. 
the number of (adult) family members. At the end of the pre-survey, respondents were invited to take part in the experiment and a survey questionnaire. If they agreed, they were told that they would be contacted again to be invited for a specific experimental session. In a second step, families were selected for and invited to the experiment. The selection of families was based on their monthly disposable equalized income per family member, which was calculated on the basis of the pre-survey data, as explained in Section 3.2.1. Families were then invited via telephone for a specific session. If possible, all family members were invited to the same time slot. Subjects first took part in the experiment. In case multiple members of the same family showed up, only one person was allowed to take part in the experiment. The other family members took part in a different experiment or in the survey questionnaire only. All subjects were interviewed for the survey questionnaire, which lasted between 30 and 90 minutes. The survey was administered either in a home visit or within the centralized sessions. ${ }^{79}$ Finally, once subjects completed all parts of the study, they received their payment for participation. To diminish the role of social image concerns, subjects' decisions were kept anonymous towards other participants and the experimenter throughout the whole experiment (Bénabou and Tirole, 2006). To guarantee anonymity during the decision making process, subjects' desks were separated by cardboard partitions that had been fixated at each desk (see Figure 10 in Appendix B). Further, subjects received their payment for the experiment from a person who had not been involved in the experimental session. As a result of the payment procedure outlined before, 25 percent of subjects were paid for Part 1. On average subjects earned about $67 \mathrm{GEL}$ in this part of the experiment, where the exchange rate was 1 Euro = 2.6 GEL in November 2015. ${ }^{80}$ Taking the median income in Tbilisi of 337 GEL as a reference, this amount constitutes about 6.1 daily median incomes (Geostat, 2015a).

\subsection{RESULTS}

In total, 113 dictators took part in the experiment with more subjects (henceforth, we will use the terms subject and dictator interchangeably) in the lower income categories (see Table 2 in Section 3.2.1). ${ }^{81}$ Since the 71 subjects sampled by the random walk method do not differ with respect to age, gender, and income from the other 42 subjects, we pool data of these subjects in our analysis. ${ }^{82} \mathrm{We}$ also pool data of subjects from all five income

79 For nine subjects the experiment as well as the survey questionnaire was conducted individually in their homes.

80 Additional to the payments in the experiment subjects received a compensation of 20 GEL for filling in the survey questionnaire. Passive subjects received on average 53 GEL in their role of a receiver (Person A, B, C, D) in Part 1 of the experiment.

81 This is mostly a result of selection, since we invited an approximately equal number of subjects per category to the experiment.

82 The two samples do not differ significantly in terms of: gender: $\left(\chi^{2}(1)=.0654, p=.798\right)$, age: $(t(98)=-1.4441, p=.152)$, income: $(t(111)=.4933, p=.623)$ (tests performed on the basis of the number of observations for which data on the respective variables are available). 
categories for the main analysis. ${ }^{83}$ Our subjects are representative of the population in Georgia with respect to age, but are slightly richer than the general population in Tbilisi. ${ }^{84}$ In addition, women are overrepresented in our sample. ${ }^{85}$ All subjects made all decisions in the five main choices (BNS isolation choices) and the five income gap choices, 112 of them made decisions in all 16 isolation choices, 111 of them in all 23 discrete choice dictator games, we have 108 observations for choice 24, and 106 for all 24 dictator game decisions. ${ }^{86}$

83 In Section 3.3.5, we analyze potential differences between these groups in terms of the distributive decisions they make.

84 On average our subjects are 39.83 years old while the average age in Georgia is 37.43 years (United United Nations, 2014). The median net equivalent income in Tbilisi in 2013 was 337 GEL, while in our sample it was 434 GEL (Geostat, 2015a).

85 Further, in Georgia 48 percent of the population are male, while in our sample this share is only 38 percent (Geostat, 2015c).

86 In total 111 dictators made decisions in the continuous choice dictator game, but we had to exclude three subjects from the analysis, since they allocated in total more than 200 GEL to the four receivers. 


\subsubsection{Main choices: Basic needs satisfaction}

Figure 1: Choice fractions BNS: Choice 1-5

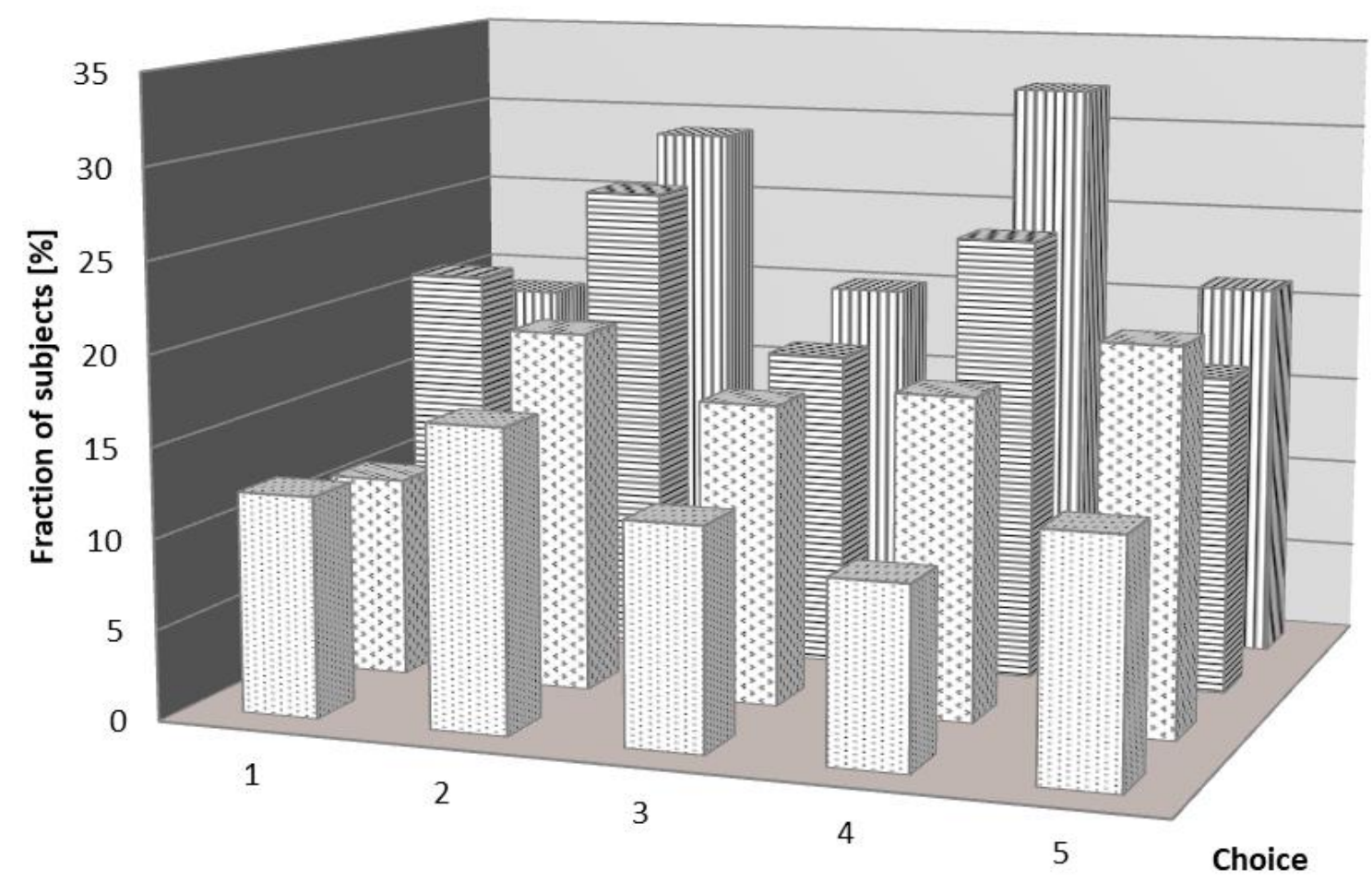

ㅂ.

Notes: Fraction of subjects choosing in line with BNS in main choices (choice 1-5) per study. The rest of subjects choose the option that is alone predicted by a different motive or the option predicted by the four remaining motives, both of which is not depicted here.

We find that BNS is prevalent in every choice with 18 to 27 percent of dictators choosing in line with the motive when it alone predicts an option (see Figure 1, "Incentivized Tbilisi"). Individual choice patterns further show that the majority of dictators (61 percent) choose the allocation that is alone predicted by BNS at least once, revealing that these dictators attach a positive weight to the motive (see Figure 2, "Incentivized Tbilisi"). In this experiment, dictators are deciding about the actual monthly income of genuine persons. In other words, receivers (Person A, B, C, and D) will, in the month of the experiment, have the income amounts depicted in an allocation chosen by the dictator. This entails that dictators can actually satisfy real-life basic needs of Person $\mathrm{C}$ and $\mathrm{D}$ in the experiment; genuine persons who are living with an income below the basic needs threshold. We thus show that the motive is important in a setting in which the fulfillment of basic needs is actually at stake. This is the main contribution of this paper. 
Figure 2: Reverse cumulative distribution: BNS per study

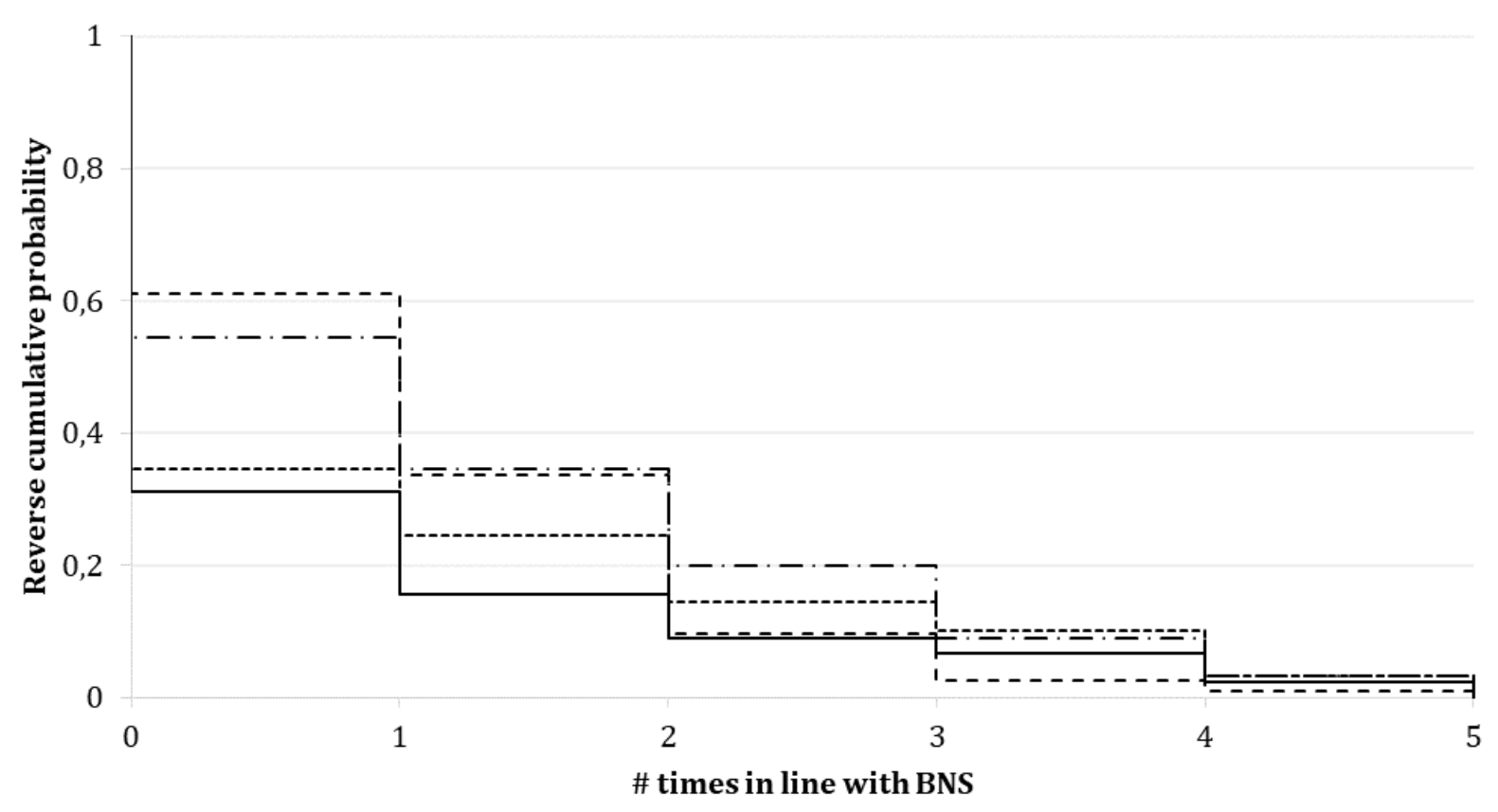

— Hypothetical Cologne ------- Incentivized Cologne - - - - Incentivized Tbilisi $\quad$ - - - Hypothetical Tbilisi

Notes: The reverse cumulative distribution indicates the fraction of subjects choosing more than $x$ times in line with BNS in main choices (choice 1-5) per study.

Next, we relate the results from the present study to those of our student sample in Cologne (see Chapter II). Results from the incentivized choices in Cologne might not be directly comparable to our results in Tbilisi. Besides disparities stemming from the fact that subjects are from different countries, there are several important differences. First, subjects in Cologne are drawn from a student subject pool, while subjects in Tbilisi are drawn from a sample of the general population. Second, the incentive structure is different in the two settings. For instance, while in Cologne, subjects were paid the respective amounts in the allocations converted to Euros, subjects in Tbilisi received the difference between their personal income reported in the pre-survey and the income amount in the allocations. Finally, and most importantly, in Tbilisi, receivers are genuine persons of whom two persons are actually living with an income below the subsistence minimum, i.e., they are actually in need. In Cologne, receivers are fellow students.

We, therefore, exposed 90 subjects from the same subject pool to the same set of choices as in the incentivized study in Tbilisi, but in a hypothetical setting. ${ }^{87}$ Holding incentives

87 Subjects were exposed to choices with the income amounts of dictators in income category I of the incentivized experiment in Tbilisi. The amounts in the hypothetical setting in Tbilisi are comparable to those used in in Cologne, since the dictator gets amounts with a similar relative distance to the amounts of the three poorer persons in the choices. In total, 108 subjects were in this experiment. We had to exclude 18 subjects because they had answered more than one of the five control questions wrongly. Subjects received 20 GEL as a fixed compensation for participation. For five subjects the experiment was conducted at their home. They received a participation reward of $10 \mathrm{GEL}$, since they did not have to incur travel costs. 
constant, we compare results from the five main choices from the hypothetical setting in Tbilisi and Cologne.

Figure 1 and 2 depict choice fractions and choice patterns, respectively, in line with BNS in the five main choices in the different experiments. Our results show that also in the hypothetical setting in Tbilisi, BNS is important in each choice with 19 to 32 percent of subjects choosing in line with the motive. In three of the five choices, these choice fractions are not statistically different from those in the hypothetical experiment in Cologne. ${ }^{88}$ With respect to choice patterns, we find that the share of subjects choosing at least four times in line with the motive is comparable across the two cities $\left(\chi^{2}(1)=.3098, p=.578\right)$. However, significantly more subjects choose at least once in line with BNS in Tbilisi than in Cologne $\left(\chi^{2}(1)=10.0088, p=.002\right) .{ }^{89}$ Hence, results from the same experiment are largely comparable across cities. Furthermore, both choice fractions and choice patterns are comparable across the different settings within each city. ${ }^{90}$ It is thus probable, that if we replicated the incentivized study - with genuine persons as receivers - in Cologne, we would also find evidence for the existence of concerns for basic needs satisfaction.

In sum, concerns for BNS are important across different subject pools and incentive structures. Across all four experiments, in the main choices, a substantial amount of 11 to 27 percent of subjects chooses in line with the motive. Individual choice patterns further reveal that 31 to 61 percent of subjects do so at least once. These subjects choose the BNS option (a) even though this entails foregoing own income and utility in terms of all other motives under consideration, and (b) in decisions about actual monthly incomes of genuine persons - two of them living below the threshold of basic needs fulfillment in their everyday lives.

88 Chi-squared tests of the null-hypothesis that the fraction of subjects choosing the option that only BNS predicts is the same in the hypothetical setting in Cologne and in Tbilisi: choice 1: $\left(\chi^{2}(1)=1.5226, p=.217\right)$, choice $2:\left(\chi^{2}(1)=3.8217, p=.051\right)$, choice $3:\left(\chi^{2}(1)=2.0142, p=\right.$ $.156)$, choice 4: $\left(\chi^{2}(1)=13.3432, p<.001\right)$, choice 5: $\left(\chi^{2}(1)=1.9095, p=.167\right)$.

89 Interestingly, this is not confined to BNS. The fraction of subjects choosing at least once (four times) in line with a motive (conditional on choosing in line with it when it alone predicts an option) is significantly different for $\operatorname{SLF}\left(\chi^{2}(1)=4.6238, p=.032\right), \operatorname{EFF}\left(\chi^{2}(1)=6.4735, p=\right.$ $.011), \operatorname{GEN}\left(\chi^{2}(1)=7.1200, p=.008\right)\left(\operatorname{MXM}\left(\chi^{2}(1)=3.1065, p=.078\right)\right.$, and $\operatorname{ENV}\left(\chi^{2}(1)=\right.$ 4.7445, $p=.029)$ ).

90 Choice fractions do not differ significantly in any choice. Chi-squared tests of the nullhypothesis that the fraction of subjects choosing the option that only BNS predicts is the same in the hypothetical and the incentivized experiment in Tbilisi: choice 1: $\left(\chi^{2}(1)=.1717, p=\right.$ $.679)$, choice 2: $\left(\chi^{2}(1)=.1373, p=.711\right)$, choice $3:\left(\chi^{2}(1)=.1734, p=.676\right)$, choice 4 : $\left(\chi^{2}(1)=1.3745, p=.241\right)$, choice $5:\left(\chi^{2}(1)=.3758, p=.540\right)$. For test results in Cologne, see Chapter II, Section 2.4.2. With respect to choice patterns, only the fraction of subjects who choose at least four times in line with BNS is larger in the hypothetical than in the incentivized experiment in Tbilisi. Chi-squared tests of the null-hypothesis that the fraction of subjects choosing at least $x$ times in line with BNS is the same in the hypothetical and the incentivized setting in Tbilisi: at least 1 time: $\left(\chi^{2}(1)=-9014, p=.342\right)$, at least 4 times: $\left(\chi^{2}(1)=3.7989\right.$, $p=.051)$, and in the hypothetical and the incentivized setting in Cologne: at least 1 time: $\left(\chi^{2}(1)=.2269, p=.634\right)$, at least 4 times: $\left(\chi^{2}(1)=.6545, p=.418\right)$. 


\subsubsection{Isolation choices}

We will now examine the importance of the other distributional motives from which we disentangled concerns for BNS. To the best of our knowledge, the importance of these motives has not yet been assessed in high stake decisions with a real-world context in which the fulfillment of basic human needs are at stake. In the five main choices, we can observe that - as found in our experiments in Cologne - MXM and SLF seem to be important motives in this context next to BNS (see also Engelmann and Strobel (2004, 2005)). Further, in the present study, also EFF, GEN, and ENV are chosen by a substantial fraction of subjects (see Figure 12 and 13 in Appendix H). ${ }^{91}$ To study the importance of these motives more closely, we will now analyze data from all 16 isolation choices in which each motive alone predicts an option five times. In this way, we can also compare the individual choice patterns across motives.

Figure 3 depicts the average percentage of subjects choosing in line with each motive in the choices in which this motive alone predicts an option. The general picture is quite similar to the results from the five main choices. Again, SLF is a very prevalent motive, chosen by over 40 percent of subjects. MXM and BNS are chosen by more and the remaining motives by less than a fifth of our subjects. Figure 4 reveals that as for BNS, the fraction of subjects choosing at least once in line with MXM is 61 percent. For SLF this share amounts to almost 80 percent. 24 percent of subjects even choose the selfish option four out of five times when it alone predicts this option. For all other motives, this share is below ten percent.

Figure 3: Average choice fractions: Isolation choices

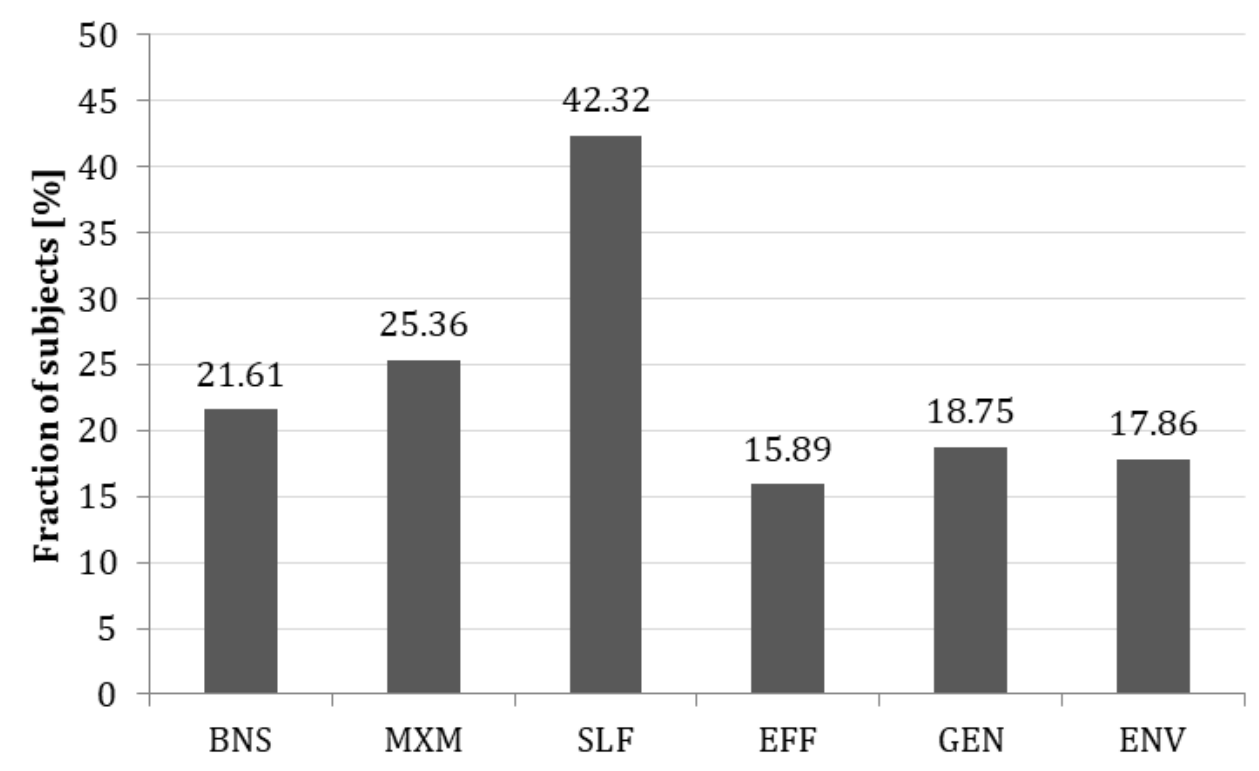

Notes: Average percentage of subjects choosing in line with each motive in isolation choices (choice 1-16). The rest of subjects choose the option predicted by the four remaining motives, which is not depicted here.

91 We also find similar results in the hypothetical setting in Tbilisi (see Figure 14 and 15 in Appendix H). 
Figure 4: Reverse cumulative distribution: Isolation choices

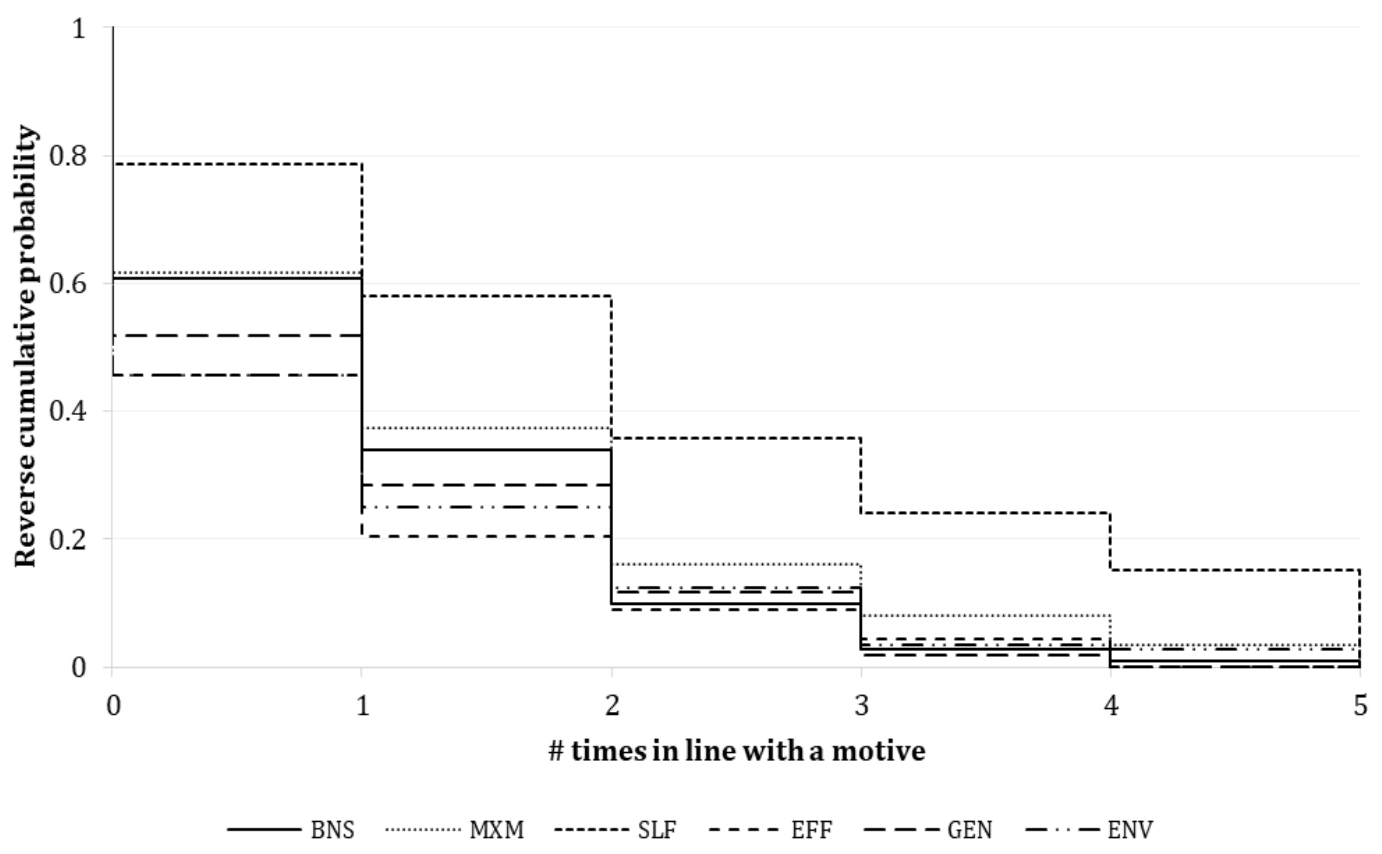

Notes: The reverse cumulative distribution indicates the fraction of subjects choosing more than $x$ times in line with a motive when it alone predicts an option in isolation choices (choice 1-16).

To study the importance of the different distributional motives in subjects' decisions parametrically, we estimate a mixed logit model (Train, 2009; Hole, 2007) using the data from the 16 isolation choices. With this model we estimate the effect the utility of an option with respect to the different distributional principles has on the probability that an option is chosen while accounting for heterogeneity in subjects' tastes. In particular, we assume that

$$
\begin{gathered}
U_{i m k}=\alpha_{i}^{S L F} x_{i k m}+\alpha_{i}^{B N S}\left[-\sum_{j=1}^{n} \max \left(t-x_{j k m}, 0\right)\right]+\alpha_{i}^{M X M} \min (x)+\alpha_{i}^{E F F} \sum_{j=1}^{n} x_{j k m}, \\
+\alpha_{i}^{G E N}\left[-\sum_{j=1}^{n} \max \left(x_{i k m}-x_{j k m}, 0\right)\right]+\alpha_{i}^{E N V}\left[-\sum_{j=1}^{n} \max \left(x_{j k m}-x_{i k m}, 0\right)\right]+\varepsilon_{i k m} \\
=\alpha_{i}^{w} c_{i k m}^{w}+\varepsilon_{i k m}
\end{gathered}
$$

is the utility a subject $i$ derives from choosing an alternative $k \in\{1,2,3\}$ in choice $m \in$ $\{1, \ldots, 10\}$, where the coefficients $\alpha_{i}^{w}$ vary over dictators, $c_{i k m}^{w}$ is a vector of distributional concerns, $w \in\{S L F, B N S, M X M, E F F, G E N, E N V\}$, and $\varepsilon_{i k m}$ is a random term that is an independently and identically extreme value distributed. For a detailed elaboration of the model, see Chapter II, Section 2.4.1. Table 3 displays the means and the standard deviations of the mixed logit estimations. Due to multicollinearity between the motives SLF, EFF, GEN, and ENV we estimate four different models, in each of which we leave 
out one of the motives. The estimations are conducted with $R=5000$ Halton draws and assuming that the coefficients are normally distributed in our sample. ${ }^{92}$ We use individual specific standard errors to account for dependencies of choices across decisions of the same subject. The comparison of the estimated means with the sample average of the conditional distribution reveals that this is indeed a reasonable assumption and that the model is correctly specified (Train, 2009).

92 We chose this number of draws because from this number onwards the coefficients remain stable (i.e., when estimating the models with e.g., 6000, 7000, 9000 draws the coefficients remain approximately the same (Hensher and Greene, 2001). 
Table 3: Mixed logit models

\begin{tabular}{|c|c|c|c|c|c|}
\hline & & $\begin{array}{c}(1) \\
\text { ENV } \\
\text { excluded }\end{array}$ & $\begin{array}{c}(2) \\
\text { GEN } \\
\text { excluded }\end{array}$ & $\begin{array}{c}(3) \\
\text { EFF } \\
\text { excluded }\end{array}$ & $\begin{array}{c}(4) \\
\text { SLF } \\
\text { excluded }\end{array}$ \\
\hline \multirow[t]{2}{*}{$\alpha^{S L F}$} & mean & $\begin{array}{c}.0556^{* * *} \\
(.0083)\end{array}$ & $\begin{array}{l}.0401^{* * *} \\
(.0081)\end{array}$ & $\begin{array}{l}.0566^{* * *} \\
(.0087)\end{array}$ & \\
\hline & $\mathrm{SD}$ & $\begin{array}{c}.0680^{* * *} \\
(.0087)\end{array}$ & $\begin{array}{l}.0708^{* * *} \\
(.0072)\end{array}$ & $\begin{array}{l}.0724^{* * *} \\
(.0086)\end{array}$ & \\
\hline \multirow[t]{2}{*}{$\alpha^{B N S}$} & mean & $\begin{array}{c}.0176^{* * *} \\
(.0040)\end{array}$ & $\begin{array}{l}.0179 * * * \\
(.0041)\end{array}$ & $\begin{array}{c}0177 * * * \\
(.0040)\end{array}$ & $\begin{array}{c}.0182^{* * *} \\
(.0039)\end{array}$ \\
\hline & $\mathrm{SD}$ & $\begin{array}{l}.0263^{* * *} \\
(.0060)\end{array}$ & $\begin{array}{l}.0259^{* * *} \\
(.0061)\end{array}$ & $\begin{array}{l}.0256^{* * *} \\
(.0061)\end{array}$ & $\begin{array}{l}.0245^{* * *} \\
(.0057)\end{array}$ \\
\hline \multirow[t]{2}{*}{$\alpha^{M X M}$} & mean & $\begin{array}{c}.0200 * * * \\
(.0056)\end{array}$ & $\begin{array}{l}.0200 * * * \\
(.0056)\end{array}$ & $\begin{array}{l}.0198^{* * *} \\
(.0055)\end{array}$ & $\begin{array}{l}.0206^{* * *} \\
(.0055)\end{array}$ \\
\hline & $\mathrm{SD}$ & $\begin{array}{c}.0483^{* * * *} \\
(.0072)\end{array}$ & $\begin{array}{l}.0488^{* * * *} \\
(.0072)\end{array}$ & $\begin{array}{l}.0478^{* * * *} \\
(.0069)\end{array}$ & $\begin{array}{l}.0473^{* * * *} \\
(.0076)\end{array}$ \\
\hline \multirow[t]{2}{*}{$\alpha^{E F F}$} & mean & $\begin{array}{c}.0007 \\
(.0014)\end{array}$ & $\begin{array}{l}.0037^{* * *} \\
(.0011)\end{array}$ & & $\begin{array}{l}.0119^{* * *} \\
(.0017)\end{array}$ \\
\hline & SD & $\begin{array}{l}.0073^{* * *} \\
(.0014)\end{array}$ & $\begin{array}{l}.0054^{* * *} \\
(.0015)\end{array}$ & & $\begin{array}{l}.0118^{* * *} \\
(.0017)\end{array}$ \\
\hline \multirow[t]{2}{*}{$\alpha^{G E N}$} & mean & $\begin{array}{c}.0031^{* * *} \\
(.0011)\end{array}$ & & $\begin{array}{l}.0032^{* * *} \\
(.0010)\end{array}$ & $\begin{array}{l}-.0081^{* * *} \\
(.0015)\end{array}$ \\
\hline & SD & $\begin{array}{l}.0043^{* * *} \\
(.0014)\end{array}$ & & $\begin{array}{l}.0031^{* *} \\
(.0015)\end{array}$ & $\begin{array}{l}.0105^{* * *} \\
(.0015)\end{array}$ \\
\hline \multirow[t]{2}{*}{$\alpha^{E N V}$} & mean & & $\begin{array}{l}.0037^{* * *} \\
(.0012)\end{array}$ & $\begin{array}{c}.0006 \\
(.0011)\end{array}$ & $\begin{array}{l}.0106^{* * *} \\
(.0014)\end{array}$ \\
\hline & SD & & $\begin{array}{l}.0071^{* * *} \\
(.0015)\end{array}$ & $\begin{array}{l}.0078^{* * *} \\
(.0014)\end{array}$ & $\begin{array}{l}.0096^{* * *} \\
(.0015)\end{array}$ \\
\hline \multicolumn{2}{|c|}{ SLL at convergence } & -1555.0662 & -1546.8135 & -1550.1766 & -1615.6452 \\
\hline \multicolumn{2}{|c|}{$\operatorname{LR} \chi^{2}(\mathrm{df})$} & $75.99(5)$ & $77.13(5)$ & $76.69(5)$ & $84.84(5)$ \\
\hline \multicolumn{2}{|c|}{ Prob $>\chi^{2}$} & $<.0001$ & $<.0001$ & $<.0001$ & $<.0001$ \\
\hline
\end{tabular}

Notes: The dependent variable is the option subjects choose in the isolation choices. The independent variables are the utilities of the options in terms of each motive. Individual specific standard errors in parenthesis. SLL = Simulated log likelihood. SD = Standard deviation. LR $\chi^{2}$ is the likelihood ratio test for the joint significance of the standard deviations (degrees of freedom in parenthesis) (Hole, 2007). $N=5376 .{ }^{*} p<.10,{ }^{* *} p<$ $.05, * * * p<.01$.

We find that in all models, the estimated coefficients of BNS, MXM, and SLF are significant and positive. Hence, the average subject seems to attach a positive weight to these motives. These results are qualitatively similar to those obtained in Chapter II. Moreover, the estimated standard deviations again reveal that there is significant heterogeneity in subjects' tastes. The relation between a coefficient's mean and its 
standard deviation reveals that between 75 and 77 percent of subjects place a positive weight on BNS, between 66 and 67 percent on MXM, and between 71 and 84 percent on SLF. For EFF, GEN, and ENV results are less clear. The coefficients vary, depending on the model, between being positive and highly significant and being insignificant (or negatively significant in the case of GEN). To summarize, the estimation results confirm that BNS, together with MXM and SLF, is an important driver of subjects' decisions in the isolation choices.

\subsubsection{BNS revisited: Income gap choices}

Figure 5: Choice fractions BNS: Main and income gap choices

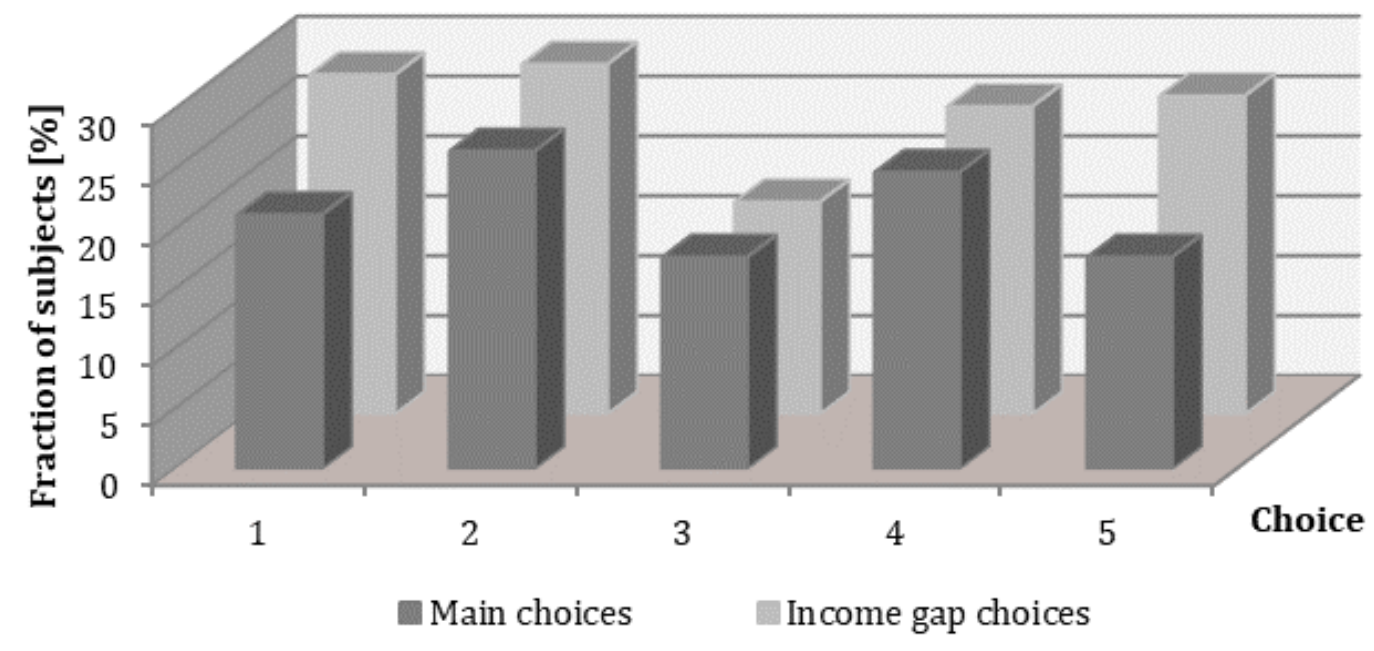

Notes: Fraction of subjects choosing in line with BNS in main choices (dark grey bars) and income gap choices (light grey bars). The rest of subjects choose the option that a different motive predicts alone or the option predicted by the four remaining motives, both of which is not depicted here.

Figure 5 depicts the fraction of subjects choosing in line with BNS in the income gap choices in comparison to the main choices. It can be seen that if anything there are more subjects choosing the BNS option in the income gap than in the main choices. A series of McNemar's change tests shows that there is no significant difference between the number of subjects who choose BNS in main choice $1(2,3,4,5)$ and the number of subjects who choose BNS in income gap choice IG1 (IG2, IG3, IG4, IG5). ${ }^{93}$ Thus, subjects choosing the options only predicted by BNS in the main choices indeed seem to be motivated by a desire

93 McNemar's change tests of the null-hypothesis that the fraction of subjects choosing the option that only BNS predicts is the same in: choice 1 and IG1: McNemar's $\chi^{2}(1)=1.52, p=.280$, choice 2 and IG2: McNemar's $\chi^{2}(1)=.26, p=.736$, choice 3 and IG3: McNemar's $\chi^{2}(1)<.01$, $p>.999$, choice 4 and IG4: McNemar's $\chi^{2}(1)<.01, p>.999$, choice 5 and IG5: McNemar's $\chi^{2}(1)=2.78, p=.133$ (exact $p$-values). 
to minimize overall unfulfilled basic needs. Note that this does not imply that they do not also care about how many persons have an income higher than the threshold. It simply means that the fact that unfulfilled basic needs are smallest in the BNS option seems to be sufficient for them to prefer this option.

\subsubsection{Predictions across games: Choice 24}

Figure 6: Helping the needy

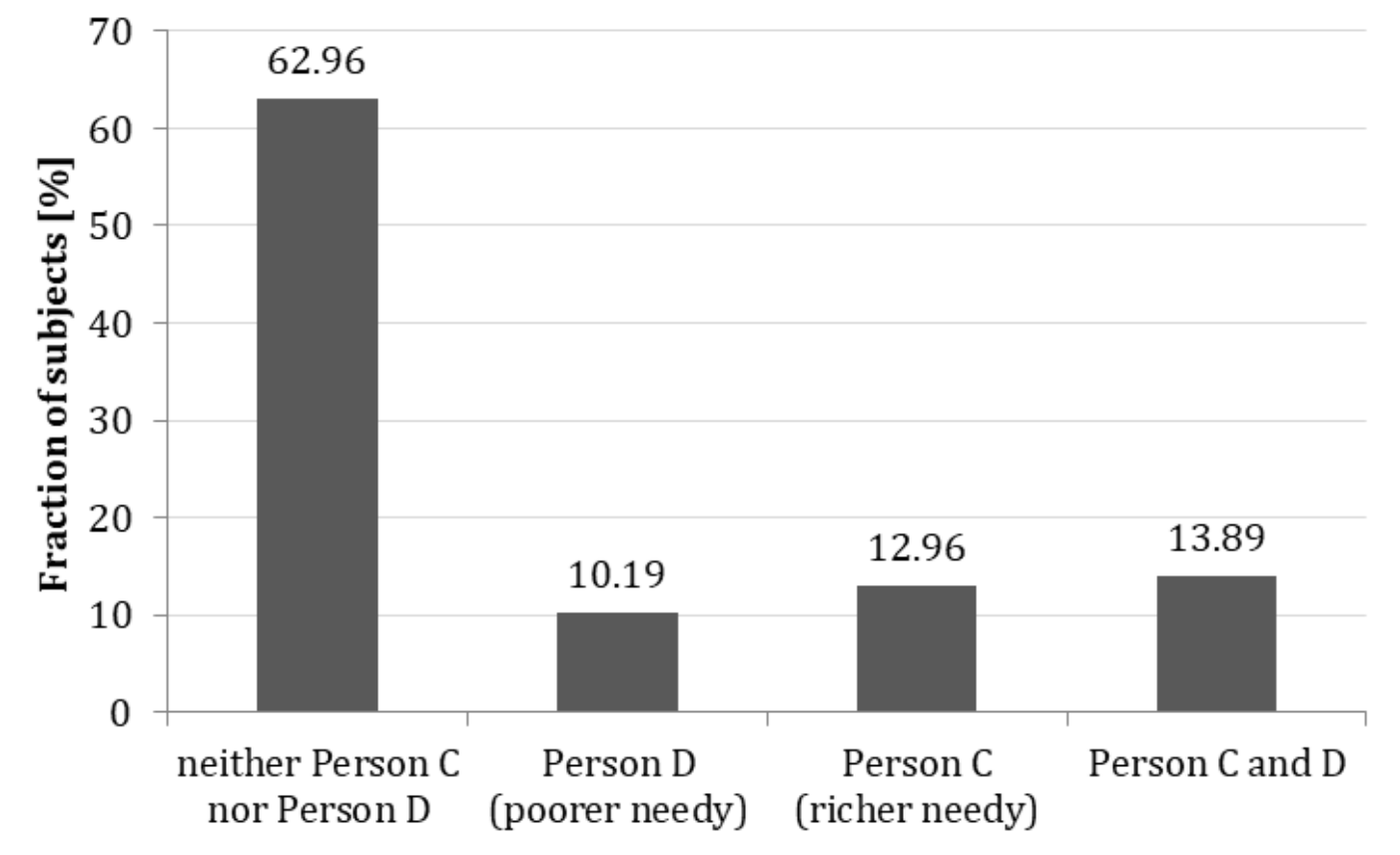

Notes: Fraction of subjects who allocate an amount to Person C and D that is sufficient to lift (1) neither Person C nor Person D, (2) Person C (richer needy), (3) Person D (poorer needy) or (4) both Person C and Person D above the threshold. $N=$ 108 .

We find that dictators in choice 24 give on average 49 percent of their endowment to the needy (Person C and D), whereas they only give 24 percent to the non-needy (Person A and B). 37 percent of subjects raise at least one needy person's income above the threshold of basic needs satisfaction (i.e., they allocate at least 57 GEL to Person C, and/or at least 90 GEL to Person D). 14 percent of subjects raise the income of both Person $\mathrm{C}$ and Person D above the threshold (see Figure 6). All subjects helping only one needy person give this person more than she would need to reach the threshold. The median amount allocated on top of the threshold is higher for the poorer than for the richer needy person (10 versus 3 GEL). Of those subjects helping both needy persons, 20 percent give both persons exactly the amounts they need to reach the threshold. More than 70 percent give both needy persons more than the amount they would need to reach the threshold. For this group of subjects the median amount allocated on top of the threshold is smaller for the poorer than for the richer needy (15 versus $20 \mathrm{GEL}$ ).

To assess whether subjects' decisions in line with BNS in the isolation choices have 
predictive power for helping the needy in choice 24 , we estimate the following logistic regression model:

$$
h_{i}=\alpha+\beta^{B N S} t^{B N S}+\varepsilon_{i},
$$

where $h_{\mathrm{i}}$ is an indicator taking the value 1 if individual $i$ helps at least one person, $t^{B N S}$ is the number of times individual $i$ chooses an option that is only predicted by BNS in the isolation choices, $\varepsilon_{i}$ is the idiosyncratic error term. The second column of Table 4 reports the marginal effects evaluated at the sample mean. We can see that choosing one more time in line with BNS in the isolation choices increases the probability of helping at least one person in choice 24 by eight percentage points. If we extend the model to include the number of times a subject chooses in line with each of the five other motives as predictor variables, this effect remains stable (see third column of Table 4). ${ }^{94}$ Further, the other motives that also entail giving to people less rich than oneself (MXM, GEN) are not associated with a higher probability of helping the needy. Choosing more often in line with SLF, EFF, or ENV decreases the probability of helping in choice 24 . These results indicate that concerns for BNS elicited in the discrete dictator game choices are indeed predictive of helping people in need in a different choice setting at the expense of subjects' own payoff. It further reinforces our conclusion from Chapter II that concerns for BNS are conceptually different from other established distributional motives that entail a concern for persons poorer than oneself.

94 We extend the model to $h_{i}=\alpha+\beta^{k} T_{i}^{k}+\varepsilon_{i}$, where $T_{i}^{k}$ is a vector of the number of times individual $i$ chooses in line with motive $k$ with $k \in\{B N S, M X M, S L F, E F F, G E N, E N V\}$ when it alone predicts an option in the isolation choices. 
Table 4: Helping the needy

\begin{tabular}{|c|c|c|}
\hline & BNS & all motives \\
\hline$\beta^{B N S}$ & $\begin{array}{l}0.080^{*} \\
(0.043)\end{array}$ & $\begin{array}{l}0.096^{*} \\
(0.054)\end{array}$ \\
\hline$\beta^{M X M}$ & & $\begin{array}{c}0.006 \\
(0.044)\end{array}$ \\
\hline$\beta^{S L F}$ & & $\begin{array}{c}-0.120^{* * *} \\
(0.041)\end{array}$ \\
\hline$\beta^{E F F}$ & & $\begin{array}{c}-0.103^{*} \\
(0.054)\end{array}$ \\
\hline$\beta^{G E N}$ & & $\begin{array}{l}-0.022 \\
(0.055)\end{array}$ \\
\hline$\beta^{E N V}$ & & $\begin{array}{c}-0.114^{* *} \\
(0.051)\end{array}$ \\
\hline
\end{tabular}

Notes: Logisitc regression estimates: Marginal effects evaluated at means of variables. Standard errors in parenthesis. The dependent variable is equal to 1 if a subject helps at least one needy person in choice 24 (i.e., allocates an amount to at least one of the Person C or D that is sufficient for these persons to have an income of at least the threshold for basic needs satisfaction in this month). The independent variables are the number of times a dictator chooses in line with a motive when it alone predicts an option in the isolation choices. ${ }^{*} p<.10,{ }^{* *} p<.05,{ }^{* * *} p<.01$, $N=106$.

\subsubsection{Heterogeneity}

Findings from prior studies suggest that the propensity to act prosocial is related to individual characteristics, such as a subject's gender, age, and income. For example, Engel (2011) finds in a meta-study on dictator game giving that women give more than men. Moreover, middle aged and elderly subjects are less likely to give nothing than children and students. Results from, for example, List (2011), Piff et al. (2010), and Smeets et al. (2015) suggest that prosocial behavior is related to a person's income. We explore how concerns for BNS as a prosocial motive are related to these characteristics. In particular, we look at how they determine how often a subject chooses in line with the motive when it alone predicts an option in choice 1-5. Since we have very few observations of subjects choosing four and five times in line with BNS, we use three categories of the number of times a subject chooses in line with BNS: (1) never, (2) one or two times, and (3) at least three times. Figure 16a to $16 \mathrm{c}$ in Appendix I show the reverse cumulative distributions by gender, age, and income. We use five different age categories (1) below 25, (2) 25-32, (3) 
33-44, (4) 44-55, (5) above 55, which we constructed based on age quintiles in our sample. The income categories correspond to those introduced in Table 2 (see Section 3.2.1) ${ }^{95} \mathrm{~A}$ Wilcoxon-Mann-Whitney test reveals that the distributions slightly differ between male and female subjects $(z=-1.718, p=.086)$. If we look a little closer, we see that in particular women are more likely to choose at least three times in line with BNS than men $(z=-2.059, p=.040) .{ }^{96}$ A Kruskal-Wallis test reveals no difference in the distribution of the number of times subjects from different age (income) categories choose in line with $\operatorname{BNS}\left(\chi^{2}(4)=1.351, p=.853\left(\chi^{2}(4)=.879, p=.928\right)\right) .{ }^{97} \mathrm{~A}$ series of pairwise WilcoxonMann-Whitney tests further shows no differences between any of the age (income) categories. ${ }^{98}$

To further investigate the demographic determinants of how strongly a subject cares for the satisfaction of basic needs, we estimate the probability that a subject chooses never, once or twice, or at least three times in line with the motive with the following ordered probit regression model:

$$
b_{i}=\alpha+\gamma_{1} \text { female }+\gamma_{2} \text { age }+\gamma_{3} \text { income }+\varepsilon_{i} .
$$

In this model $b_{i}$ is a categorical variable taking the value 0 if individual $i$ chooses never in line with BNS in choice 1-5, 1 if she does so one or two times, and 2 if she does so at least three times. The independent variables are subjects' gender, and two categorical variables for subjects' age and income, $\varepsilon_{i}$ is the idiosyncratic error term. Table 5 shows the ordered probit estimates. The estimation confirms the non-parametric results of a gender, but no age or income effect on concerns for BNS. ${ }^{99}$ In terms of gender differences, women are more likely to choose more often in line with BNS than men. In particular, the marginal effects of the ordered probit estimation suggest that the probability to choose never in line with BNS is 18.18 percentage points lower for women (see Table 6). Further, women are 10.38 percentage points more likely to choose one or two times and 7.80 percentage points more likely to choose at least three times in line with the motive. This is in line with prior results that women are more prone to engage in prosocial behavior

95 Note that in which income category a dictator falls at the same time determines which type of choice sets she gets, since her income amounts in the choices and those of the person richer than herself (Person A) are adjusted for dictators' income.

96 Gender differences are insignificant if we compare the distributions of subjects choosing at least once (twice) in line with BNS versus the rest of subjects $(z=-1.140, p=$ $.254(z=.522, p=.601))$.

97 There are also no age (income) differences if we compare the distributions of subjects choosing at least once, twice, three times in line with BNS versus the rest of subjects: smallest $p$-value: $.764(.585)$.

98 Smallest p-value: .268 (.367).

99 Table 9 in Appendix I shows that estimates are robust to using subjects' nominal age and income instead of categories and that there is neither a linear, nor a quadratic relation between these variables and the number of times subjects' choose in line with BNS in choice 1-5. 
than men. Concerns for the satisfaction of basic needs, however, seem to be independent of subjects' age and income.

Table 5: Determinants of individual choice patterns (BNS)

\begin{tabular}{cccc}
\hline & Model 1 & Model 2 & Model 3 \\
\hline Female & $.4445^{*}(.2383)$ & $.4395^{*}(.2476)$ & $.4748^{*}(.2523)$ \\
Age & & & \\
$25-32$ & & $-.1356(.3508)$ & $-.0899(.3554)$ \\
$33-44$ & & $-.2413(.3589)$ & $-.2290(.3658)$ \\
$44-55$ & $.0577(.3499)$ & $.0776(.3560)$ \\
$>55$ & $-.0029(.3509)$ & $-.0050(.3538)$ \\
Income category & & & $-.2758(.3284)$ \\
II & & & $-.3051(.3276)$ \\
III & & & $-.0468(.3522)$ \\
IV & & & $-.2763(.4801)$ \\
V & & & $-.2316(.3273)$ \\
Constant 1 & $-.0474(.1922)$ & & $1.3616(.3527)$ \\
Constant 2 & $1.5408(.2390)$ & & $-985(.2775)$ \\
& & & -93.4129 \\
LL & -94.3000 & 4.60 & 5.95 \\
LR of joint & 3.51 & .0241 & .0312 \\
significance & .0183 & 100 & 100 \\
Pseudo r-squared & 101 & & \\
N & & & \\
\hline
\end{tabular}

Notes: Ordered probit regression estimates. Standard errors in parenthesis. Categories of the dependent variable are: choosing in line with BNS in choice 1-5 (1) never, (2) 1 or 2 times, (3) at least 3 times. The independent variables are subjects' gender, age, and income (see Table 2 for the income categories). ${ }^{*} p<.10,{ }^{* *} p<.05,{ }^{* * *} p<.01$.

Table 6: Determinants of individual choice patterns (BNS):

Marginal effects

\begin{tabular}{cccc}
\hline & never & 1 or 2 times & at least 3 times \\
\hline Female & $-.1818^{*}(.0964)$ & $.1038^{*}(.0628)$ & $.0780^{*}(.0406)$ \\
Age & & & \\
$25-32$ & $.0341(.1350)$ & $-.0183(.0730)$ & $-.0159(.0624)$ \\
3311 & $.0884(.1415)$ & $-.0515(.0853)$ & $-.0369(.0583)$ \\
$44-55$ & $-.0286(.1308)$ & $.01339(.0610)$ & $.0152(.0702)$ \\
$>55$ & $.0019(.1324)$ & $-.0009(.0666)$ & $-.0009(.0658)$ \\
Income & & & \\
II & $.1032(.1227)$ & $-.0524(.0651)$ & $-.0508(.0611)$ \\
III & $.1147(.1229)$ & $-.0595(.0671)$ & $-.0552(.0601)$ \\
IV & $.01676(.1264)$ & $-.0069(.0527)$ & $-.0099(.0739)$ \\
V & $.1034(.1837)$ & $-.0525(.1056)$ & $-.0509(.0812)$ \\
\hline
\end{tabular}

Notes: Ordered probit regression estimates (Model 3 in Table 5): Marginal effects evaluated at means of variables. Standard errors in parenthesis. The independent variables are the subject's gender, age, income (see Table 2 for the income categories). $N=100 .{ }^{*} p<.10,{ }^{* *} p<.05,{ }^{* * *} p<.01$. 


\subsection{CONCLUDING REMARKS}

In this experiment, dictators are deciding about actual monthly incomes. In other words, the dictator and the receivers (Person A, B, C, and D) will, in the month of the experiment, have the income amounts depicted in the allocation chosen by the dictator. This entails that dictators can actually satisfy basic needs of Person C and D in the experiment genuine persons who are living with an income below the basic needs threshold in their everyday lives. We thus show that concerns for basic needs satisfaction are important in a setting in which the fulfillment of basic needs is actually at stake. In particular, in each choice, a substantial fraction of subjects chooses in line with the motive when it alone predicts an option. The majority of subjects do so at least once, revealing that they attach a positive weight to the motive.

Overall, our findings in this experiment confirm our results and reinforce our conclusion of Chapter II: Concerns for basic needs satisfaction are an important behavioral driving force in decisions about the distribution of incomes. The motive should, therefore, be taken seriously in discussions about optimal design of redistributive policies.

\subsection{APPENDIX}

\section{A Outline experiment}

Figure 7: Outline of the study

\begin{tabular}{|c|c|c|c|c|c|c|c|}
\hline Step 1 & & Step 2 & & Step 3 & Step 4 & & Step 5 \\
\hline Pre-survey & $\rightarrow$ & $\begin{array}{l}\text { Select and } \\
\text { invite } \\
\text { participants }\end{array}$ & $\rightarrow$ & Experiment & $\rightarrow \begin{array}{c}\text { Survey } \\
\text { questionnaire }\end{array}$ & $\rightarrow$ & Payment \\
\hline
\end{tabular}




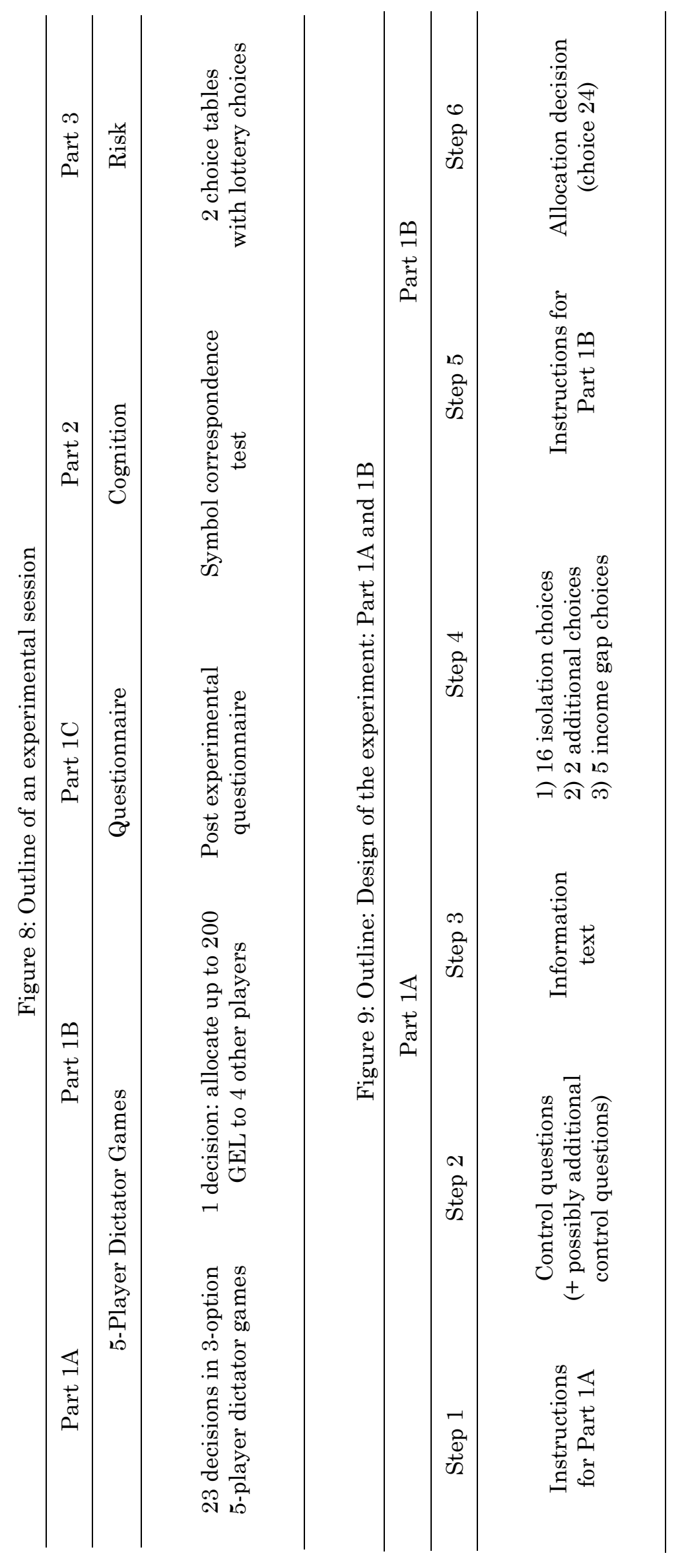




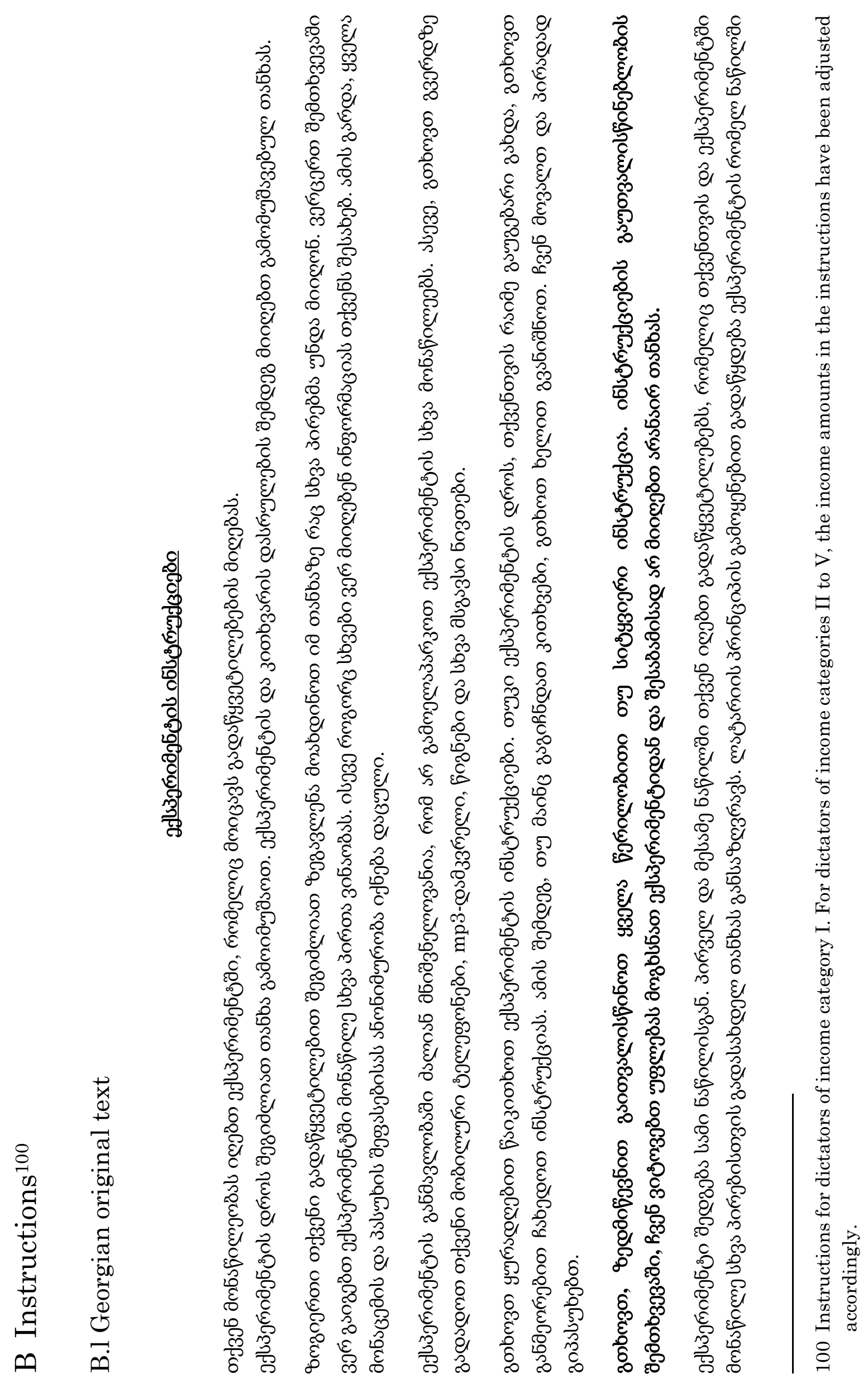




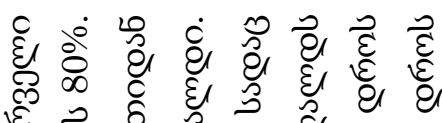

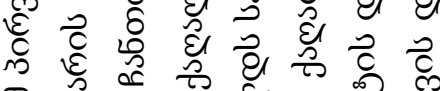

施

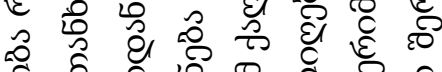

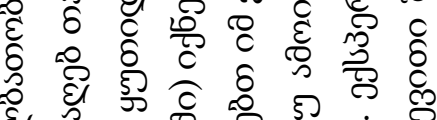
乡

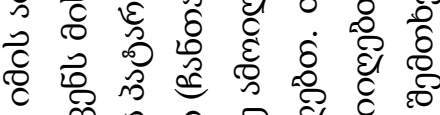

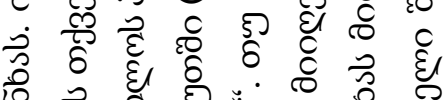

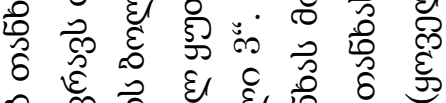

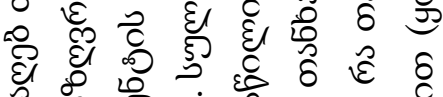

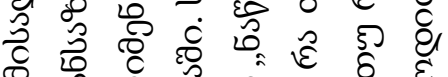

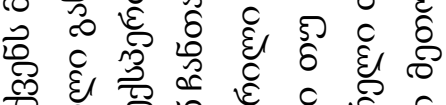

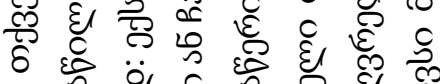

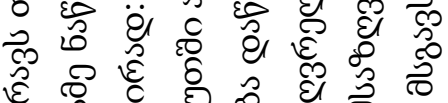

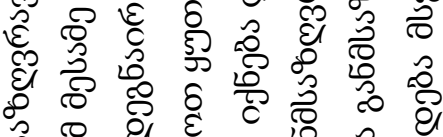

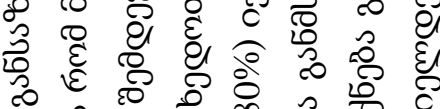

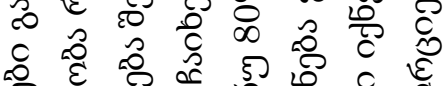

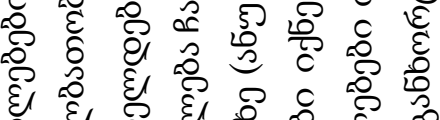
है है है है है

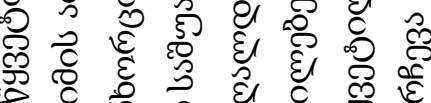

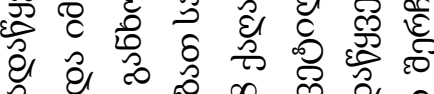

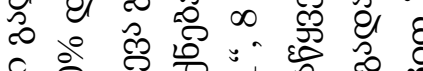

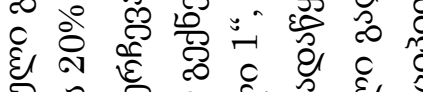
影 ध

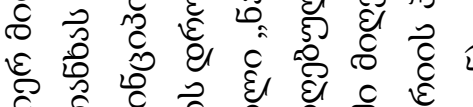

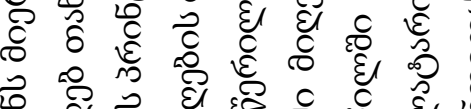

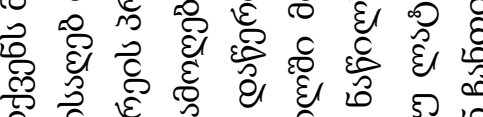

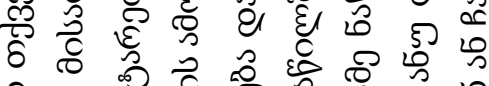

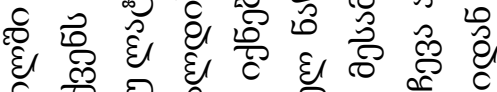
है 要

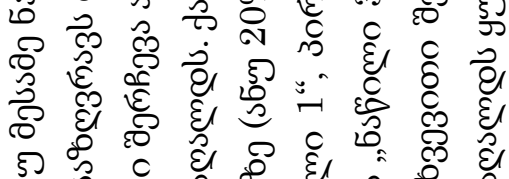

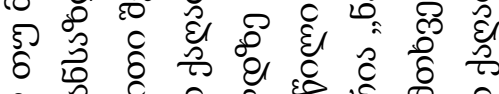

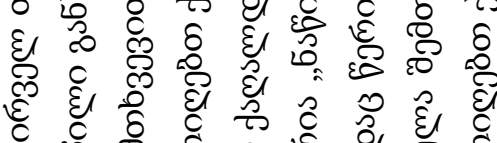

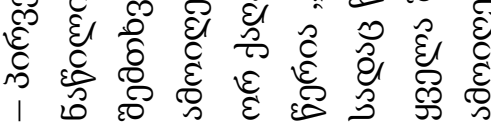

응 है के

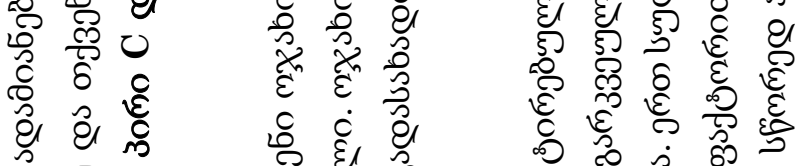

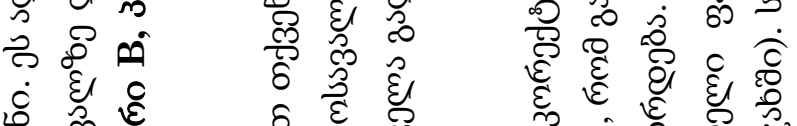

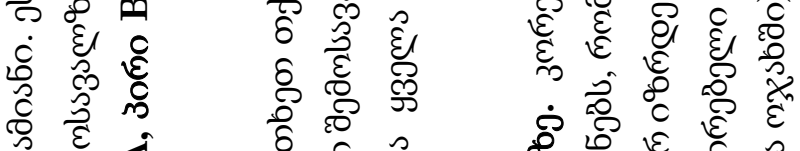
$\begin{array}{lll} & \\ 0 & \\ 0\end{array}$

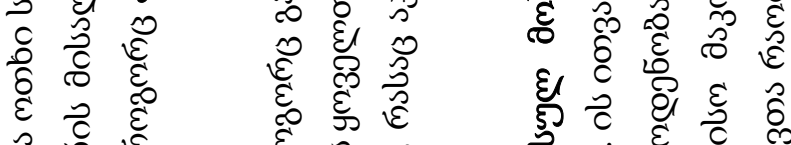

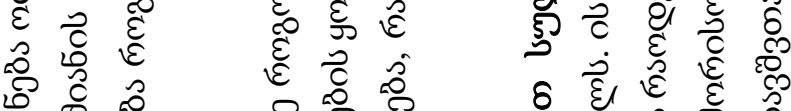

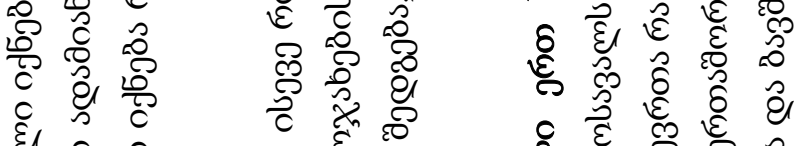
ध

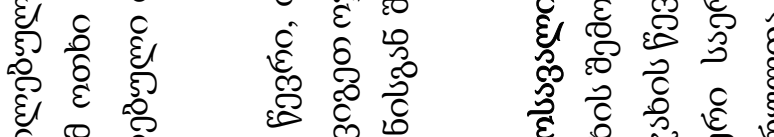

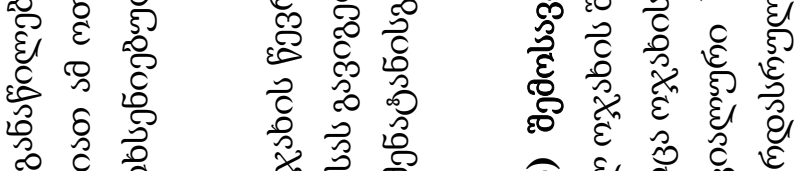

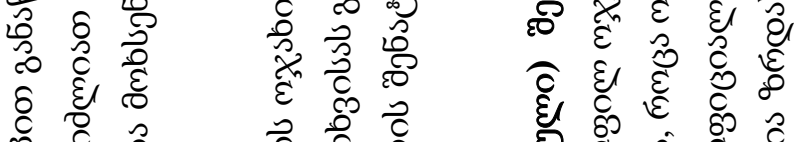

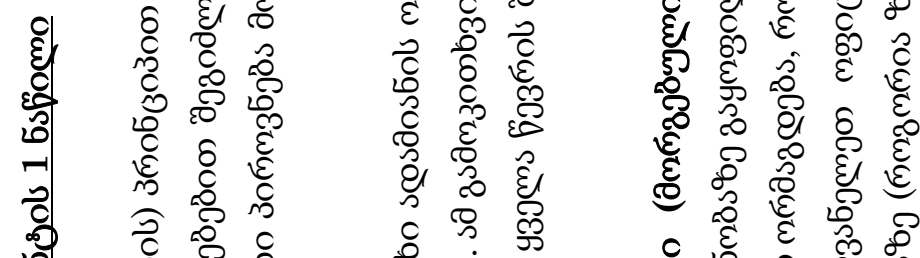

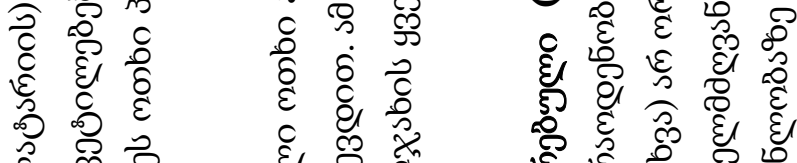
ह

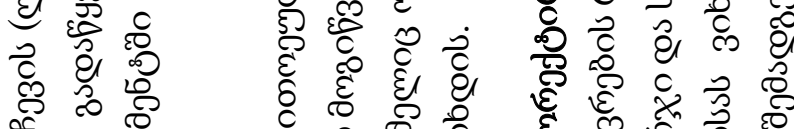

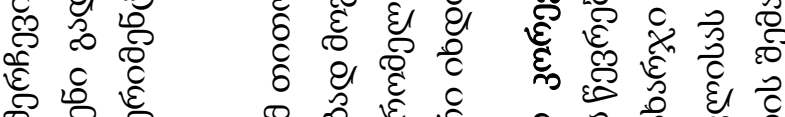

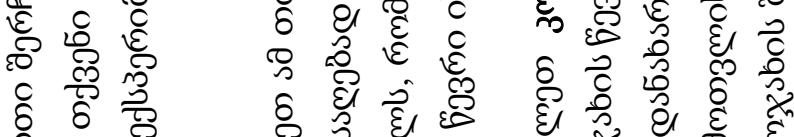

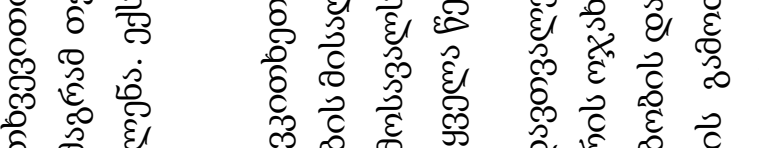

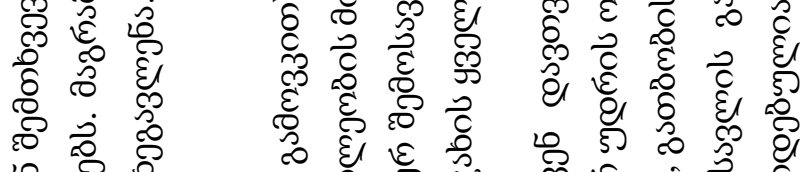

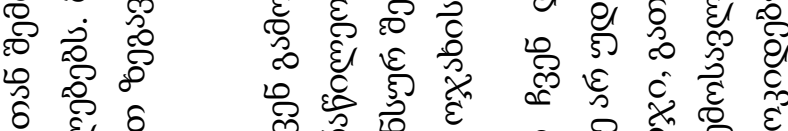

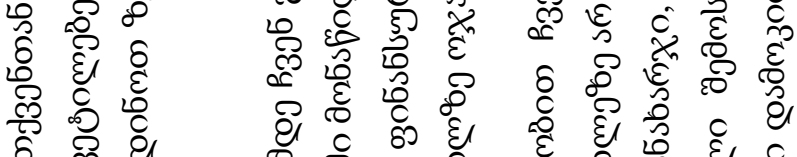

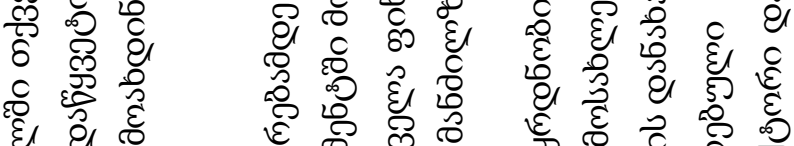

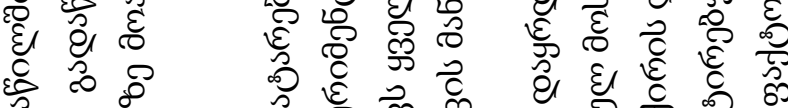

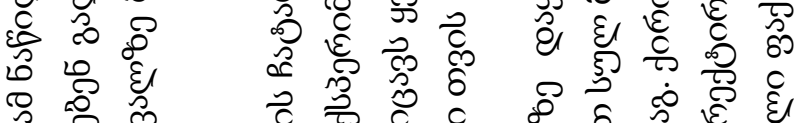

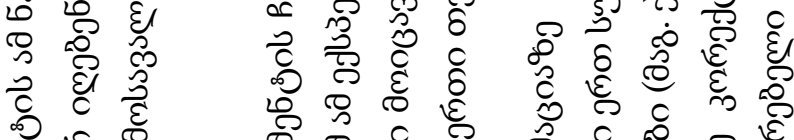

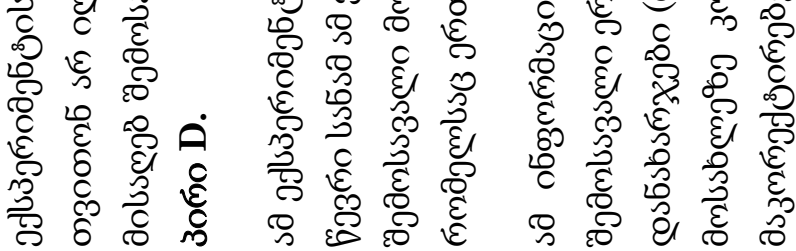




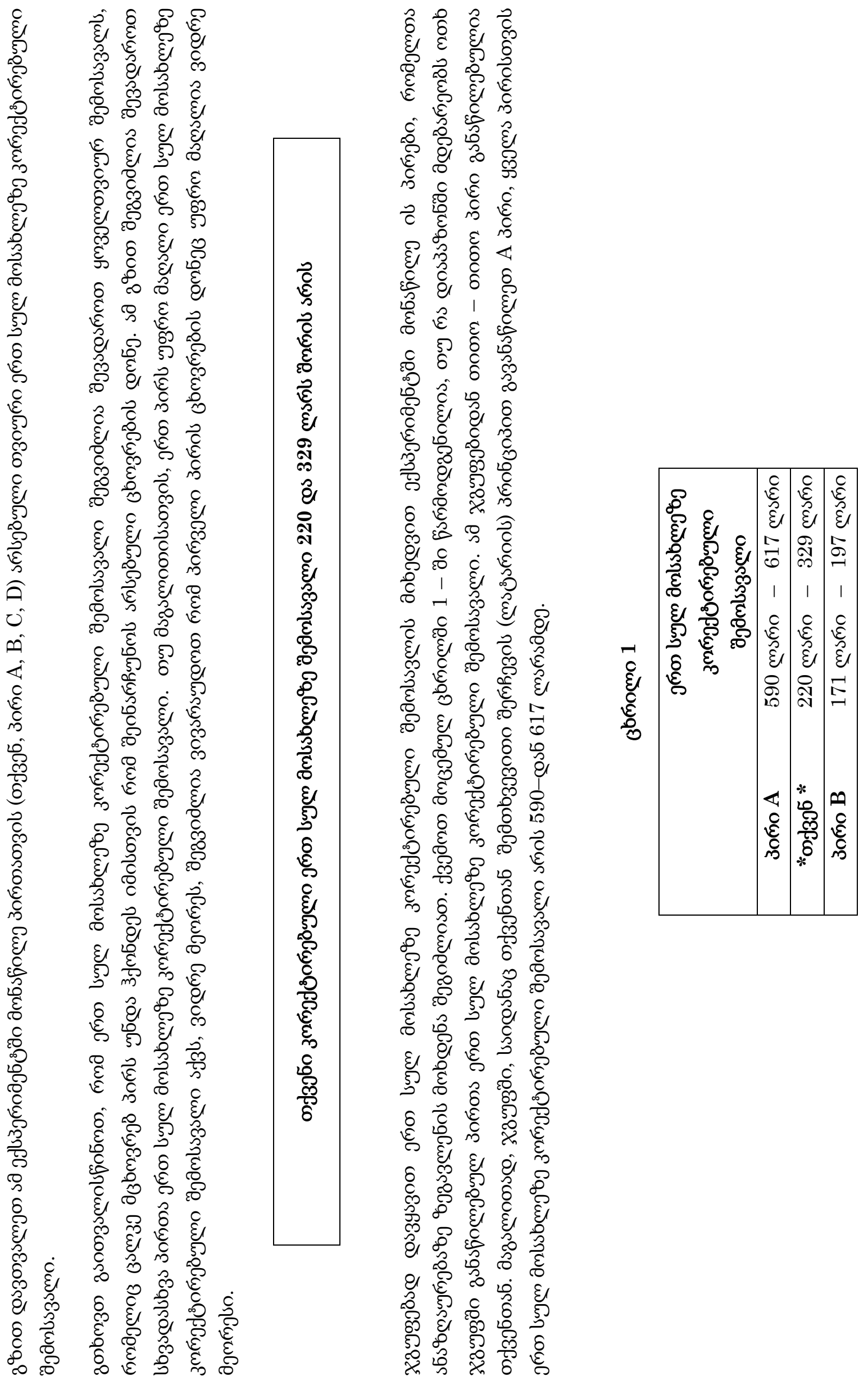



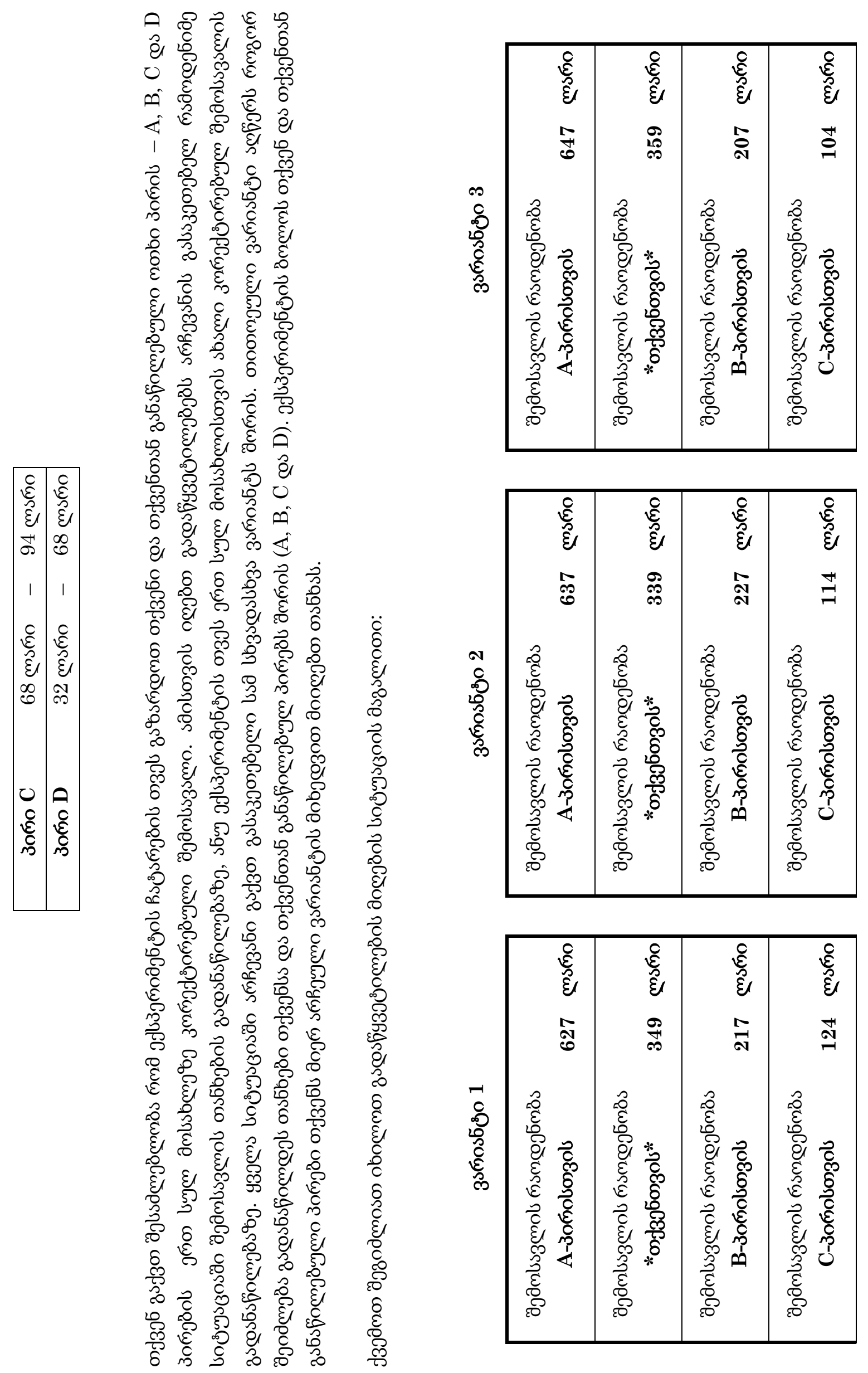

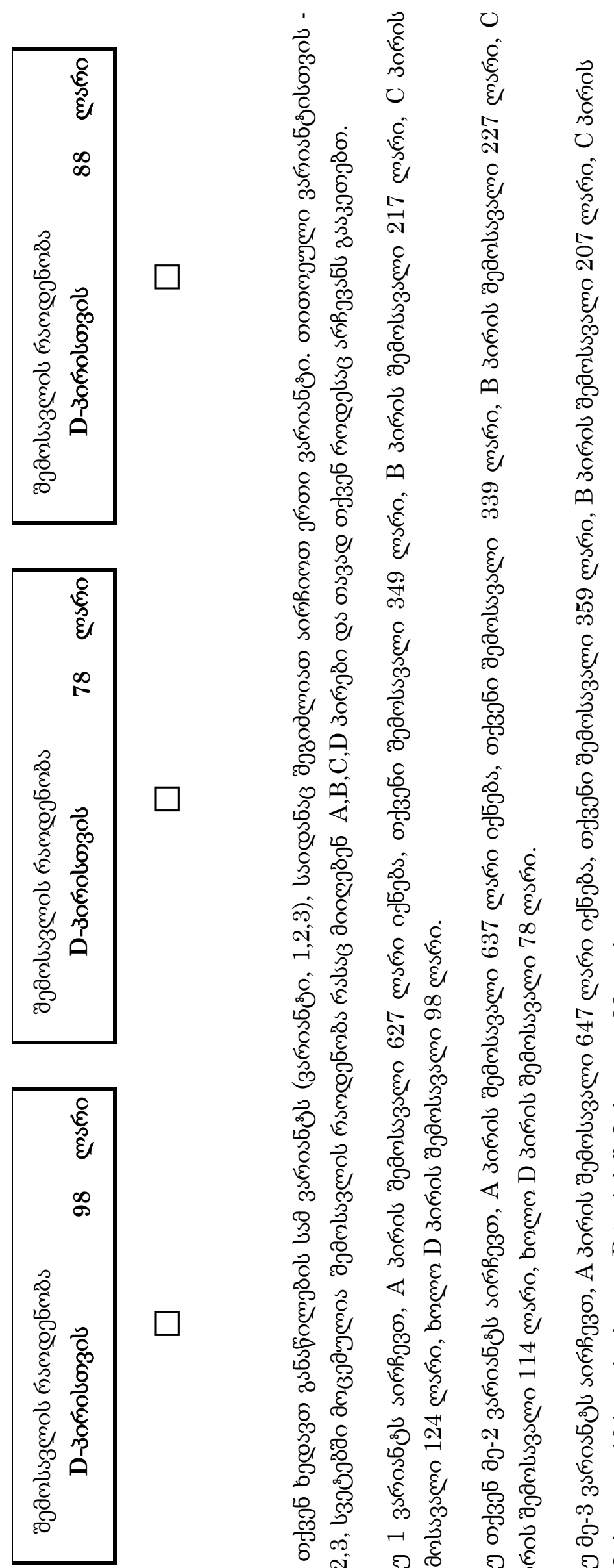

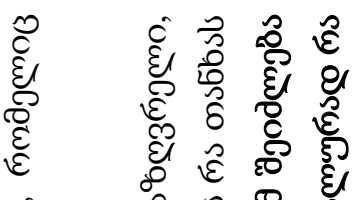

战

\&

总

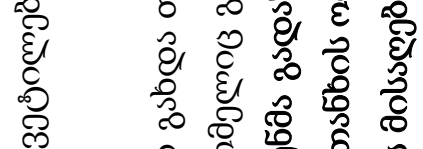

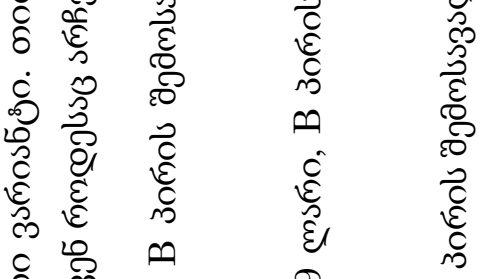

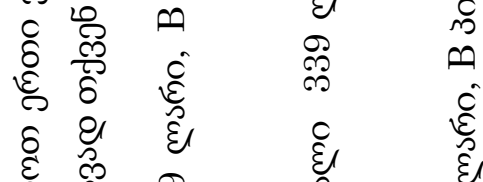

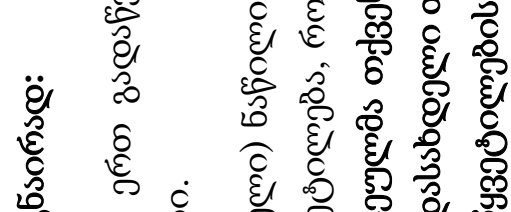

范

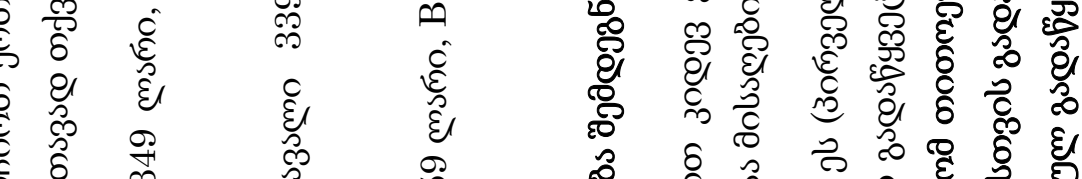

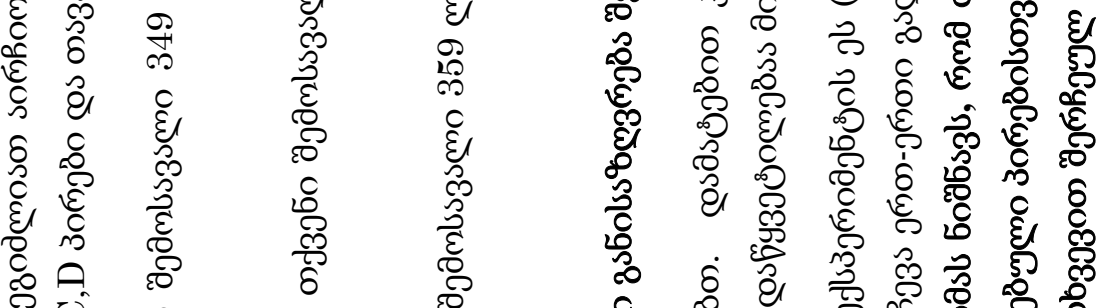

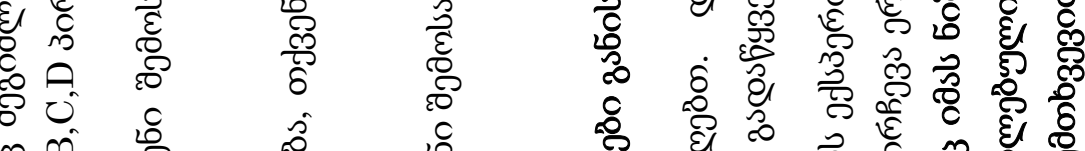

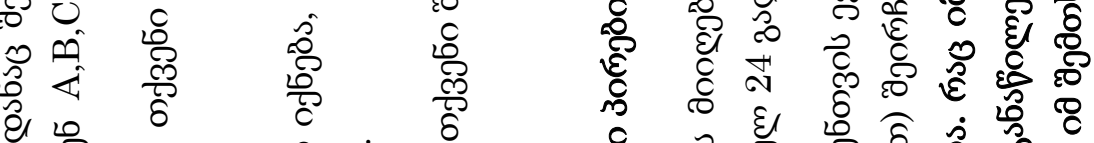

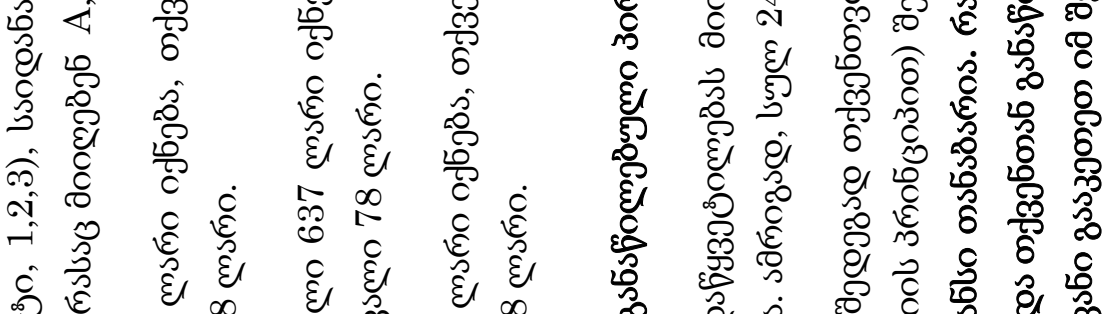

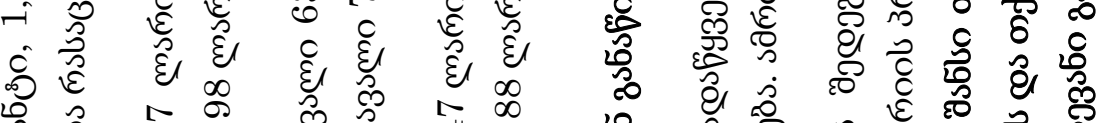

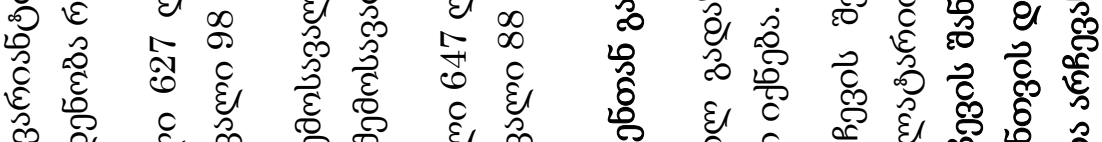
ब $\begin{gathered}0 \\ \text { \& }\end{gathered}$ की है है

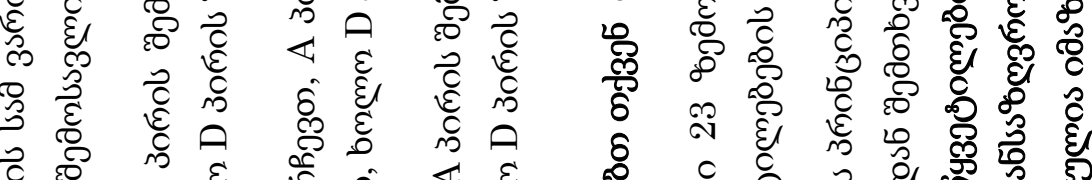

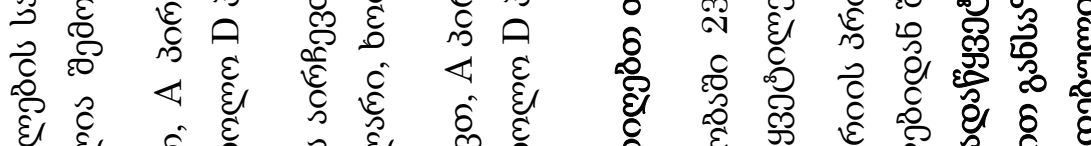

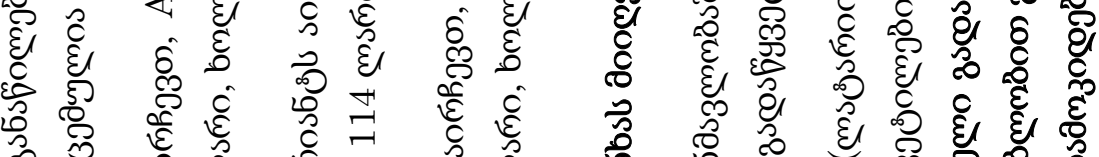

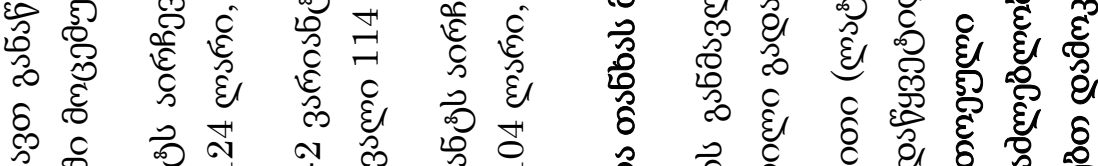

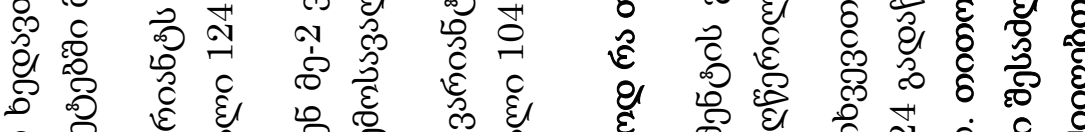

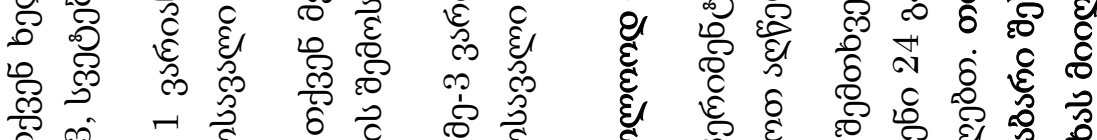

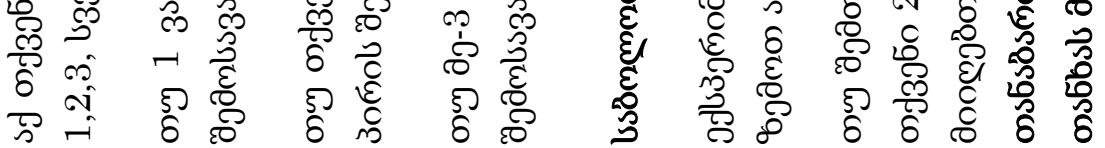




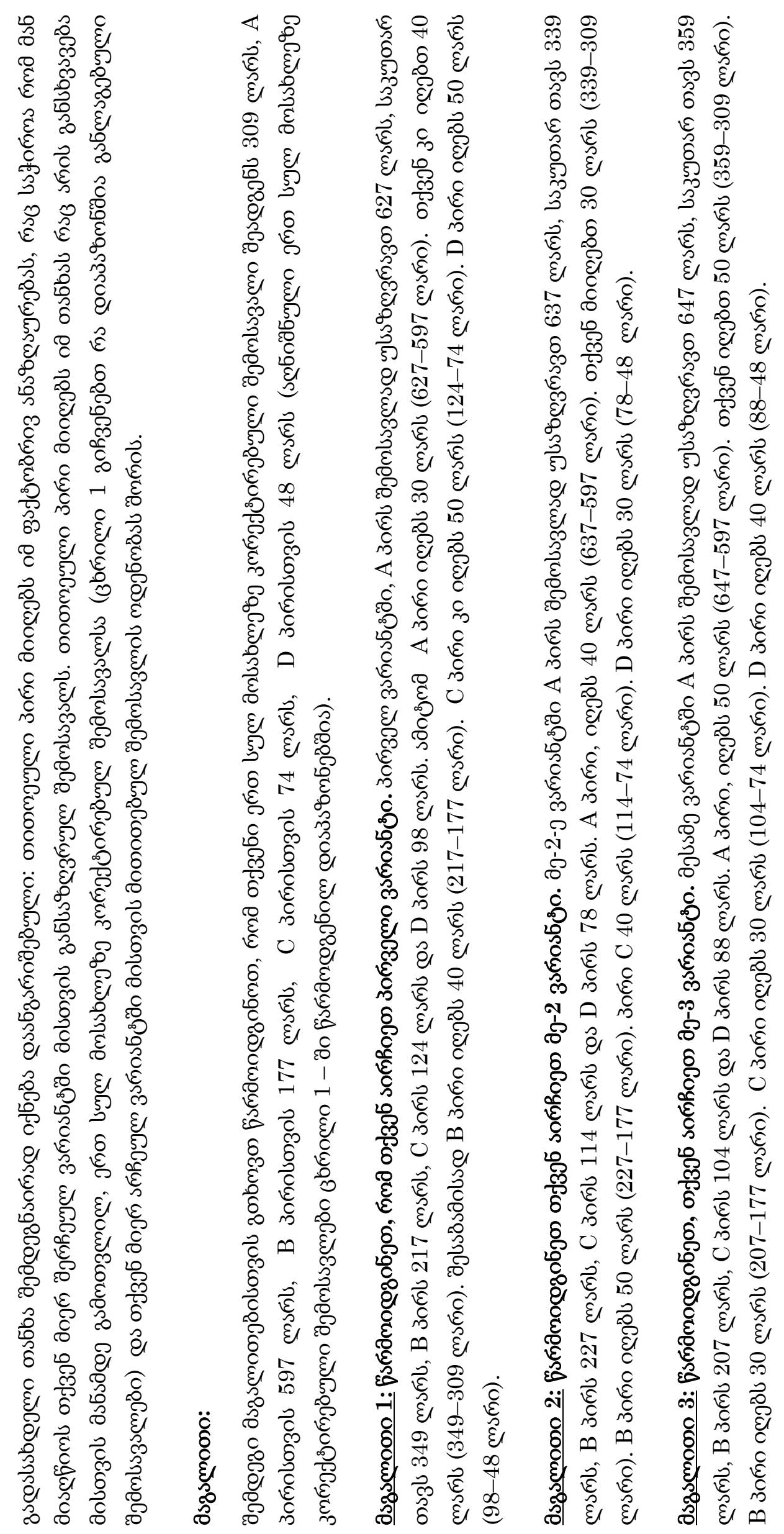




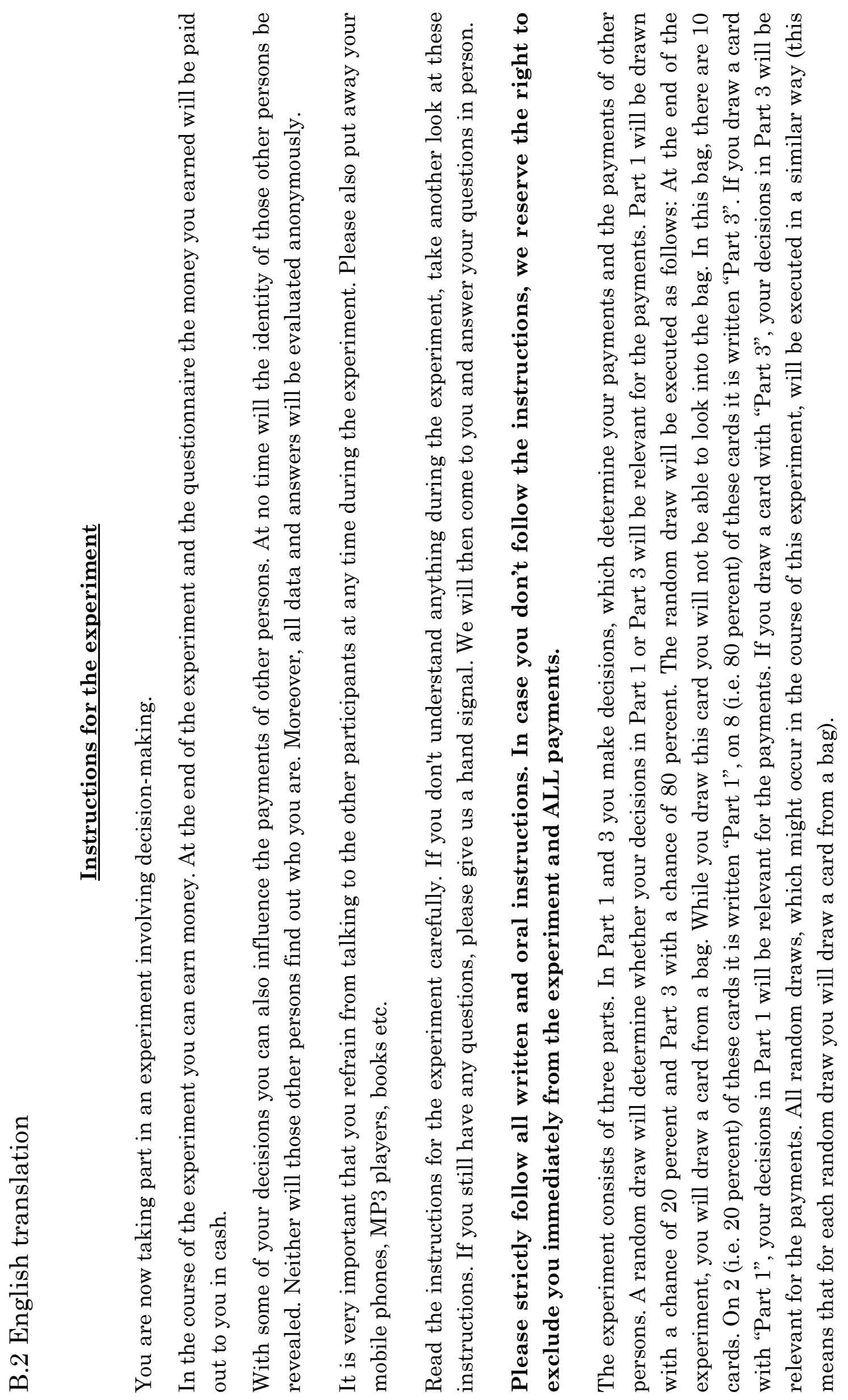




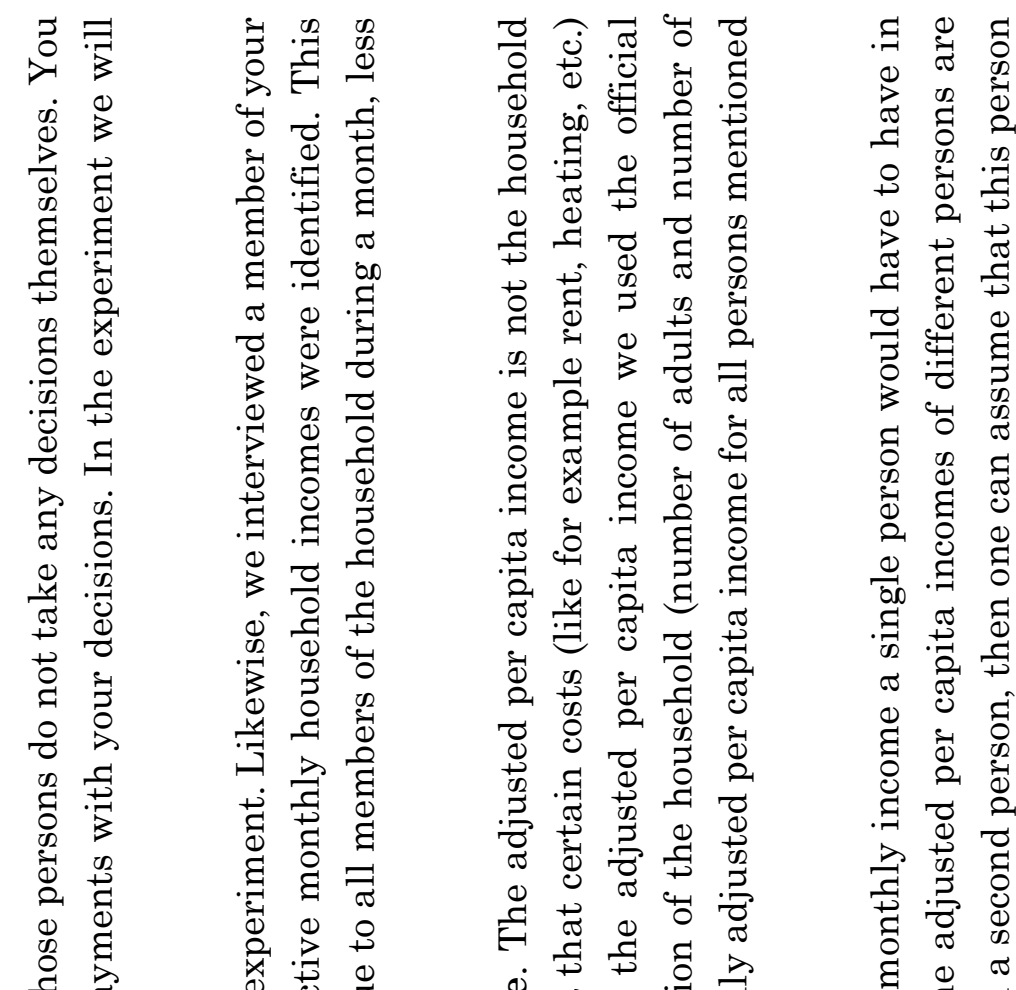

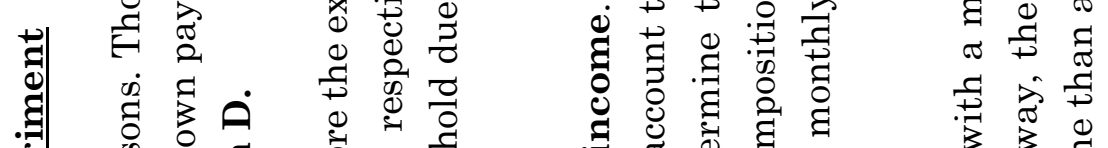

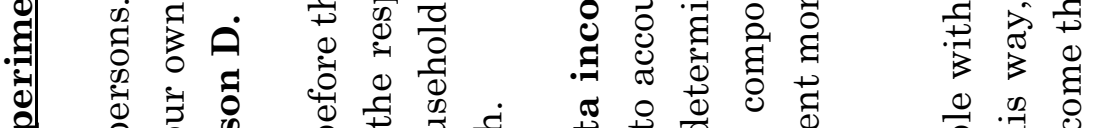

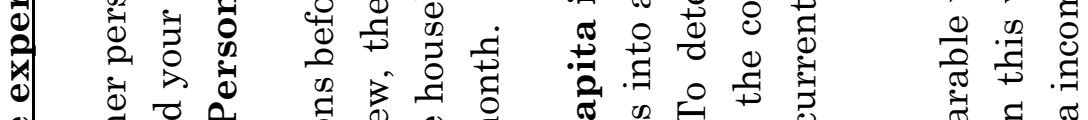

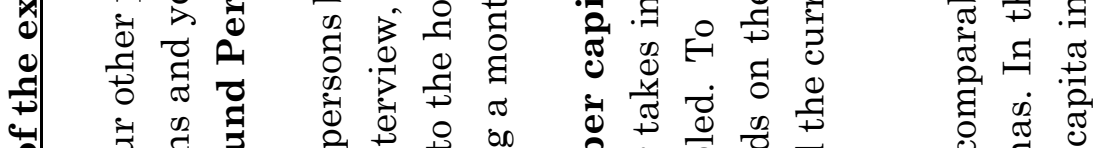

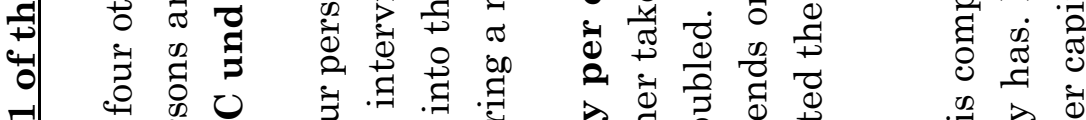

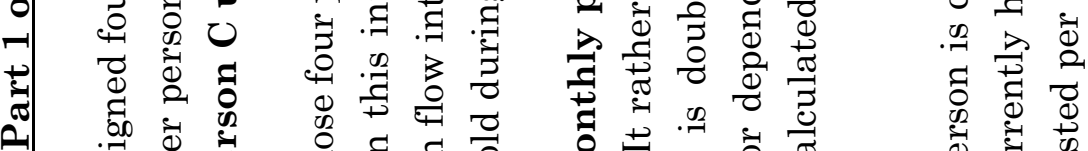

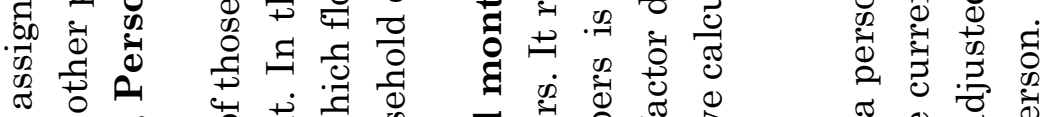

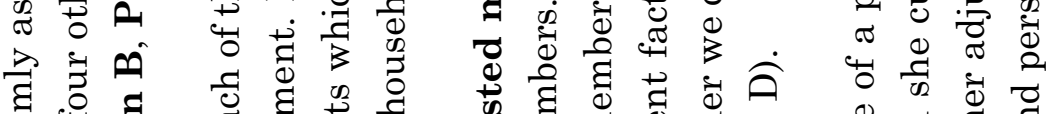

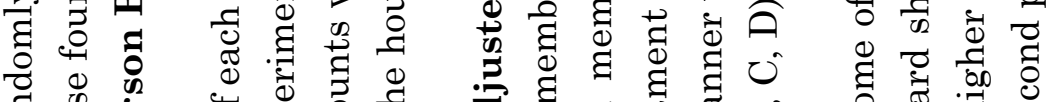

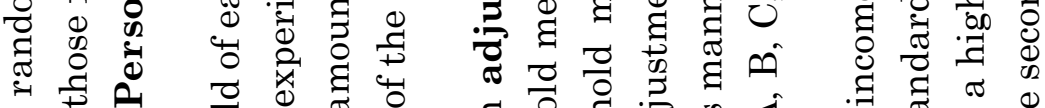

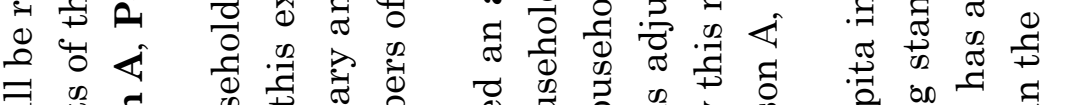

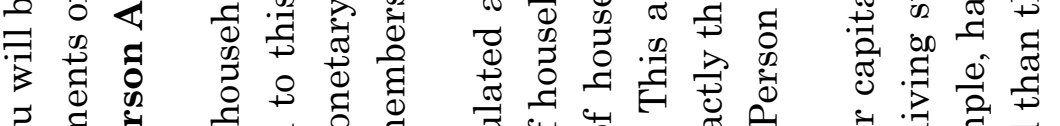

₹

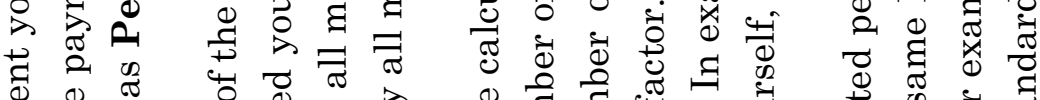

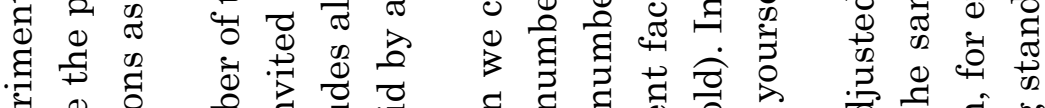

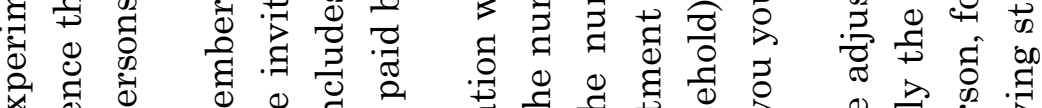

霍至

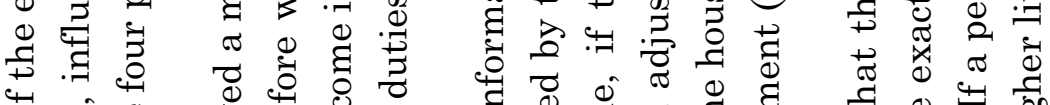

फी

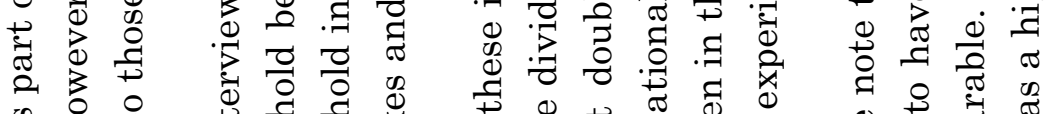

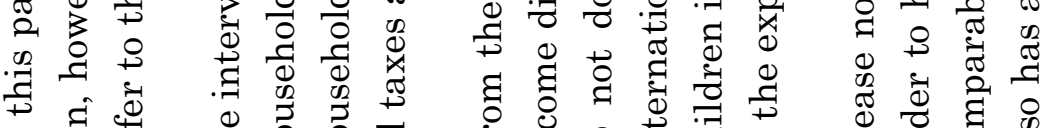

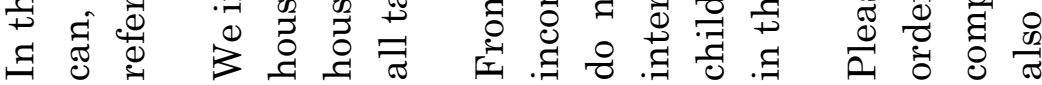

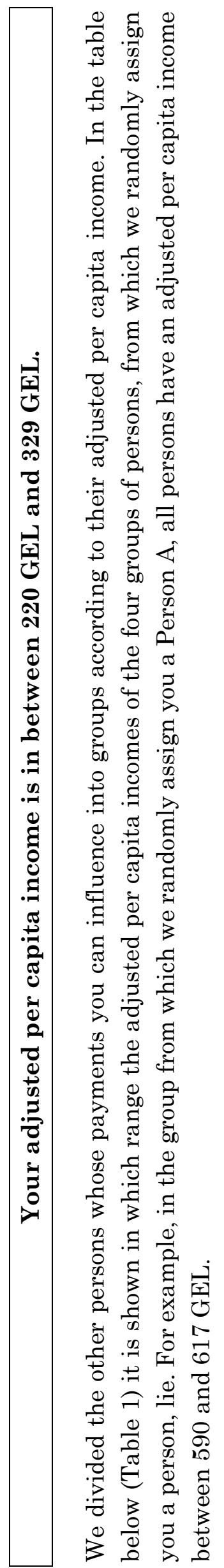




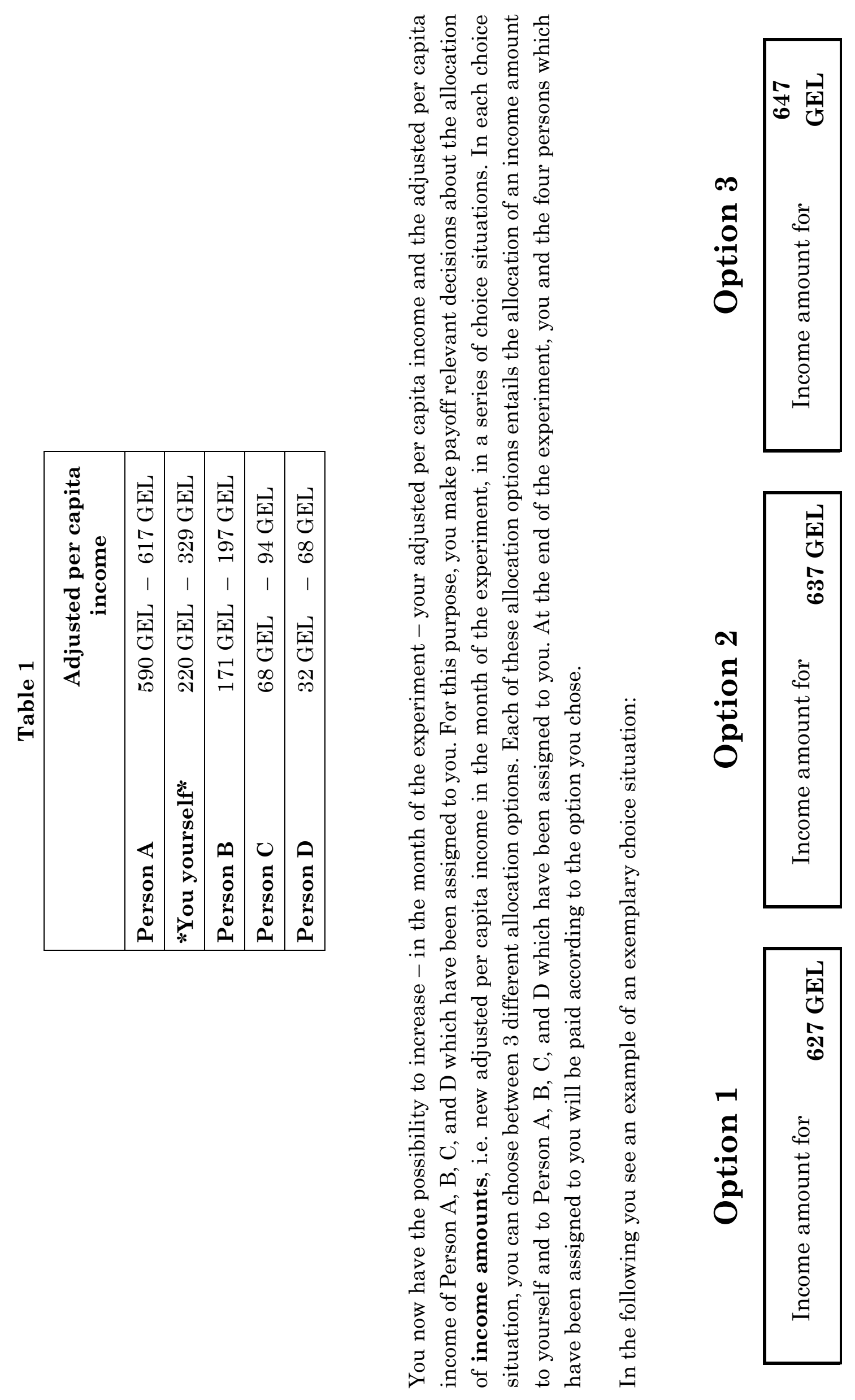



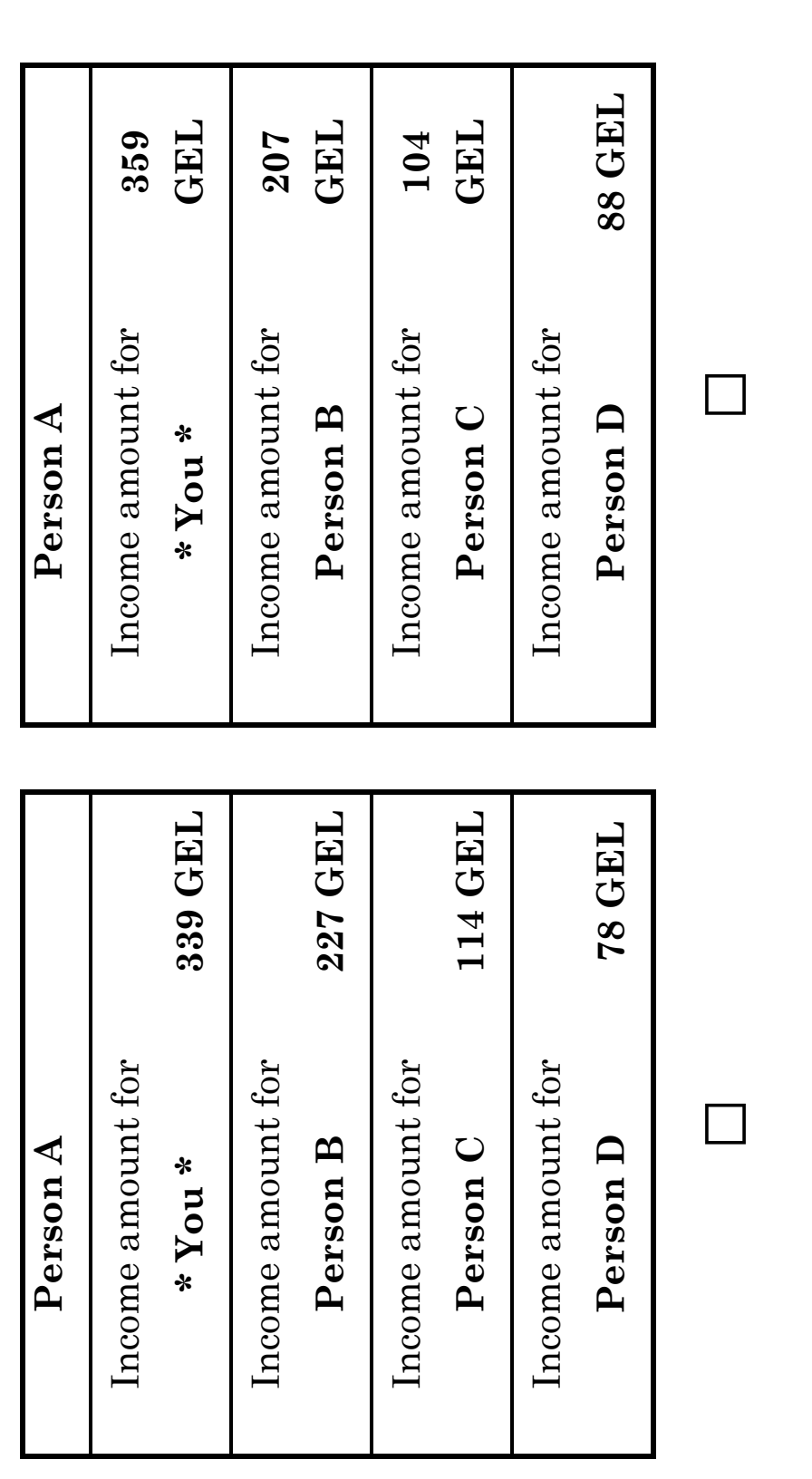

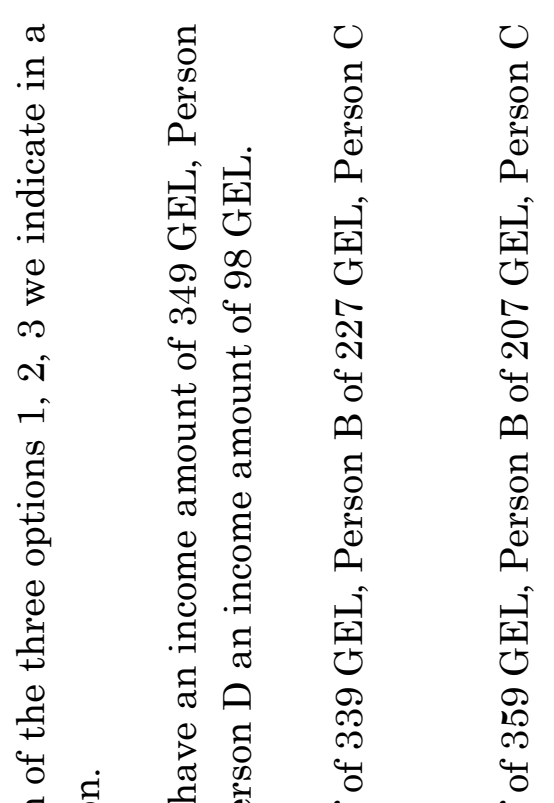

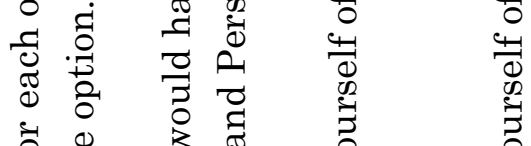

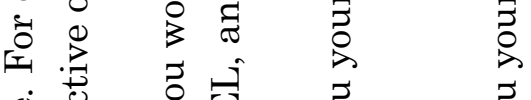

范

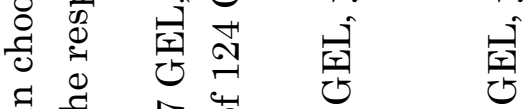

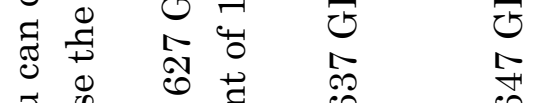

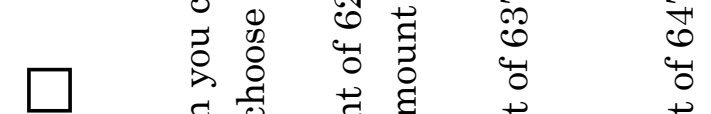

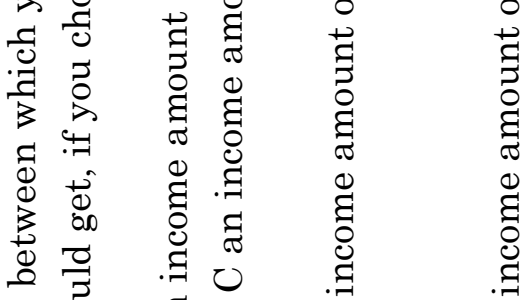

๙ิ

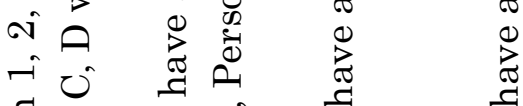

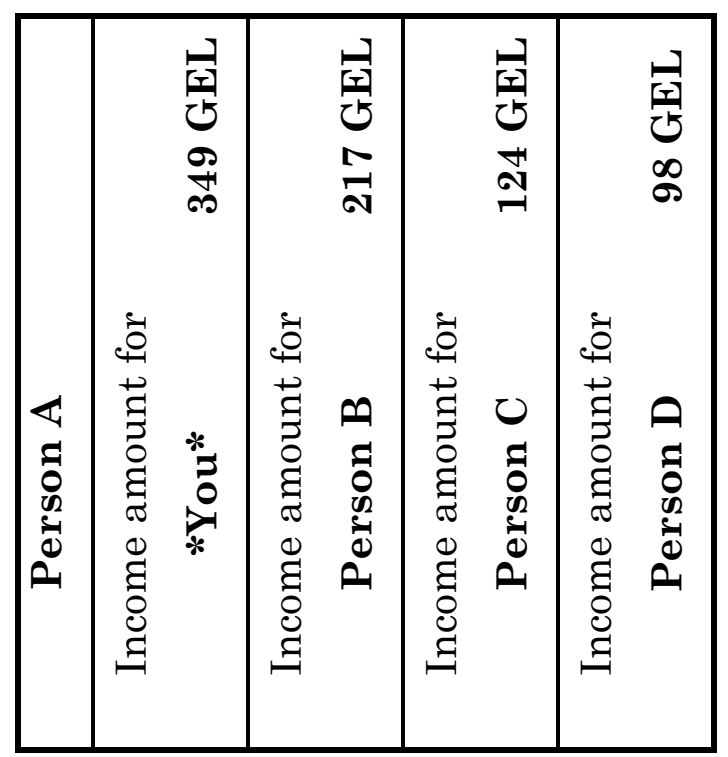

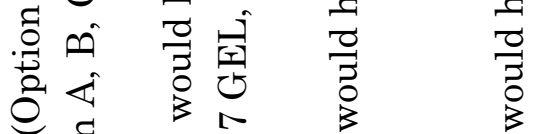

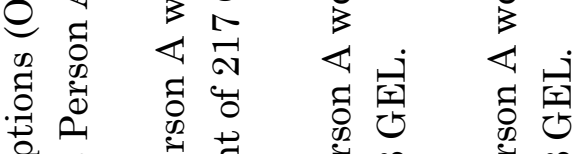

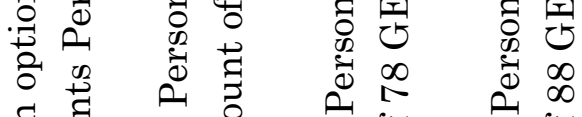

वี

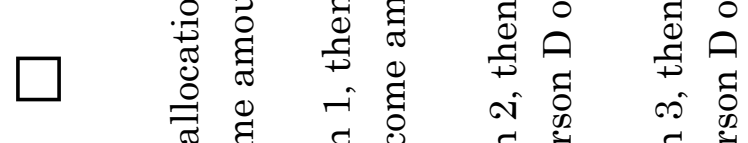

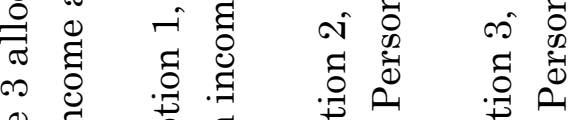

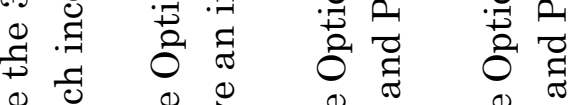

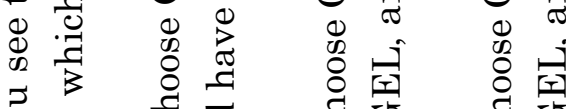

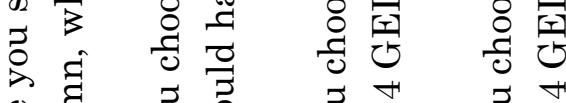

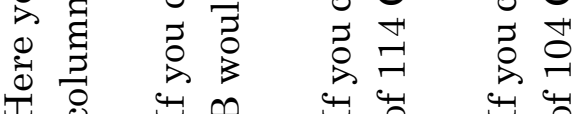

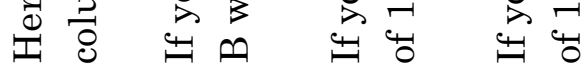




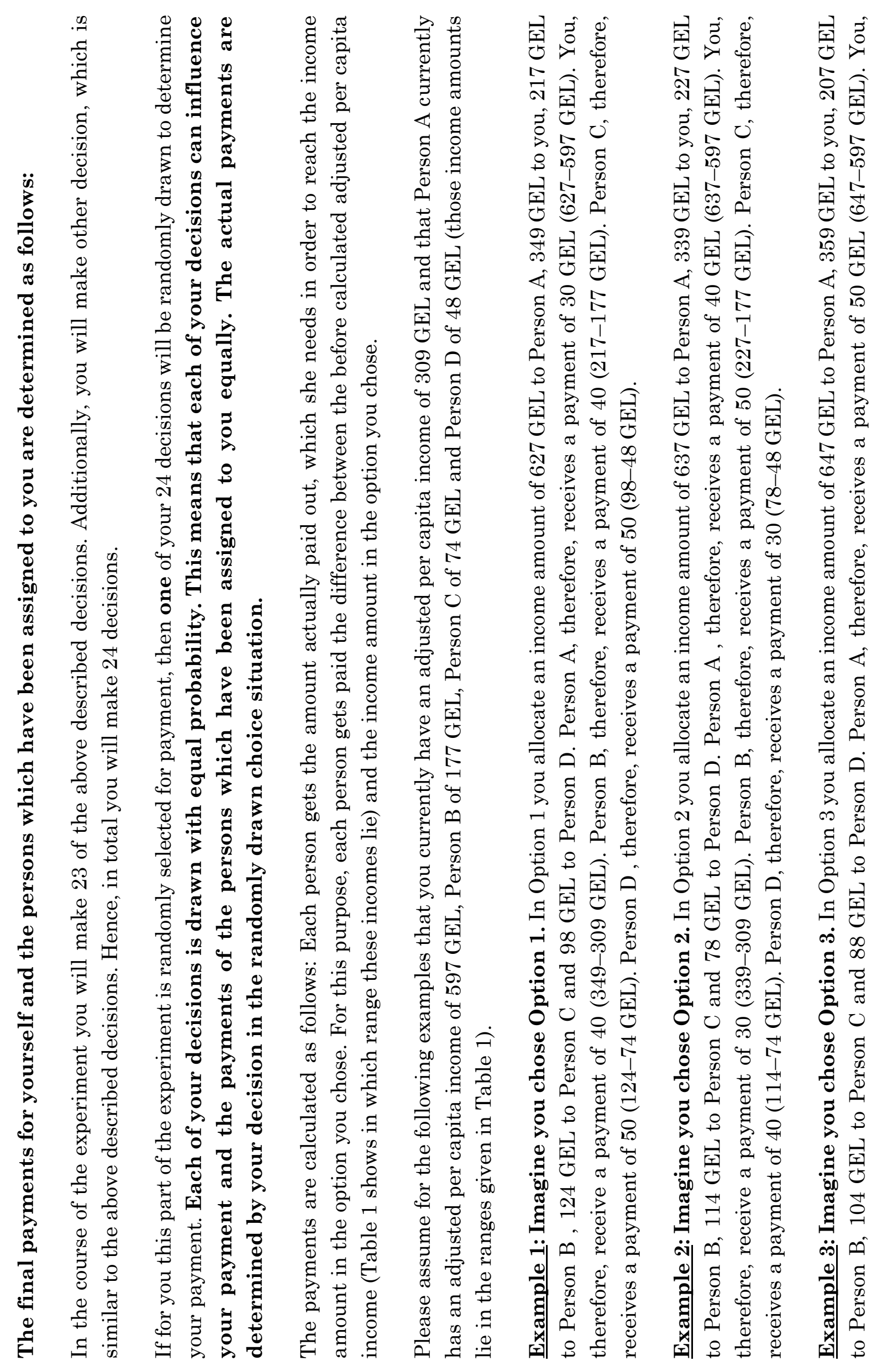




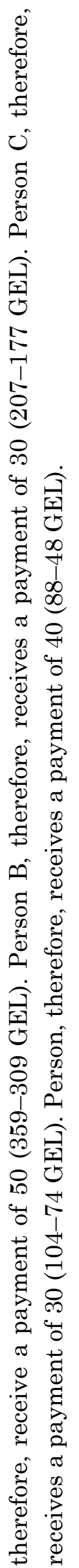




\section{Information text}

\section{C.l Georgian original text}

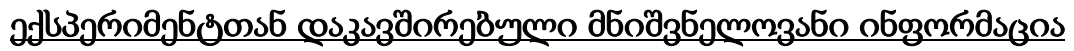

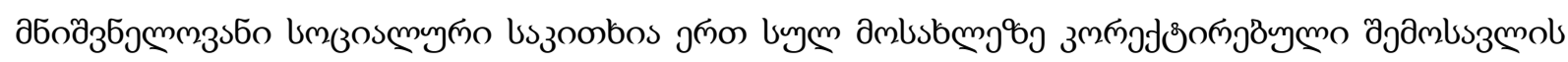

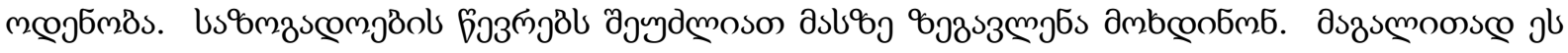

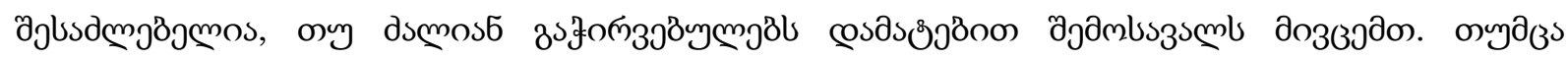

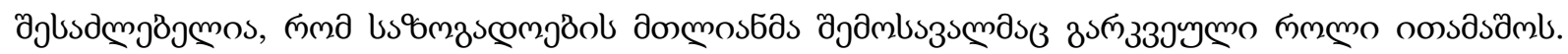

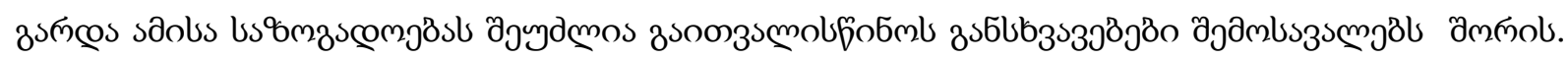

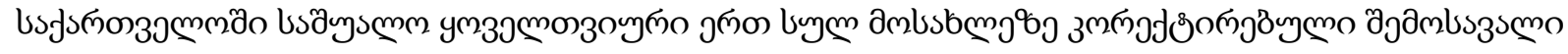

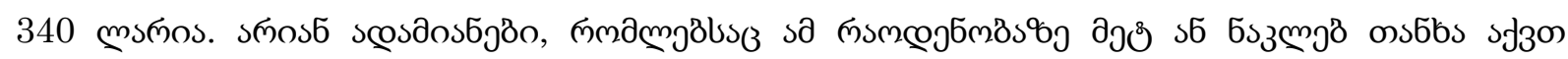

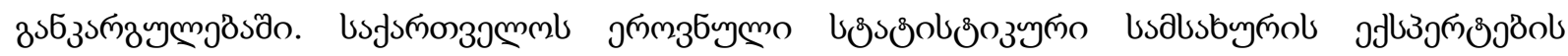

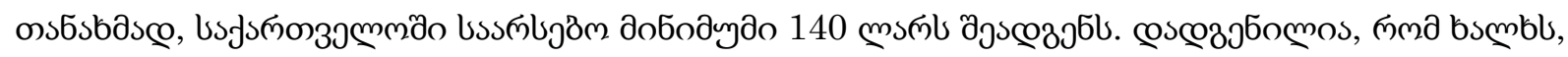

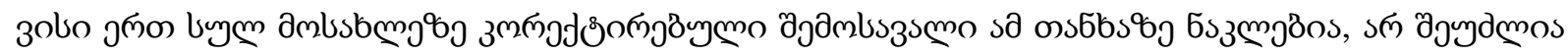

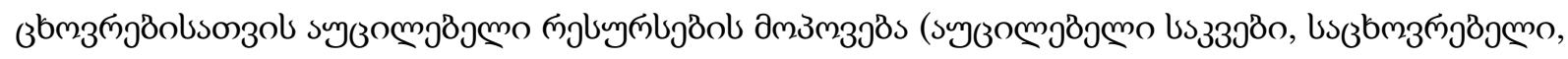
sstoolsambo).

\section{C.2 English translation}

\section{Important information regarding the experiment}

One important social issue is the amount of adjusted per capita income. The members of a society are able to influence this, for example by paying extra income to the poorest. However, the income available to the society as a whole can also play a part. Moreover, the society can also take differences in adjusted per capita income into account, for example when compared to the monthly net median adjusted per capita income. In Georgia, the monthly net median adjusted per capita income for a single person is 340 GEL. There are also people who have more or less than this amount at their disposal. According to experts at the National Statistics Office of Georgia, the subsistence minimum is $140 \mathrm{GEL}$. It was found that people whose adjusted per capita income is lower than this amount are unable to acquire the resources required to subsist (basic foods, shelter, clothes). 


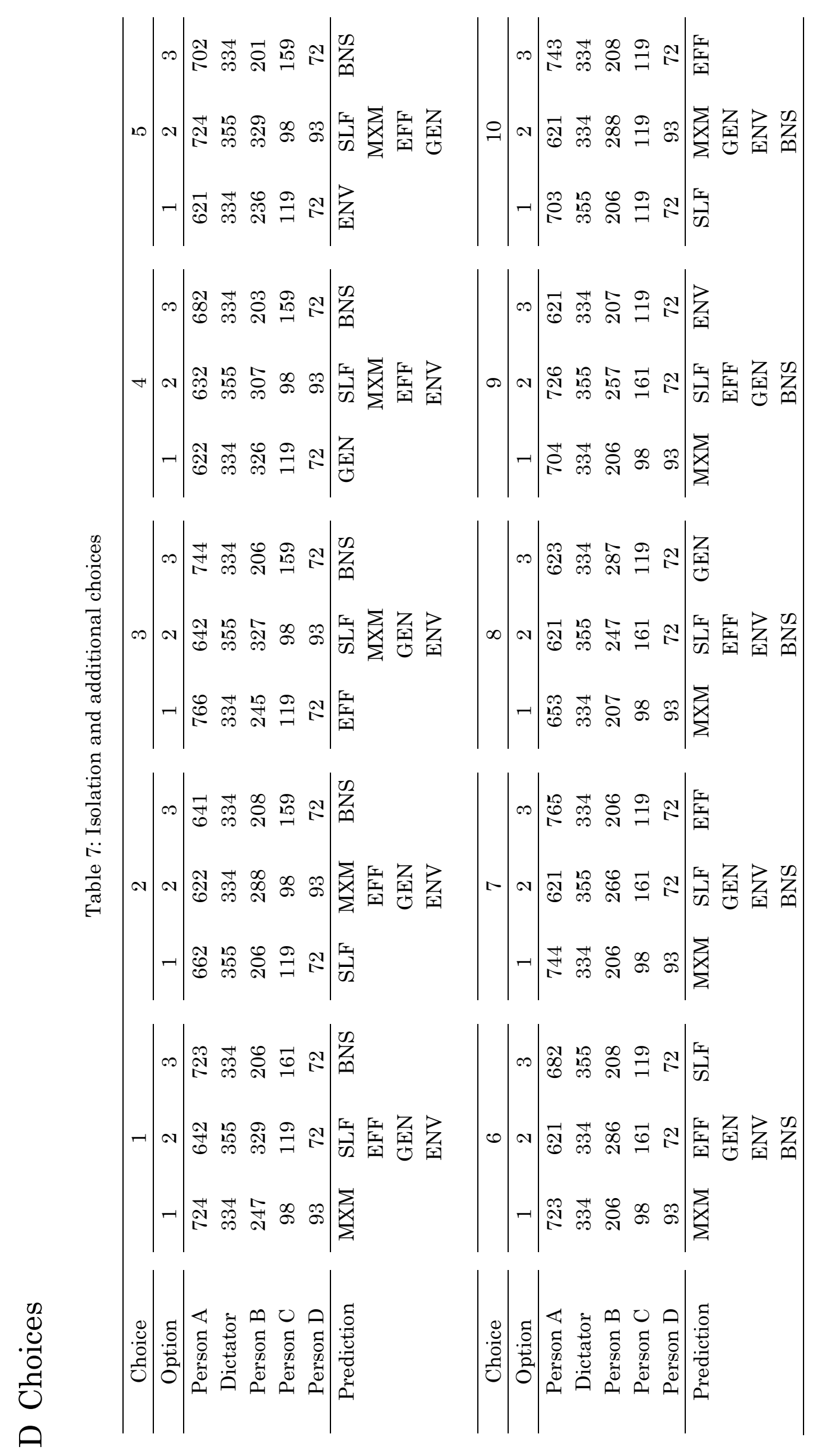




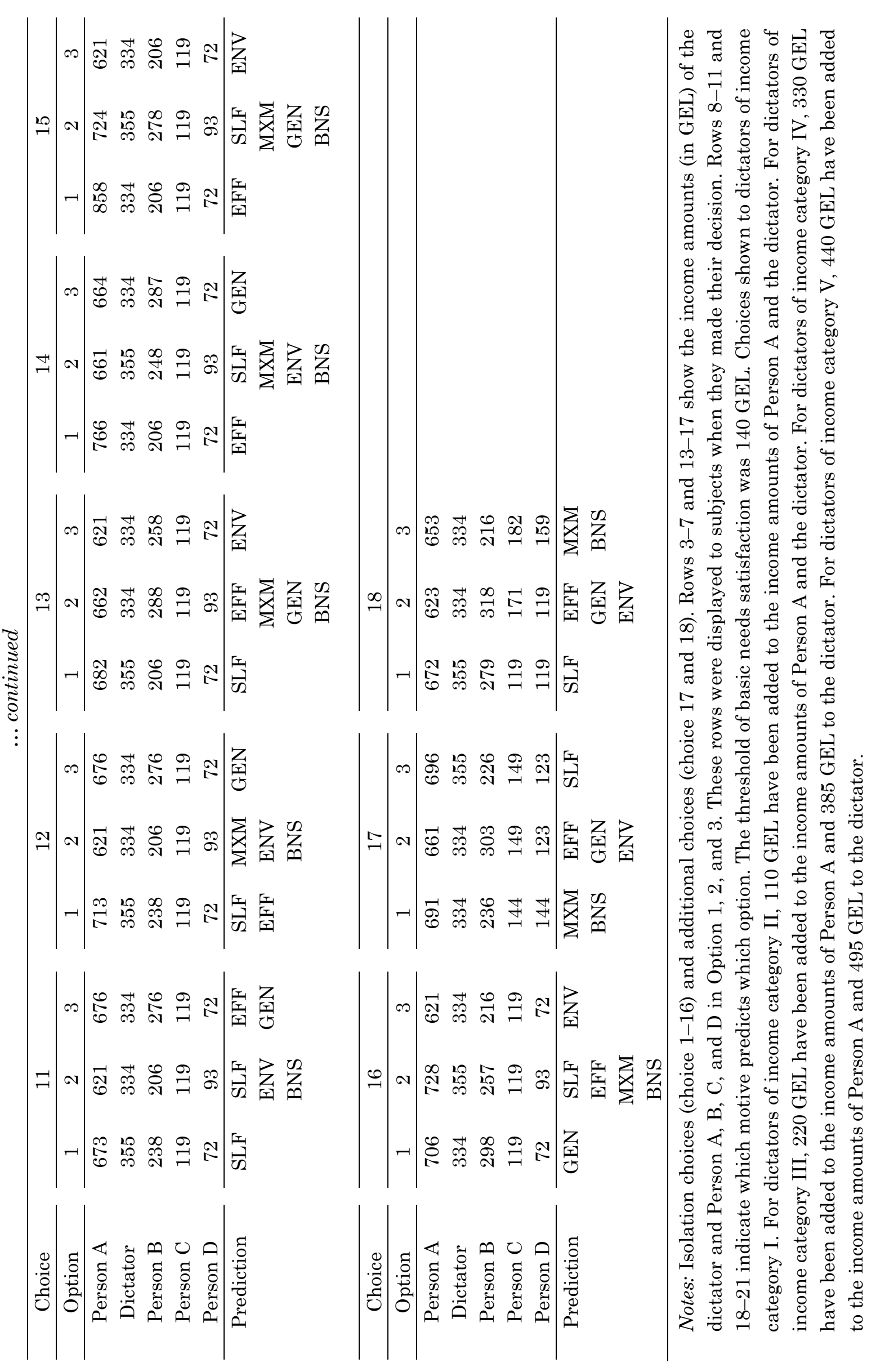




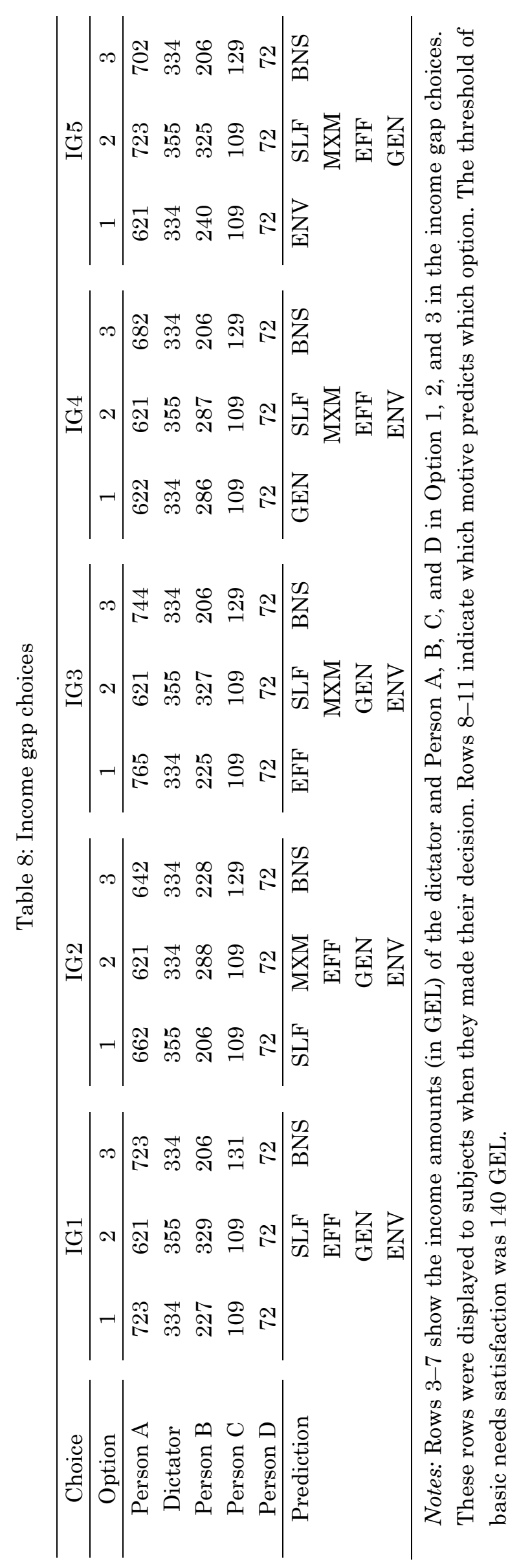




\section{E Income receivers in choice 24}

Table 9: Income receivers in choice 24

\begin{tabular}{ccccc}
\hline Income category dictator & Person A & Person B & Person C & Person D \\
\hline I & 600 & 183 & 83 & 50 \\
II & 714 & 183 & 83 & 50 \\
III & 800 & 183 & 83 & 50 \\
IV & 1000 & 183 & 83 & 50 \\
V & 1071 & 183 & 83 & 50 \\
\hline
\end{tabular}

Notes: Personal income of receivers (in GEL) shown to dictators in income category I-V in choice 24 . 


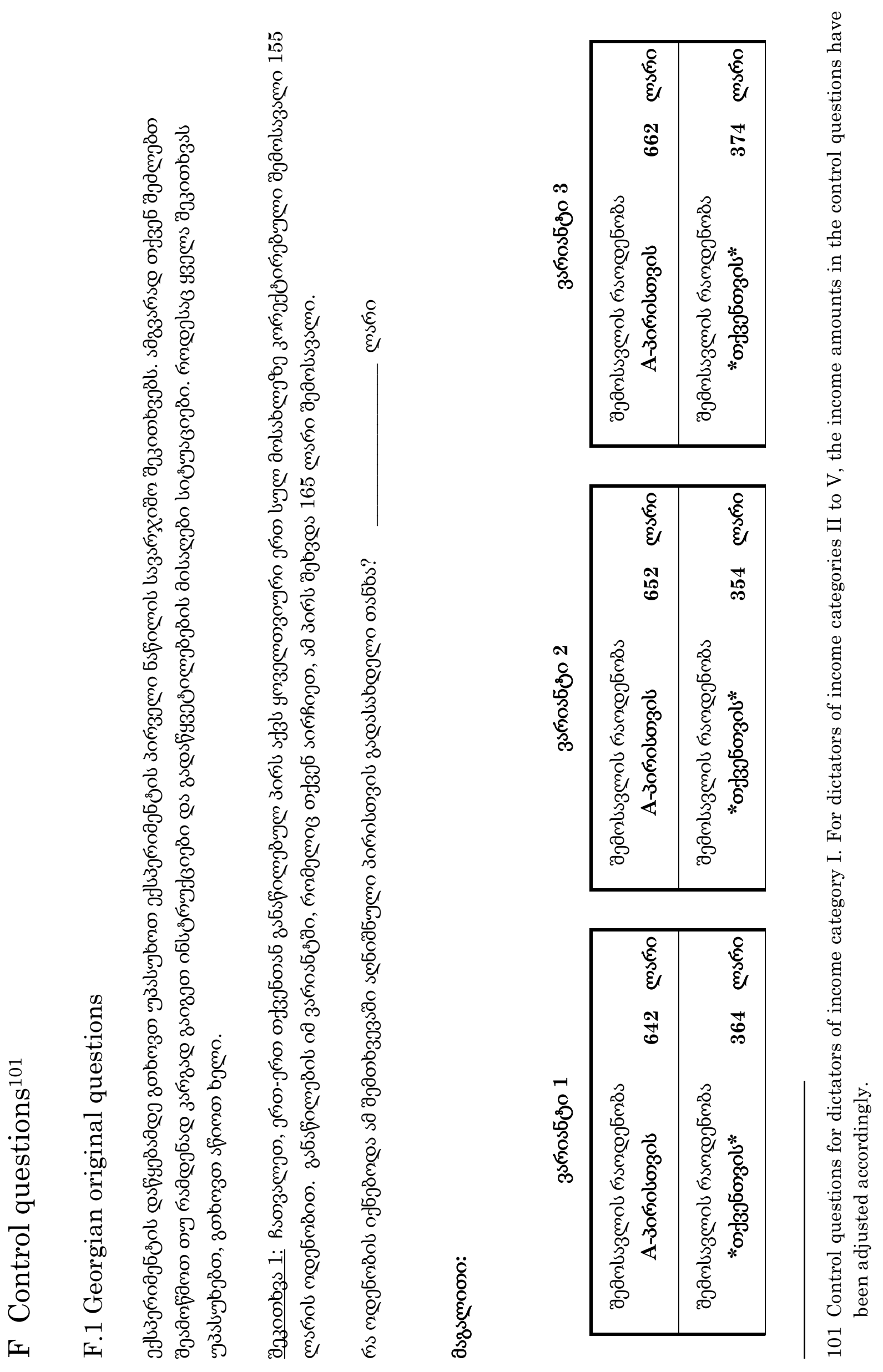



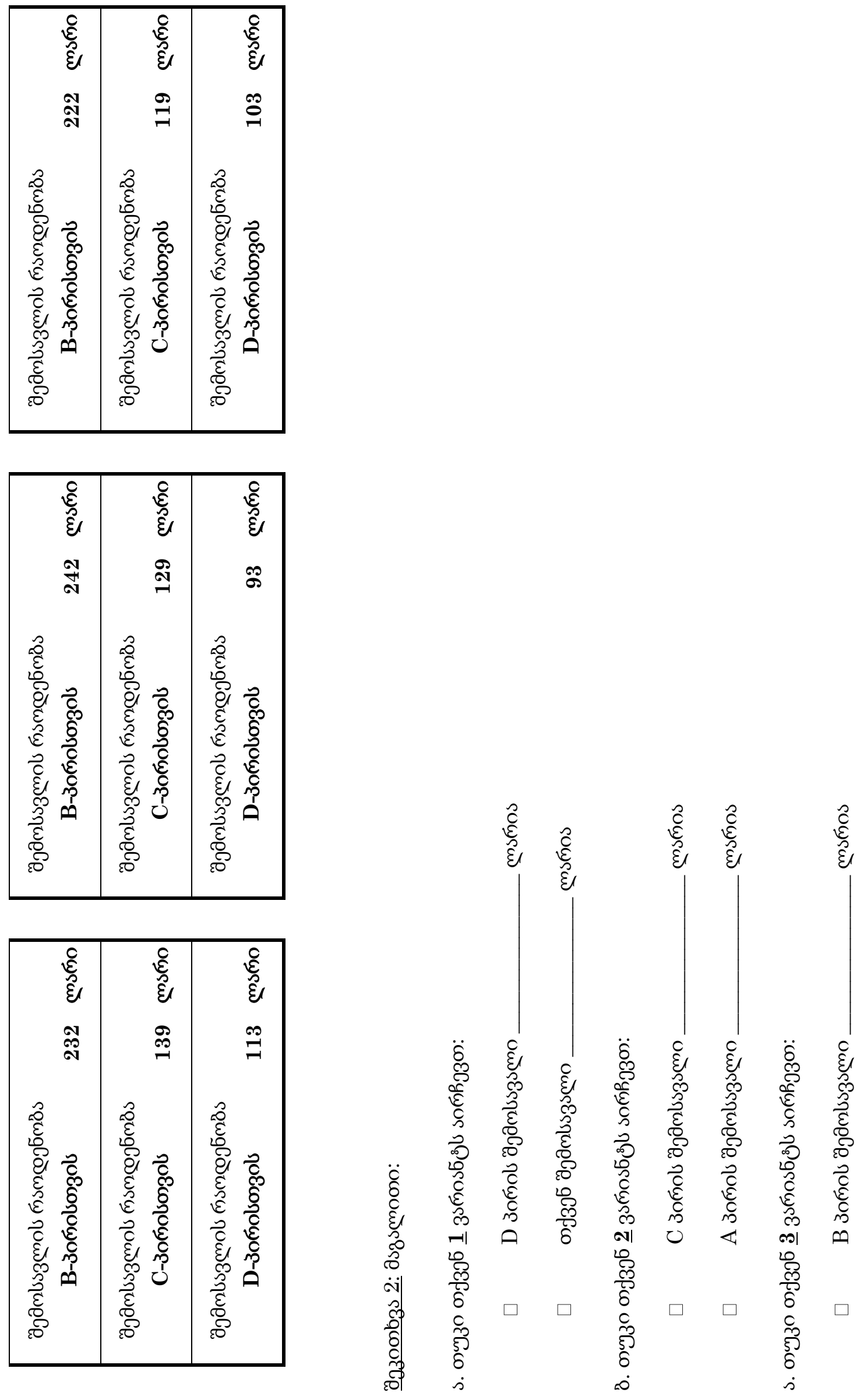


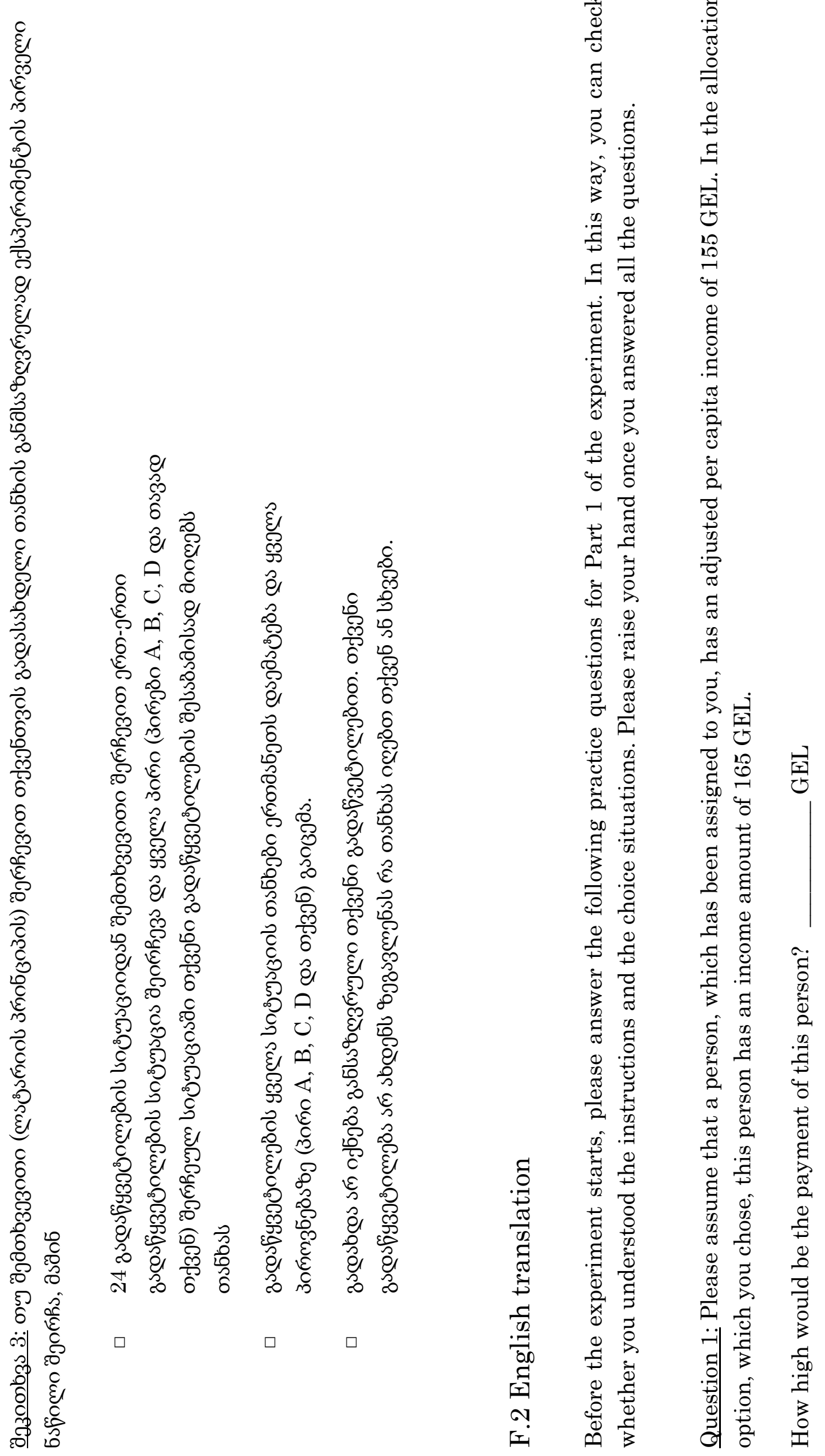



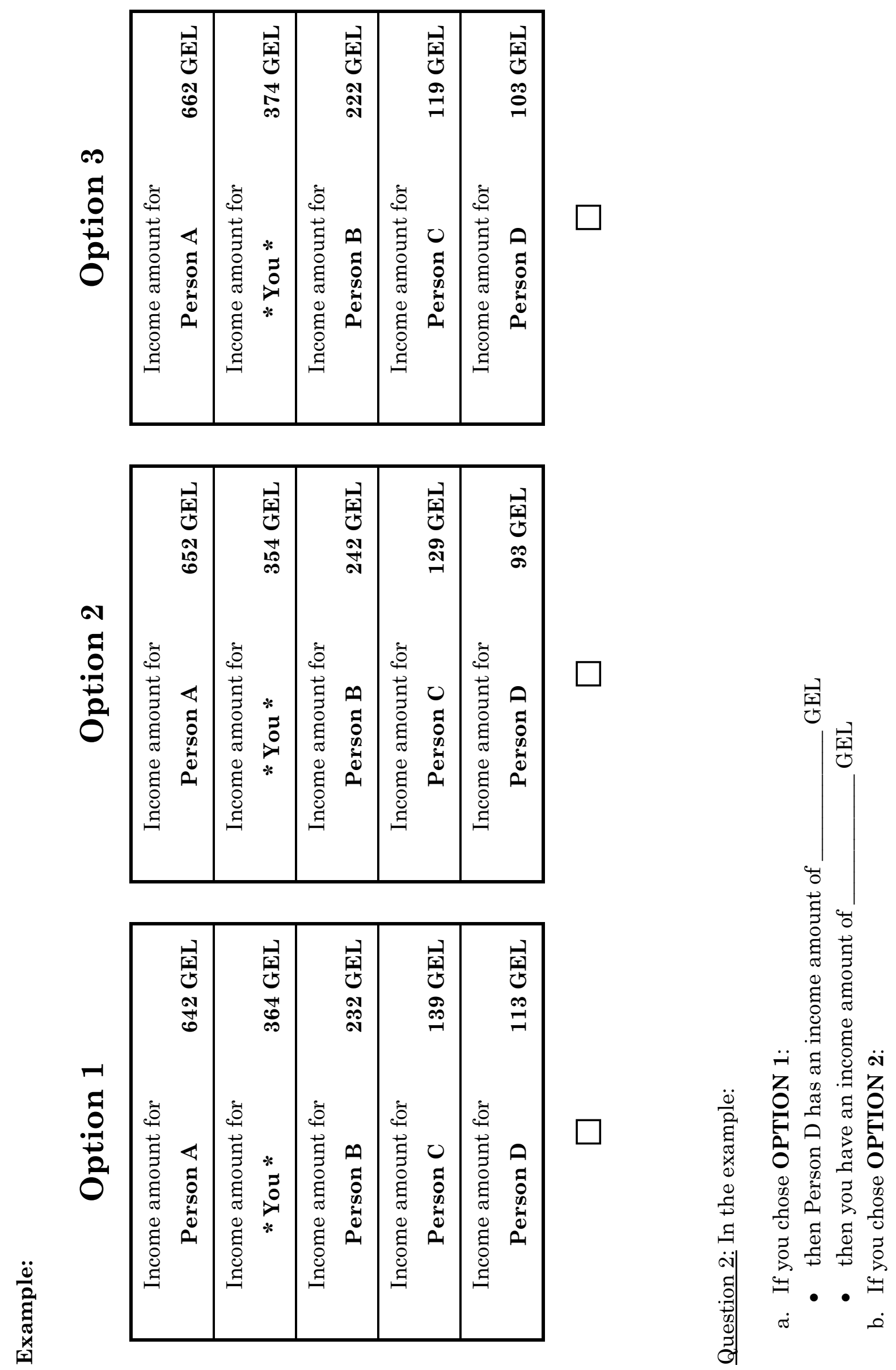


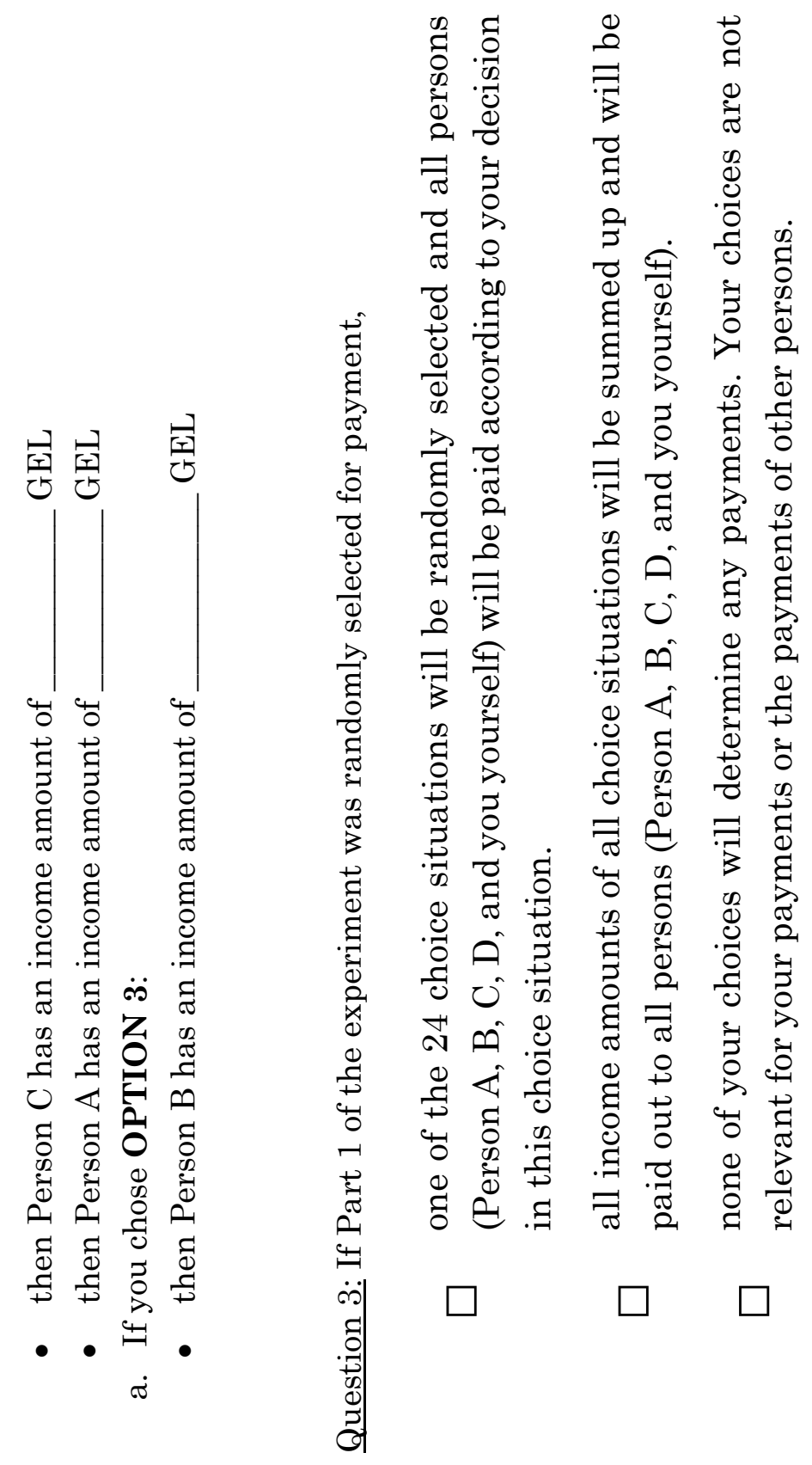




\section{G Experimental facilities}

Figure 10:

Experiment room

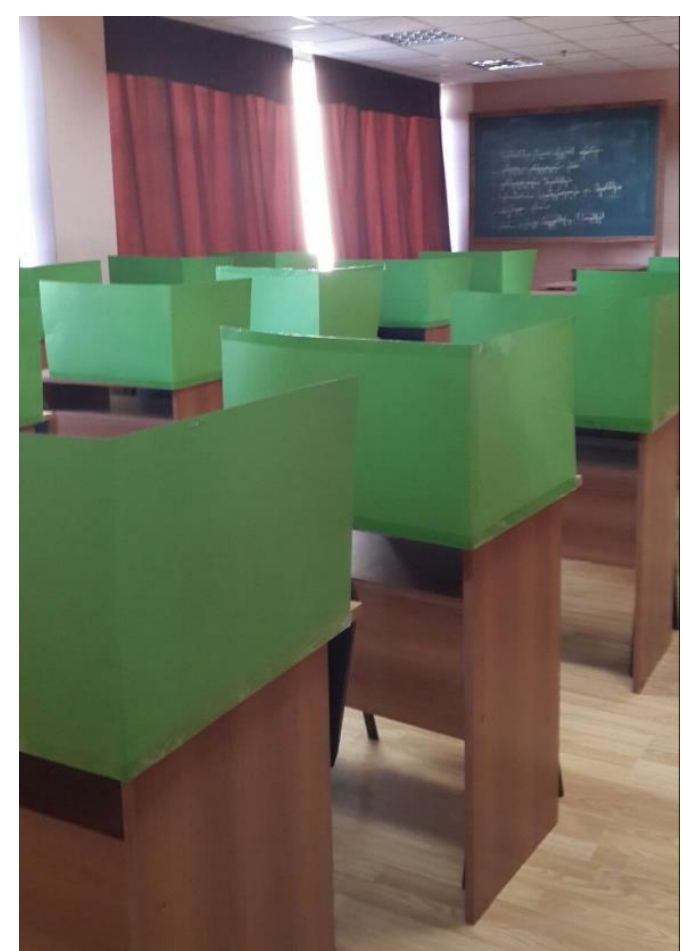

Figure 11:

Payment

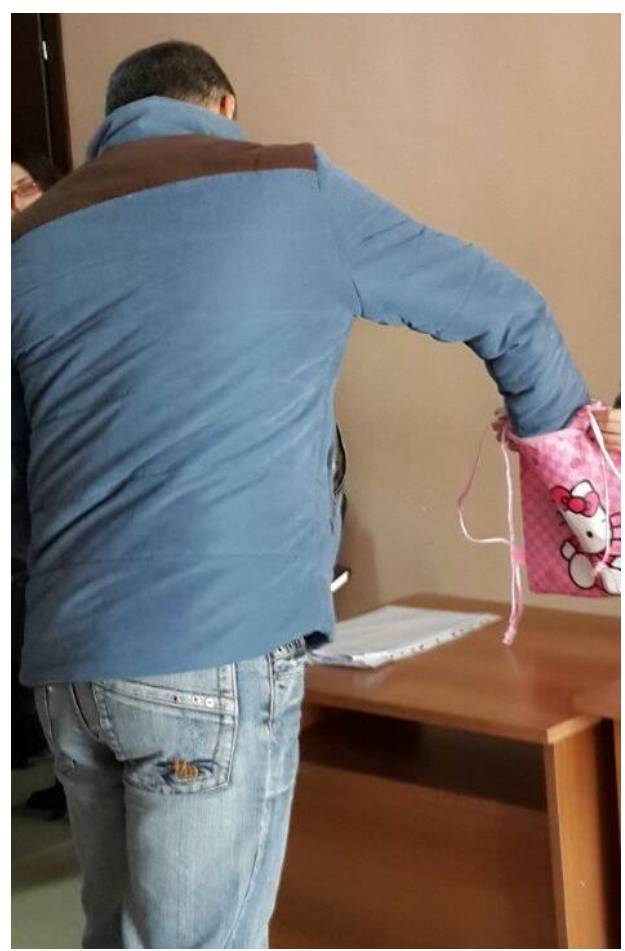




\section{H Main choices: All motives}

Figure 12: Choice fractions: Choice 1-5 (incentivized setting)

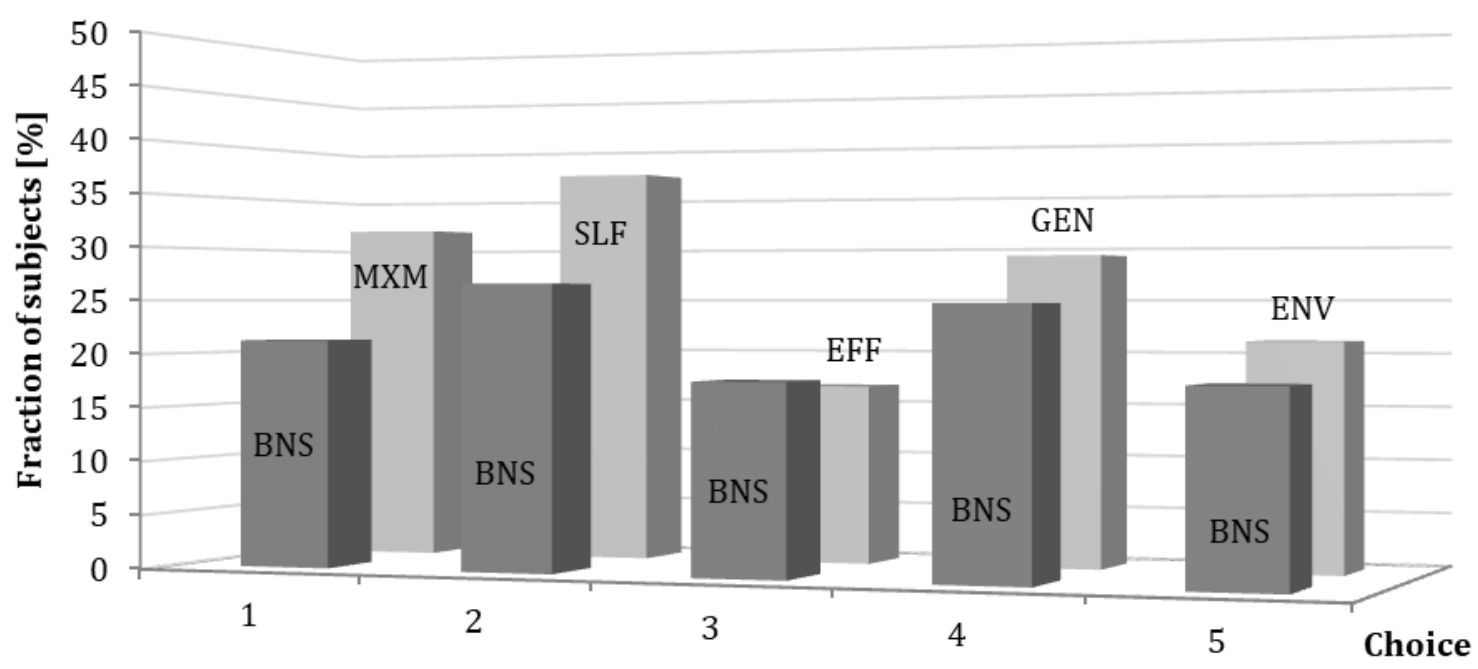

Notes: Fraction of subjects choosing Option 3 and thus attaching a positive weight to BNS (dark grey bars) and fraction of subjects choosing Option 1 and thus attaching a positive weight to the respective motive predicting this option (light grey bars) in main choices (choice 1-5) in the incentivized setting. The remaining subjects choose Option 2 (the option predicted by the four remaining motives), which is not depicted here. 
Figure 13: Reverse cumulative distribution: Choice 1-5 (incentivized setting)

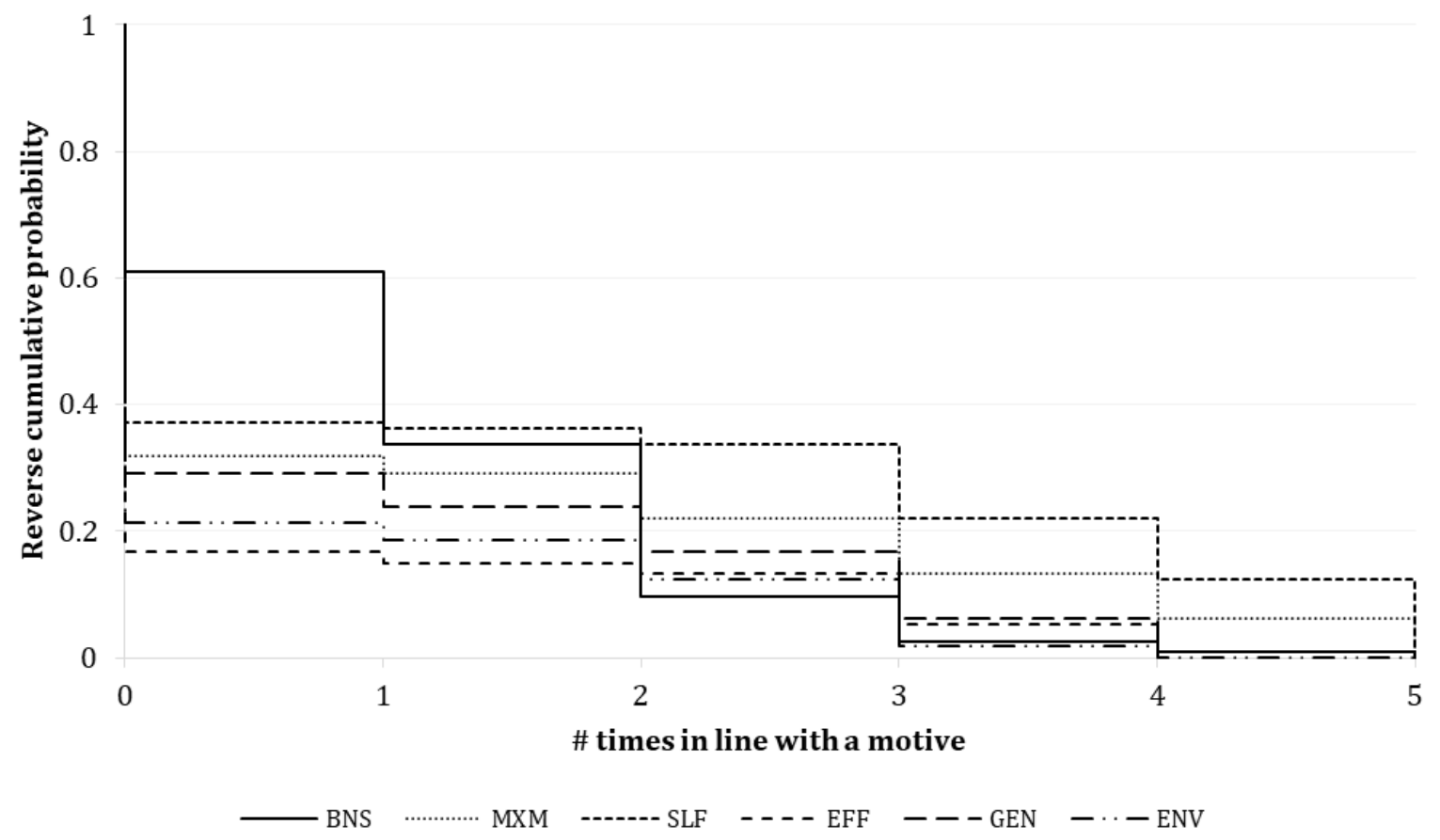

Notes: The reverse cumulative distribution indicates the fraction of subjects choosing more than $\mathrm{x}$ times in line with a motive, conditional on choosing in line with this motive when it alone predicts an allocation in main choices (choice 1-5) in the incentivized setting. This means that for MXM, SLF, EFF, GEN, and ENV the motive has to be chosen when the respective motive alone predicts an option (in case of MXM this is, for example, Option A in choice 1) in order to qualify as choosing $x$ times in line with this motive.

Figure 14: Choice fractions: Choice 1-5 (hypothetical setting)

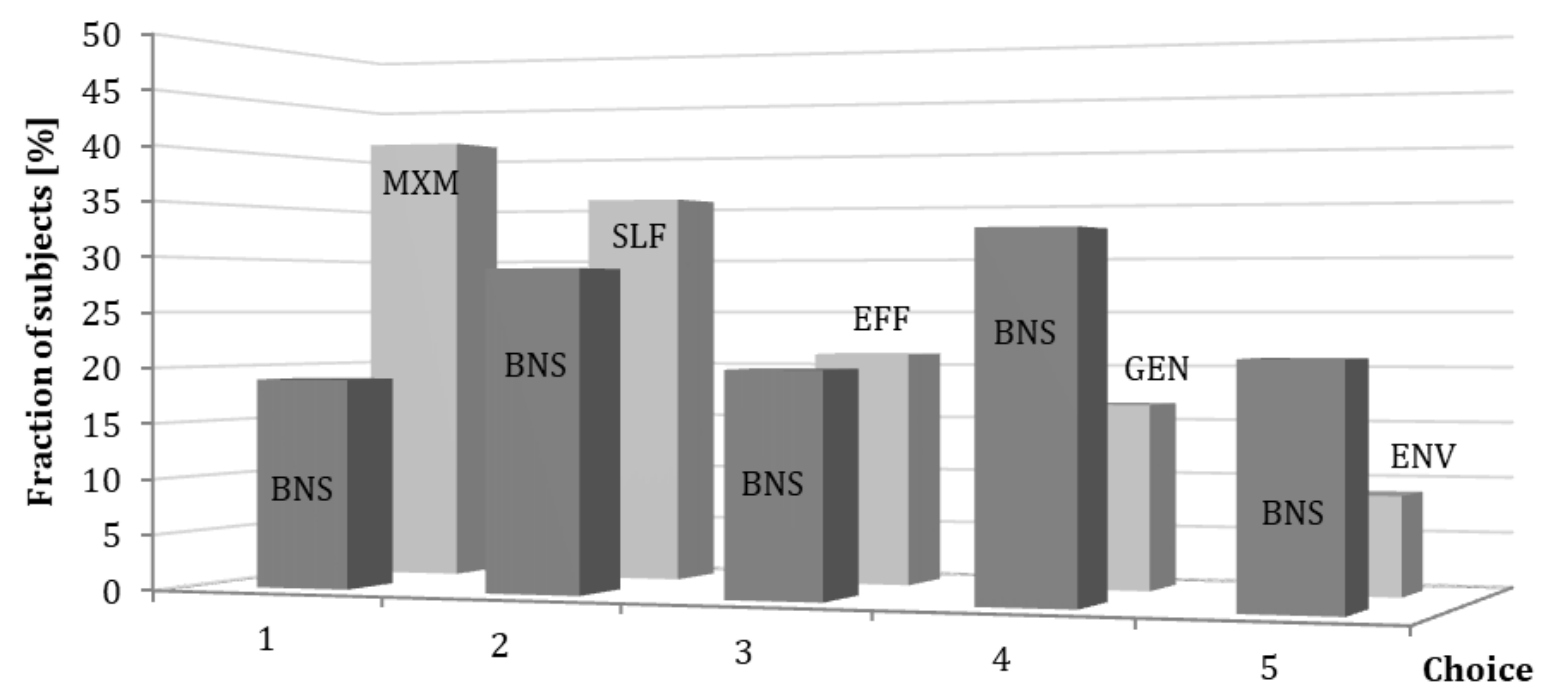

Notes: Fraction of subjects choosing Option 3 and thus attaching a positive weight to BNS (dark grey bars) and fraction of subjects choosing Option 1 and thus attaching a positive weight to the respective motive predicting this option (light grey bars) in main choices (choice 1-5) in the hypothetical setting. The remaining subjects choose Option 2 (the option predicted by the four remaining motives), which is not depicted here. 
Figure 15: Reverse cumulative distribution: Choice 1-5 (hypothetical setting)

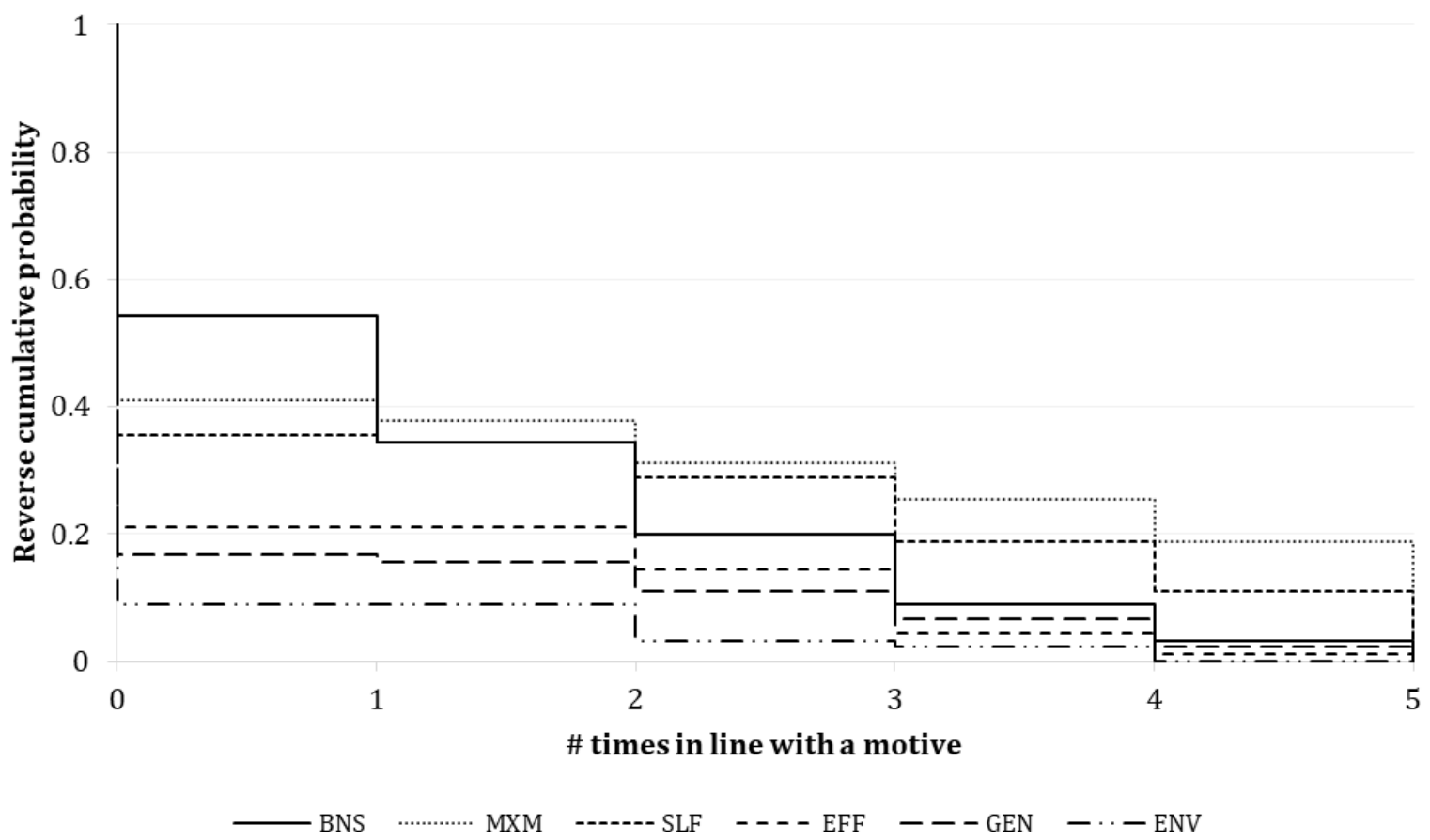

Notes: The reverse cumulative distribution indicates the fraction of subjects choosing more than $\mathrm{x}$ times in line with a motive, conditional on choosing in line with this motive when it alone predicts an allocation in main choices (choice 1-5) in the hypothetical setting. This means that for MXM, SLF, EFF, GEN, and ENV the motive has to be chosen when the respective motive alone predicts an option (in case of MXM this is, for example, Option A in choice 1 ) in order to qualify as choosing $x$ times in line with this motive. 


\section{Heterogeneity analysis}

Figure 16: Reverse cumulative distribution BNS: Choice 1-5

(a) by gender

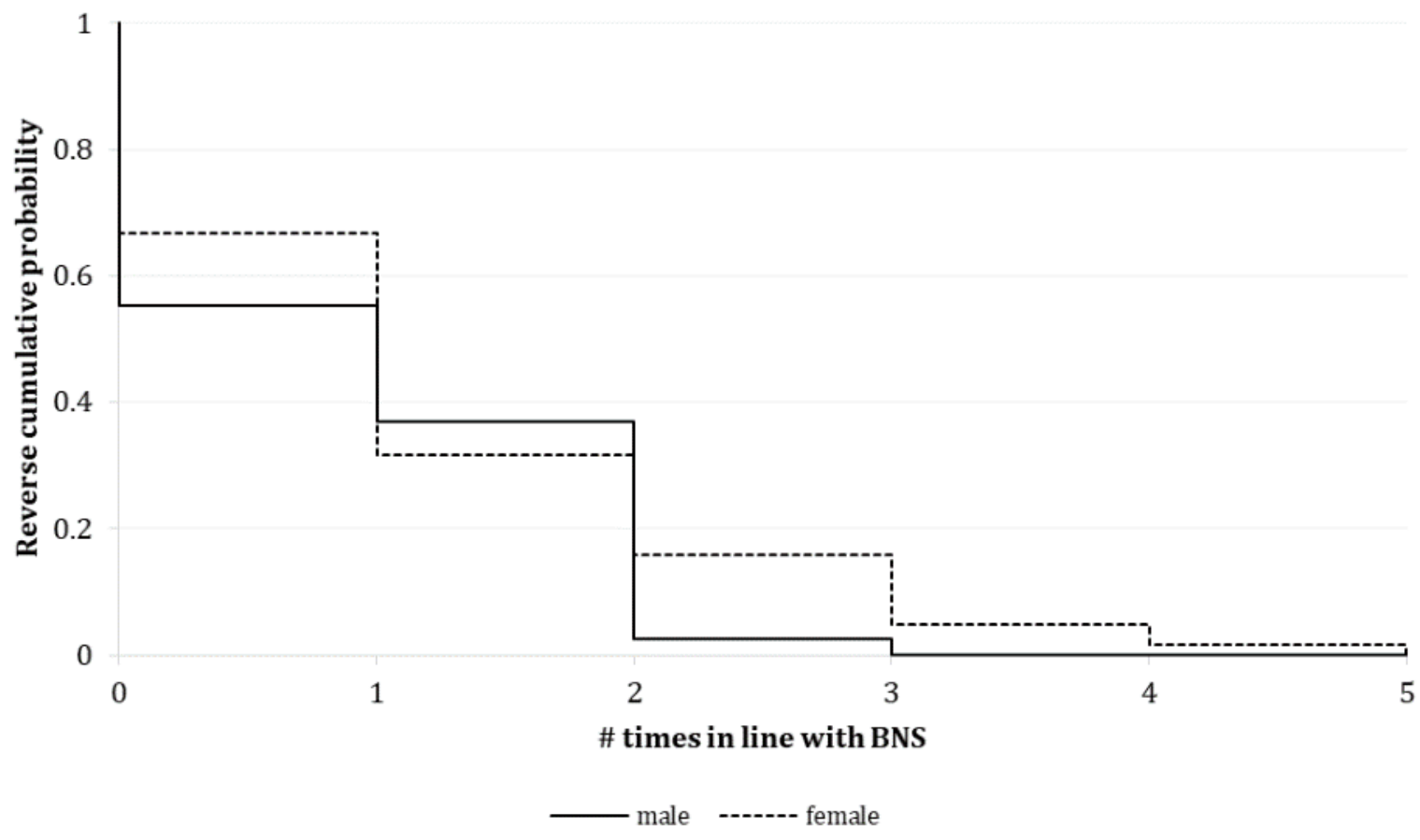

(b) by age

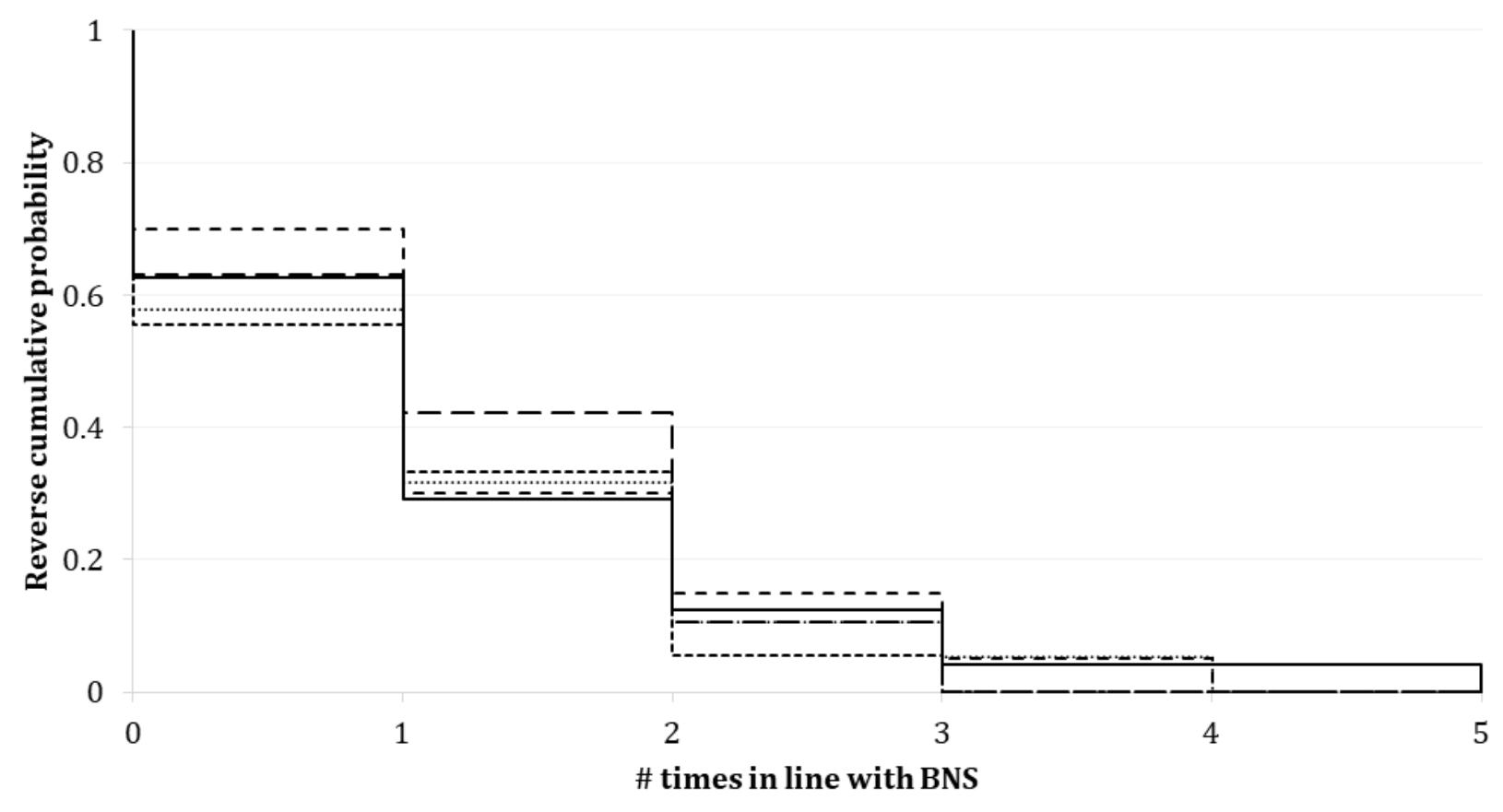


(c) by income

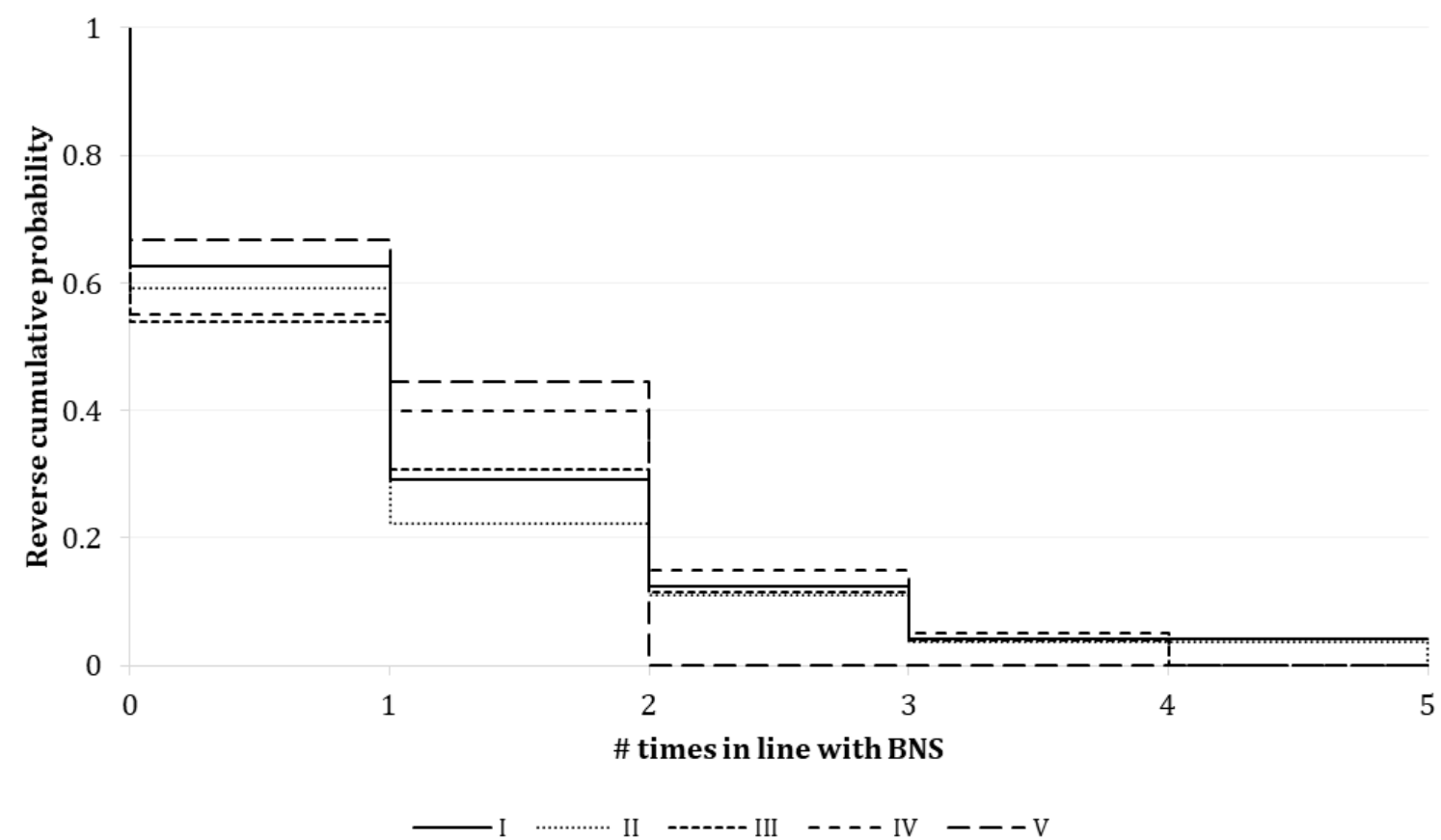

Notes: The reverse cumulative distribution indicates the fraction of subjects choosing more than $x$ times in line with BNS in choice 1-5 (a) by gender, (b) by age, (c) by income category (see Table 2 in Section 3.2.1 for the income categories). 
Table 9: Determinants of individual choice patterns (BNS): Robustness

\begin{tabular}{cc}
\hline & Model 1 \\
\hline Female & $.4893^{* *}$ \\
& $(.2440)$ \\
Age & -.0239 \\
& $(.0433)$ \\
Age ${ }^{2}$ & .0003 \\
& $(.0005)$ \\
Income & -.0034 \\
& $(.0050)$ \\
Income ${ }^{2}$ & $2.96 \mathrm{e}-06$ \\
& $(5.21 \mathrm{e}-06)$ \\
Constant 1 & -.0474 \\
& $(.1922)$ \\
Constant 2 & 1.5408 \\
& $(.2390)$ \\
\hline LL & -94.3000 \\
LR of joint significance & 3.51 \\
Pseudo r-squared & .0183 \\
$\mathrm{~N}$ & 101 \\
\hline
\end{tabular}

Notes: Ordered probit regression estimates. Standard errors in parenthesis. Categories of the dependent variable are: choosing in line with BNS in choice 1-5 (1) never, (2) 1 or 2 times, (3) at least 3 times. The independent variables are subjects' gender, age, age squared, income, and income squared. ${ }^{*} p<$ $.10,{ }^{* *} p<.05,{ }^{* * *} p<.01$. 


\section{CHAPTER IV \\ Need games ${ }^{102}$}

\subsection{INTRODUCTION}

In the choice experiments of Chapter II and III, we have shown that concerns for basic needs satisfaction are an important distributional motive alongside selfishness, and other distributional motives such as maximin. Thereby, we assume that a person's distributional preferences are affected by various motives, which are traded off against each other (Konow, 2001). In these experiments, satisfying basic needs entails forgoing own income. Cappelen et al. (2007), for example, show that most subjects attach a positive weight both to fairness concerns and self-interest.

In this chapter, we introduce a strategic motive to satisfy basic needs. We address the question whether behavior in line with concerns for basic needs satisfaction can be reinforced if there are also strategic motives to satisfy these needs. In an evolutionary context, it might be good to satisfy basic needs of all members of one's group, since the group's survival depends on the survival of its members (Bowles and Gintis, 2005). Behavior in line with basic needs satisfaction in situations in which group survival is at stake might thus be hard-wired.

For this purpose, we implemented an experimental game - the need game - which subjects played for multiple rounds. The need game is a variant of the dictator game (Forsythe et al., 1994) in which receivers are at risk of being eliminated from subsequent rounds of the experiment if their final payoff in a given round falls short of a certain threshold. The game was designed to mimic the fact that persons suffer (in this case exiting the experiment and hence being deprived from possible future gains in the experiment) when their needs are not met. By systematically varying the initial endowments of subjects, we manipulated whether the receiver is in need or not in three variants of the need game. There was a strategic motive for dictators to satisfy the receivers' needs, i.e., to transfer at least as much as they need in order to reach the threshold that ensures participation in the next round. If only one receiver remained in the game, the game was stopped. Since dictators did not receive an endowment when the game ended, earnings not only of receivers but also of dictators depended on the survival of the receivers. Hence, besides a desire to satisfy receivers' needs, dictator giving might also be influenced by the fact that they want to benefit from potential earnings in subsequent rounds. We thus expect to find that more subjects decide to fulfill the receiver's

102 This chapter is based on joint work with Thomas Dohmen and Gari Walkowitz. The authors are grateful to Kevin Breuer, Jonas Radbruch for excellent research assistance. 
need in this game as compared to the experiment in Chapter II. ${ }^{103}$

We find that the majority of dictators indeed transfer a sufficient amount to needy receivers. This amount constitutes half of the endowment that the dictator can distribute - a share that typically far less subjects are willing to give up (Engel, 2011). Most of these dictators, in turn, give exactly the amount necessary for the receiver to reach the threshold. This suggests that the main other-regarding motivation behind this increased generosity is the desire to fulfill the receiver's need (as opposed to, for example, maximin concerns). ${ }^{104}$ Hence, when need fulfillment is aligned with dictators' self-interest to continue the game, the prevalence of behavior in line with concerns for basic needs satisfaction increases.

The strategic motive to ensure survival of the receiver for reasons of self-interest (i.e., ensuring future own payoffs) should, however, not lead to strong increases in basic needs satisfaction. This is because the probability of the game ending is fairly low, due to the way that the experiment is parameterized. Only if dictators have sufficiently pessimistic beliefs about the amounts given by other dictators or exhibit a high degree of risk aversion, satisfaction of basic needs might result from self-interest. Otherwise, the self-interested choice is still not to give anything to the receiver. We observe that many dictators who repeatedly choose the selfish option in the choice experiment of Chapter II (henceforth: selfish dictators), satisfy receivers' needs in the need game. We show that this does not seem to be due to risk aversion or pessimistic beliefs about giving behavior of other dictators. Hence, even though the selfish choice would be to give nothing at all, selfish dictators now choose to satisfy needs and by this give up half of their endowment. It might thus be that the salience of the importance of the threshold amount for the receiver's and ultimately also the group's - survival has triggered dictators' motives to satisfy basic needs which they bear in them alongside self-interest. This is consistent with the notion that human beings are predisposed to act in accordance with the motive in situations in which it is evolutionarily important (Bowles and Gintis, 2005).

The remainder of the chapter is organized as follows. Section 4.2 outlines the experimental design, the identification strategy, and the procedures. Section 4.3 presents the results. Section 4.4 presents a concluding discussion.

\subsection{EXPERIMENT}

\subsubsection{Design}

We parameterized the need game such that each player needed a payoff of 100 Monetary Units (MU) in order to avoid an undesirable consequence. In our parameterization,

103 Results of Bartling et al. (2013) suggest that if there are strategic motives to behave in a fair way, selfish subjects can be induced to do so. In a game in which the principal can offer the agent two types of contracts, they find that the fraction of subjects offering the agent the better contract and not abusing their power to exploit the agent is significantly higher in the condition with the possibility of multiple interactions than in the one without the possibility to build a reputation.

104 Maximin concerns would predict equalizing payoffs and thus give $150 \mathrm{MU}$ to the receiver. 
dictators were always endowed with an amount that exceeds this threshold, which was common knowledge in the experiment. In case the receiver had a payoff of less than 100 MU after the allocation decision of the dictator, she exited the experiment with a probability that depended on the distance to the threshold. In particular, if a receiver fell $Y \mathrm{MU}$ short of the $100 \mathrm{MU}$, she did not proceed to the next round with a $Y$ percent chance. For example, if a receiver had a payoff of $70 \mathrm{MU}$, she lacked $30 \mathrm{MU}$; and hence exited with a chance of 30 percent. This feature mimics the fact that in reality, a person faces more severe negative consequences the more money she lacks in order to purchase basic necessities.

Table 1: Variants of the need game

\begin{tabular}{cccc}
\hline & \multicolumn{2}{c}{ Endowment } & D can \\
Variant & $\mathrm{D}$ & $\mathrm{R}$ & distribute \\
\hline 1 & 300 & 100 & 200 \\
2 & 300 & 0 & 200 \\
3 & 400 & 100 & 200 \\
\hline
\end{tabular}

Notes: D: dictator; R: receiver

We systematically varied subjects' initial endowments in three variants (see Table 1). In all variants, the dictator could allocate up to $200 \mathrm{MU}$ from her initial endowment to the receiver. In variant 1, the dictator got an endowment of $300 \mathrm{MU}$ and the receiver of 100 MU. In variant 3, the dictator's endowment was increased to $400 \mathrm{MU}$. Hence, in both variants the receiver already had enough money to proceed to the next round (and hence to avoid any undesirable consequence). In variant 2 , however, the receiver got an endowment of 0 MU. Thus, the receiver needed $100 \mathrm{MU}$ in order to survive with certainty to the next round.

Before the first round, in each session, one half of the 30 subjects was randomly assigned the role of the dictator, the other half the role of the receiver, and subjects learned which role they had been assigned to. The game was played for ten rounds in the following order. In rounds $1-3$, dictators made one decision in each variant of the game in a randomized order. In rounds 4-6 and 7-9, this procedure was repeated. In the last round, each dictator made one final decision in variant 1 of the game. ${ }^{105}$ Receivers remained passive in all rounds, i.e., they did not make any decision. One round consisted of five steps (see Figure 3 in Appendix A). In step 1, subjects were randomly matched into pairs. In the case that in a round, there were fewer receivers than dictators (because a receiver had been eliminated), more than one dictator was matched to the same receiver. In step 2 , the computer randomly determined which variant subjects played in this round. In step 3, both players in a pair were informed about the endowments of the dictator and the receiver in this round. In step 4, the dictator could allocate an amount of up to $200 \mathrm{MU}$ from her

105 This round only had the purpose to make decisions in round 9 meaningful and is not considered in the evaluation. 
endowment to the receiver. In step 5, the computer checked for each receiver whether her payoff is at least $100 \mathrm{MU}$. If this was not the case, the computer randomly determined whether the receiver was eliminated from subsequent rounds. The probability of elimination depended on the receiver's payoff. If a subject lacked $Y \mathrm{MU}$, then she was eliminated with a $Y$ percent chance. If a receiver was indeed eliminated, she did not take part in the remaining rounds of this part of the experiment. The dictator, however, took part in subsequent rounds. ${ }^{106}$ If only one receiver remained, the game was stopped. It was thus also in the dictators' strategic interest to not eliminate all receivers. ${ }^{107}$

At the end of the experiment, one round of the ten rounds was randomly selected for payment, where 150 MU equaled 1 Euro. The receiver's payment depended on the decision of the dictator she had been assigned to in this round. In case a receiver had been assigned to more than one dictator, it was first randomly determined which of these dictators determine her payment. The dictator's payment was determined by her own decision in the selected round. In case the game had already ended in the selected round or a receiver had not reached this round, the respective subjects did not receive any payoff for this part of the experiment.

The need game tests one specific aspect of concerns for basic needs satisfaction. It assesses whether subjects are sensitive to a certain monetary threshold that implies the possibility of a negative consequence in case this threshold is not met. The adverse condition subjects face in the event of not reaching the threshold in the experiment mimics the fact that a person suffers negative consequences in case her basic needs are not met. If a person lacks, for instance, sufficient food, she is likely to suffer from hunger, increased health risks, and eventually increased mortality risk. Not ensuring a receiver's 'survival' to the next round and thereby depriving her from possible future gains in subsequent rounds of the experiment is clearly not in the receiver's interest. We thus assume that dictators in the experiment believe that the receiver would be better off if she did not have to face the consequence. Hence, the fact that a receiver does not meet the threshold with her initial endowment can evoke dictators' considerations for the receiver's need.

\subsubsection{Identification strategy}

We test whether dictators take into account the payoff threshold by varying subjects' initial endowments in three variants (see Table 1). By this, we manipulate whether the receiver needs money from the dictator in order not to be threatened to be eliminated from the experiment. Variant 1 is similar to the choice situation in a standard dictator game. There is no binding payoff threshold and both subjects have the same fixed payoff (in this case of $100 \mathrm{MU}) .{ }^{108}$ This variant allows us to gauge whether subjects in our experiment behave differently from what is typically observed in dictator games. ${ }^{109}$

106 Since this entails that there are more dictators than receivers, it was randomly determined to which dictators the remaining receivers would be matched in subsequent rounds in case a receiver was eliminated.

107 For the complete German original instructions and the English translation, see Appendix B.

108 The fixed payoff can be viewed as, for instance, an additional show up fee.

109 It could be that, for example, the fact of mentioning a payoff threshold alters dictators' behavior 
In order to assess the impact of the receiver's need on giving behavior, we first compare giving in variant 2 and 3 . In both variants, the dictator has a total endowment that is 300 MU higher than that of the receiver. Giving a certain amount to the receiver in the two variants thus results in the same payoff difference between dictator and receiver. The crucial difference between the two variants is, however, the fact that the receiver in variant 2 is in need of $100 \mathrm{MU}$ in order to survive with certainty to the next round, while in variant 3 she is not. Hence, if dictators on average care for helping the needy receiver, more dictators should give exactly $100 \mathrm{MU}$ in variant 2 than in variant 3 . By choosing a threshold of exactly 50 percent of the amount that the dictator can distribute, we parameterize the experiment such that it is possible to observe dictators' reactions to the threshold. ${ }^{110}$ In a second step, we assess the share of dictators who would have put their receivers at risk of elimination if the dictators had given in variant 2 (with the receiver in need) what they gave in variant 1 and 3 (without the receiver in need). We further examine how dictators who give $100 \mathrm{MU}$ in variant 2 choose in the choice experiment of Chapter II.

\subsubsection{Procedures}

The experiment took place at the University of Cologne and involved a total of 90 subjects who were recruited through ORSEE (Greiner, 2015). The experiment was programmed in ztree (Fischbacher, 2007). It was common knowledge that throughout the whole experiment subjects remained anonymous towards other participants and the experimenter. ${ }^{111}$ The experiment was the third part of the experiment described in Chapter II (see Figure 6 in Appendix A of Chapter II). Note that subjects did not get to know the outcome of other parts of the experiment before the third part was finished. This was done in order not to potentially distort their behavior by this information. On average, subjects earned 1.20 Euros with earnings ranging from 0 to 2.67 Euros.

compared to a standard setup of the dictator game.

110 In a situation in which the threshold is so low that most dictators would in any case give more than the amount needed to reach the threshold, we cannot observe whether dictators increase their giving up to the threshold level in order to fulfill receivers' needs. If the threshold was, for example, only 20 percent of the endowment to be allocated, we would expect that about 46 percent of dictators give at least this amount (Engel, 2011).

111 Anonymity of subjects makes potential social image concerns less likely, since they do not have to worry about what other people might think of their decisions (Hoffman et al., 1996). 


\subsection{RESULTS}

Figure 1: Cumulative distribution:

Amount given per variant

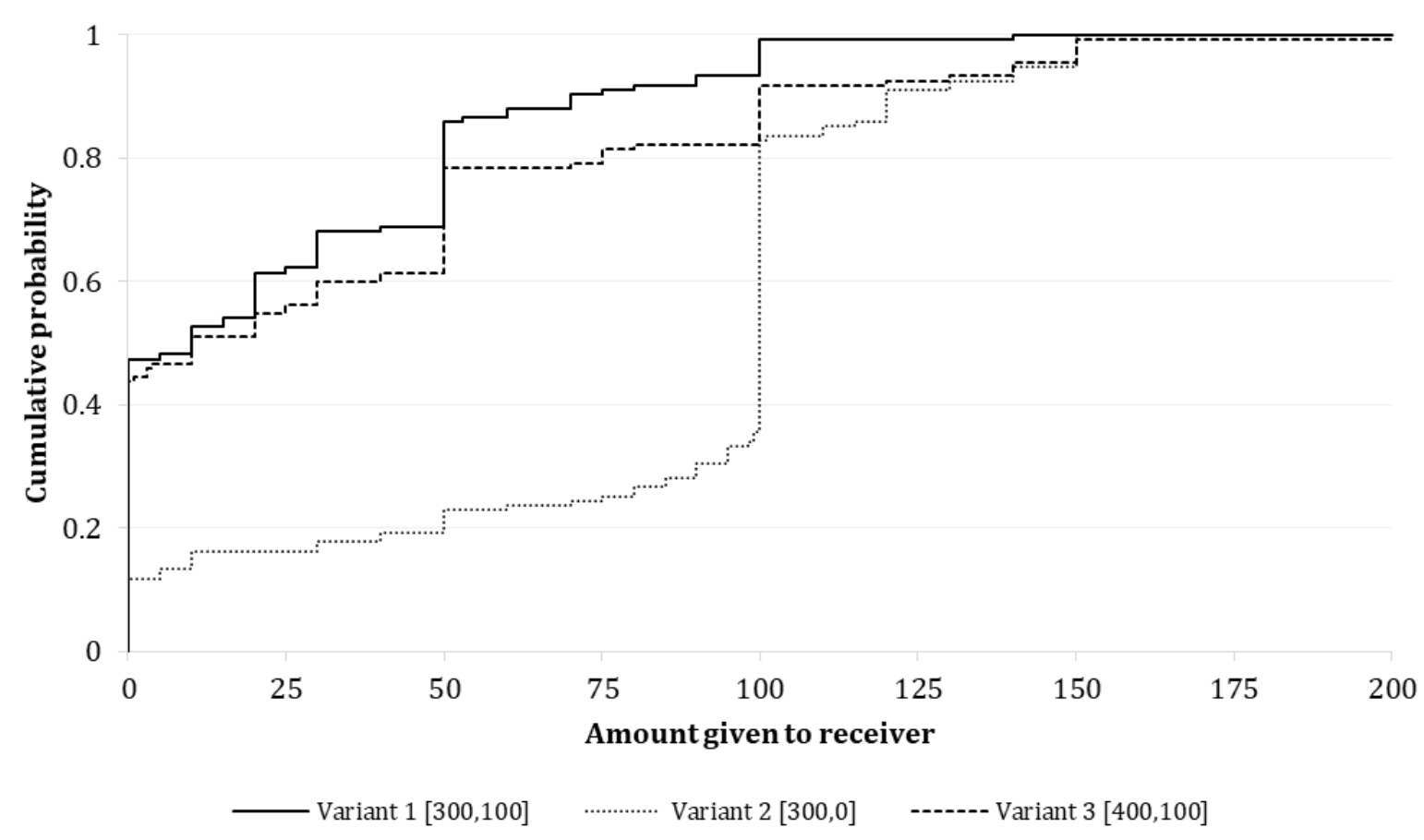

Notes: Cumulative distribution of amount given to receiver (in MU) per variant. N=135

Figure 1 shows the cumulative distribution of the amount given to receivers (in MU) per variant. In variant 2 , dictators are, on average, more generous than in variant 1 or 3 $(t(44)=11.3055, p<.0001, t(44)=7.8594, p<.0001)$. The figure further reveals that this seems to be predominantly driven by dictators giving $100 \mathrm{MU}$ to the needy receiver in variant 2: Almost half of choices are to give 100 MU. One could suspect that giving 100 MU in variant 2 primarily occurs towards the end of the game, since the risk that too few receivers remain in the game is smaller. Figures $2 a-2 c$ show the cumulative distributions per triplet of rounds and reveal that this is not the case. Instead, giving $100 \mathrm{MU}$ is stable across the triplet of rounds. ${ }^{112}$

112 Rounds $1-3$ vs. $4-6:$ McNemar's $\chi^{2}(1)=.3173, p=.6250$; rounds $1-3$ vs. 7-9: McNemar's $\chi^{2}(1)=.0833, p=.2500 ; 4-6$ vs. $7-6:$ McNemar's $\chi^{2}(1)=.3173, p \geq .9999$. 
Figure 2: Cumulative distribution: Amount given per variant

a) rounds $1-3$

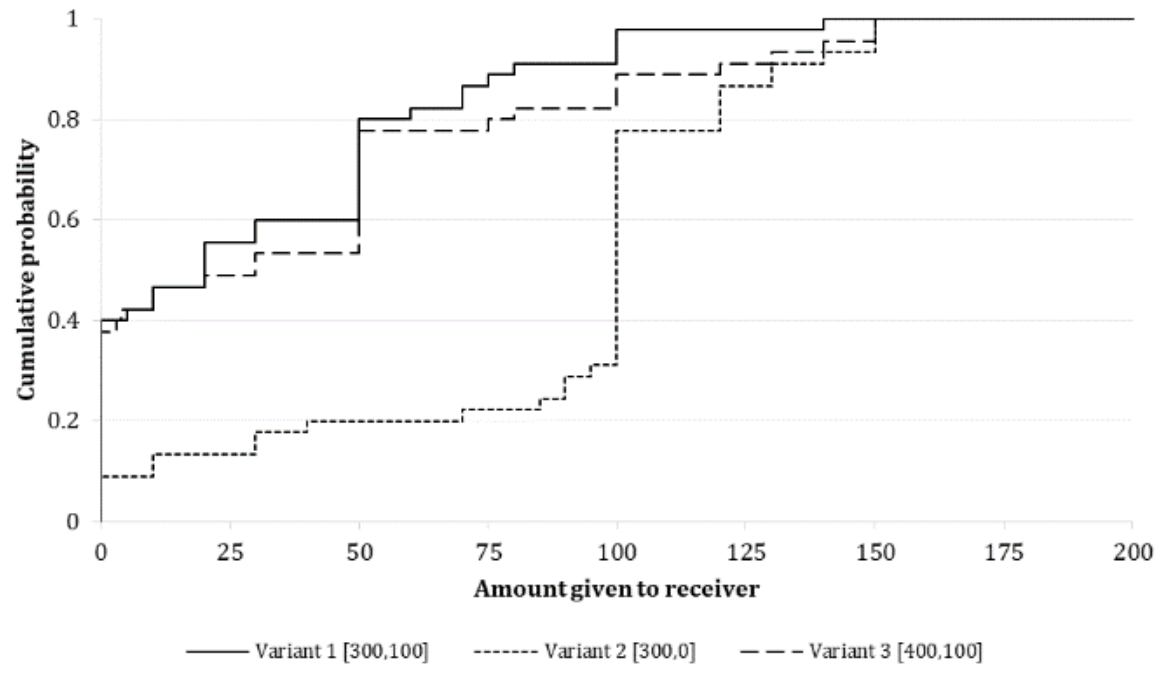

b) rounds $4-6$

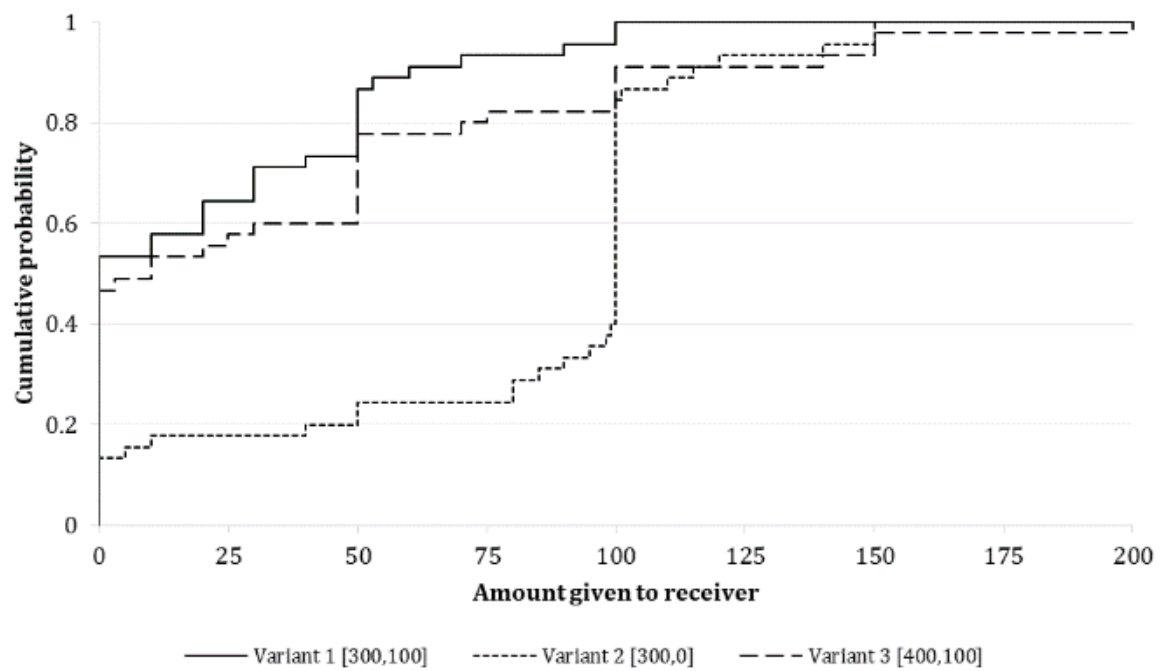

c) rounds $7-9$

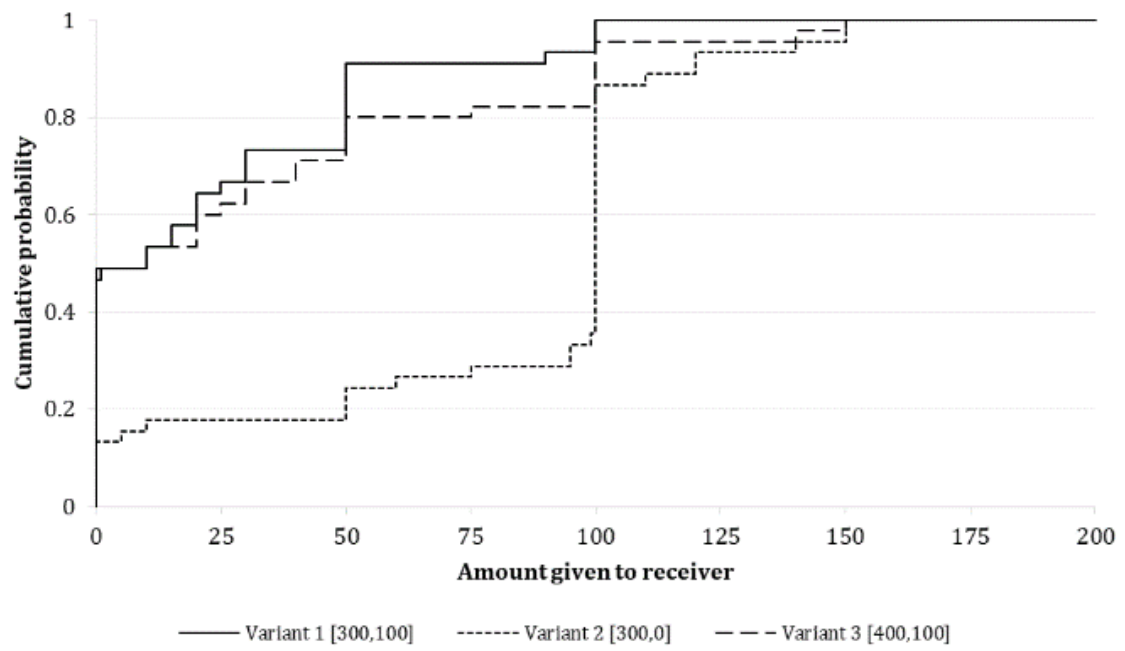

Notes: Cumulative distribution of amount given to receiver (in MU) per variant in each triplet of rounds. $\mathrm{N}=45$. 
On average, 64 percent of dictators give at least $100 \mathrm{MU}$ to the needy receiver in variant 2 , i.e., an amount sufficient to lift her above the threshold needed to stay in the game for sure. This percentage is a lot higher than the fraction of subjects satisfying basic needs in the choice experiment of Chapter II. It is unlikely that this giving behavior is predominately driven by other motives such as generosity or maximin. Generosity should lead to comparable giving behavior in variant 2 and 3, while the strict application of maximin should lead to a transfer of 150 in both variant 2 and 3 . However, this is not observed in the data. ${ }^{113}$ Moreover, maximin entails giving 100 in variant 1 , but not in variant 2 , while concerns for basic needs satisfaction leads to giving 100 in variant 2 . Strikingly, in variant 1 and 3 (in which the receiver is not in need), on average, only 7 and 18 percent of dictators give at least $100 \mathrm{MU}$ to the receiver, respectively. In variant 2, however, the modal amount transferred is $100 \mathrm{MU}$ : on average, 47 percent give exactly $100 \mathrm{MU}$ and 64 percent of dictators transfer an amount that is larger or equal to $100 \mathrm{MU}$.

Moreover, giving $100 \mathrm{MU}$ in variant 2 constitutes a third of the dictator's total endowment and half of the transferable amount. The experimental literature has found that typically about 17 percent of dictators give exactly half (Engel, 2011) of the total amount that can be transferred to the receiver. In variant 1 , which resembles the standard dictator game with a fixed endowment of $100 \mathrm{MU}$ for both dictator and receiver, on average, only 6 percent of dictators split the pie equally. This also shows that merely mentioning the threshold of $100 \mathrm{MU}$ in the instructions of our experiment did not trigger a significant share of subjects to give exactly this amount. In variant 3 , the average share of dictators giving $100 \mathrm{MU}$ is 10 percent, which is also lower than the percentage found in the literature. In variant 2 , however, the mean fraction of dictators giving exactly $100 \mathrm{MU}$ to the - in this variant needy - receiver increases to 47 percent.

In each triplet of rounds, the fraction of dictators giving $100 \mathrm{MU}$ to the receiver is significantly greater in variant 2 than in variant 3 (rounds 1-3: $\operatorname{McNemar}^{\prime} \chi^{2}(1)=16.20$, $p=.0001$, rounds 4-6: McNemar's $\chi^{2}(1)=12.80, p=.0003$, rounds 7-9: McNemar's $\chi^{2}(1)=12.57, p=.0004$ (exact $p$-values)). Hence, despite the fact that in both variants, giving $100 \mathrm{MU}$ entails a payoff difference of $100 \mathrm{MU}$ between the dictator and the receiver, dictators are much more likely to give half when the receiver is in need of this amount in order to survive to the next round. This suggests that the dictators' desire to prevent receivers from elimination is the driver for giving these 100 MU. ${ }^{114}$ We further see that of all dictators, 36 percent give exactly $100 \mathrm{MU}$ all three times they are exposed to the needy receiver in variant 2 .

To get a glimpse at the significance of concerns for BNS among our dictators, we consider the share of dictators who would have let their receivers face the undesirable

113 On average, less than 4 percent of subjects give exactly $150 \mathrm{MU}$ in variant 2 and 3 , respectively.

114 As outlined in Chapter II, maximin or generosity concerns could still explain an increase in giving in variant 2 . This is because the elimination from the experiment entails disutility for the receiver. If a dictator took into account this disutility, she could decide to give to the needy person because of maximin considerations rather than because she wants to fulfill her needs. Nevertheless, we believe that it is most plausible that giving exactly the amount to fulfill the receiver's need is indeed motivated by a desire to satisfy this very need. 
consequence if the dictators had given in variant 2 (with the receiver in need) what they gave in variant 1 and 3 (without the receiver in need). If dictators gave in variant 2 what they gave in variant 1 (variant 3), then, on average, 34 (30) dictators would put the receivers assigned to them at risk of being eliminated from subsequent rounds. In variant 2 , however, on average, only 10 dictators actually put receivers at risk of elimination. Hence, in expectation, on average 22 dictators (i.e., almost 50 percent) save their receivers in variant 2 by allocating a bigger share to them than in the other variants. ${ }^{115}$

Table 2: Giving at least $100 \mathrm{MU}$ in variant 2

\begin{tabular}{ccccccc}
\hline & \multicolumn{7}{c}{ \# times in line with BNS in allocation choice of Chapter II } \\
& 0 & 1 & 2 & 3 & 4 & 5 \\
\hline Rounds 1-3 & 60.71 & 75.00 & 100.00 & 50.00 & 75.00 & 100.00 \\
Rounds 4-6 & 57.14 & 50.00 & 100.00 & 0.00 & 75.00 & 66.67 \\
Rounds 7-9 & 60.71 & 75.00 & 75.00 & 50.00 & 75.00 & 66.67 \\
\hline $\mathrm{N}$ & 28 & 4 & 4 & 2 & 4 & 3 \\
\hline
\end{tabular}

\# times in line with SLF in allocation choice of Chapter II

\begin{tabular}{ccccccc} 
& 0 & 1 & 2 & 3 & 4 & 5 \\
\hline Rounds 1-3 & 83.87 & 50.00 & - & - & 0.00 & 40.00 \\
Rounds 4-6 & 70.97 & 50.00 & - & - & 0.00 & 40.00 \\
Rounds 7-9 & 74.19 & 50.00 & - & - & 0.00 & 50.00 \\
\hline N & 31 & 2 & 0 & 0 & 2 & 10 \\
\hline
\end{tabular}

Notes: Percentage of dictators giving at least $100 \mathrm{MU}$ to the needy receiver in variant 2 by the number of times dictators choose in line with BNS / SLF in the five main choices of the choice experiment in Chapter II.

We now assess how dictators who give $100 \mathrm{MU}$ in variant 2 choose in the choice experiment of Chapter II. Table 2 reveals that both dictators who often and those who seldomly or never choose in line with basic needs satisfaction in the choice experiment of Chapter II, give at least $100 \mathrm{MU}$ to the needy receiver in variant 2. Interestingly, even dictators who always choose the selfish option in the five main choices of the choice experiment in Chapter II (henceforth: selfish dictators) do so - in fact 40 to 50 percent of selfish dictators.

This does not seem to be due to risk aversion or pessimistic beliefs about giving behavior of other dictators. Selfish dictators who give at least $100 \mathrm{MU}$ are not significantly more risk averse than those who give less (Wilcoxon-Mann-Whitney: rounds 1-3: $z=$ $.650 p=.516$; rounds $4-6: z=-.433 p=.665$; rounds $7-9: z=.530 p=.596) .{ }^{116}$

115 'In expectation' refers to the different probabilities of elimination in case a receiver has $Y$ MU less than $100 \mathrm{MU}$.

116 Risk aversion was measured by a self-reported risk index ranging from 0 (completely unwilling to take risk) to 10 (completely willing to take risk) (question: "How do you see yourself: Are you generally a person who is fully willing to take risks or do you try to avoid taking risks?") (Dohmen et al., 2011). German original question: "Wie schätzen Sie sich persönlich ein: Sind 
Regarding beliefs about other dictator's giving behavior, they are even more optimistic about the number of receivers who are still in the game (Wilcoxon-Mann-Whitney: rounds $1-3: z=-2.138 p=.033$; rounds $4-6 ; z=-1.390 p=.1645$; rounds $7-9: z=-2.305 p=$ .021). ${ }^{117,118}$ On average, they believe that 12 receivers remain in the game, while for selfish dictators who give less than the threshold amount it is 8 receivers. A selfish dictator's concern that the game might end if the receiver she is matched with in this round is eliminated is thus unlikely to be the reason for her giving behavior. Hence, although the selfish choice would be to give nothing at all, even a big share of selfish dictators chooses to satisfy needs and give up half of their endowment. Hence, the behavior of selfish types cannot be solely explained by selfish strategic motives. A plausible explanation for their behavior is that the salience of the importance of the $100 \mathrm{MU}$ for the receiver's - and ultimately also the group's - survival has triggered dictators' desire to ensure their very survival - even at relatively high costs. This is consistent with the notion that human beings are predisposed to act in accordance with the motive in situations in which it is evolutionarily important.

\subsection{CONCLUDING DISCUSSION}

In the choice experiments of Chapter II and III, we have demonstrated that basic needs satisfaction is important for a substantial amount of subjects across different subject pools and incentive structures. In the present chapter, we have shown that if there is a minimal selfish strategic incentive to satisfy needs in order to ensure the survival of the receiver in the game, the prevalence of behavior in line with concerns for basic needs satisfaction increases substantially. Even subjects displaying a considerable amount of self-interest in the choice experiment of Chapter II choose to satisfy the receiver's need - and by this give up half of the amount that they can distribute - in the need game. These results cannot be explained by selfish subjects' risk aversion or beliefs about other dictators' giving behavior. This suggests that behavior in line with concerns for basic needs satisfaction is unlikely to be driven by pure self-interest. It is more plausible that these subjects carry both selfish motives and concerns for the satisfaction of basic needs inside them. We conclude that the salience of the importance of the $100 \mathrm{MU}$ for the receiver's - and

Sie im Allgemeinen ein risikobereiter Mensch oder versuchen Sie, Risiken zu vermeiden?"; 0 (gar nicht risikobereit) - 10 (sehr risikobereit).

117 Subjects were asked the following question to assess their beliefs about the number of receivers who are still in the game after $2(5,7,10)$ rounds of the game: "How many persons B (of 15) do you think, have reached round $2[5,7,10]$ ?". German original question: "Wie viele Personen B (von 15), glauben Sie, haben Runde 2 [5, 7, 10] erreicht?". Test results are based on the average of dictators' answers to these four questions.

118 This is also true when taking into account all dictators (Wilcoxon-Mann-Whitney tests: Risk aversion: Rounds $1-3: z=1.164 p=.244$; rounds $4-6: z=1.182 p=.237$; rounds $7-9: z=$ $1.258 p=.209$; beliefs about the number of receivers still in the game: Rounds $1-3 ; ; z=$ $-3.439 p<.001$ ); rounds $4-6: z=-3.029 p=.002$; rounds $7-9: z=-4.063, p<.001$. On average, those dictators who give at least $100 \mathrm{MU}$ believe that 12 receivers remain in the game, while those who give less are with 9 receivers also less optimistic. 
ultimately also the group's - survival might have triggered dictators' desire to fulfill receivers' needs in the need game. We remark that this is consistent with the notion that human beings are predisposed with several motives and act in accordance with a given motive in situations in which this motive is evolutionarily important. ${ }^{119}$

An important challenge in the measurement of people's concerns for the fulfillment of basic needs is to disentangle the motive from other distributional concerns aimed at generosity towards those who are less well off than themselves. Relevant motives in this realm are, for example, the desire to maximize the welfare of the least well-off person (maximin (e.g., Charness and Rabin, 2002; Andreoni and Miller, 2002; Engelmann and Strobel, 2004, 2005)), or to minimize the inequality between oneself and persons who are worse off (generosity (e.g., Fehr and Schmidt, 1999; Engelmann and Strobel, 2004, 2005; Blanco et al., 2011)). Even though it is most plausible that the social motive behind giving $100 \mathrm{MU}$ in the need game is the desire to fulfill the receiver's need and by this ensure her survival in the game, other motives, such as maximin and generosity might also play a role (see Section 4.3). Further, the dynamic element in the game introduces (minimal) strategic concerns that might increase the prevalence of behavior in line with concerns for basic needs satisfaction. The choice experiments described in Chapter II and III, have, on the one hand, the advantage to disentangle concerns for basic needs satisfaction clearly from these motives. The disadvantage is, on the other hand, that the implementation is quite complex and comprehensive. ${ }^{120}$

We therefore propose to develop a modified version of the need game that is - as the original need game from this chapter - easy to implement in a laboratory setting, and at the same time suitable to measure concerns for basic needs satisfaction in an unconfounded way. For this purpose, we propose to implement the need game in a oneshot setting, in which subjects play three rounds of the game, pairs are not rematched and roles within pairs are fixed. A possible adverse consequence for the receiver in case she does not have a sufficient amount to reach the threshold is a tedious task (e.g., correctly count the number of ' 2 's in a list containing ' 2 's and ' $Z$ ') that subjects have to fulfill at the end of the experiment without any extra payment, while the rest of subjects is allowed to leave already (see, for example, Abeler, 2011). ${ }^{121}$ Having to face this consequence is likely to entail negative implications for affected receivers within the experiment. After the experiment, it can be assumed that subjects would prefer to get their payment immediately and leave, rather than first having to solve this task. We hence expect that dictators in the experiment believe that the receiver would be better off if she did not have

119 Social preference models, as well as our theoretical model of Chapter II assume that people can be motivated both by self-interest and social motives (see, for example, Fehr and Schmidt, 1999; Charness and Rabin, 2001; Cappelen et al., 2007). Frohlich et al. (2004), for example, further show how the prevalence of selfishness varies depending on the context.

120 Subjects have to read rather long-winded instructions and an information text. Further, the setup requires a multiple of five subjects per session, since subjects are matched into groups of five in order to determine payoffs.

121 Ideally, the adverse consequence would be the deprivation of a basic need, such as water or food. This is, however, difficult to implement due to ethical considerations. 
to face this consequence. Thus, the fact that a receiver does not meet the threshold with her initial endowment can evoke dictators' considerations for the receiver's need.

In order to make sure that behavior is indeed driven by concerns for basic needs satisfaction, it is plausible to relate it to decisions in the choice experiment. In particular, we propose to expose dictators both to a set of choices similar to the isolation choices in Chapter III, and to the three variants of the need game. ${ }^{122}$ We plan to relate giving (exactly) as much as the receiver needs to reach the threshold to the number of times a dictator chooses in line with a given motive when it alone predicts an option in the choice experiment. Thereby, we assume that the more often a subject chooses in line with a motive, the more important this motive is to her. We expect that choosing selfishly in the choice experiment is negatively related to helping the needy receiver, since allocating money to the receiver is costly for the dictator and there is no strategic motive for the dictator to help the receiver. If choosing in line with basic needs satisfaction in the choice experiment is positively related to helping the needy receiver in variant 2 of the need game (but not to giving the threshold amount in variant 1 and 3 , in which the threshold is not binding), then this suggests that concerns for basic needs satisfaction are indeed the social motive driving dictators' decisions in this game. If additionally the latter is not related to choosing in line with maximin or generosity in the choice experiment, then it is unlikely to be explained by these motives. If this is the case, giving behavior in this one-shot need game can serve as a measure for concerns for basic needs satisfaction.

It is possible that the motive for basic needs satisfaction plays a central role in experiments designed to measure other social preferences, such as altruism or generosity, particularly when payoffs of receivers are very low (see also Chapter II, Section 2.4.1). Researchers might thus be interested in eliciting the motive, for instance as a control variable. The need game is straightforward to implement in a laboratory setting in an incentive compatible way. It can thus be incorporated easily into an existing experiment in order to obtain a measure of concerns for basic needs satisfaction.

This workhorse experiment is suitable to test relevant manipulations in order to explore the motive further. Relevant propositions are, for example, how a person's responsibility for being in need affects the propensity to incur costs to fulfill those needs (e.g., Konow, 2001; Schwettmann, 2012), whether the institutionalized guarantee of basic needs fulfillment entails efficiency losses, and the further exploration of how exactly individuals take into account needs fulfillment in distributional decisions in order to inform theoretical formulation of the motive. Chapter VI of this thesis elaborates on these propositions.

\subsection{APPENDIX}

\section{A Outline experiment}

122 Hereby, it is important to expose some subjects first to the choice experiment and some first to the need game. In this way, it is possible to control for possible confounding effects that making decisions in the respective other experimental setup might have on the other experiment. 


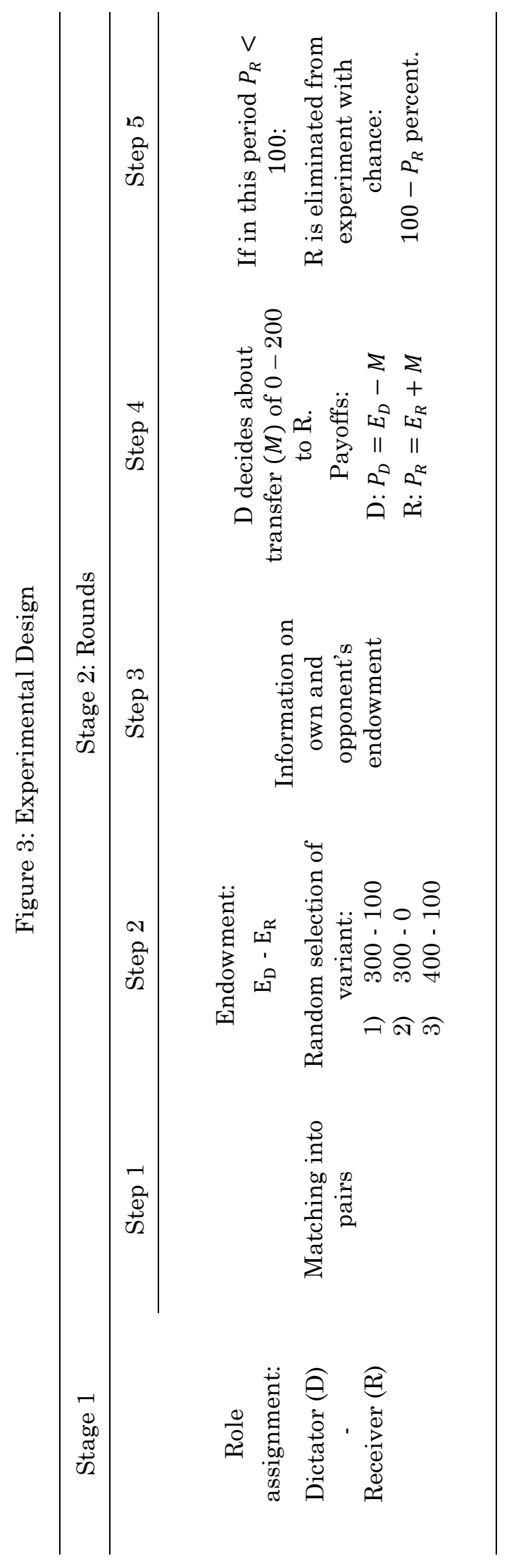




\title{
B Instructions for the experiment
}

\author{
B.1 German original text
}

\section{Dritter Teil des Experiments}

Dieser Teil des Experiments besteht aus 10 Entseheidungsrunden. In jeder Runde geht es um die Aufteilung eines Betrages in Höhe von 200 Talern zwischen zwei Personen, die im Folgenden als Person A und als Person B bezeichnet werden. Zu Beginn des Experiments wird erneut zufällig (und unabhängig vom letzten Teil des Experiments) bestimmt, welche Rolle Sie übernehmen. Es gibt zu Beginn des Experiments genauso viele Personen A wie Personen B.

Person A bestimmt in jeder Runde (also insgesamt 10 mal), wie der Betrag von 200 Talern zwischen ihr und (einer jeweils neu zugeordneten) Person B aufgeteilt wird. Person B trifft keine Aufteilungsentseheidung. Jede Runde besteht aus 4 Schritten. Im Folgenden wird der Ablauf einer Runde genau beschrieben:

\begin{tabular}{|c|l|}
\hline Schritt & Beschreibung \\
\hline 1. Schritt & $\begin{array}{l}\text { Jeder Person A wird ein Teilnehmer mit der Rolle von Person B zufällig } \\
\text { zugeordnet. (Diese Zuordnung besteht eine Runde. Am Anfang der nächsten } \\
\text { Runde gibt es eine neue zufällige Zuordnung.) }\end{array}$ \\
\hline 2. Schritt & $\begin{array}{l}\text { Person A erhält eine individuelle Ausstattung zwischen } 300 \text { und 400 Talern, } \\
\text { Person B erhält eine individuelle Ausstattung zwischen 0 und 100 Talern. } \\
\text { Die Ausstattungen für Person A und B werden jeweils zufällig vom } \\
\text { Computer bestimmt. }\end{array}$ \\
\hline 3. Schritt & $\begin{array}{l}\text { Person A und Person B erfahren die Höhe der individuellen Ausstattungen } \\
\text { von beiden Personen. }\end{array}$ \\
\hline 4. Schritt & $\begin{array}{l}\text { Person A kann einen Betrag in Höhe von 200 Talern von ihrer Ausstattung } \\
\text { zwischen sieh und Person B aufteilen. Dabei kann Person A jeden Betrag } \\
\text { (in 1 Taler-Schritten) zwischen 0 und 200 Talern an Person B schicken. }\end{array}$ \\
\hline
\end{tabular}

Damit ist die Entseheidungsrunde für beide Personen beendet.

Am Ende einer Runde haben Person A und Person B jeweils die Beträge, die aus ihrer jeweiligen Ausstattung in dieser Runde und der Aufteilungsentseheidung von Person A in dieser Runde resultieren:

- Person A hat ihre individuelle Ausstattung abzüglich des Betrages, den sie an Person B geschickt hat.

- Person B hat ihre individuelle Ausstattung zuzüglich des Betrages, den ihr Person A geschickt hat. 
Nach Beendigung einer jeden Runde werden diese Beträge von Person A und Person B vom Computer überprüft. Die Höhe der individuellen Beträge bestimmt, ob eine Person die nächste Runde erreicht oder nicht. Erreicht eine Person die nächste Runde nicht, ist für diese Person der dritte Teil des Experiments beendet. Dabei werden zwei Fälle unterschieden:

\section{Fall 1:}

Wenn eine Person am Ende einer Runde einen Betrag in Höhe von 100 Talern oder mehr hat, erreicht sie die nächste Runde mit Sicherheit.

\section{Fall 2:}

Wenn eine Person am Ende einer Runde einen Betrag von weniger als 100 Talern hat, erreicht sie die nächste Runde mit einer bestimmten Wahrscheinlichkeit nicht.

Die Wahrscheinlichkeit, dass eine Person die nächste Runde nicht erreicht, hängt davon ab, wie viele Taler dieser Person zum Erreichen der 100 Taler fehlen und bestimmt sieh wie folgt: Fehlen einer Person Y Taler zum Erreichen der 100 Taler, dann erreicht diese Person die nächste Runde mit einer Wahrscheinlichkeit von Y Prozent nicht. Das bedeutet, je mehr Taler einer Person zum Erreichen der 100 Taler fehlen, desto höher ist die Wahrscheinlichkeit, dass diese Person die nächste Runde nicht erreicht. Umgekehrt bedeutet dies, je weniger Taler einer Person zum Erreichen der 100 Taler fehlen, desto geringer ist die Wahrscheinlichkeit, dass diese Person die nächste Runde nicht erreicht. Ob eine Person, die weniger als 100 Taler am Ende einer Runde hat, die nächste Runde erreicht, wird auf Basis der erreehneten Wahrscheinlichkeit vom Computer bestimmt.

Hier sehen Sie 4 Beispiele für die oben beschriebenen Fälle:

\begin{tabular}{|l|l|}
\hline Fall & Konsequenz \\
\hline $\begin{array}{l}\text { Eine Person hat am Ende } \\
\text { einer Runde 150 Taler. }\end{array}$ & Die Person erreicht die nächste Runde sicher. \\
\hline $\begin{array}{l}\text { Eine Person hat am Ende } \\
\text { einer Runde 100 Taler. }\end{array}$ & Die Person erreicht die nächste Runde sicher. \\
\hline $\begin{array}{l}\text { Eine Person hat am Ende } \\
\text { einer Runde 60 Taler. }\end{array}$ & $\begin{array}{l}\text { Die Person erreicht die nächste Runde mit einer } \\
\text { Wahrscheinlichkeit von 40\% nicht, d.h. die Person } \\
\text { erreicht die nächste Runde mit einer Wahrscheinlichkeit } \\
\text { von 60\%. }\end{array}$ \\
\hline $\begin{array}{l}\text { Eine Person hat am Ende } \\
\text { einer Runde 30 Taler. }\end{array}$ & $\begin{array}{l}\text { Die Person erreicht die nächste Runde mit einer } \\
\text { Wahrscheinlichkeit von 70\% nicht, d.h. die Person } \\
\text { erreicht die nächste Runde mit einer Wahrscheinlichkeit } \\
\text { von 30\%. }\end{array}$ \\
\hline
\end{tabular}

Nach der Überprüfung der Beträge und der Bestimmung des Erreichens der nächsten 
Runde beginnt für die Teilnehmer, die die nächste Runde erreicht haben, diese nächste Runde.

\section{So bestimmen sich die Auszahlungen:}

Am Ende des Experiments wird zufällig ausgewählt, welche der 10 Runden auszahlungsrelevant wird, Person A und Person B bekommen dann die Beträge, die aus Ihrer jeweiligen Ausstattung in der ausgewählten Runde und aus der Aufteilungsentseheidung von Person A in dieser Runde resultieren:

- Person A bekommt ihre eigene Ausstattung abzüglich des Betrages, den sie in dieser Runde an Person B geschickt hat.

- Person B bekommt ihre eigene Ausstattung zuzüglich des Betrages, den ihr Person A in dieser Runde geschickt hat.

\section{Eine Person, die diese auszahlungsrelevante Runde nicht erreicht hat, erhält eine Auszahlung in Höhe von 0 Talern.}

Bitte beachten Sie außerdem:

Durch die beschriebene Prozedur kann es Vorkommen, dass sieh zu Beginn einer Runde eine ungleiche Anzahl von Personen A und B in diesem Teil des Experiments befinden. Für den Fall, dass in einer Runde mehr Personen A als Personen B vorhanden sind, werden mindestens einer Person B jeweils mehrere Personen A zufällig zugeordnet. Für Person B ist dann in dieser Runde die Aufteilungsentseheidung einer der zufällig zugeordneten Personen A relevant. Welche Person A dies ist, wird am Ende dieser Runde zufällig bestimmt. Wenn in einer Runde weniger als 2 Personen B vorhanden sind, wird dieser Teil des Experiments vorzeitig beendet. In diesem Fall wird die auszahlungsrelevante Runde für alle Teilnehmer aus der Menge der absolvierten Runden der zuletzt verbliebenen Teilnehmer bestimmt.

Beträge, die durch das Nichterreichen einer Runde von einer Person nicht ausgezahlt werden (durch die Entscheidungen von überschüssigen Personen A), werden von den Experimentatoren in anderen Experimenten an die Teilnehmer ausgezahlt, d.h. diese Beträge gehen nicht verloren.

\section{B.2 English translation}

\section{Third part of the experiment}

This part of the experiment consists of 10 decision rounds. Each round is about the distribution of an amount of 200 coins between two persons who, henceforth, will be labeled Person A and Person B. At the beginning of the experiment, it will again be 
randomly (and independently of the previous part of the experiment) determined which role you will have. At the beginning of the experiment, there are exactly as many Persons A as Persons B.

Person A decides in each round (i.e., 10 times in total), how to distribute the amount of 200 coins between herself and (the each round anew assigned) Person B. Person B does not make any distribution decision. Each round consists of 4 steps. In the following, the procedure in each round is outlined in detail:

\begin{tabular}{|l|l|}
\hline Step & Description \\
\hline Step 1 & $\begin{array}{l}\text { Each Person A will be matched with another participant in the role of Person } \\
\text { B. (This matching lasts for one round. At the beginning of the next round, there } \\
\text { will be a new random matching.) }\end{array}$ \\
\hline Step 2 & $\begin{array}{l}\text { Person A gets an individual endowment between } 300 \text { and } 400 \text { coins. Person B } \\
\text { gets an individual endowment between 0 and } 100 \text { coins. The endowments of } \\
\text { Person A and B will be randomly determined by a computer. }\end{array}$ \\
\hline Step 3 & $\begin{array}{l}\text { Person A and Person B are informed about the amounts of the individual } \\
\text { endowments of both persons. }\end{array}$ \\
\hline Step 4 & $\begin{array}{l}\text { Person A can distribute an amount of 200 coins of her endowment between } \\
\text { herself and Person B. Thereby, Person A can send each amount (in 1-coin } \\
\text { steps) between 0 and 200 coins to Person B. }\end{array}$ \\
\hline
\end{tabular}

Therewith, the decision round ends for both persons.

At the end of each round, Person A and Person B have the amounts that result from their respective endowment in this round and the distribution decision of Person $\mathrm{A}$ in this round:

- Person A has her individual endowment minus the amount she sent to Person B,

- Person B has her individual endowment plus the amount Person A sent to her.

At the end of each round these amounts are cheeked by the computer. The individual amounts determine whether a person reaches the next round or not. If a person does not reach the next round, the third part of the experiment ends for this person. Thereby, two eases exist:

\section{Case 1:}

If, at the end of a round, a person has an amount of $\mathbf{1 0 0}$ coins or more, she reaches the next round with certainty.

\section{Case 2:}

If, at the end of a round, a person has an amount of less than 100 coins, she does not reach the next round with a certain probability. 
The probability with which a person does not reach the next round depends on the amount of coins a person lacks for reaching the 100 coins and is determined as follows: If a person is lacking $\mathrm{Y}$ coins for reaching the 100 coins, then she does not reach the next round with a chance of $\mathbf{Y}$ percent. This means that the more coins a person is lacking for reaching the 100 coins, the higher the probability that a person does not reach the next round. Conversely, this means that the fewer coins a person is lacking for reaching the 100 coins, the lower the probability that a person does not reach the next round. Whether a person indeed reaches the next round, is randomly determined by a computer on the basis of the calculated probability.

Here you can see four examples for the above described eases:

\begin{tabular}{|l|l|}
\hline Case & Consequence \\
\hline $\begin{array}{l}\text { At the end of the selected } \\
\text { round, a person has } 150 \text { coins. }\end{array}$ & This person reaches the next round with certainty. \\
\hline $\begin{array}{l}\text { At the end of the selected } \\
\text { round, a person has } 100 \text { coins. }\end{array}$ & This person reaches the next round with certainty. \\
\hline $\begin{array}{l}\text { At the end of the selected } \\
\text { round, a person has } 60 \text { coins. }\end{array}$ & $\begin{array}{l}\text { This person does not reach the next round with a chance } \\
\text { of } \% \text {, i.e., this person reaches the next round with a } \\
\text { chance of } 60 \% .\end{array}$ \\
\hline $\begin{array}{l}\text { At the end of the selected } \\
\text { round, a person has } 30 \text { coins. }\end{array}$ & $\begin{array}{l}\text { This person does not reach the next round with a chance } \\
\text { of } 70 \%, \text { i.e., this person reaches the next round with a } \\
\text { chance of } 30 \% .\end{array}$ \\
\hline
\end{tabular}

After the computer has cheeked the amounts and determined whether a person reaches the next round, the next round starts for those participants who have reached this next round.

\section{Payments are determined as follows:}

At the end of the experiment, one of the 10 decision rounds will be selected randomly for payment. Person A and Person B get the amounts that result from their endowment in the selected round and the distribution decision of Person A in this round.

- Person A receives her individual endowment minus the amount she sent to Person B.

- Person B receives her individual endowment plus the amount Person A sent to her.

\section{A person who has not reached this round relevant for payment receives a payment of 0 coins.}


Please further note the following:

Due to the described procedure, there may be an unequal number of Persons A and Persons $\mathrm{B}$ at the beginning of a round in this part of the experiment. In case in a round, there exist more Persons A than Persons B, to at least one Person B there will be randomly assigned more than one Person A, respectively. For Person B, the distribution decision of one of the randomly assigned Persons $\mathrm{A}$ is then relevant for payment. It will be randomly determined at the end of the respective round which of these Persons A this is. If in a round there are fewer than 2 Persons $\mathrm{B}$, this part of the experiment ends prematurely. In this case, the round relevant for payment will be drawn from all completed rounds of the last remaining participants.

Amounts not paid out due to a person not reaching a round (due to decisions by surplus Persons A) will be paid to participants in other experiments by the experimenters. This means that these amounts will not be lost. 



\section{CHAPTER V \\ Redistributional attitudes, preferences, and beliefs of the wealthy ${ }^{123}$}

\subsection{INTRODUCTION}

Due to the problem of rising economic inequality, economic scholars have argued for increasing taxes for the economic elite, for example, by augmenting taxes on wealth (Piketty and Saez, 2013). In recent years, this issue also entered prominently into political discussions in a variety of countries. ${ }^{124}$ Norton and Ariely (2011) further document that people prefer a distribution of wealth that is more equal than the actual one. Yet, wealth taxes - which would mainly affect the rich - remain extremely low (OECD, 2018c; Evans, 2013).

One explanation is the disproportional political influence of the rich (Gründler and Köllner, 2017; Gilens and Page, 2014; Giger et al., 2012; Rosset et al., 2013). Such an argument implicitly assumes that the rich are less supportive of redistribution than other groups in society. This conjecture has been confirmed empirically (e.g., Fong, 2001; Alesina and La Ferrara, 2005; Alesina and Giuliano, 2009). We assess attitudes towards redistribution of a sample of Dutch millionaires ${ }^{125}$, and compare them to a control sample that is more representative of the population in the Netherlands (henceforth: general population). We confirm the above conjecture, as we find that in our study, the wealthy are less inclined towards redistribution than the general population as measured by their political orientation, their general attitude towards income inequality, and their attitudes towards raising taxes on income or wealth.

These differences in redistributional attitudes could stem from disparities in preferences to level income inequality that arises from sources, such as luck, or individual effort (i.e., their preferences for redistribution) (Konow, 2000; Almås et al., 2017), in beliefs about the role of these sources in determining individual incomes (Piketty, 1995; Fong,

123 This chapter is based on joint work with Paul Smeets. The experiment was designed and executed together with Lasse Jessen, Alain Cohn, and Marko Klašnja. The authors would like to thank participants of the BEELab Proposal Meeting at Maastricht University, and participants of seminars at University of California Los Angeles, Harvard Business School, and the CPB Netherlands Bureau of Policy Analysis for helpful comments and suggestions. We are grateful to Niels Mourmans for excellent research assistance.

124 See for example, Mayeda (2017), Cohen (2015), Steffen (2017), and van Uffelen (2014).

125 This sample consists of clients from ABN AMRO MeesPierson, which is a private bank in the Netherlands that exclusively serves clients who have more than 1 million Euros in their bank account (see also Section 5.2.1). 
2001), and in constraints and prices (e.g., the absolute monetary amounts at stake). In this chapter, we focus on the role of both subjects' preferences for redistribution and beliefs about the sources of income inequalities in determining the observed differences in redistributional attitudes.

In a second step, we therefore elicit preferences for redistribution in a controlled, incentive compatible experiment both for the wealthy and the general population. In particular, we employed third-party redistribution situations in which spectators made a choice that had real monetary consequences for two workers who had completed the same work assignment. In our experiment, spectators' choices only affected workers' payments, not their own. Spectators were told that one worker had been allocated 6 US dollars for completing the assignment, while the other worker received nothing. Spectators were randomly allocated to one of two treatments in which we varied the rule that the initial allocations of workers' earnings had been based upon. In treatment LUCK, we randomly determined which of the two workers got paid for the task. In treatment MERIT, the worker who performed better on the task in the pair of workers would earn 6 US dollars. Spectators were then given the possibility to redistribute the initial earnings between the workers. ${ }^{126}$ In this way, we can assess the degree to which spectators are willing to level income differences in earnings that are due to luck or individual effort, while controlling for subjects' beliefs about the role of luck and effort, and holding stake sizes constant across subject pools. We find that millionaires and the general population are indeed remarkably similar in terms of their preferences for redistribution both when differences in earnings are due to luck, or individual performance. For given beliefs about the source of income inequalities, heterogeneity in their preferences to level income differences that stem from luck or effort can thus not explain the observed differences in redistributional attitudes between the two samples.

Beliefs about how income differences came about are, however, a possible explanation for the observed differences in redistributional attitudes - even if preferences for redistribution are similar for the two samples. Suppose, for example, two persons who prefer to decrease income inequality caused by luck but not one caused by individual effort. Imagine further that one person believes that income inequality is mainly caused by luck, while the other person beliefs that it is mainly caused by differences in individual effort. The former will be in favor of redistribution, while the latter will be against it. Beliefs about the role of luck and effort thus determine how preferences for redistribution translate into redistributional decisions or attitudes. In the experiment, we control for beliefs by design, by inducing a specific belief in each treatment. In the LUCK treatment, spectators know that differences in earnings are due to pure luck (i.e., they are randomly determined), while in the MERIT treatment, they know that earnings are determined by performance in a task. Redistribution decisions are thus assumed to reflect spectators' undistorted preferences for redistribution. When indicating their attitudes towards redistribution in the field (e.g., towards existing redistributive policies in the Netherlands), however, subjects' answers are likely to be influenced by both their actual

126 Our design strongly builds on Almås et al. (2017). 
preferences to reward luck and effort and by their beliefs about the role of luck and effort in determining incomes. Consequently, even if millionaires have similar preferences for redistribution as people from the general population, differences in beliefs can cause them to exhibit different attitudes towards redistribution.

In order to measure subjects' beliefs, they were asked to assess how important they think luck and hard work is for determining success in life. We find that, compared to the general population, millionaires attach more importance to hard work and less importance to luck. Most importantly, our results from a Blinder-Oaxaca decomposition analysis (Oaxaca, 1973; Blinder, 1973) show that in particular the difference in the importance attached to hard work accounts for a significant part of the gap in attitudes towards redistribution.

As a final step, we examine possible explanations for the observed differences in beliefs between the wealthy and the general population in our study. First, according to Piketty (1995), experiences in social mobility are important for shaping people's beliefs about what matters for getting ahead in life, which then ultimately influences their attitudes towards redistribution. ${ }^{127}$ A person who experienced upward social mobility, for example, is more likely to believe that individual effort is important for being successful - at least if her wealth does not stem from an inheritance or from winning in a lottery. Arguably, millionaires are in general more likely to have experienced upward social mobility than subjects from the general population. These differences in social mobility experience could thus be a driver for the observed differences in beliefs. Second, millionaires have an incentive to not increase taxes, while for poorer people this incentive is smaller or even reverse. Since the wealthy would actually be affected by, for example, increasing the wealth or income taxes, they have an incentive to not increase those taxes further. By contrast, people with lower income or wealth are more likely to profit from tax-funded redistribution either by transfer payments or indirectly via the progressivity of the tax system (Causa and Hermansen, 2018). A rich person might thus have a higher incentive to develop the belief that hard work is important for success in life in order to keep a positive image of their social group and view the system that facilitated their advancement as just (Jost et al., 2004).

To study these explanations further, we look at three main groups among our sample of wealthy subjects: (1) millionaires who got rich through an inheritance, (2) millionaires who got rich from their salary, and (3) millionaires who got rich through their own business. ${ }^{128}$ It is plausible to assume that those who got rich from their salary or their own business are more likely to have experienced upward social mobility than those who got rich through an inheritance. Thus, if among the wealthy, employees and entrepreneurs attach a greater importance to hard work and less importance to luck than do heirs, then

127 According to Piketty (1995), experienced social mobility can influence people's attitudes towards redistribution by altering beliefs "regarding societies' mobility parameters" (p.554) (i.e., predetermined factors as opposed to individual effort).

128 These three groups constitute 87 percent of our sample of millionaires. For the general population, 75 percent of the sample consists of employees. We thus limit our analysis to the millionaire sample. 
the mere experience of upward social mobility could be a driver for the differences in beliefs between the wealthy and people from the general population. If, however, there are no differences (i.e., people with similar stakes in redistribution have similar beliefs), then the difference in stakes in redistribution in the field might be a reason for the observed differences in beliefs between the wealthy and the general population.

Our results are mixed. While we find that among the wealthy, heirs indeed believe that hard work is less important than do entrepreneurs and employees, we find no difference in the importance both groups attribute to luck. Our evidence thus reveals that differences in beliefs about what determines success in life might stem from differences in actual experienced social mobility, and from an incentive of millionaires to develop a narrative in order to keep a positive self-image. Interestingly, our results also reveal that in terms of redistributional attitudes (and also preferences for redistribution measured in the experiment) entrepreneurs are the group that differs from the rest of millionaires. Differences in beliefs in the importance of hard work between heirs and the rest of millionaires did thus not translate into differences in redistributional attitudes. We further present suggestive evidence that being confronted with merit considerations in professional life is an important channel for shaping preferences for and attitudes towards redistribution, explaining the observed differences between entrepreneurs and other types of millionaires.

This chapter contributes to the literature that assesses the role of beliefs and preferences in shaping redistributional attitudes. While so far, researchers have been mostly concerned with either beliefs (Fong, 2001; Alesina et al., 2001; Corneo and Grüner, 2002) or preferences (Fisman et al., 2015; Almås et al., 2017), we simultaneously look at the effect of both factors. This allows us to assess whether they both have an independent impact on participants' redistributional attitudes. While we confirm that both preferences and beliefs can generally predict attitudes towards redistribution for millionaires, this is not true for the general population. Moreover, the observed differences between millionaires and the general population in redistributional attitudes can only be explained by differences in the importance they attach to hard work.

Our findings further add to the literature concerned with differences in redistributional attitudes, preferences, and beliefs between an economic elite and people from the general public. Our results confirm a large body of literature asserting that richer people have a less favorable attitude towards redistribution (e.g., Alesina and Guiliano, 2009; Alesina and Ferrera, 2005; Piketty, 1995; Norton and Ariely, 2011; Fong, 2001). As outlined above, this chapter further offers an explanation for this disparity. Moreover, we do not find that the wealthy are different in terms of their social preferences (in our case their preferences for redistribution) as might be inferred, for example, from results of Piff et al. (2010), Smeets et al. (2015), and Fisman et al. (2015). This might be, among other reasons, due to the fact that, in our experiment, we control for selfish considerations and the marginal utility of money, as decisions in the experiment only have monetary consequences for third parties, but not for the decision makers themselves. Our results are rather in line with Piketty's (1995) conjecture that "people from different social backgrounds share wide consensus about abstract principles of distributive justice [...]", e.g., that, "[p]eople can deserve unequal rewards only on the basis of features - such as 
effort - that are subject to voluntary control", (p. 555) as expressed in their preferences towards redistribution in the experiment. We can further confirm results of Fong (2001) that richer people believe more strongly in self-determination, since in our sample the wealthy had a stronger believe in hard work for determining success in life.

The remainder of this chapter is organized as follows. Section 5.2 outlines the research design. Section 5.3 presents the results. Section 5.4 concludes.

\subsection{RESEARCH DESIGN}

\subsubsection{Outline and sample}

Participants of our study were drawn from two different subject pools. The first sample consists of clients from ABN AMRO MeesPierson, which is a private bank in the Netherlands that exclusively serves clients who have more than 1 million Euros in their bank account. ${ }^{129}$ We will refer to subjects from this subject pool as millionaires or wealthy. We are confident that our millionaire sample is a representative portray of Dutch millionaires. ${ }^{130}$ Subjects were asked to participate in the experiment as part of a survey on philanthropy conducted by the bank. ${ }^{131}$ Participation in the survey as well as in the experiment was voluntary and not remunerated. The experiment was the second of five parts in the survey. In the first part, subjects answered a few demographic questions, as well as questions about life satisfaction and their risk attitude. After the experiment, subjects answered a series of other questions including our questions about what they believe determines success in life, as well as our questions about their political orientation and their attitudes towards income inequality and specific taxes. In total, our sample of millionaires consists of 304 individuals. ${ }^{132}$ The second sample consists of 212 subjects of a nationally representative sample drawn from Flycatcher, an internet survey panel of a diverse adult population living in the Netherlands. ${ }^{133}$ We will refer to subjects from this

129 Note that, however, about 26 percent of our millionaire sample reported a total wealth of less than 1 million Euros.

130 Van Lanschot (2015) reports that 5 percent of millionaires are younger than 40 years, while 75 percent are older than 50 years. In our millionaire sample, 5.26 percent are younger than 40 years and 83 percent are older than 50 years. They further state that 20 percent of millionaires are women, which with about 30 percent is slightly higher in our sample. Further, 78 percent of our millionaires are married or living together, which is comparable to 70 percent married or living in a registered partnership reported in Arts (2017). Moreover, 16 percent of our millionaires live in a single-person household, which is close to 18 percent reported in Arts (2017).

131 Participants knew that the questionnaire was about philanthropy. However, they have only been exposed to questions about their philanthropic activities and attitudes after the experiment.

132 In total, 445 millionaires took part in both the survey and the experiment. The additional 141 millionaires were exposed to a third treatment, which will not be the focus of this chapter. Additionally, 245 millionaires took part only in the survey. Naturally, we restrict our sample of millionaires to those who participate both in the survey and the experiment.

133 Additionally, 94 subjects from the general population were exposed to a third treatment of the 
pool as general population. These subjects completed the experiment as well as a post experimental questionnaire including the beliefs and the redistributional attitudes questions. As a reward for their participation, participants from Flycatcher received points, as is usual in this panel.

\subsubsection{Redistributional attitudes}

Subjects were asked four questions to measure their attitude towards redistribution ranging from a very broad question about their political orientation to questions regarding specific taxes in the Netherlands. The first question was a self-assessment of whether subjects are politically oriented towards the left or right, respectively. ${ }^{134}$ The second question asked about their general attitude towards income inequality outside the experiment. The third and fourth question assessed their support for raising the wealth and income taxes in the Netherlands. ${ }^{135}$ Table 1 shows the English translation of the questions posed to subjects, as well as the scale. The original Dutch questions can be found in Table 6 in Appendix A.

experiment, which, as mentioned before, will not be the focus of this chapter.

134 The distinction between left and right is one of the most important dimensions of political ideology (Jost, 2006). Self-assessed political orientation (left-right) is related to the fairness dimension of moral foundations (Van Leeuwen and Park, 2009 (Dutch student sample); Nilsson and Erlandsson, 2015; Kivikangas et al., 2017).

135 It might be argued that subjects do not view taxes entirely as an instrument for redistribution. Unfortunately, we did not ask subjects about their assessment on what the Dutch government spends taxes. In the Netherlands, however, social expenditures make up almost half (49.3 percent in 2013) of the total governmental spending (OECD, 2018b). 
Table 1: Questions on redistributional attitudes

\begin{tabular}{|c|c|}
\hline Question & Scale \\
\hline $\begin{array}{l}\text { (i) } \underline{\text { Political orientation }}^{\text {a }} \\
\text { In politics, one talks about left and right. Where would you } \\
\text { place yourself on a scale from } 0 \text { to } 10 \text {, where } 0 \text { means "left" } \\
\text { and } 10 \text { means "right". }\end{array}$ & $\begin{array}{l}\text { 0: left- } \\
\text { 10: right }\end{array}$ \\
\hline $\begin{array}{l}\text { (ii) Income inequality } \\
\text { Please indicate to what extent you agree or disagree with the } \\
\text { following statement: "A society should aim to equalize } \\
\text { incomes." }\end{array}$ & $\begin{array}{l}\text { 1: strongly disagree - } \\
\text { 7: strongly agree }\end{array}$ \\
\hline (iii) Taxes & \\
\hline $\begin{array}{l}\text { Wealth tax } \\
\text { Currently, everyone pays } 1.2 \% \text { tax on wealth above } 21,000 \\
\text { euro. In your opinion, should people with wealth beyond } 1 \\
\text { million euro pay a lower, the same, or a higher wealth tax? }\end{array}$ & $\begin{array}{l}\text { 1: a much lower tax rate; } \\
\text { 2: a bit lower tax rate; } \\
\text { 3: the same; } \\
\text { 4: a bit higher tax rate; } \\
\text { 5: a much higher tax rate }\end{array}$ \\
\hline $\begin{array}{l}\text { Income tax } \\
\text { The marginal tax rate for annual incomes above } 57,585 \text { euro } \\
\text { in the Netherlands is currently } 52 \% \text {. In your opinion, should } \\
\text { the tax rate for people with annual incomes above } 57,585 \\
\text { euro be lower, stay the same, or higher? }\end{array}$ & $\begin{array}{l}\text { 1: a much lower tax rate; } \\
\text { 2: a bit lower tax rate; } \\
\text { 3: the same; } \\
\text { 4: a bit higher tax rate; } \\
\text { 5: a much higher tax rate }\end{array}$ \\
\hline
\end{tabular}

Notes: a Adapted from World Values Survey (Inglehart et al., 2012). ${ }^{b}$ Adapted from Almås et al. (2017). English translation of the original questions. For questions in Dutch, see Appendix A.

\subsubsection{Preferences for redistribution}

Our experimental design builds strongly on Almås et al. (2017). We employed third-party redistribution situations in which spectators made a choice that had real monetary consequences for two workers who had completed the same work assignment. Spectators' choices only affected workers' payments, not their own. Subjects were randomly exposed to one of two treatments that only differ in the source of the initial earnings inequality between the two workers. For an outline of the experimental design, see Figure 8 in Appendix B.

\section{Workers}

Workers received a flat payment of 1 US dollar for completing a work assignment and a short questionnaire. After reading the instructions and completing a practice task to ensure understanding, all workers worked on the same real-effort task for 5 minutes. After completing the task and answering the questionnaire, workers were informed that they would potentially earn additional money. To determine their bonus payments, workers were randomly matched in pairs. One of the two workers in the pair earned an additional 6 US dollars (henceforth, worker A), whereas the other worker received nothing (henceforth, worker B). The basis for the initial allocation of bonus payments (i.e., the source of income inequality) varied across treatments using a between-subjects design. Workers were further told that they were matched to a spectator and that this spectator 
could decide about the final allocation of the bonus payments between the two workers. ${ }^{136}$

Workers' task consisted of double checking entries from a digitized list of participant IDs and finding as many mistakes as possible. In particular, they saw a handwritten list of IDs on the left side of the screen and a digitized list on the right side of the screen. They were instructed to check every row and type in the correct ID in case the digitized ID did not correspond to the handwritten ID. Each ID consisted of two letters followed by eight numbers.

\section{Spectators}

Each spectator was assigned to one worker-pair and made one redistribution choice that had real monetary consequences for these two workers, but not for herself. Spectators were first informed about the nature of the task, the 1-US dollar show-up fee for the workers, and the basis for the bonus allocation depending on the treatment. Spectators were further told that workers only learned about the potential bonus payment and the way it would be determined after they had completed the task. In a second step, spectators decided whether and how much of the bonus payment they want to redistribute from worker A to worker B. ${ }^{137}$ They could choose any possible combination of allocation in 1-US dollar steps, including not redistributing at all (i.e., 6/0, 5/1, .., 0/6 US dollars (income worker A/Income worker B)). ${ }^{138}$ This choice serves as the basis for our measure of implemented inequality.

\section{Implemented inequality}

We are interested in spectators' preferences for redistribution - in particular in the income inequality they implement. The income inequality implemented by spectator $i$ in the choice experiment is equal to:

$$
e_{i}=\frac{\mid \text { Income worker } A_{i} \text {-Income worker } B_{i} \mid}{\text { Total income }}=\left|2 y_{i}-1\right| \in[0,1],
$$

where $y$ is the share of total income allocated to the worker with zero initial earnings by spectator $i$, i.e., to the unlucky/worse performing worker B (see Almås et al., 2017). The implemented inequality is equal to one in both treatments before any redistribution, and is equal to zero if a spectator decided to completely equalize workers' incomes (see Table 2).

136 For the complete worker instructions, see Appendix C.

137 For easier implementation, in the spectator instructions worker A is always the worker who receives the 6.00 US dollar, and worker B always the worker who receives 0 US dollar.

138 For the complete spectator instructions, see Appendix D. 
Table 2: Redistribution choice and implemented inequality

\begin{tabular}{cc}
\hline Redistribution choice & $\begin{array}{c}\text { Implemented } \\
\text { inequality }\end{array}$ \\
\hline $6 / 0$ & 1 \\
$5 / 1$ & 0.667 \\
$4 / 2$ & 0.333 \\
$3 / 3$ & 0 \\
$2 / 4$ & 0.333 \\
$1 / 5$ & 0.667 \\
$0 / 6$ & 1 \\
\hline
\end{tabular}

Notes: ${ }^{\text {a }}$ Income worker A / income worker B.

This measure of inequality treats subjects who implement inequality that is favorable for the unlucky/worse performing worker B equally as those subjects who accept inequality that is favorable for the lucky/better performing worker A. For example, both a spectator who allocates everything to worker B and a spectator who allocates everything to worker A implement an income inequality of 1 . In our sample, there are only five people who redistributed more than 3 US dollars (i.e., who implemented an inequality favorable for the unlucky/worse performing worker B). Since we are primarily interested in inequality acceptance when it is favorable for the lucky/better performing worker A, we drop these cases from our analysis. ${ }^{139}$ Hence, we can assert that the less a spectator redistributes from worker $A$ to worker B, the higher the inequality implemented by her and thus the higher her inequality acceptance. ${ }^{140}$

\section{Treatments}

Independent of the treatment, one of the two workers in each pair was allocated initial earnings of 6 US dollars (worker A) and the other worker received nothing (worker B). The basis for this initial allocation (i.e., the source of income inequality) varied across two different treatments using a between-subjects design. In the LUCK treatment, we randomly determined which of the two workers got paid for the task. In the MERIT treatment, the worker in each pair who performed best on the assignment earned 6 US dollars. Performance was determined as the total number of mistakes found. In particular, workers received one point for each wrong ID they had entered correctly and they were deducted one point for each ID they had entered wrongly.

139 In Appendix F, we redo the main analysis including these five subjects to demonstrate that results are not affected by dropping these individuals.

140 It can be argued that the fact that the default distribution is set at $6 / 0$ US dollars influences redistribution behavior. This was done in order to ensure comparability of the result to those of Almås et al. (2017). When comparing redistributional preferences of millionaires to those of subjects from the general population, the influence of this default effect is not likely to influence the results, since it is not clear why these two groups should be affected differently. 


\section{Incentives}

Workers received a 1-US dollar show-up fee and a bonus payment between 0 and 6 US dollar. The amount of the final bonus payment of workers was determined by the decision of the spectator they had been matched with.

Spectators' decisions did not have any monetary consequences for themselves.

\section{Procedures}

The experiment was conducted online and computer-based. Workers were recruited via Amazon Mechanical Turk (AMT). AMT is an international online market place on which workers can be hired anonymously to complete tasks online. Workers received the 1-US dollar show-up fee directly after completing the assignment. They received the bonus payment once we collected all responses from the spectators.

\subsubsection{Beliefs}

Subjects were posed the following question about the importance of different factors for success in life: "How important do you think are each of the following factors for getting ahead in life?" Thereby, they were asked about five factors in a randomized order: "How important is: a) Hard work; b) Being lucky; c) Being intelligent; d) Having connections; e) Coming from a wealthy family". ${ }^{141}$ In this chapter, we focus on the factors "Hard work" and "Being lucky", since these two factors correspond to those in the two experimental treatments. Subjects were asked to provide their answers on a scale from 1 to 7 , where 1 means "Not important at all" and 7 means "Very important".

\subsubsection{Source of wealth}

To determine how millionaires got rich we asked them the following question: "What was the main source of your household's wealth?". ${ }^{142}$ In total, 97 percent of our millionaire sample answered this question. Among them are 100 heirs, 66 whose main source of wealth is their salary, and 91 for whom it was income from self-employment. ${ }^{143}$ To validate our self-reported measure of subjects' main source of wealth, we first look at demographic data of subjects (see also Table 7 in Appendix E).

141 Dutch original question: "Hoe belangrijk zijn volgens $u$ de volgende factoren om vooruit te komen in het leven?": a) hard werken, b) geluk hebben, c) intelligent zijn, d) connecties hebben, e) uit een rijke familie komen. Answer categories: 1 "helemaal niet belangrijk" - 7 "zeer belangrijk".

142 Dutch original question: "Wat is de belangrijkste bron geweest voor het vermogen van uw huishouden?".

143 Beside the three categories mentioned in the text (inheritance, salary, own business) respondents could also select property, lottery, or other. Dutch original answer categories: Erfenis of familievermogen, inkomen uit loondienst, inkomen uit eigen bedrijf, onroerend goed, loterij, anders. 
We can see that heirs have on average a lower job prestige (SIOPS score (Ganzeboom and Treiman, 1996)) than employees. ${ }^{144,145}$ Furthermore, both entrepreneurs and employees are less likely to be female than heirs. ${ }^{146}$ Moreover, 69 percent of those who say their main source of wealth was their own business also say that they currently own their own company (see employment status in Table 7 in Appendix E). For comparison, among heirs this share is 16 percent and among employees 11 percent. Of those who got rich through their salary, 79 percent also indicate that they are employed at the moment. We further look at data from Statistics Netherlands who assess that 30 percent of working millionaires are entrepreneurs (CBS, 2017). In our study, this is true for 39 percent of working millionaires. Hence, altogether, we are confident that we have a valid measure of millionaires' main source of wealth.

\subsection{RESULTS}

\subsubsection{Sample characteristics}

Table 3 shows sample characteristics of the wealthy and subjects from the general population. Among the wealthy, there are fewer women, wealthy subjects are on average slightly older, and are a lot more likely to hold a university degree than subjects from the general population. Moreover, they are more likely to perceive their social status as high and hold jobs with a high prestige ${ }^{147}$ Because we recruited millionaires, they are a lot more likely to have a high income and high wealth. For an overview of sample characteristics of millionaires by source of wealth, see Table 7 in Appendix E.

144 Treiman's Standard International Occupational Prestige Scale (SIOPS) is a coding for job prestige based on occupational prestige polls and the International Standard Classification of Occupation 1988 (ISCO88), where the higher the score, the higher the prestige assigned to this job (Ganzeboom and Treimann, 1996). The lowest assigned value is 6 (ISCO category 6154: Hunters \& trappers [incl. whaler]), the highest is 78 (ISCO category 2310: Higher education teaching professionals [incl. university professor]). For our sample, a student assistant coded subjects' reported occupations acoording to ISCO88 and then assigned the respective SIOPS score according to Ganzeboom and Treimann (1996).

145 Results of Chi-squared tests: $\chi^{2}(1)=6.7051, p=.010$. This makes intuitive sense, since their job is not the major way in which heirs obtained their wealth, whereas for entrepreneurs this is the case. The difference between heirs and employees is (marginally) insignificant $\left(\chi^{2}(1)=\right.$ $1.7934, p=.181)$, whereas employees and entrepreneurs are very similar in their job prestige $\left(\chi^{2}(1)=0.0038, p=.951\right)$.

146 Female are less likely to be self-employed than men (Blanchflower, 2004). Results of Chisquared tests: Employees vs. heirs: $\chi^{2}(1)=3.1189, p=.077$; Entrepreneurs vs. heirs: $\chi^{2}(1)=$ $6.4665, p=.011$.

147 Non-parametric test results: female: $\chi^{2}(1)=9.7296, p=.002$; age: $t(514)=-8.0416, p<.0001$; university degree: $\chi^{2}(1)=161.2696, p<.001$; high social status: $\chi^{2}(1)=92.1715, p<.001$; $\chi^{2}(1)=30.9043, p<.001$. 
Table 3: Sample characteristics

\begin{tabular}{|c|c|c|c|c|}
\hline \multirow[b]{2}{*}{ Variable } & \multicolumn{2}{|c|}{ General population } & \multicolumn{2}{|c|}{ Wealthy } \\
\hline & $\%$ of sample & $\mathrm{N}$ & $\%$ of sample & $\mathrm{N}$ \\
\hline Female & 42.92 & 212 & 29.61 & 304 \\
\hline Age & $\begin{array}{c}51.24 \\
(16.08)^{\mathrm{a}}\end{array}$ & 212 & $\begin{array}{c}61.37 \\
(12.50)^{\mathrm{a}}\end{array}$ & 304 \\
\hline University degree & 8.49 & 212 & 64.47 & 304 \\
\hline Income & & 198 & & 253 \\
\hline low (€0-€49,999) & 56.56 & & 15.02 & \\
\hline middle $(€ 50,000-€ 99,999)$ & 36.87 & & 33.20 & \\
\hline high (more than $€ 100,000$ ) & 7.58 & & 51.78 & \\
\hline Wealth & & 190 & & 251 \\
\hline low $(€ 0-€ 9,999)$ & 40.53 & & & \\
\hline middle $(€ 10,000-€ 99,999)$ & 30.53 & & & \\
\hline high (more than $€ 100,000$ ) & 28.95 & & & \\
\hline low (€0-€1 million) & & & 24.30 & \\
\hline middle ( $€ 1$ million- $€ 5$ million) & & & 61.75 & \\
\hline high (more than $€ 5$ million) & & & 13.94 & \\
\hline High subjective social status ${ }^{b}$ & 59.69 & 196 & 94.81 & 289 \\
\hline High prestige jobc & 34.26 & 108 & 69.78 & 139 \\
\hline $\begin{array}{l}\text { Notes: Sample characteristics of } \\
\text { population. a Mean (standard devi } \\
\text { society, there are groups at the top } \\
\text { If } 1 \text { was the bottom and } 100 \text { the } \\
\text { scale?". }{ }^{148} \text { c Treiman's Standard } \\
\text { (SIOPS) (Ganzeboom and Treiman }\end{array}$ & $\begin{array}{l}\text { the wealthy a } \\
\text { ation); b Answe } \\
\text { and at the bot } \\
\text { top, where w }\end{array}$ & $\begin{array}{l}\mathrm{sub} \\
>50 \\
m \text { of } t\end{array}$ & $\begin{array}{l}\text { cts from the } \\
\text { the question: } \\
\text { e income distr } \\
\text { put yourself }\end{array}$ & $\begin{array}{l}\text { eneral } \\
\text { In our } \\
\text { ution. } \\
n \text { this }\end{array}$ \\
\hline
\end{tabular}

\subsubsection{Redistributional attitudes of the wealthy and subjects from the general population}

Figure 1 shows summary statistics of spectators' redistributional attitudes as measured by their political orientation, their attitude towards income inequality, and towards raising income and wealth taxes, respectively. We can see that for all four questions, millionaires' answers are significantly different from those of the general population. In particular, they are more inclined towards the political right, have a less favorable attitude towards equalizing incomes, and are less likely to support higher wealth and income taxes. Results from OLS regressions confirm our parametric results even when adding relevant demographic control variables (see Table 9 in Appendix G). Altogether, in our study, the wealthy are hence less supportive of redistribution than subjects from the general

148 Dutch original question: „In onze samenleving zijn er groepen aan de bovenkant en onderkant van de inkomensverdeling. Als 1 de onderkant is en 100 de top van de schaal, waar zou u zichzelf plaatsen op die schaal?“. 
population.

Figure 1: Redistributional attitudes

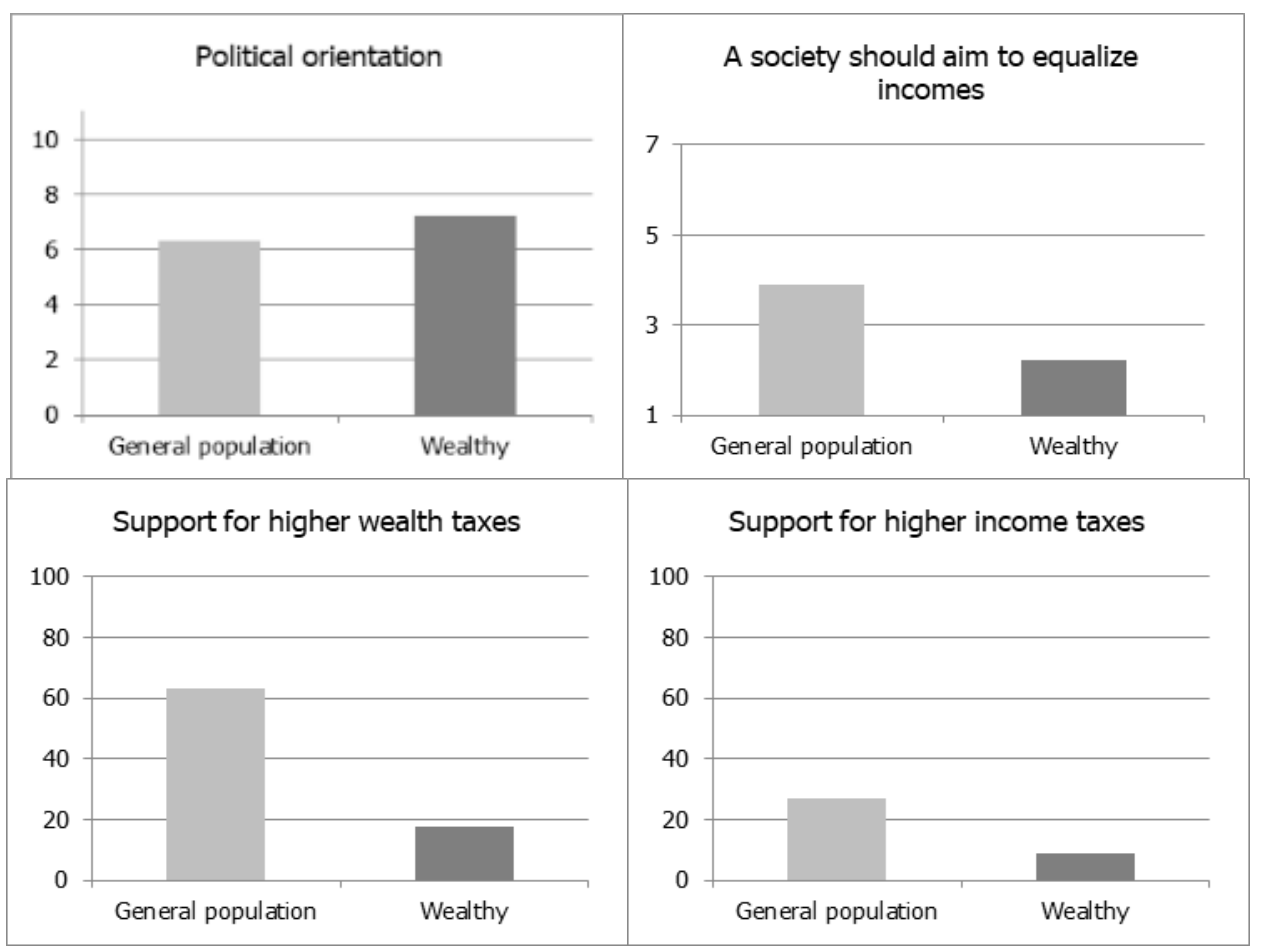

Notes: Mean answers by sample. Support for higher wealth/income tax: Percentage of sample who is in favor of a higher tax rate (answer 4: a bit higher tax rate or 5: a much higher tax rate). Differences between the general population and the wealthy are staistically significant in all measures of attitudes towards redistribution (political orientation: Wilcoxon-MannWhitney: $z=-4.480, p \leq .001$, income inequality: Wilcoxon-Mann-Whitney: $z=10.371, p \leq .001$, support for higher wealth (income) taxes: $\chi^{2}(1)=$ $\left.109.5985, p \leq .001\left(\chi^{2}(1)=30.1286, p \leq .001\right)\right)$.

\subsubsection{The role of preferences and beliefs}

\section{Preferences for redistribution}

Table 4 shows the number of spectators from each sample per treatment in the experiment.

Table 4: Number of spectators per sample and treatment

\begin{tabular}{lcc}
\hline & \multicolumn{2}{c}{ Treatment } \\
\hline Sample & Luck & Merit \\
\hline General population & 109 & 103 \\
Wealthy & 149 & 155 \\
\hline
\end{tabular}


Figure 2 depicts the mean implemented inequality in earnings between the two workers per treatment and sample. We can see that spectators from both samples implement on average a higher degree of inequality in the MERIT than in the LUCK treatment (Wilcoxon-Mann-Whitney: General population: $z=-10.699, p \leq .0001$, Wealthy: $z=-11.558, p \leq .0001)$. In other words, both groups of spectators are more inequality accepting if differences in initial earnings are due to luck rather than when they are due to individual merit (i.e., workers' performance in the task). These results are in line with previous findings in the literature (e.g., Frohlich et al., 2004; Cappelen et al., 2007; Almås et al., 2017).

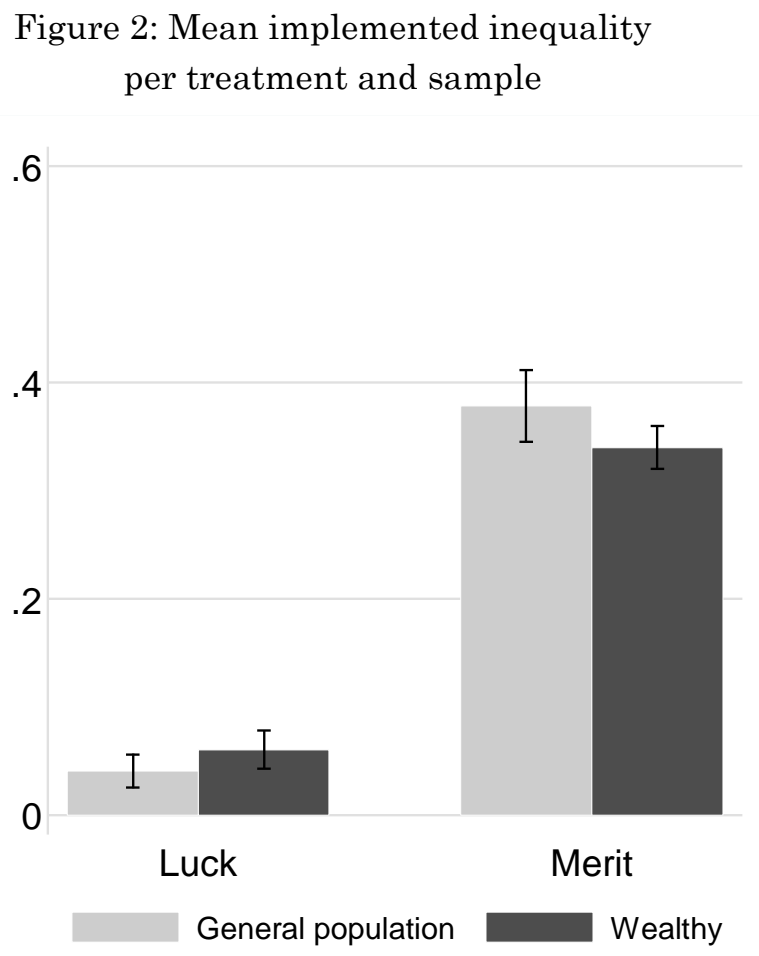

The novel result is that we do not find a difference in inequality acceptance across samples neither in the LUCK (Wilcoxon-Mann-Whitney: $z=-.140, p=.8888$ ) nor in the MERIT treatment (Wilcoxon-Mann-Whitney: $z=.345, p=.7299$ ). Interestingly, even the distributions of the inequality implemented by spectators of the different samples are remarkably similar (see Figure 9 in Appendix I) ${ }^{149}$.

Results of a series of OLS regressions with and without demographic control variables again confirm our non-parametric results and show that millionaires are not different from the general population in terms of their preferences for redistribution in neither treatment. Results of a pooled estimation across treatments with an interaction term for treatment and sample reveal that there is also no difference in the treatment effect

149 A pair of Kolmogorov-Smirnov tests reveals that the two distributions are not statistically different neither in the LUCK $(D=0.0348, p>.999)$, nor in the MERIT treatment $(D=$ $0.1130, p=.412$ ). 
between the two samples (see Table 11 in Appendix J).

\section{Beliefs about success in life}

Figure 3 depicts subjects' beliefs about success in life by sample. A pair of Wilcoxon-MannWhitney tests reveals that the wealthy attach a greater importance to working hard $(z=$ $-4.520, p \leq .0001)$ and less importance to being lucky $(z=1.879, p=.0603) .{ }^{150}$

Figure 3: Mean beliefs about success in life per sample

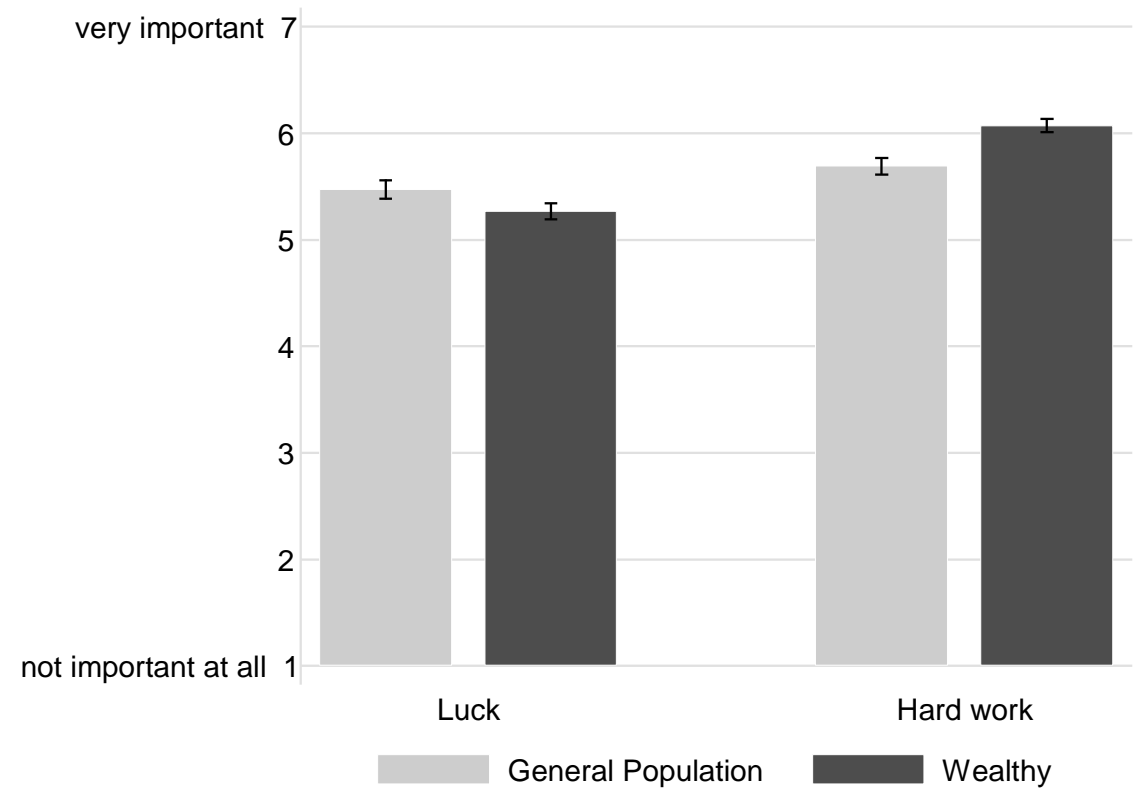

Notes: Mean and standard errors of subjects' answers to the two beliefs about success in life questions (Luck / Hard work) by sample.

\section{Predicting differences in redistributional attitudes}

We use a detailed Blinder-Oaxaca decomposition (Oaxaca, 1973; Blinder, 1973; Jann, 2008) in order to examine how much of the difference in redistributional attitudes between the wealthy and the general population is due to differences in preferences for redistribution, or participants' beliefs about the importance of hard work and luck, respectively. The (mean) difference in redistributional attitude

$$
l \in\{\text { political orientation, income inequality, wealth tax, income tax }\})
$$

can be decomposed as follows:

$$
\Delta_{l}=\left\{E\left(e_{G}\right)-E\left(e_{W}\right)\right\}^{\prime} \beta^{*}+\left\{E\left(e_{G}\right)^{\prime}\left(\beta_{G}-\beta^{*}\right)+E\left(e_{W}\right)^{\prime}\left(\beta^{*}-\beta_{W}\right)\right\},
$$

where $E\left(e_{G}\right)$ is the expected value of the income inequality implemented by the general

150 A series of OLS regressions with and without demographic controls confirm these nonparametric results (see Table 10 in Appendix H). 
population, $E\left(e_{W}\right)$ is the expected value of the income inequality implemented by the wealthy, $\beta_{G}$ and $\beta_{W}$ the coefficient of the general population and the wealthy, respectively, and $\beta^{*}$ is a nondiscriminatory coefficient vector. The first summand is the part of the difference in redistributional attitude $l$ that is due to differences in the predictor variables (i.e., the explained part of the difference), and the second summand is the part that is due to differences in observed differences between the two groups. Since we are interested in the contribution of the single predictors (i.e., implemented inequality, beliefs in the importance of hard work and luck, respectively), we estimate a detailed decomposition model with the total of the explained part being the sum of the contributions of each single predictor. We estimate $\beta^{*}$ from a pooled model with a group indicator (Jann, 2008). ${ }^{151}$

We find that the difference in the importance attached to hard work accounts for a vast majority of the explained part of the outcome differences between the wealthy and the general population in all measures of redistributional attitudes (see Table 5). For political orientation, for example, the wealthy attaching a greater importance to hard work accounts for about 85 percent of the explained part of the gap in political attitude. The contribution to the difference in political orientation and attitudes towards income inequality is statistically significant, while the contribution to the difference in attitudes towards increasing income taxes is marginally insignificant. The difference between the wealthy and the general population in the importance attached to luck or their preference for redistribution does not seem to be important for explaining the outcome differences in any measure of redistributional attitudes. Overall, the differences in preferences and beliefs account for about 17 percent of the difference in political orientation, and for 6 percent of the difference in attitudes towards income inequality. Furthermore, when looking at the prediction regressions per sample, we see that both choices in the experiment and beliefs in hard work can generally predict redistributional attitudes of millionaires, but not of the general population (see Table 12 in Appendix K). We hence partly confirm findings on the impact of preferences and beliefs on attitudes towards redistribution (e.g., Almås et al., 2017; Fong, 2001). However, it is only for beliefs about the importance of hard work that the difference between the wealthy and the general population can explain differences in redistributional attitudes between the two groups. Our results thus add to the literature on the importance of beliefs in predicting attitudes towards redistribution in the field (Fong, 2001; Alesina et al., 2001; Corneo and Grüner, 2002) and offer one possible explanation for why richer people are found to have a less favorable attitude towards redistribution (e.g., Alesina and Guiliano, 2009; Alesina and Ferrera, 2005; Piketty, 1995; Norton and Ariely; 2011; Fong, 2001).

To summarize, we see that millionaires and subjects from the general population

151 Results are also qualitatively robust to specifications of the model from the viewpoint of either group instead of using the nondiscriminatory coefficient vector $\beta^{*}$, with the exception that when estimating the model from the viewpoint of the wealthy, also the contribution of the belief about hard work to the difference in attitudes towards the wealth tax becomes significant, and when estimating the model from the viewpoint of the general population, the contribution of the belief about luck (instead of the belief about hard work) to the difference in attitudes towards income inequality becomes significant. 
display remarkably similar preference for redistribution in the experiment, in which we control for beliefs about the role of luck and effort. Due to differences in these beliefs, however, preferences translate into different redistributional attitudes in the field. In particular, millionaires attach a greater importance to hard work and, therefore, express less support for, for instance, equalizing incomes.

Table 5: Differences in redistributional attitudes

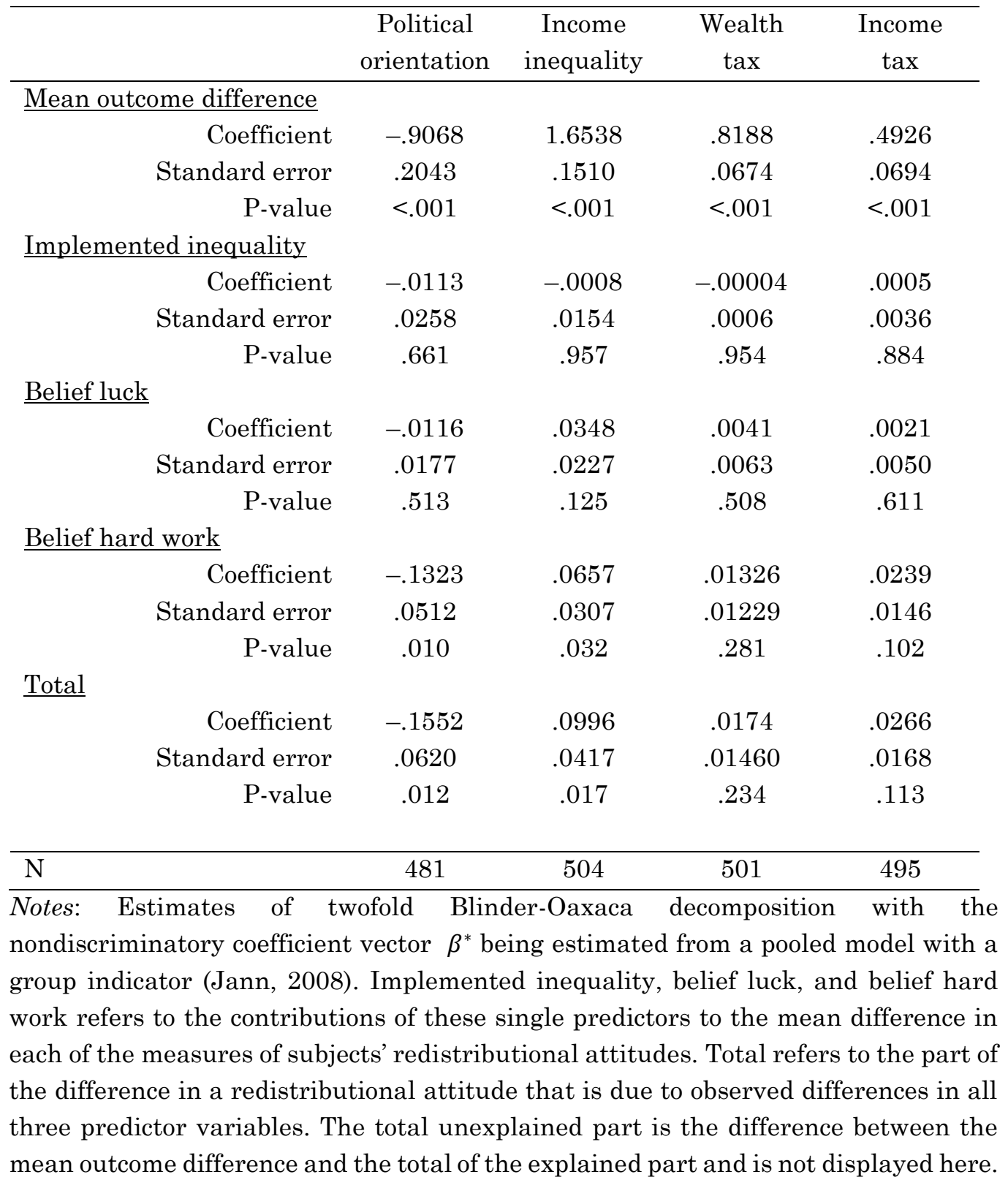

\subsubsection{Source of wealth}

Figure 4 depicts millionaires' mean belief about the importance of luck and hard work for success in life by source of wealth. A pair of Wilcoxon-Mann-Whitney tests reveals that heirs indeed attach less importance to hard work than employees $(z=-2.288, p=.0221)$ 
and entrepreneurs $(z=-2.841, p=.0045) .{ }^{152}$ While the latter is also confirmed by OLS regressions (also when adding demographic control variables), the former is not (see Table 13 in Appendix L). There is no difference between either of the groups of millionaires in the importance they attach to luck for getting ahead in life. ${ }^{153}$

Interestingly, our results reveal that in terms of redistributional attitudes as well as preferences for redistribution, entrepreneurs are the group that differs from the rest of millionaires. In particular, they favor less redistribution than the other two groups of millionaires, both in and outside the experiment. In comparison to heirs and employees, respectively, entrepreneurs are oriented more towards the political right and less likely to support higher wealth taxes. They are also less supportive of decreasing income inequality than heirs (see Figure 5). ${ }^{154}$ In the experiment, entrepreneurs are more inequality accepting than heirs both in the LUCK $(z=-1.770, p=.0767)$ and in the MERIT treatment $(z=-2.712, p=.0067)$, and than employees in the MERIT treatment $(z=$ $-1.700, p=.0892$ ) (see also Figure 6). ${ }^{155}$ Heirs and employees, on the contrary, are statistically indistinguishable both in their redistributional attitudes, as well as in the level of inequality they implement between the two workers in either treatment of the experiment. ${ }^{156}$ All results are largely confirmed by OLS estimates with and without demographic control variables (see Table 15 and 16 in Appendix $\mathrm{N}$ and $\mathrm{O}$ ).

152 There is no difference between employees and entrepreneurs in the importance they attach to hard work: $z=-0.128, p=.8983$.

153 Results of Wilcoxon-Mann-Whitney tests: Heirs vs. employees: $z=-7.05, p=.4810$; Heirs vs. entrepreneurs: $z=-0.693, p=.4881$; Employees vs. entrepreneurs: $z=0.051, p=.9591$.

154 Political orientation (Wilcoxon-Mann-Whitney tests): Entrepreneurs vs. heirs: $z=-3.485, p=$ .0005 ; entrepreneurs vs. employees: $z=-1.951, p=.0510$. Wealth tax (Chi-squared tests): Entrepreneurs vs. heirs: $\chi^{2}(1)=6.9081, p=.009$; entrepreneurs vs. employees: $\chi^{2}(1)=$ $5.1512, p=.023$. Income inequality (Wilcoxon-Mann-Whitney tests): Entrepreneurs vs. heirs: $z=2.055, p=.0399$; entrepreneurs vs. employees: $z=0.947, p=.3439$. Income tax (Chisquared tests): Entrepreneurs vs. heirs: $\chi^{2}(1)=0.0937, p=.759$; entrepreneurs vs. employees: $\chi^{2}(1)=0.3953, p=.530$.

155 For an overview of the number of millionaires by source of wealth and treatment, see Table 14 in Appendix M.

156 Redistributional attitudes: Results of Wilcoxon-Mann-Whitney tests: Political orientation: $z=$ $-1.352, p=.1762$; Income inequality: $z=0.924, p=.3555$. Results of Chi-squared tests: Wealth tax: $\chi^{2}(1)=0.0283, p=.866$; Income tax: $\chi^{2}(1)=0.8165, p=.366$. Implemented inequality: Results of Wilcoxon-Mann-Whitney tests: LUCK: $z=-1.033, p=.3015$; MERIT: $z=$ $-0.928, p=.3534$. 
Figure 4: Mean beliefs about success in life by source of wealth

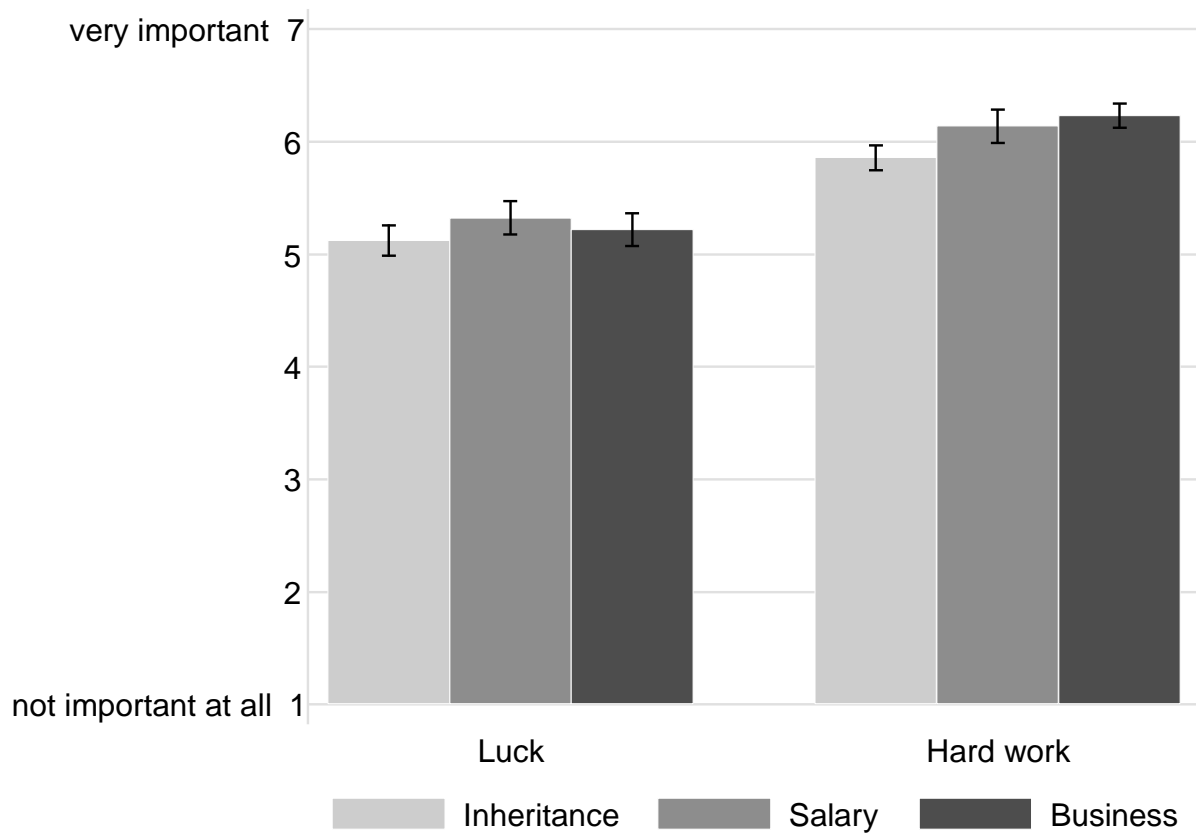

Notes: Mean and standard errors of millionaires' answers to the two beliefs about success in life questions (Luck/Hard work) by source of wealth.

Figure 5: Redistributional attitudes by source of wealth

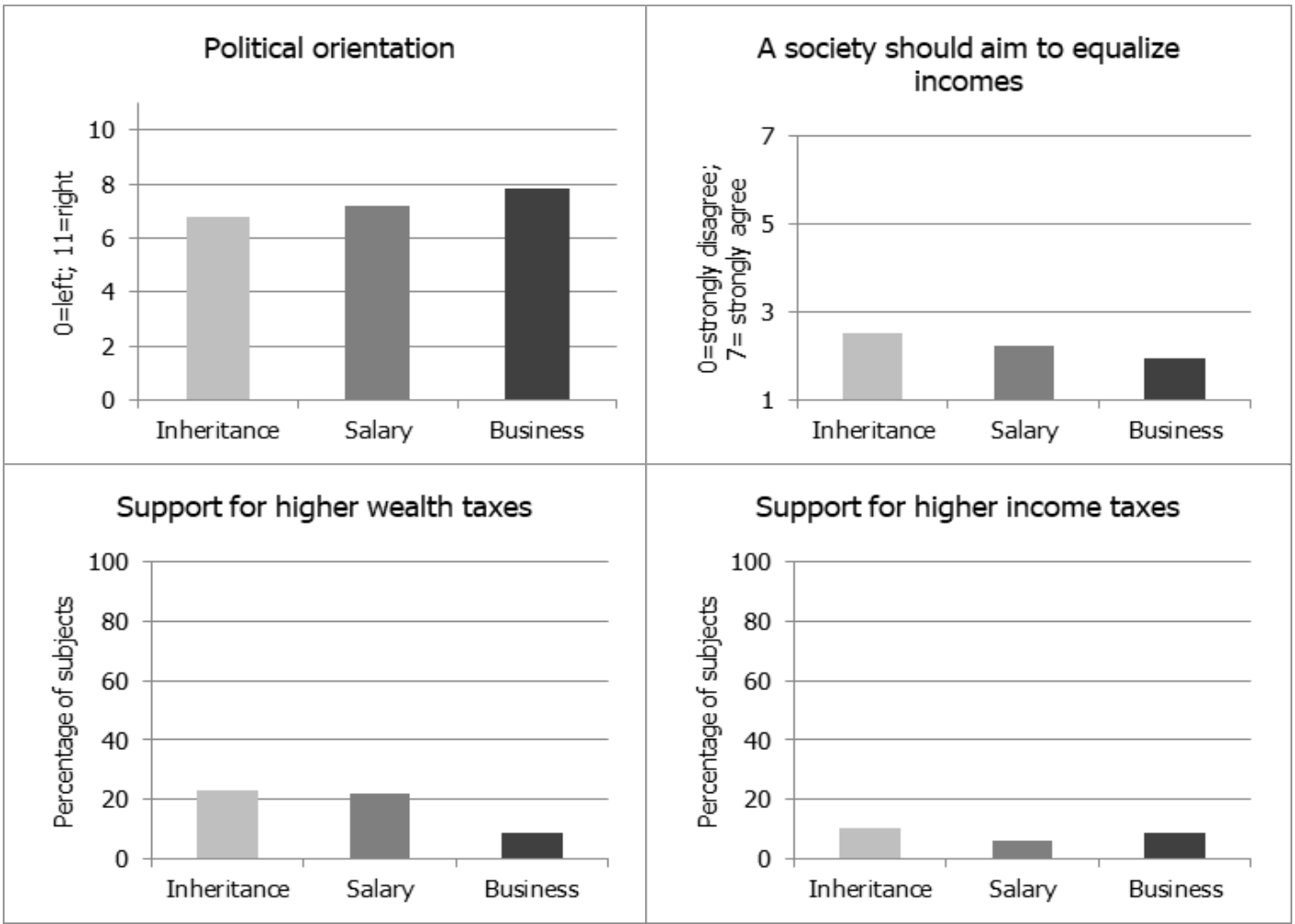

Notes: Mean answers of millionaires by source of wealth. Support for higher wealth/income tax: Percentage of sample who is in favor of a higher tax rate (answer 4: a bit higher tax rate or 5: a much higher tax rate). 
Figure 6: Mean implemented inequality by source of wealth

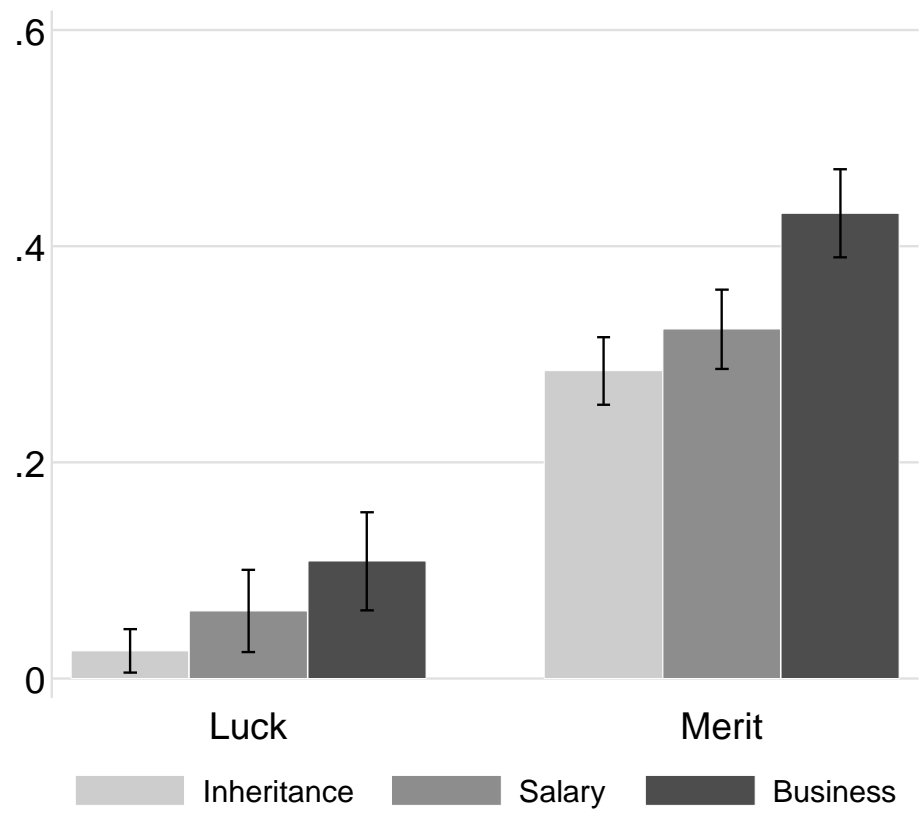

Notes: Mean and standard errors of implemented inequality by millionaires in the experiment by source of wealth.

One plausible explanation for the otherness of entrepreneurs is that they are more likely to have been confronted with merit considerations in their professional life. ${ }^{157} \mathrm{As}$ business owners, they are likely to have had experience with evaluating workers' performance, effort related payment, or determining payment schemes in order to increase workers' performance. These experiences might bias them towards favoring rewarding individual effort and thus having a less positive attitude towards redistribution. In our sample, 55 percent of entrepreneurs are a CEO (ISCO code 1210) or general manager (ISCO code 1310). ${ }^{158}$ For heirs and employees, this share is only 16 and 27 percent, respectively. These differences are statistically significant (entrepreneurs vs. heirs $\left(\chi^{2}(1)=15.3538, p<.001\right)$; entrepreneurs vs. employees $\left.\left(\chi^{2}(1)=5.4427, p=.020\right)\right)$. Among the wealthy, we also see that CEOs and general managers are less in favor of redistribution in three of our four measures of redistributional attitudes. ${ }^{159}$ They also

157 Other possible explanations are that entrepreneurs differ, for example, in personality traits that might be related to redistribution.

158 Those who are not a CEO or general manager are, for example, other managers (e.g., "production department managers business services [incl. banker, bank manager]" (ISCO code 1227)), "dentists" (ISCO code: 2222), "accountants" (ISCO code: 2411) or "business professionals [incl. publicity agent, patent agent, home economist, market researcher]" (ISCO code: 2419$)$.

159 Results of Wilcoxon-Mann-Whitney tests: Political orientation: $z=-3.604, p=.0003$; Income inequality: $z=1.857, p=.0633$. Results of Chi-squared tests: Wealth tax: $\chi^{2}(1)=4.1309, p=$ .043 ; Income tax: $\chi^{2}(1)=.0350, p=.852$. These results are qualitatively similar when we look at the whole sample. 
implement a higher payment inequality between the two workers in the MERIT treatment. This difference is, however, not statistically significant. ${ }^{160}$ Entrepreneurs also desire a much higher inequality between earnings of different professions, such as a chairman of a company and an unskilled worker, both than heirs and employees (see Figure 7). In particular, when asked about how much they think (1) a chairman of a large company, (2) a congress member, (3) an elementary school teacher, and (4) an unskilled worker should earn, they, on average, desire a higher inequality (as measured in the Gini index of the desired earnings) than heirs $(t(189)=-2.1170, p=.0356)$ and employees $(t(154)=-1.7891, p=.0756) .{ }^{161,162}$ Again, heirs and employees, however, are statistically indistinguishable both in the share of managers among them $\left(\chi^{2}(1)=1.2391, p=.266\right)$, as well as in the desired earnings inequality $(t(163)=-0.2343, p=.8150)$.

Overall, these results thus partly support the conjecture that experience in (upward) social mobility is a driver of differences in beliefs between millionaires and subjects from the general population (Piketty, 1995). We show that also among millionaires, those who have experienced social mobility believe more strongly in hard work than those who have not. This difference in beliefs translates, however, not necessarily into differences in redistributional attitudes. Further, in terms of the importance attached to luck, heirs are not different from other types of millionaires, suggesting that this very difference we find between millionaires and people from the general population might be due to an increased incentive of millionaires to develop a narrative in order to keep a positive self-image. Moreover, being confronted with merit considerations in professional life might be an important channel for shaping preferences for and attitudes towards redistribution.

160 Wilcoxon-Mann-Whitney: $z=-1.446, p=.1481$. In the LUCK treatment, they even implement lower inequality, again the difference not being statistically significant: Wilcoxon-MannWhitney: $z=.537, p=.5916$. These results are again qualitatively similar when we look at the whole sample.

161 The Gini index was calculated using the fastgini command in Stata (Sajaia, 2007).

162 On average, entrepreneurs would desire earnings that amount to a Gini index of 0.62 , heirs of 0.55 , and employees of 0.56 . Note that this computed Gini index is not directly comparable to the actual Gini index in the Netherlands, since we only use (desired) earnings for four occupations assuming the latter are equally distributed in the society. 
Figure 7: Gini index of desired earnings by source of wealth

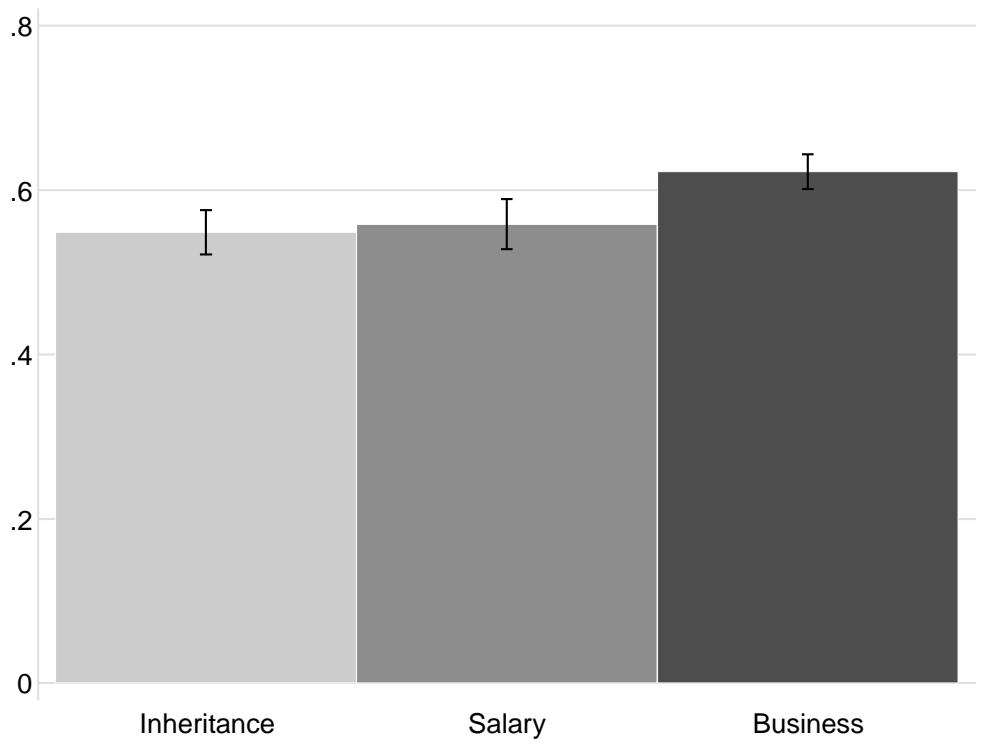

Notes: Gini index computed from what millionaires think how much (1) a chairman of a large company, (2) a congress member, (3) an elementary school teacher, and (4) an unskilled worker should earn.

Our findings from the heterogeneity analysis regarding millionaires' source of wealth further add to the experimental research on entrepreneurs. This literature reveals that (small scale) entrepreneurs are different in important ways. They are different in terms of their preference, for instance, they are less risk averse (Stewart Jr. and Roth, 2001; Elston et al., 2005) and are more patient (Andersen et al., 2014) than others. ${ }^{163}$ Further, they differ from the rest of the population in terms of their beliefs about their own chances of success (overconfidence) (Busenitz and Barney, 1997). Finally, and most closely related to our research, Lee-Ross (2015) finds that entrepreneurs are more likely to view it as less unfair to reward individual performance both than employees and the general population. ${ }^{164}$ Our findings show that also among the wealthy, there exist important differences in economic preferences, beliefs, and attitudes between (successful) entrepreneurs on the one side, and heirs and employees on the other side.

\subsection{CONCLUDING REMARKS}

This chapter confirms that the wealthy have a substantially less favorable attitude towards redistribution than people from the general population as measured by their political orientation, their general attitude towards income inequality, and their attitudes towards raising taxes on income or wealth. Our results suggest that these differences are

163 Andersen et al. (2014), however, find no difference in risk preferences between small business entrepreneurs and the general population.

164 Lee-Ross (2015) asks participants to indicate whether they find the following fair or unfair: "Two secretaries doing same job but one earns more than other but is better at job". 
not due to differences in preferences for redistribution, but rather disparities in beliefs in the importance of hard work for success in life. Assessing the relation between a millionaire's source of wealth and her beliefs suggests that these disparities between millionaires and subjects from the general population in beliefs about the role of hard work stem from differences in actual experienced social mobility.

On the one hand, some studies argue that the rich are more selfish than other groups in society. Piff et al. (2010), for example, find that individuals from a higher social class give more in a dictator game and think that a lower share of people's income should be spent on charitable donations as compared to lower class individuals. ${ }^{165,166}$ Alstadsæter et al. (2018) show that the rich are more likely to engage in tax evasion. Fisman et al. (2015) find that a (future) political elite in the US puts a higher weight on efficiency as opposed to equality and behaves less fair-mindedly in an experiment than the US general public. ${ }^{167}$ On the other hand, Korndörfer et al. (2015) show that people from a higher social class give a higher percentage of their family income to a charitable cause and are more helpful. ${ }^{168}$ In Andreoni et al. (2017), the rich are twice as likely to return misdelivered envelopes as the poor. However, once the authors control for "pressures associated with poverty and the marginal utility of money" (p.1), there is no difference in prosocial behavior. Smeets et al. (2015) find that millionaires give substantially more than subjects usually give in a dictator game when matched to another subject with low income. In a recent study, Smeets et al. (2018) show that even though millionaires have approximately the same amount of time available for leisure as subjects from the general population, they spend more of this time volunteering than the latter. Evidence on the differences in selfishness between wealthier people and the rest of the population is thus mixed. Thereby, the findings clearly depend on the design of the study, for example, on the relative stakes involved for the different parties. ${ }^{169}$

It could come to mind that - if the rich were more selfish than people from the general population, then millionaires in our sample could be more reluctant to redistribution because they are less willing to have their income or wealth taxed in order to finance redistribution. Such an argument neglects the fact that richer people have higher stakes in redistribution policies. In other words, the price for acting non-selfishly is higher for them than for people from the general population. ${ }^{170}$ For example, increasing the wealth

165 In the former, social class was measured by subjective socioeconomic status, while in the latter relative social class was induced by manipulating subjects' perceived social rank.

166 A large scale replication study with 2.5 times the original sample size fails to replicate the findings (Jung et al., 2018).

167 Subjects of the (future) political elite sample are students of Juris Doctor (J.D.) at Yale Law School. Results even hold when controlling for age, gender, and education level.

168 The authors use subjects' income, education and occupational prestige score to construct an objective measure of social class. Being helpful is a self-reported measure of how often subjects' had engaged in everyday social deeds in the last 12 months, such as giving food or money to a homeless person, or offering their seat in the bus to a stranger (Korndörfer et al., 2015).

169 Korndörfer et al. (2015) further find an influence of the measure of social class, the type of prosocial behavior, and the country in which the study was conducted.

170 In line with Chapter II to IV of this thesis, we assume that people carry both self-interest 
tax in the Netherlands from $1.2 \%$ to $2 \%$, a person with 1 million Euros in her bank account would have to pay 8,000 Euros more in taxes per year, while for someone with 30,000 Euros, it would only be 240 Euros. A person who has less than 21,000 Euros is even exempt from paying wealth taxes in the Netherlands. Hence, even if rich people and people from the general population are equally selfish, differences in stakes could cause them to be less in favor of redistribution in the field. Note that in the experiment, however, there are no monetary stakes involved for neither group, since their decision does not affect their own payoff.

Nevertheless, if millionaires were indeed more self-interested than people from the general population, this could further augment the difference between the two groups in their attitudes towards redistribution in the field. We use a validated survey measure to assess subjects' altruism (Falk et al., 2016). We find that in our study, the wealthy are even more altruistic than the general population according to this measure. Increased selfishness of millionaires is thus unlikely to be a driver behind the observed differences in attitudes towards redistribution in our study. If anything, it could have decreased this difference.

and (different) social motives inside them which they trade off against each other. People can thus display different degrees of self-interest and other regarding behavior. 


\subsection{APPENDIX}

\section{A Redistributional attitudes: Dutch original questions}

Table 6: Questions on redistributional attitudes in Dutch (original)

\begin{tabular}{|c|c|}
\hline Question & Scale \\
\hline $\begin{array}{l}\text { (i) Political orientation } \\
\text { In de politiek spreekt men vaak over links en rechts. } \\
\text { Waar zou u uzelf omschrijven op een schaal van } 0 \\
\text { tot } 10 \text { waar } 0 \text { betekent links en } 10 \text { betekent rechts? }\end{array}$ & $\begin{array}{l}0: \text { links - } \\
10: \text { rechts }\end{array}$ \\
\hline $\begin{array}{l}\text { (ii) Income inequality } \\
\text { Een samenleving zou er naar moeten streven om } \\
\text { inkomens gelijk te maken. }\end{array}$ & $\begin{array}{l}\text { 1: helemaal oneens - } \\
\text { 7: helemaal eens }\end{array}$ \\
\hline (iii) Taxes & \\
\hline $\begin{array}{l}\frac{\text { Wealth tax }}{\text { Momenteel betaalt iedere Nederlander } 1,2 \%} \\
\text { belasting op vermogen boven } 21.000 \text { euro. Naar uw } \\
\text { mening, zouden mensen met een vermogen boven } 1 \\
\text { miljoen euro een lager, hetzelfde of een hoger } \\
\text { percentage belasting moeten betalen? }\end{array}$ & $\begin{array}{l}\text { 1: Een veel lager percentage belasting; } \\
\text { 2: Een lager percentage belasting; } \\
\text { 3: Hetzelfde percentage belasting; } \\
\text { 4: Een hoger percentage belasting; } \\
\text { 5: Een veel hoger percentage belasting }\end{array}$ \\
\hline $\begin{array}{l}\text { Income tax } \\
\text { Het marginale belastingpercentage voor jaarlijks } \\
\text { inkomen boven } 57.585 \text { euro is momenteel } 52 \% \text {. } \\
\text { Naar uw mening, zou dit belastingpercentage voor } \\
\text { mensen met een inkomen boven } 57.585 \text { euro lager } \\
\text { moeten zijn, hetzelfde of hoger? }\end{array}$ & $\begin{array}{l}\text { 1: Een veel lager percentage belasting; } \\
\text { 2: Een lager percentage belasting; } \\
\text { 3: Hetzelfde percentage belasting; } \\
\text { 4: Een hoger percentage belasting; } \\
\text { 5: Een veel hoger percentage belasting }\end{array}$ \\
\hline
\end{tabular}




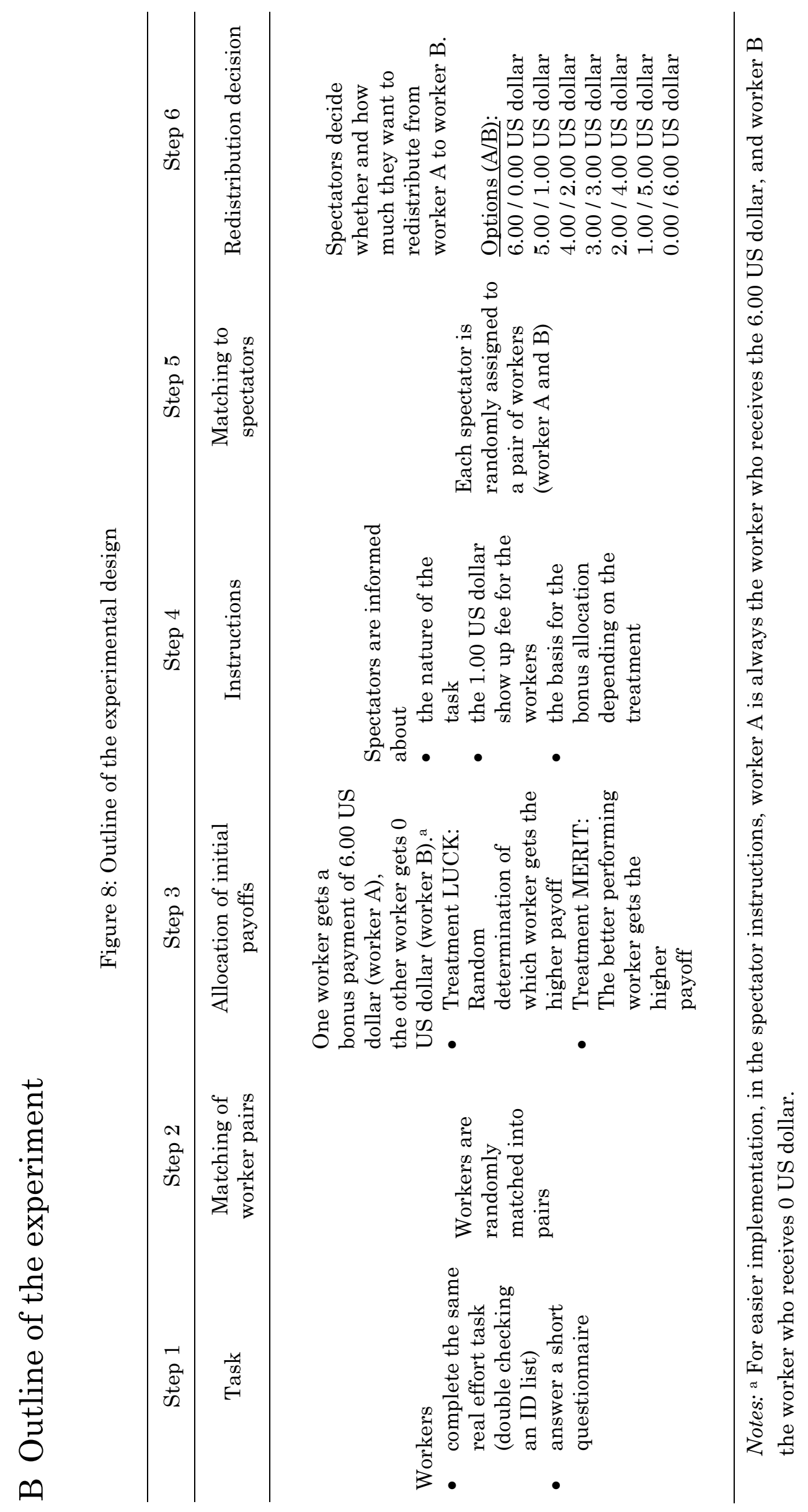




\section{Worker instructions}

\section{Before accepting the HIT (information about the HIT on mturk)}

Title: Checking digitized entries from a list of ID numbers

Description: This HIT consists of double checking digitized entries from a list of ID numbers, followed by a short questionnaire.

Payment: $\$ 1.00$

Expected time: 10 minutes

\section{After accepting the HIT (Qualtrics)}

\section{Screen 0}

Welcome!

We are researchers at the University of Maastricht and are hiring workers for a simple work assignment. The assignment consists of double checking digitized entries from a list of ID numbers. The work assignment is followed by a short questionnaire. None of the questions will involve sensitive topics.

\section{DURATION:}

The work assignment takes exactly 5 minutes to complete, not including the time for reading the task instructions and completing the questionnaire. Overall, it should take 10 minutes or less to complete the HIT.

\section{COMPENSATION:}

You will receive $\$ 1.00$ for your participation. You have to complete the work assignment and questionnaire to qualify for payment. You will receive a secret key after the questionnaire that will allow you to complete the HIT on Amazon Mechanical Turk.

\section{CONFIDENTIALITY:}

We will not reveal any personally identifying information about you.

Please indicate, in the box below, that you have read and understand this consent form.

$\mathrm{X} \quad \mathrm{I}$ have read the consent form and agree to participate in this task.

\section{Screen 1}

\section{Instructions:}

We are hiring workers to double check digitized entries from a list of ID numbers.

Your task is to check as many entries as possible and to correct any mistakes you find. 
You will have exactly 5 minutes to work on this task.

On the next screens you will first see an example of how to perform the task, and then we will give you a short practice task to make sure you understand the assignment. The 5 -minute working period starts once you have completed the practice task.

\section{Screen 2}

Example:

This is an example of how to perform the task. You do not have to fill in anything yet.

\begin{tabular}{|c|c|c|}
\hline & & $\begin{array}{l}\text { Enter the correct ID number here } \\
\text { if the digitized entry is incorrect } \\
\text { (leave empty if correct) }\end{array}$ \\
\hline 3701525725 & BF01525725 & \\
\hline$V \neq 09854617$ & VZO99854617 & \\
\hline$\angle F 35018070$ & LF35818979 & \\
\hline
\end{tabular}

On the left hand side you see a list of handwritten ID numbers that have been digitized.

Your task will be to detect mistakes and to correct them. If a digitized entry is incorrect, fill in the correct ID number from the handwritten list in the corresponding field. If the entry is correct, leave the corresponding field empty. ID numbers always start with 2 capital letters, followed by 8 numbers.

In the above example, only the last ID is not digitized correctly. On the next screen you will see how you should fill out this table. 
Screen 3

Example (with solution):

\begin{tabular}{|c|c|c|}
\hline & & $\begin{array}{l}\text { Enter the correct ID number here } \\
\text { if the digitized entry is incorrect } \\
\text { (leave empty if correct) }\end{array}$ \\
\hline 3701525725 & BF01525725 & \\
\hline$V \neq 09854617$ & VZ09854617 & \\
\hline$\angle F 35018070$ & LF35818979 & LF35018070 \\
\hline
\end{tabular}

\section{Screen 4}

\section{Practice Task:}

This is a practice task.

For each row, please check whether the digitized entry is correct. If it is incorrect, fill in the correct ID number from the handwritten list in the corresponding field. If the entry is correct, leave the corresponding field empty. Remember, ID numbers always start with 2 capital letters, followed by 8 numbers.

\begin{tabular}{|c|c|c|}
\hline & & $\begin{array}{l}\text { Enter the correct ID number here } \\
\text { if the digitized entry is incorrect } \\
\text { (leave empty if correct) }\end{array}$ \\
\hline 7534761217 & JS34761217 & \\
\hline $0 Q 53623846$ & OQ53623846 & \\
\hline FLO 02404329 & JL02404339 & \\
\hline
\end{tabular}

If a worker did not complete the task correctly, the following error message is displayed:

"Your answer is not correct. Please read the instructions carefully and try again."

If a worker completes the task correctly, she or he can go on to Screen 5.

\section{Screen 5}

You have successfully completed the practice task. Now you can proceed to the work assignment. 
The 5-minute working period will start once you continue to the next screen.

\section{Screen 6}

Countdown timer starting at 5 minutes at the top of the screen.

Work Assignment:

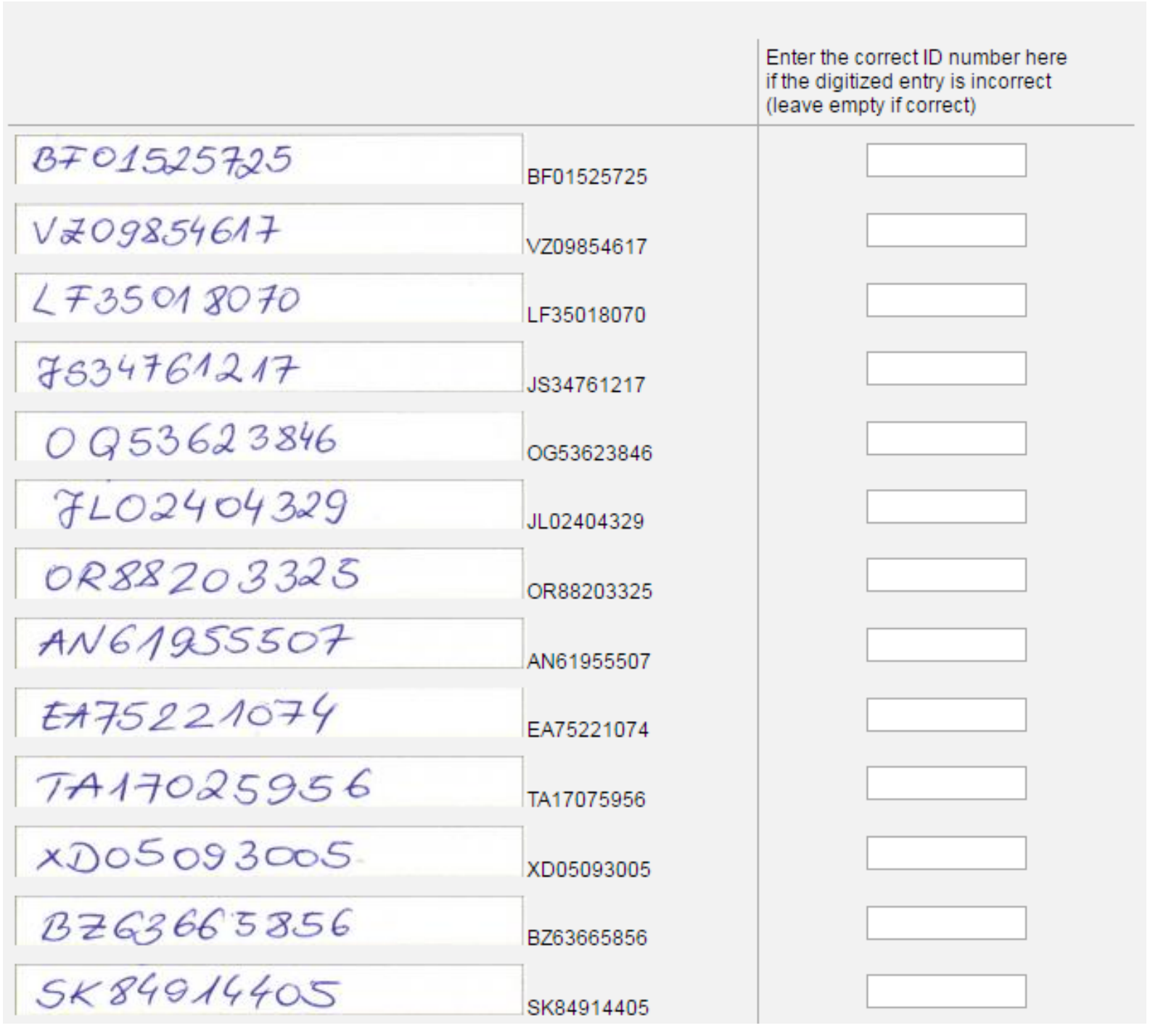

Screen 7

The 5-minute working period is over.

Finally, please provide us with some basic information about yourself. 
Q1 What is your age?

Q2 What is your gender?

- Male (1)

- Female (2)

Q3 What is the primary ethnicity or race you identify with?

- Asian/Asian American (1)

- Black/African American (2)

- White/European American (3)

- Hispanic/Latino (4)

- Other (5)

Q4 Which category best describes your highest level of education?

- High school/GED or less (1)

- Some college (2)

- College degree (3)

- Master's or professional degree (for example: JD, MD, MBA) (4)

- Doctoral degree (5)

Q5 What is your current employment status?

- Full-time employee (1)

- Part-time employee (2)

- Self-employed or small business owner (3)

- Unemployed and looking for work (4)

- Student (5)

- Not in labor force (for example: retired, or full-time parent) (6)

Q6 What is your household income compared to the average household income in your country?

- Much lower than average income1 (1)

- $2(2)$

- $3(3)$

- $4(4)$

- $5(5)$

- $6(6)$

- Much higher than average income7 (7)

Q7 In general, to what extent are you politically liberal or conservative?

- Very liberal 1 (1)

- $2(2)$

- $3(3)$

- $4(4)$

- $5(5)$

- $6(6)$ 
- $\quad$ Very conservative7 (7)

Final Screen

Thank you for completing the HIT!

Your secret key is: $\mathrm{XX}$

Please copy the key and paste it into AMT before you close this window. If the key you entered is correct, you will receive a payment of US $\$ 1.00$.

\section{Treatment 1: LUCK}

\section{Bonus Payment:}

You may receive a bonus payment for completing the work assignment. Whether or not you will receive any additional money depends on the decision made by a participant of an ongoing research study.

You will be matched to another worker who completed the same assignment. The size of the bonus payment for you and the other worker is determined by chance:

- The worker who is chosen by chance earns US $\$ \mathbf{6 . 0 0}$ for the assignment.

- The other worker earns nothing for the assignment.

A third person will be informed about which worker receives the bonus payment and then gets the opportunity to redistribute the earnings between you and the other worker. This person can choose to redistribute any amount in $\$ 1.00$ steps (for example $\$ 5.00 / \$ 1.00, \$ 4.00 / \$ 2.00$ etc.). He or she can also choose to redistribute the whole amount or no money at all. We will not reveal any personally identifying information about you to this third person.

You will receive the bonus payment once all workers have completed the assignment and the third person has made a decision. This can take a few weeks.

Thank you for your participation!

\section{Treatment 2: MERIT}

\section{Bonus Payment:}

You may receive a bonus payment for completing the work assignment. Whether or not you will receive any additional money depends on the decision made by a participant of an ongoing research study. 
You will be matched to another worker who completed the same assignment. The size of the bonus payment of you and the other worker is determined by your performance on the task:

- The worker who performs better on the work assignment earns US $\$ \mathbf{6 . 0 0}$ for the assignment.

- The other worker earns nothing for the assignment.

A third person will be informed about which worker performed better and receives the bonus payment and then gets the opportunity to redistribute the earnings between you and the other worker. This person can choose to redistribute any amount in $\$ 1.00$ steps (for example $\$ 5.00 / \$ 1.00, \$ 4.00 / \$ 2.00$ etc.). He or she can also choose to redistribute the whole amount or no money at all. We will not reveal any personally identifying information about you to this third person.

You will receive the bonus payment once all workers have completed the assignment and the third person has made a decision. This can take a few weeks.

Thank you for your participation!

\section{Spectator instructions}

\section{D.1 Dutch original text}

Zo meteen start het wetenschappelijk keuze-experiment. Dit is interactief met andere deelnemers aan het onderzoek. Het geeft inzicht in de manier waarop u financiële en maatschappelijke beslissingen neemt.

U kunt uw keuzes op een later tijdstip vergelijken met die van anderen, via www.paulsmeets.eu.

Het experiment duurt ongeveer $\underline{5 \text { minuten. }}$

\section{Treatment 1: LUCK}

In tegenstelling tot de andere vragen in deze vragenlijst gaat $\mathrm{u}$ nu een keuze maken die een invloed heeft op de uitbetaling aan andere mensen. We vragen u daarom de instructies goed door te lezen.

Recent hebben we via een internationaal online platform twee mensen ingehuurd om een taak te vervullen. Laten we hen Werker A en Werker B noemen. De taak was voor beiden gelijk en bestond uit het handmatig controleren van ID-nummers van deelnemers. Als vergoeding voor hun deelname ontvingen beide werkers $\$ 1$, ongeacht 
hun eventuele verdienste voor de taak.

Nadat ze de taak hadden afgerond, hebben we de werkers verteld dat hun verdiensten voor de taak bepaald worden door toeval:

- De werker die door toeval is gekozen verdient $\$ \mathbf{6}$ voor de taak

- De andere werker verdient niks voor de taak.

$\underline{\text { Verdiensten van de werkers: }}$

Werker A is door toeval gekozen. Hij of zij verdient daarom $\$ 6$ voor de taak. Werker $B$ verdient daarom niks voor de taak.

We hebben de werkers zelf niet geïnformeerd over wie door toeval is gekozen. We vertelden hun enkel dat een derde persoon op de hoogte wordt gesteld van deze uitkomst. Ook vertelden we de werkers dat deze persoon de gelegenheid krijgt om hun verdiensten te herverdelen.

U bent deze derde persoon en kunt beslissen of $\mathrm{u}$ de verdiensten voor de taak wilt herverdelen tussen Werker A en Werker B. Uw beslissing is volledig anoniem. De werkers ontvangen na afloop van de studie de door u bepaalde betaling, maar krijgen verder geen informatie.

Denk goed na over uw beslissing, want $\$ 6$ is een aanzienlijk bedrag in deze arbeidsmarkt.

Uw beslissing:

U kunt nu de verdiensten herverdelen tussen de twee werkers.

Werker A was de gelukkige werker die door toeval was gekozen. Werker A verdient daarom $\$ 6$ en Werker B krijgt $\$ 0$.

Kies alstublieft een van de volgende opties:

Ik wil de verdiensten niet herverdelen:

- $\quad$ Werker A krijgt $\$ 6$ en Werker B krijgt $\$ 0$ betaald

Ik wil de verdiensten herverdelen:

- $\quad$ Werker A krijgt $\$ 5$ en Werker B krijgt $\$ 1$ betaald

- $\quad$ Werker A krijgt $\$ 4$ en Werker B krijgt $\$ 2$ betaald

- $\quad$ Werker A krijgt $\$ 3$ en Werker B krijgt $\$ 3$ betaald

- $\quad$ Werker A krijgt $\$ 2$ en Werker B krijgt $\$ 4$ betaald

- Werker A krijgt $\$ 1$ en Werker B krijgt $\$ 5$ betaald 
- $\quad$ Werker A krijgt $\$ 0$ en Werker B krijgt $\$ 6$ betaald

\section{Treatment 2: MERIT}

In tegenstelling tot de andere vragen in deze vragenlijst gaat u nu een keuze maken die een invloed heeft op de uitbetaling aan andere mensen. We vragen $u$ daarom de instructies goed door te lezen.

Recent hebben we via een internationaal online platform twee mensen ingehuurd om een taak te vervullen. Laten we hen Werker A en Werker B noemen. De taak was voor beiden gelijk en bestond uit het handmatig controleren van ID-nummers van deelnemers. Als vergoeding voor hun deelname ontvingen beide werkers $\$ 1$, ongeacht hun eventuele verdienste voor de taak.

Nadat ze de taak hadden afgerond, hebben we de werkers verteld dat hun verdiensten voor de taak bepaald worden door hun prestatie:

- De werker die het beste presteert verdient $\$ \mathbf{6}$ voor de taak

- De andere werker verdient niks voor de taak.

Verdiensten van de werkers:

Werker A heeft het beste gepresteerd in de taak. Hij of zij verdient daarom $\$ 6$ voor de taak. Werker B verdient daarom niks voor de taak.

We hebben de werkers zelf niet geïnformeerd over wie het beste had gepresteerd. We vertelden hun enkel dat een derde persoon op de hoogte wordt gesteld van deze uitkomst. Ook vertelden we de werkers dat deze persoon de gelegenheid krijgt om hun verdiensten te herverdelen.

U bent deze derde persoon en kunt beslissen of $\mathrm{u}$ de verdiensten voor de taak wilt herverdelen tussen Werker A en Werker B. Uw beslissing is volledig anoniem. De werkers ontvangen na afloop van de studie de door u bepaalde betaling, maar krijgen verder geen informatie.

Denk goed na over uw beslissing, want $\$ 6$ is een aanzienlijk bedrag in deze arbeidsmarkt.

\section{Uw beslissing:}

U kunt nu de verdiensten herverdelen tussen de twee werkers. Werker A had het beste gepresteerd in de taak. Werker A verdient daarom $\$ 6$ en Werker B krijgt \$0.

Kies alstublieft een van de volgende opties: 
Ik wil de verdiensten niet herverdelen:

- Werker A krijgt $\$ 6$ en Werker B krijgt $\$ 0$ betaald

Ik wil de verdiensten herverdelen:

- $\quad$ Werker A krijgt $\$ 5$ en Werker B krijgt $\$ 1$ betaald

- $\quad$ Werker A krijgt $\$ 4$ en Werker B krijgt $\$ 2$ betaald

- $\quad$ Werker A krijgt $\$ 3$ en Werker B krijgt $\$ 3$ betaald

- $\quad$ Werker A krijgt $\$ 2$ en Werker B krijgt $\$ 4$ betaald

- $\quad$ Werker A krijgt $\$ 1$ en Werker B krijgt $\$ 5$ betaald

- $\quad$ Werker A krijgt $\$ 0$ en Werker B krijgt $\$ 6$ betaald

\section{D.2 English translation}

Next, the scientific choice experiment will start. It is interactive with other participants of the study. It gives insight into the way you make financial and social decisions.

You can compare your choices at a later point in time with those of the other participants, via www.paulsmeets.eu.

The experiment takes about $\underline{5 \text { minutes. }}$

\section{Treatment 1: LUCK}

Unlike the other questions in this survey, you will now make a choice that has real monetary consequences for other people. We therefore ask you to pay careful attention to the instructions.

We recently hired two individuals via an online platform to work on an assignment. Let us call them worker A and worker B. The assignment was the same for both workers and consisted of manually double checking entries from a list of participant ID numbers. Each worker received a flat payment of $\$ 1.00$ for signing up, regardless of their potential earnings for the assignment.

After completing the assignment, we told the workers that their earnings for the assignment will be determined by chance:

- The worker who is chosen by chance earns $\mathbf{\$ 6 . 0 0}$ for the assignment.

- The other worker earns nothing for the assignment.

Earnings of the workers:

Worker A was chosen by chance and therefore earns $\$ 6.00$ for the assignment. Thus, 
worker B earned nothing for the assignment.

We did not inform the workers about who was chosen by chance. However, we told the workers that a third person will be informed about this outcome. We also told them that this person would get the opportunity to redistribute the earnings.

You are the third person and will now choose whether to redistribute the earnings for the assignment between worker A and worker B. Your decision is completely anonymous. The workers will receive the payment that you choose once the study is complete, but they will not receive any further information.

Please consider your decision carefully, as $\$ 6.00$ is a considerable amount of money for these workers.

\section{Your decision}

You can now redistribute the earnings of the two workers.

Worker A was chosen by chance and therefore earns $\$ 6.00$ for the assignment. Thus, worker B earned nothing for the assignment.

Please choose one of the following options:

I do not want to redistribute earnings:

- Worker A is paid $\$ 6.00$ and Worker B is paid $\$ 0.00$

I want to redistribute earnings:

- Worker A is paid $\$ 5.00$ and Worker B is paid $\$ 1.00$

- Worker A is paid $\$ 4.00$ and Worker B is paid $\$ 2.00$

- Worker A is paid $\$ 3.00$ and Worker B is paid $\$ 3.00$

- Worker A is paid $\$ 2.00$ and Worker B is paid $\$ 4.00$

- Worker A is paid $\$ 1.00$ and Worker B is paid $\$ 5.00$

- Worker A is paid $\$ 0.00$ and Worker B is paid $\$ 6.00$

\section{Treatment 2: MERIT}

Unlike the other questions in this survey, you will now make a choice that has real monetary consequences for other people. We therefore ask you to pay careful attention to the instructions.

We recently hired two individuals via an online platform to work on an assignment. Let us call them worker A and worker B. The assignment was the same for both workers and consisted of manually double checking entries from a list of participant ID numbers. Each worker received a flat payment of $\$ 1.00$ for signing up, regardless of their potential earnings for the assignment.

After completing the assignment, we told the workers that their earnings for the 
assignment will be determined by their performance on the assignment:

- $\quad$ The worker who performs best earns $\$ \mathbf{\$ 6 . 0 0}$ for the assignment.

- The other worker earns nothing for the assignment.

Earnings of the workers:

Worker A performed best and therefore earns $\$ 6.00$ for the assignment. Thus, worker B earns nothing for the assignment.

We did not inform the workers about who performed best. However, we told the workers that a third person will be informed about this outcome. We also told them that this person would get the opportunity to redistribute the earnings.

You are the third person and will now choose whether to redistribute the earnings for the assignment between worker A and worker B. Your decision is completely anonymous. The workers will receive the payment that you choose once the study is complete, but they will not receive any further information.

Please consider your decision carefully, as $\$ 6.00$ is a considerable amount of money for these workers.

\section{Your decision}

You can now redistribute the earnings of the two workers.

Worker A performed best and therefore earns $\$ 6.00$ for the assignment. Thus, worker $B$ earns nothing for the assignment.

Please choose one of the following options:

I do not want to redistribute earnings:

- Worker $\mathrm{A}$ is paid $\$ 6.00$ and Worker B is paid $\$ 0.00$

I want to redistribute earnings:

- Worker $\mathrm{A}$ is paid $\$ 5.00$ and Worker B is paid $\$ 1.00$

- Worker A is paid $\$ 4.00$ and Worker B is paid $\$ 2.00$

- $\quad$ Worker A is paid $\$ 3.00$ and Worker B is paid $\$ 3.00$

- Worker A is paid $\$ 2.00$ and Worker B is paid $\$ 4.00$

- Worker A is paid $\$ 1.00$ and Worker B is paid $\$ 5.00$

- Worker A is paid $\$ 0.00$ and Worker B is paid $\$ 6.00$ 


\section{E Sample characteristics millionaires by source of wealth}

Table 7: Sample characteristics millionaires by source of wealth

\begin{tabular}{|c|c|c|c|c|c|c|c|c|}
\hline & \multicolumn{2}{|c|}{ Total } & \multicolumn{2}{|c|}{ Inheritance } & \multicolumn{2}{|c|}{ Salary } & \multicolumn{2}{|c|}{ Own business } \\
\hline Variable & $\begin{array}{l}\text { \% of } \\
\text { sample }\end{array}$ & $\mathrm{N}$ & $\begin{array}{l}\text { \% of } \\
\text { sample }\end{array}$ & $\mathrm{N}$ & $\begin{array}{l}\text { \% of } \\
\text { sample }\end{array}$ & $\mathrm{N}$ & $\begin{array}{l}\text { \% of } \\
\text { sample }\end{array}$ & $\mathrm{N}$ \\
\hline Female & 29.61 & 304 & 41.91 & 136 & 28.85 & 104 & 22.39 & 134 \\
\hline Age & $\begin{array}{c}61.37 \\
(12.50)^{\mathrm{a}}\end{array}$ & 304 & $\begin{array}{c}61.68 \\
(12.23)^{\mathrm{a}}\end{array}$ & 136 & $\begin{array}{c}62.00 \\
(12.56)^{\mathrm{a}}\end{array}$ & 104 & $\begin{array}{c}59.84 \\
(12.02)^{\mathrm{a}}\end{array}$ & 134 \\
\hline $\begin{array}{l}\text { University } \\
\text { degree }\end{array}$ & 64.47 & 304 & 62.50 & 136 & 70.19 & 104 & 56.72 & 134 \\
\hline Income & & 253 & & 119 & & 88 & & 113 \\
\hline low (€0-€49,999) & 15.02 & & 23.53 & & 10.23 & & 12.39 & \\
\hline $\begin{array}{r}\text { middle }(€ 50,000- \\
€ 99,999)\end{array}$ & 33.20 & & 40.34 & & 26.14 & & 35.40 & \\
\hline $\begin{array}{r}\text { high (more than } \\
€ 100,000)\end{array}$ & 51.78 & & 36.13 & & 63.64 & & 52.21 & \\
\hline Wealth & & 251 & & 116 & & 86 & & 113 \\
\hline $\begin{array}{r}\text { low }(€ 0-€ 1 \\
\text { million) }\end{array}$ & 24.30 & & 30.17 & & 33.72 & & 14.16 & \\
\hline $\begin{array}{r}\text { middle }(€ 1 \\
\text { million-€5 } \\
\text { million) }\end{array}$ & 61.75 & & 62.93 & & 56.98 & & 64.60 & \\
\hline $\begin{array}{r}\text { high (more than } \\
€ 5 \text { million) }\end{array}$ & 13.94 & & 6.90 & & 9.30 & & 21.24 & \\
\hline $\begin{array}{l}\text { High subjective } \\
\text { social status }\end{array}$ & 94.81 & 289 & 92.25 & 129 & 96.04 & 101 & 96.85 & 127 \\
\hline $\begin{array}{l}\text { High prestige } \\
\text { job }^{c}\end{array}$ & 69.78 & 139 & 56.14 & 57 & 77.50 & 40 & 77.33 & 75 \\
\hline $\begin{array}{l}\text { Employment } \\
\text { status }^{\mathrm{d}}\end{array}$ & & 304 & & 45 & & 28 & & 49 \\
\hline Own company & 38.73 & & 15.56 & & 10.71 & & 69.39 & \\
\hline Freelance & 19.01 & & 26.67 & & 10.71 & & 20.41 & \\
\hline Employee & 42.25 & & 57.78 & & 78.57 & & 10.20 & \\
\hline
\end{tabular}

Notes: a Mean (standard deviation); b Answer $>50$ to the question: "In our society, there are groups at the top and at the bottom of the income distribution. If 1 was the bottom and 100 the top, where would you put yourself on this scale?" (Dutch original question: „In onze samenleving zijn er groepen aan de bovenkant en onderkant van de inkomensverdeling. Als 1 de onderkant is en 100 de top van de schaal, waar zou u zichzelf plaatsen op die schaal?"); c Treiman's Standard International Occupational Prestige Scale (SIOPS) (Ganzeboom and Treiman, 1996) score $>55$. d Only working millionaires. The remaining answer categories are retired, houseman or -wife, and other. 


$$
a_{i j}=\alpha+\delta W_{i}+\gamma X_{i}+\epsilon_{i}
$$

where $a_{i j}$ is spectator $i$ 's attitude toward each redistribution "policy" $j \in$ \{political orientation, income inequality, wealth tax,income tax $\}, W_{i}$ is an indicator taking the value of 1 if a subject is wealthy (i.e., from the millionaire sample), $X_{i}$ is a vector of individual background variables (age, gender, education), and $\epsilon_{i}$ is the idiosyncratic error term. 


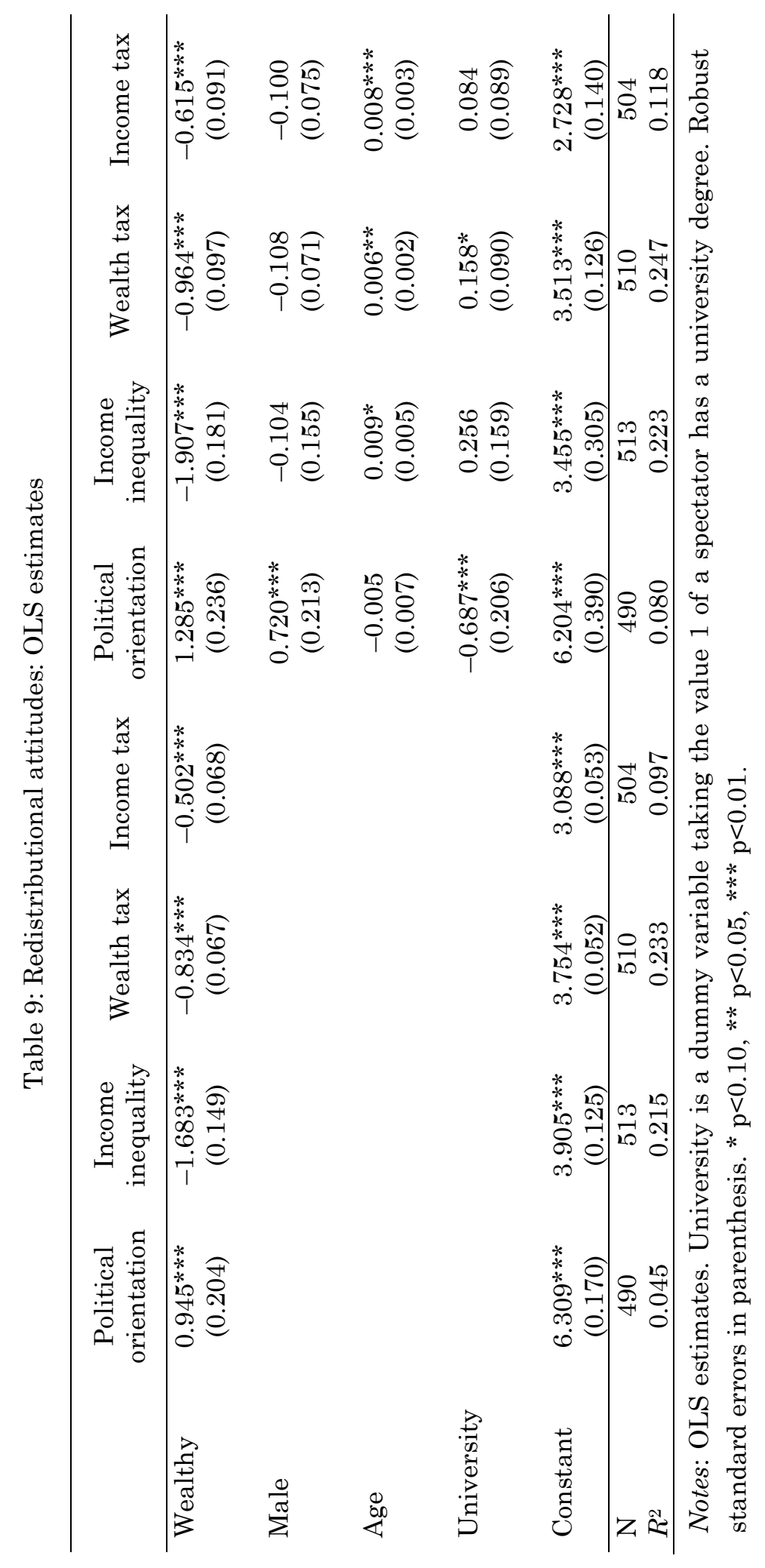




\section{H OLS regressions: Beliefs about success in life}

In order to assess the differences in beliefs between millionaires and the general population parametrically we run the following OLS regression model:

$$
b_{i j}=\alpha+\delta W_{i}+\gamma X_{i}+\epsilon_{i},
$$

where $b_{i j}$ is spectator $i$ 's belief about the importance of each factor $j \in\{l u c k$, hard work , $W_{i}$ is an indicator taking the value of 1 if a subject is wealthy (i.e., from the millionaire sample), $X_{i}$ is a vector of individual background variables (age, gender, education), and $\epsilon_{i}$ is the idiosyncratic error term.

Table 10: Beliefs about success in life: OLS estimates

\begin{tabular}{lcccc}
\hline & $\begin{array}{c}\text { Hard } \\
\text { work }\end{array}$ & Luck & $\begin{array}{c}\text { Hard } \\
\text { work }\end{array}$ & Luck \\
\hline Wealthy & $0.393^{* * *}$ & $-0.216^{*}$ & $0.488^{* * *}$ & $-0.366^{* *}$ \\
& $(0.102)$ & $(0.114)$ & $(0.127)$ & $(0.142)$ \\
Male & & & -0.098 & 0.087 \\
& & & $(0.105)$ & $(0.125)$ \\
Age & & & -0.002 & 0.004 \\
& & & $(0.004)$ & $(0.004)$ \\
University & & & & \\
& & & -0.115 & 0.169 \\
Constant & $5.686^{* * *}$ & $5.481^{* * *}$ & $5.837^{* * *}$ & $5.200^{* * *}$ \\
& $(0.080)$ & $(0.086)$ & $(0.197)$ & $(0.220)$ \\
\hline N & 513 & 512 & 513 & 512 \\
$R^{2}$ & 0.028 & 0.007 & 0.033 & 0.014 \\
\hline
\end{tabular}

Notes: OLS estimates. University is a dummy variable taking the value 1 of a spectator has a university degree. Robust standard errors in parenthesis. ${ }^{*} p<.10,{ }^{* *} p<.05,{ }^{* * *} p<.01$. 


\section{Distribution of implemented inequality}

Figure 9: Distributions of implemented inequality

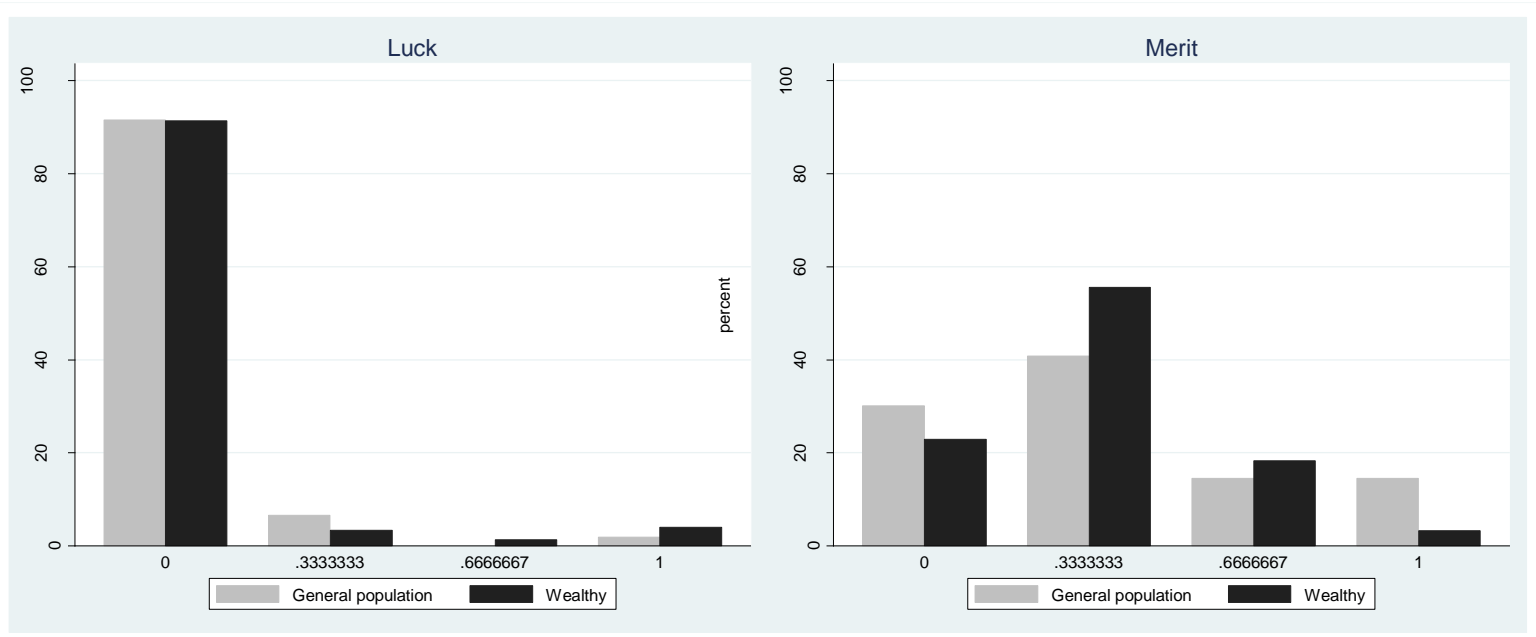

Notes: Distributions of implemented inequality by treatment and sample.

\section{J OLS regressions: Preferences for redistribution}

In order to assess the differences in preferences for redistribution between millionaires and the general population parametrically we run the following regression models using OLS separately for each treatment:

$$
e_{i}=\alpha+\delta W_{i}+\gamma X_{i}+\epsilon_{i}
$$

where $e_{i}$ is the income inequality implemented by spectator $i, W_{i}$ is an indicator variable for whether a spectator is wealthy (i.e., from the millionaire sample), $X_{i}$ is a vector of individual background variables (age, gender, education), and $\epsilon_{i}$ is the idiosyncratic error term.

We further run the following pooled OLS regression model:

$$
e_{i}=\alpha+\delta W_{i}+\lambda M_{i}+\eta W_{i} M_{i}+\gamma X_{i}+\epsilon_{i}
$$

where $M_{i}$ is an indicator variable for whether a spectator is in the MERIT treatment. Consequently, $\eta$ measures the difference in the treatment effect between the wealthy and the general population. 
Table 11: Inequality acceptance: OLS estimates

\begin{tabular}{|c|c|c|c|c|c|c|}
\hline & Luck & Merit & Luck & Merit & Pooled 1 & Pooled 2 \\
\hline Wealthy & $\begin{array}{c}0.020 \\
(0.023)\end{array}$ & $\begin{array}{l}-0.039 \\
(0.039)\end{array}$ & $\begin{array}{c}0.041 \\
(0.037)\end{array}$ & $\begin{array}{l}-0.033 \\
(0.048)\end{array}$ & $\begin{array}{c}0.020 \\
(0.023)\end{array}$ & $\begin{array}{c}0.037 \\
(0.031)\end{array}$ \\
\hline Merit & & & & & $\begin{array}{c}0.338^{* * *} \\
(0.036)\end{array}$ & $\begin{array}{c}0.337 * * * \\
(0.036)\end{array}$ \\
\hline Merit \# Wealthy & & & & & $\begin{array}{l}-0.058 \\
(0.045)\end{array}$ & $\begin{array}{l}-0.063 \\
(0.045)\end{array}$ \\
\hline Male & & & $\begin{array}{c}0.055^{* *} \\
(0.022)\end{array}$ & $\begin{array}{l}0.070^{*} \\
(0.039)\end{array}$ & & $\begin{array}{c}0.063^{* * *} \\
(0.021)\end{array}$ \\
\hline Age & & & $\begin{array}{l}-0.000 \\
(0.001)\end{array}$ & $\begin{array}{c}0.002 \\
(0.001)\end{array}$ & & $\begin{array}{c}0.001 \\
(0.001)\end{array}$ \\
\hline University & & & $\begin{array}{l}-0.048 \\
(0.035)\end{array}$ & $\begin{array}{l}-0.062 \\
(0.040)\end{array}$ & & $\begin{array}{c}-0.056^{* *} \\
(0.027)\end{array}$ \\
\hline Constant & $\begin{array}{c}0.041^{* * *} \\
(0.015)\end{array}$ & $\begin{array}{c}0.379 * * * \\
(0.033)\end{array}$ & $\begin{array}{c}0.021 \\
(0.042)\end{array}$ & $\begin{array}{c}0.268^{* * *} \\
(0.068)\end{array}$ & $\begin{array}{c}0.041^{* * *} \\
(0.015)\end{array}$ & $\begin{array}{l}-0.026 \\
(0.042)\end{array}$ \\
\hline $\begin{array}{l}\mathrm{N} \\
R^{2}\end{array}$ & $\begin{array}{c}255 \\
0.002\end{array}$ & $\begin{array}{c}256 \\
0.004\end{array}$ & $\begin{array}{c}255 \\
0.029\end{array}$ & $\begin{array}{c}256 \\
0.032\end{array}$ & $\begin{array}{c}511 \\
0.281\end{array}$ & $\begin{array}{c}511 \\
0.299\end{array}$ \\
\hline
\end{tabular}

Notes: OLS estimates. Dependent variable: Implemented inequality. Column 2-5: Results of equation (4), columns 6-7: Results of equation (5). University is a dummy variable taking the value 1 of a spectator has a university degree. Robust standard errors in parenthesis. * $p<.10,{ }^{* *} p<.05,{ }^{* * *} p<.01$. 


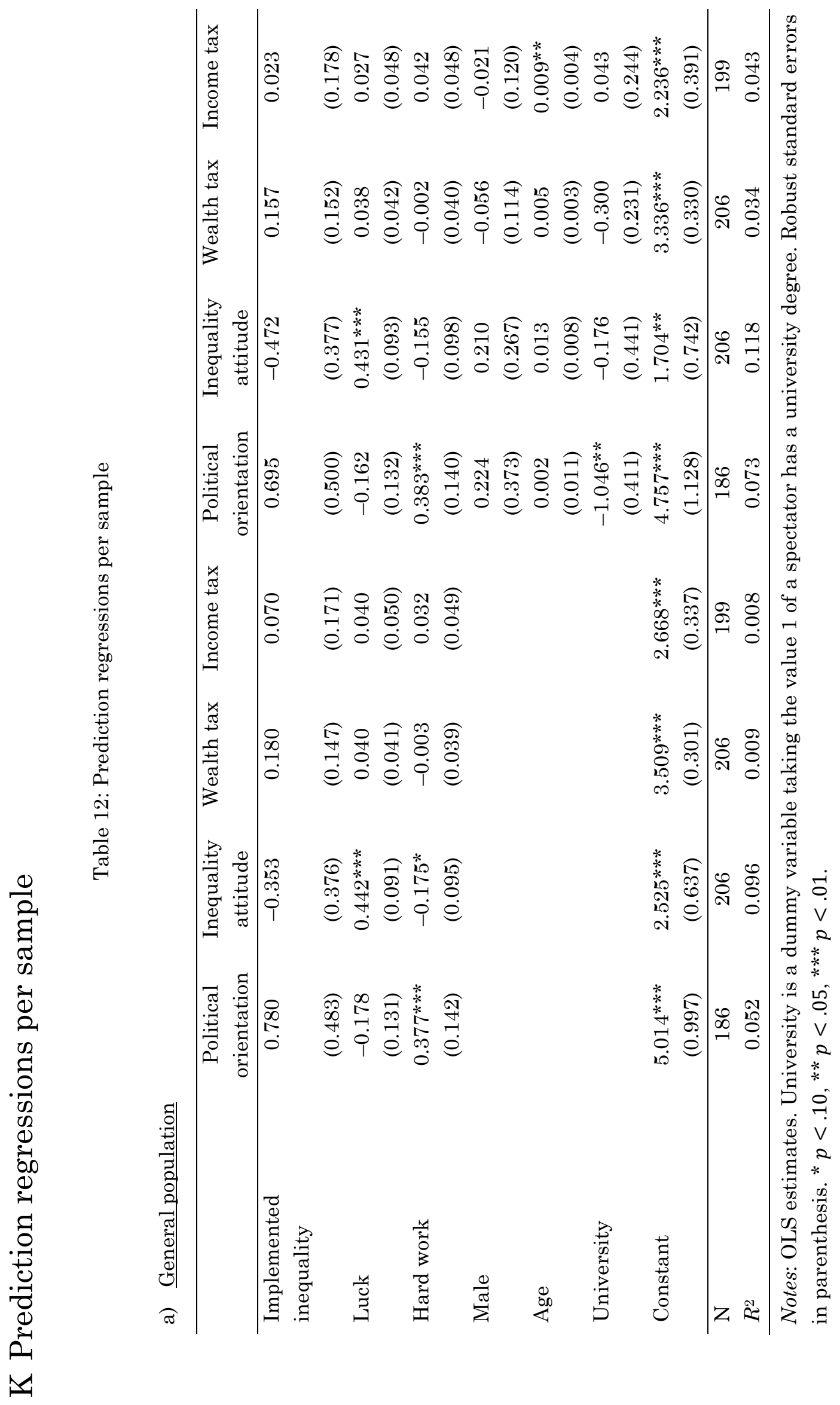




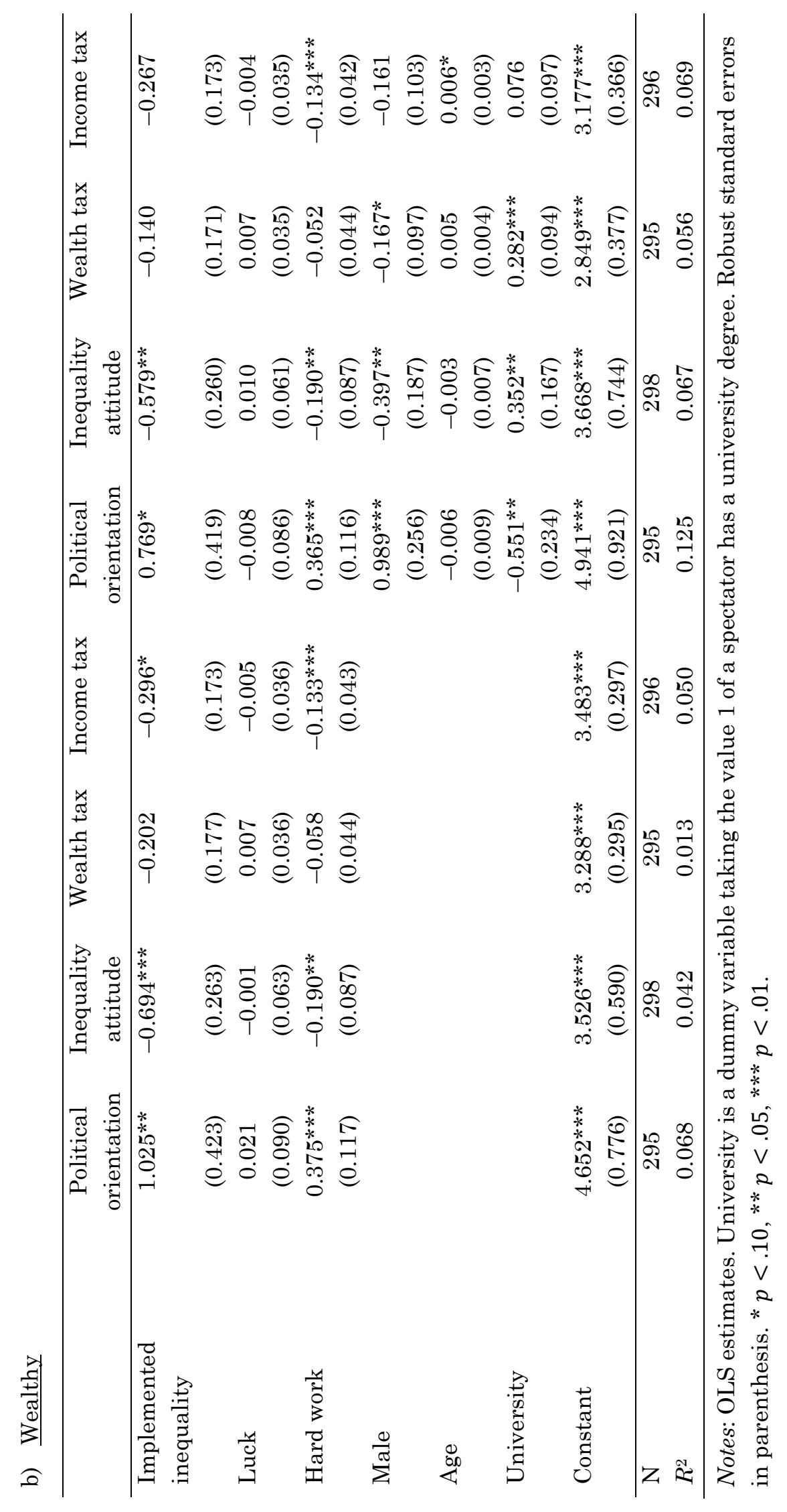




\section{Beliefs about success in life by source of wealth: OLS estimates}

We estimate the following OLS regression model:

$$
b_{i j}=\alpha+\delta_{I} I_{i}+\delta_{s} S_{i}+\gamma X_{i}+\epsilon_{i}
$$

where $b_{i j}$ is spectator $i$ 's belief about the importance of each factor $j \in\{$ luck, hard work\}, $I_{i}$ is an indicator variable taking the value of 1 if a millionaire got rich through an inheritance, $S_{i}$ is an indicator variable taking the value of 1 if a millionaire got rich from her salary, $X_{i}$ is a vector of individual background variables (age, gender, education), and $\epsilon_{i}$ is the idiosyncratic error term.

Table 13: Beliefs about success in life of millionaires:

OLS estimates

\begin{tabular}{lcccc}
\hline & Luck & $\begin{array}{c}\text { Hard } \\
\text { work }\end{array}$ & Luck & $\begin{array}{c}\text { Hard } \\
\text { work }\end{array}$ \\
\hline Inheritance & -0.097 & $-0.372^{* *}$ & -0.050 & $-0.375^{* *}$ \\
& $(0.196)$ & $(0.155)$ & $(0.206)$ & $(0.163)$ \\
Salary & 0.068 & -0.079 & 0.082 & -0.063 \\
& $(0.208)$ & $(0.182)$ & $(0.211)$ & $(0.184)$ \\
Male & & & 0.272 & -0.058 \\
& & & $(0.200)$ & $(0.164)$ \\
Age & & & -0.001 & -0.002 \\
& & & $(0.006)$ & $(0.005)$ \\
University & & & -0.005 & -0.132 \\
& & & $(0.179)$ & $(0.151)$ \\
Constant & $5.220^{* * * *}$ & $6.231^{* * *}$ & $5.068^{* * *}$ & $6.448^{* * *}$ \\
& $(0.144)$ & $(0.107)$ & $(0.434)$ & $(0.364)$ \\
\hline $\mathrm{N}$ & 255 & 256 & 255 & 256 \\
$R^{2}$ & 0.003 & 0.023 & 0.011 & 0.027 \\
\hline
\end{tabular}

Notes: OLS estimates. Independent variables are the source of wealth of millionaires. University is a dummy variable taking the value 1 of a spectator has a university degree. Robust standard errors in parenthesis. ${ }^{*} p<.10,{ }^{* *} p<.05$, $* * * p<.01$.. A series of F-tests confirms that heirs are not different from employees in the importance they attach to luck $(F(1,252)=.68, p=.4113)$ or to hard work $(F(1,253)=$ 2.53, $p=.1127$ ) (test results for regressions without control variables). 


\section{Millionaires by source of wealth and treatment}

Table 14: Number of spectators from millionaire sa
\begin{tabular}{lcc}
\multicolumn{3}{c}{ by source of wealth } \\
\hline Sample & Luck & Merit \\
\hline Inheritance & 52 & 48 \\
Salary & 32 & 34 \\
Business & 43 & 48 \\
\hline
\end{tabular}

\section{N Redistributional attitudes: by source of wealth: OLS estimates}

We estimate the following OLS regression model:

$$
a_{i j}=\alpha+\delta_{I} I_{i}+\delta_{S} S_{i}+\gamma X_{i}+\epsilon_{i},
$$

where $a_{i l}$ is spectator $i$ 's attitude toward each redistribution "policy" $j \in$ \{political orientation, income inequality, wealth tax, income tax $\}, I_{i}$ is an indicator variable taking the value of 1 if a millionaire got rich through an inheritance, $S_{i}$ is an indicator variable taking the value of 1 if a millionaire got rich from her salary, $X_{i}$ is a vector of individual background variables (age, gender, education), and $\epsilon_{i}$ is the idiosyncratic error term. 


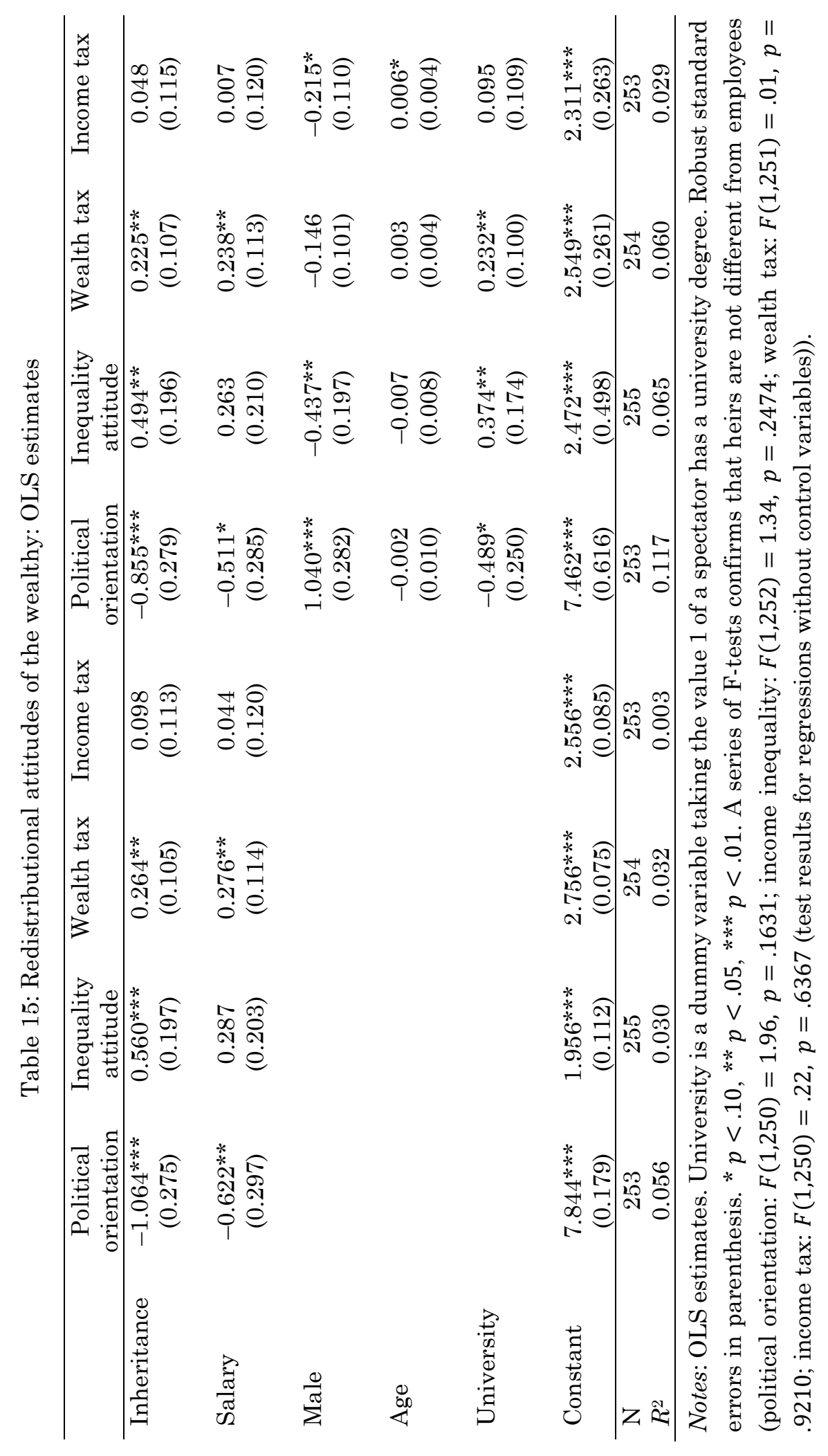




\section{O Preferences for redistribution by source of wealth: OLS estimates}

We run the following regression models using OLS separately for each treatment:

$$
e_{i}=\alpha+\delta_{I} I_{i}+\delta_{s} S_{i}+\gamma X_{i}+\epsilon_{i}
$$

where $\mathrm{e}_{\mathrm{i}}$ is the income inequality implemented by spectator $i, I_{i}$ is an indicator variable taking the value of 1 if a millionaire got rich through an inheritance, $S_{i}$ is an indicator variable taking the value of 1 if a millionaire got rich from her salary, $X_{i}$ is a vector of individual background variables (age, gender, education), and $\epsilon_{i}$ is the idiosyncratic error term.

Table 16: Inequality acceptance of millionaires by source of wealth: OLS estimates

\begin{tabular}{lcccc}
\hline & Luck & Merit & Luck & Merit \\
\hline Inheritance & $-0.083^{*}$ & $-0.146^{* * *}$ & -0.076 & $-0.143^{* * *}$ \\
& $(0.050)$ & $(0.052)$ & $(0.050)$ & $(0.050)$ \\
Salary & & & & \\
& -0.046 & $-0.107^{*}$ & -0.046 & $-0.108^{*}$ \\
Male & $(0.059)$ & $(0.055)$ & $(0.057)$ & $(0.058)$ \\
& & & & \\
& & & 0.053 & 0.027 \\
Age & & & $(0.037)$ & $(0.053)$ \\
& & & 0.000 & 0.001 \\
University & & & $(0.001)$ & $(0.002)$ \\
& & & -0.049 & 0.009 \\
Constant & $0.109 * *$ & $0.431^{* * *}$ & 0.098 & $0.313^{* * *}$ \\
& $(0.045)$ & $(0.041)$ & $(0.119)$ & $(0.116)$ \\
\hline $\mathrm{N}$ & 127 & 129 & 127 & 129 \\
$R^{2}$ & 0.025 & 0.068 & 0.045 & 0.076 \\
\hline
\end{tabular}

Notes: OLS estimates. Dependent variable: implemented inequality. University is a dummy variable taking the value 1 of a spectator has a university degree. Robust standard errors in parenthesis. ${ }^{*} p<.10,{ }^{* *} p<.05,{ }^{* * *} p<.01$. A series of F-tests confirms that heirs are not different from employees in the LUCK $(F(1,124)=.74, p=.3917)$ or the MERIT treatment $(F(1,126)=$ $.63, p=.4276$ ) (test results for regressions without control variables). 



\section{CHAPTER VI \\ Concluding remarks}

In this thesis, I have investigated motives that drive people's willingness to (re-) distribute income and wealth.

In Chapter II-IV, I explored concerns for basic needs satisfaction as a motive for the distribution of income. In Chapter II, I showed that a non-negligible fraction of subjects cares for the satisfaction of basic needs. In my experiment with subjects from a student sample in Cologne (Germany), the motive can explain choices that cannot be explained by other established motives related to caring about the incomes of relatively poorer people in a society; maximin and generosity. Hence, I have established concerns for basic needs satisfaction as an important distinct distributional motive. Further, subjects are willing to sacrifice some of their own income, efficiency, and utility in terms of envy in order to satisfy additional basic needs. In addition, I showed that in choices in which concerns for basic needs satisfaction and maximin predict the same allocation, this allocation is chosen by a large percentage of subjects. Strong basic needs types are especially likely to choose this option. This highlights that in such situations basic needs satisfaction is another important driver next to maximin. This suggests that if basic needs satisfaction was ignored as a motive, we would ascribe behavior driven by this motive to maximin. Hence, in these situations, the prevalence of maximin would be overestimated if basic needs satisfaction was ignored as a behavioral motive. Furthermore, if subjects have to sacrifice more of their own income or the income of the worst-off person in order to satisfy needs, a substantial fraction of subjects still chooses to fulfill those needs. Finally, questionnaire results support the meaningfulness of subjects' choices in the experiment, showing that subjects choosing in line with basic needs satisfaction, maximin, or selfishness indeed took their decisions based on these concerns.

In Chapter III, I demonstrated that concerns for basic needs satisfaction are likewise important in a setting in which the fulfillment of basic needs is actually at stake. In this experiment, subjects from the general population in Tbilisi (Georgia) are deciding about actual monthly incomes. In other words, the dictator and the receivers will, in the month of the experiment, have the income amounts depicted in an allocation chosen by the dictator. This entails that dictators can actually satisfy basic needs of genuine persons who are living with an income below the basic needs threshold in their everyday lives. Results from additional choices revealed that the basic needs option is not simply chosen because there are fewer persons below the threshold. Instead, subjects (also) care - as proposed in the theoretical formulation of the motive in Chapter II - for the sum of unfulfilled needs. Moreover, the extent to which subjects display concerns for basic needs satisfaction is related to helping a needy receiver in a different choice setting. Finally, a heterogeneity analysis revealed that females care more strongly for the fulfillment of basic needs, while there is no relation of the motive to age or income. 
In Chapter IV, I observed that if there is a minimal strategic incentive to satisfy needs in order to ensure the survival of the receiver in the game, the prevalence of behavior in line with concerns for basic needs satisfaction increases substantially. Even subjects displaying a considerable amount of self-interest in the choice experiment, choose to satisfy the receiver's need - and by this give up half of the amount that they can distribute - in the need game. Given that these results cannot be explained by risk aversion or beliefs about other dictators' giving behavior, I concluded that the salience of group survival might have triggered dictators' desire to fulfill receivers' needs. I further remarked that this is consistent with the notion that human beings are predisposed to act in accordance with the motive in situations in which it is evolutionarily important.

Altogether, these findings suggest that the motive of basic needs satisfaction is an important consideration in the distribution of incomes. I have shown that the motive is a behavioral driving force in distributional decisions across different incentive structures and subject pools. These experiments constitute, to the best of my knowledge, the first attempt to provide clean evidence on the existence of concerns for basic needs satisfaction, by disentangling the motive from other important distributional concerns related to caring for poorer persons, such as maximin, in an incentive compatible way.

The knowledge about people's distributional motives can be informative for the design and acceptance of social security systems. Frohlich and Oppenheimer (1992) note that fairness considerations can influence, for example, the perceived fairness of tax systems as mechanisms for implementing redistributive policies. This, in turn, can have severe impacts on the acceptance of these systems and, thereby, ultimately of the political regime. Barth et al. (2013), for example, show that people's fairness concerns are related to the probability of justifying and actually engaging in tax evasion. The fact that the fulfillment of basic needs matters alongside other motives has relevant implications for policy. In discussions about the optimal design of redistributive policies, people with different motives for redistribution are likely not only to hold different positions, but also to discuss about different things. When arguing about redistribution, advocates of maximin will be concerned with how, for example, incomes, wealth, and education possibilities can be equalized in a society. For this purpose, they might also consider raising taxes from the very rich, but not from those with incomes below the mean, in order to further equalize incomes. On the contrary, proponents of basic needs fulfillment will discuss about securing means of subsistence for the needy and would raise taxes from all those with incomes above the basic needs threshold. They might regard an adequate amount of social security benefits and a more extensive public funding of, for example, education and basic health care and infrastructure as valuable policy instruments for redistribution, but might at the same time object to redistribution of income beyond the basic needs threshold. Understanding people's distributional motivations can therefore have important implications for the design, extent, and acceptance of different kinds of redistributive policies and for structuring the political debate. My findings are a first step towards understanding the importance of basic needs satisfaction as an individual concern for the distribution of incomes in a society.

As already addressed in Chapter II (Section 2.4.1), the estimated prevalence of concerns for basic needs satisfaction in the choice experiment is likely to be a rather 
conservative estimate. ${ }^{171}$ First, if maximin is taken seriously, it would call for income transfers until income equality is achieved. It is questionable whether subjects choosing (repeatedly) in line with maximin in my experiment would go as far as to promote total equality or at least a large amount of unconditional redistribution. It is more likely that at least some choices in line with maximin are potentially driven by a desire to fulfill the needs of the poorest person. A subject choosing the maximin option simply gives priority to the "needier" person at the expense of the sum of unfulfilled basic needs. Hence, it might be that a part of subjects choosing in line with maximin in the experiment are motivated by ensuring basic needs fulfillment, but with a different utility term for the latter (Weiss et al., 2017). Second, when decisions affect the 'survival' of a fellow subject - and ultimately also of the group - then BNS becomes a lot stronger. Of the same subjects of whom, on average, 17 percent choose the basic needs option in the choice experiment of Chapter II, almost 50 percent of dictators give up half of their endowment if this ensures the receiver's survival to the next round in the need game of Chapter IV. ${ }^{172}$ Even subjects choosing selfishly before, now decide to help a needy person, which is consistent with the notion that people are motivated by different concerns and that behavior in line with these concerns is context dependent (Konow, 2001). Third, in the student sample in Tbilisi, in which participants knew the group of potential receivers, we saw that concerns for basic needs satisfaction are extremely strong (see Chapter II, Section 2.4.2). Given its implications for social policy, its potential crucial significance as a behavioral driver and the relatively modest attention it has received in the economics literature so far, it is thus important to further investigate the motive.

In Section 4.4 of Chapter IV, I made a proposition for a one-shot need game that can serve as a workhorse experiment for future research on the motive. In the following, I provide an outlook of how the game can be used for this purpose, exploring the propositions put forward at the end of Chapter IV. This research can help to further assess the significance of the motive, its impact on economic outcomes such as efficiency, and how its application relates to important factors such as a person's responsibility for being in need.

With respect to a person's responsibility for being in need, I will focus on two main cases. A person can be responsible for being in need because she made a risky choice or because she exerted too little effort to avoid her dire situation. The first case can be modeled in the need game by introducing a lottery choice to determine the endowment of the receiver. In particular, the receiver is presented with a choice between a safe amount that guarantees need fulfillment and a lottery with an amount lower than the threshold as the unlucky outcome, and an amount a lot higher than the threshold and the safe amount as the lucky outcome. If the receiver chooses the risky choice and is unlucky, she can thus be held responsible for the fact of being in need (see Cappelen et al., 2013a). The second case gets at the trade-off between equity or merit and need and can be incorporated into the need game by varying the source of the endowment in the style of Frohlich et al. (2004). In one treatment, the endowment is provided by the experimenter as manna from

171 The estimated prevalence additionally relies on the theoretical formulation of the motive (see Chapter II, Section 2.2 and 2.4.1).

172 I consider subjects assigned the role of the dictator in the need game. 
heaven. In a second treatment, the endowment is allocated to subjects based on performance in a real effort task. In this treatment, it is thus again a receiver's responsibility if her initial endowment is lower than the threshold.

It is important to investigate the influence of these two types of responsibilities for being in need on an individual's willingness to fulfill these needs, since they relate to redistribution policies in the field. In a society with high needs-based redistribution, people's willingness to incur the costs for this redistribution is crucial for social cohesion. This willingness is, in turn, likely to depend on their propensity to take into account individual responsibility for being in need. A person's willingness to incur costs to fulfill basic needs might be reduced when the person in need is responsible for her dire situation. Firstly, being in need due to a risky decision can be related to situations in which people suffer from health problems that are a direct consequence from hazardous behavior, like heavy drinking, or pursuing extreme sports. The societal costs of alcoholism alone are estimated to sum up to 27 billion Euros per year (Hinz, 2010). People's willingness to incur these costs in cases in which the affected individuals are (at least partly) responsible for the emergence of these costs, therefore, deserves empirical attention. Secondly, the relative importance of merit and need claims is relevant for assessing people's support for the redistribution of incomes in the field. In a market economy, a person's pre-tax work income is typically based on her productive contribution, i.e., on meritocratic grounds. It is a stable finding in the experimental economics literature that people generally like to give people the fruits of their productivity (e.g., Frohlich et al., 2004; Cappelen et al., 2007; Almås et al., 2017). Depending on the size of the (welfare) state, these incomes are taxed and a part of these taxes are spent on redistributive purposes. Redistribution, in turn, is based to a large extent on ensuring people's basic necessities (see Section 2.1 in Chapter II). In other words, in these types of welfare states, people are currently paying to cover the basic necessities for those, whose income is not high enough to do this by themselves. It is therefore an important question, how people trade off the fulfillment of needs against meritocratic claims. ${ }^{173}$

With respect to the relation between needs fulfillment and efficiency, an important question is whether an institutionalized guarantee of basic needs fulfillment entails efficiency losses. Okun (1975) postulated that there is a trade-off between redistribution and efficiency, since the former undermines individuals' motivation to exert effort. ${ }^{174}$ This is especially the case if the rule on which redistribution is based, is perceived as unjust. It is an interesting question whether the relation between redistribution and efficiency depends on the rule upon which the latter rests, i.e., whether the relationship is different

173 Cappelen et al. (2013b) show that when subjects have to trade off entitlements against need considerations, both motives are important. In their design, however, the possibility of need considerations is introduced by letting subjects of rich countries play with participants from poor countries. This relies on the assumption that subjects from the poor countries are indeed viewed as needy. This is not unproblematic, since subjects are all students, i.e., individuals who are typically not deprived of their basic needs even in poor countries.

174 See, for example Andersen and Maibom (2016), for a recent analysis of this trade-off using data on 34 OECD countries. 
if the primary goal of redistribution is the satisfaction of basic needs as opposed to reducing general inequality. Frohlich and Oppenheimer (1992) implement an experiment in which a tax system redistributes participants' earnings above a certain floor level to those who did not manage to reach this minimum. ${ }^{175}$ They find that subjects' overall productivity even increases when experiencing redistribution through such a tax system. ${ }^{176}$ The remarkable finding is that this is the case for beneficiaries, as well as net tax payers. In the light of the present thesis, it is important to investigate whether these results extend to the experimental setup of the need game in which falling short of the threshold has real consequences for subjects. I further propose to explore whether the positive effect of redistribution also holds under an alternative rule for redistributing the earnings, for example, achieving a certain degree of income equality. For this purpose, the need game with a production phase could be augmented by an additional redistribution phase in which earnings are redistributed according to the respective rule. This research could be a brick for designing optimal redistribution policies while at the same time minimizing adverse incentive effects.

Finally, the need game can be used to dig deeper into how exactly individuals take into account needs fulfillment in distributional decisions in order to inform theoretical formulation of the motive (see Chapter II, Section 2.2; Siebel, 2017; Traub et al., 2017). An important issue is whether and to what extent individuals are concerned with the overall amount of unfulfilled basic needs, and/or the number of persons falling below the threshold. In a first attempt in this direction, I showed in Chapter IV that people do not only care for the number of persons lifted above the threshold, but also for the overall amount of unfulfilled needs. As a next step, I propose to systematically vary the number of persons in need and the amount of unfulfilled needs in order to explore the relative importance of these two factors. Another related question is whether individuals care more generally for the distribution of unfulfilled needs, which is especially relevant in situations of resource scarcity. Do they have a preference for equal relative needs fulfillment as suggested by Siebel (2017), or do they give priority to a needy person who lacks fewer resources in order to reach the threshold over another needy person who lacks more resources, as could be derived from Weiss et al. (2017)? Or do they, alternatively, give

175 In the experiment, subjects get paid according to their performance in a real effort task. Subjects who earn more than a certain floor level get taxed. This money is assigned to subjects who earned less than this minimum. Thus, the height of the tax depends on the task performance of the least productive members of the group. The experiment is played for three rounds. Before this stage of the experiment, they let subjects rank four principles of distributive justice after briefly introducing those principles. This ranking does not have any consequences for their payoffs. The principles are maximizing either the floor or the average income, the average with a floor, or the average with a range constraint. The floor is defined as income of the least well-off individual. The principle of maximizing the average with a floor constraint "ensure(s) that individuals 'at the bottom' receive a specific minimum" (Frohlich and Oppenheimer, 1992, p. 36). They find that roughly 57 percent of the subjects ranked this principle as first.

176 Note that they find this effect only in treatments in which the principle was adopted in a democratic process. 
priority to a poorer needy person? This issue also relates to the above mentioned possibility that part of behavior in line with maximin in the choice experiments of Chapter II and III might actually be motivated by a desire to help the person with the highest needs.

In Chapter V, I showed that in terms of preferences to level income differences that stem from luck, or individual effort, the wealthy are not different from people from the general population in my study. They do, however, have different beliefs about the importance of hard work for success in life. I showed that this difference in beliefs partly explains differences in attitudes towards redistribution. Millionaires believe that hard work is crucial for determining earnings in the field and are therefore less willing to redistribute those earnings. People from the general population, however, attach less importance to hard work in determining these earnings and are therefore less reluctant to redistributing part of these very earnings. I have thus identified one explaining factor for the differences in support for redistribution in the field between those with potentially high political power and the average citizen.

This chapter shows that while it is important to investigate (re-)distributional concerns of the general population, it is also crucial to look at the preferences of those groups in society with a disproportionate policy impact (Fisman et al., 2015). Even though this might not be desirable in a democracy, one cannot neglect the fact that the very wealthy have disproportionate power to enforce their political ideas. The global trend towards even higher inequality of wealth and income is seen as a threat to social order (Alvaredo et al., $2017 b)$. In order to fight this trend by any political means, knowledge about what drives support for redistribution of the wealthy is therefore indispensable.

One interpretation of my findings is that the rich are actually less in favor of redistribution because they believe more strongly in the importance of individual effort for determining the very earnings that are to be redistributed. In other words, they might believe that other members of the society have a lower income because they are lazy. This means that - provided that the rich assign too much responsibility to individual effort one way of increasing their willingness to redistribute is to raise awareness that differences in earnings are to a large part also determined by luck. One possibility could be, for example, to provide them with information about actual social mobility or equality of opportunities in their society. This could increase, for example, tax honesty, which is found to be particularly low among the rich (Alstadsæter et al., 2017). If the low importance attached to luck is - as suggested by my results - driven by a desire to develop a narrative in order to maintain a positive self-image, millionaires might, however, be reluctant to give up this belief.

Relating the two main parts of this thesis, Chapter V revealed that beliefs about determinants for success in life can mediate how preferences for redistribution translate into support for redistribution in the field. These beliefs might also influence support for redistributive policies aimed at securing basic needs fulfillment. A person who strongly believes that hard work is important for success in life is also likely to believe that someone who is unsuccessful did not work hard; in other words, that someone who is poor is responsible for her dire situation. As a consequence, an individual who, as in the example of Chapter V (Section 5.1), is not willing to redistribute income that was generated through individual effort, might take into account a person's responsibility for being in need. She 
might thus be reluctant to satisfy needs of a person who could have provided for herself if she had exerted more effort. This view corresponds to German social security legislation in SGB XII that permits benefit cuts if a beneficiary does not comply with her duties to take up work (§39a SGB XII). In contrast, the idea of an unconditional basic income does not tie this income to any individual responsibility of providing individual effort in order to earn this income. Instead, the satisfaction of basic needs is viewed as a basic human right (Werner, 2018). This also reflects the idea behind the formulation of the principle in Chapter II (Section 2.2) of this thesis that everybody has an equal right to satisfy her basic human needs (Shue, 1996) and of basic needs fulfillment as having priority even in cases in which a person has full responsibility over her misfortune (Fleurbaey, 1995).

Drawing on Chapter II to IV and possible extensions described in the present chapter, an important question is thus whether the relevance of individual responsibility also extends to the satisfaction of basic needs. If a person is reluctant to redistribute income that was generated by individual effort from a richer to a poorer person - even if the latter would be, without redistribution, be deprived of her basic needs - then her beliefs about individual responsibility can potentially play a role. This can help to structure policy discussions about the introduction of a universal basic income to replace current transfer systems. The former is ultimately an expression of society's acknowledgement of basic needs fulfillment as a basic right that arises merely from being a member of this society and is thus independent from any individual merit. 



\section{Bibliography}

Abeler, J., Falk, A., Goette, L., and Huffman, D. (2011). Reference points and effort provision. American Economic Review, 101(2): 470-92.

Aguiar, F., Brañas-Garza, P., and Miller, L. M. (2008). Moral distance in dictator games. Judgment and Decision Making, 5(4): 344-354.

Alesina, A., and Giuliano, P. (2009). Preferences for redistribution. NBER Working Paper (14825).

Alesina, A., and La Ferrara, E. (2005). Preferences for redistribution in the land of opportunities. Journal of Public Economics, 89(5-6): 897-931.

Alesina, A., Glaeser, E. L., and Sacerdote, B. (2001). Why doesn't the United States have a European-style welfare state? Brookings Papers on Economic Activity, 2001(2): 187277.

Algemene Bijstandswet (ABW): Hoofdstuk I (2003). URL: http://www.stab.nl/abwh01.htm, Accessed: 2015-04-22.

Almås, I., Cappelen, A., and Tungodden, B. (2017). Cutthroat capitalism versus cuddly socialism: Are Americans more meritocratic and efficiency-seeking than Scandinavians? HCEO Working Paper Series (2017-003).

Alstadsæter, A., Johannesen, N., and Zucman, G. (2018). Tax evasion and inequality. NBER Working Paper (23772).

Alvaredo, F., Chancel, L., Piketty, T., Saez, E., and Zucman, G. (2017a). Global inequality dynamics: New findings from WID.world. American Economic Review, 107(5): 404-09.

Alvaredo, F., Chancel, L., Piketty, T., Saez, E., and Zucman, G. (2017b). World Inequality Report 2018. World Inequality Lab.

Andersen, S., Di Girolamo, A., Harrison, G. W., and Lau, M. I. (2014). Risk and time preferences of entrepreneurs: Evidence from a Danish field experiment. Theory and Decision, 77(3): 341-357.

Andersen, T, M, and J, Maibom (2016). The big trade-off between efficiency and equity: Is it there? C.E.P.R. Discussion Papers (11189).

Andreoni, J., and Miller, J. (2002). Giving according to GARP: An experimental test of the consistency of preferences for altruism. Econometrica, 70(2): 737-753.

Andreoni, J., Nikiforakis, N., and Stoop, J. (2017). Are the rich more selfish than the poor, or do they just have more money? A natural field experiment. NBER Working Paper (23229).

Arts, K. (2017). Miljonairs in cijfers: revisie en update 2015: Onderzoek naar miljonairshuishoudens 2007-2015 op verzoek van Van Lanschot Bankiers. CBS, URL: https://www.cbs.nl/-/media/_pdf/2017/36/rapport2017.pdf, Accessed: 2018-05-23.

Asylbewerberleistungsgesetz (AsylbLG) (2003). URL: https://www.gesetze-iminternet.de/ asylblg/AsylbLG.pdf, Accessed: 2018-08-13.

Barth, E., Cappelen, A. W., and Ognedal, T. (2013). Fair tax evasion. Nordic Journal of Political Economy, 38(2): 1-16.

Bartling, B., Fehr, E., and Schmidt, K. M. (2013). Use and abuse of authority: A behavioral foundation of the employment relation. Journal of the European Economic Association, 11(4): 711-742. 
Bénabou, E., and Tirole, J. (2006). Incentives and prosocial behavior. American Economic Review, 96(5): 1652-1678.

Blanchflower, D. G. (2004). Self-employment: More may not be better. NBER Working Paper (10286).

Blanco, M., Engelmann, D., and Normann, H. T. (2011). A within-subject analysis of otherregarding preferences. Games and Economic Behavior, 72(2): 321-338.

Blinder, A. S. (1973). Wage discrimination: Reduced form and structural estimates. Journal of Human Resources, 8(4): 436-455.

Böcking, D. (2018). Bundestagswahl 2017: So viel Umverteilung gibt es in Deutschland. Spiegel Online. URL: http://www.spiegel.de/wirtschaft/soziales/bundestagswahl-2017 so-viel-umverteilung-gibt-es-in-deutschland-a-1158799.html, Accessed: 2018-08-03.

Bowles, S., and Gintis, H. (2005). Can self-interest explain cooperation? Evolutionary and Institutional Economics Review, 2(1): 21-41.

Brañas-Garza, P. (2006). Poverty in dictator games: Awakening solidarity. Journal of Economic Behavior \& Organization, 60(3): 306-320.

Brislin, E. W. (1970). Back-translation for cross-cultural research. Journal of CrossCultural Psychology, 1(3): 185-216.

Busenitz, L. W., and Barney, J. B. (1997). Differences between entrepreneurs and managers in large organizations: Biases and heuristics in strategic decision-making. Journal of Business Venturing, 12(1): 9-30.

Cappelen, A. W., Hole, A. D., Sørensen, E. Ø., and Tungodden, B. (2007). The pluralism of fairness ideals: An experimental approach. American Economic Review, 97(3): 818-827.

Cappelen, A. W., Konow, J., Sørensen, E. Ø., and Tungodden, B. (2013a). Just luck: An experimental study of risk-taking and fairness. American Economic Review, 103(4): 1398-1413.

Cappelen, A. W., Moene, K. O., Sørensen, E, Ø., and Tungodden B. (2013b). Needs versus entitlements: An international fairness experiment. Journal of the European Economic Association, 11(3): 574-598.

Causa, O., and Hermansen, M. (2018). Income redistribution through taxes and transfers across OECD countries. VOX (CEPR's Policy Portal), URL: https://voxeu.org/article/income-redistribution-through-taxes-and-transfers, Accessed: 2018-05-23.

CBS (2017). 8 in 10 working millionaires are self-employed. URL: https://www.cbs.nl/engb/news/2017/37/8-in-10-working-millionaires-are-self-employed, Accessed: 2017-1120 .

Chakravarty, S. R. (2009). Inequality, polarization and poverty: Advances in distributional analysis. New York: Springer.

Charness, G., and Rabin, M. (2002). Understanding social preferences with simple tests. Quarterly Journal of Economics, 117(3): 817-869.

Cohen, P. (2015). What could raising taxes on the 1\% do? Surprising amounts. The New York Times, URL: https://www.nytimes.com/2015/10/17/business/putting -numbers-toa-tax-increase-for-the-rich.html, Accessed: 2017-11-13.

Corneo, G., and Grüner, H. P. (2002). Individual preferences for political redistribution. 
Journal of Public Economics, 83(1): 83-107.

Dannenberg, A., Riechmann, T., Sturm, B., and Vogt, C. (2007). Inequity aversion and individual behavior in public good games: An experimental investigation. $Z E W$ discussion paper (07-34).

Dohmen, T., Falk, A., Huffman, D., Sunde, U., Schupp, J., and Wagner, G. (2011). Individual risk attitudes: Measurement, determinants, and behavioral consequences. Journal of the European Economic Association, 9(3): 522-550.

Dur, R. A. J., Teulings, C. N. (2003). Education and efficient redistribution. Tinbergen Institute Discussion Paper (TI 2001-090/03).

Durante, R., Putterman, L., and van der Weele, J. (2014). Preferences for redistribution and perception of fairness: An experimental study. Journal of the European Economic Association, 12(4): 1059-1086.

Eidelson, J. (2018). U.S. income inequality hits a disturbing new threshold. Bloomberg, URL: https://www.bloomberg.com/news/articles/2018-03-01/america-s-wage-growth remains-slow-and-uneven, Accessed: 2018-08-09.

Elston, J. A., Harrison, G. W., and Rutström, E. E. (2005). Characterizing the entrepreneur using field experiments. Working Paper.

Engel, C. (2011). Dictator games: A meta study. Experimental Economics, 14(4): 583-610.

Engelmann, D. and Strobel, M. (2004). Inequality aversion, efficiency, and maximin preferences in simple distribution experiments. American Economic Review, 94(4): 857869.

Engelmann, D. and Strobel, M. (2005). Fairness on the internet: The role of distributional concerns in dictator games with high social distance. Unpublished manuscript.

Eurostat (2018). General government expenditure in the EU in 2016. URL: https://ec.europa.eu/eurostat/documents/2995521/8725251/2-09032018-AP-

EN.pdf/c60aed76-c37b-413e-9f99-58a8370f0ea6, Accessed: 2018-09-07.

Evans, C. (2013). Wealth taxes: Problems and practice around the world. CHASM Briefing Paper, URL: https://www.birmingham.ac.uk/Documents/college-social- sciences/socialpolicy/CHASM/briefing-papers/2013/wealth-taxes-problems-and-practices-around-theworld.pdf, Accessed: 2018-01-14.

Falk, A., Becker, A., Dohmen, T., Huffman, D., and Sunde, U. (2016). The preference survey module: A validated instrument for measuring risk, time, and social preferences. IZA Discussion Papers (9674).

Faravelli, M. (2007). How context matters: A survey based experiment on distributive justice. Journal of Public Economics, 91(7): 1399-1422.

Fehr, E., and Schmidt, K. M. (1999). A theory of fairness, competition, and cooperation. Quarterly Journal of Economics, 114(3): 817-868.

Felbermayr, G., Battisti, M., Lehwald, S., (2016). Einkommensungleichheit in Deutschland - Teil 2: Die Rolle der Umverteilung. In Ifo-Schnelldienst 14/2016, IfoInstitut für Wirtschaftsforschung an der Universität München, München: 22-29.

Fischbacher, U. (2007). z-tree: Zurich toolbox for ready-made economic experiments. Experimental Economics, 10(2): 171-178.

Fisman, R., Jakiela, P., and Kariv, S. (2017). Distributional preferences and political behavior. Journal of Public Economics, 155: 1-10. 
Fisman, R., Jakiela, P., Kariv, S., and Markovits, D. (2015). The distributional preferences of an elite. Science, 349(6254): aab0096.

Fleurbaey, M. (1995). Equal opportunity or equal social outcome? Economics and Philosophy, 11(1): 25-55.

Forsythe, R., Horowitz, J. L., Savin, N. E., and Sefton, M. (1994). Fairness in simple bargaining experiments. Games and Economic Behavior, 6(3): 347-369.

Frank, A. (2018). Ungleichheit in Deutschland: Das Geld aus dem Fenster werfen. Spiegel Online, URL: http://www.spiegel.de/kultur/tv/ungleichland-ard-ueber- globalismusdas-geld-aus-dem-fenster-werfen-a-1206562.html, Accessed: 2018-08-11.

Frohlich, N., and Oppenheimer, J. A. (1992). Choosing justice: An experimental approach to ethical theory. Berkeley: University of California Press.

Frohlich, N., Oppenheimer, J., and Kurki, A. (2004). Modeling other-regarding preferences and an experimental test. Public Choice, 119(1-2): 91-117.

Gaertner, W., and Schokkaert, E. (2012). Empirical social choice: Questionnaireexperimental studies on distributive justice. New York: Cambridge University Press.

Gaertner, W., Jungeilges, J., and Neck, E. (2001). Cross-cultural equity evaluations: A questionnaire-experimental approach. European Economic Review, 45(4): 953-963.

Ganzeboom, H. B., and Treiman, D. J. (1996). Internationally comparable measures of occupational status for the 1988 International Standard Classification of Occupations. Social Science Research, 25(3): 201-239.

Geostat (2015a). Median equalized income and consumption in Tbilisi. Data provided by Geostat.

Geostat (2015b). Subsistence minimum (Georgia, GEL). URL: http://www.geostat.ge/cms/site_images/_files/english/households/Subsistenceminimum.xls, Accessed: 2015-09-16.

Geostat (2015c). Women and men in Georgia. URL: http://www.geostat.ge/cms/site _images/files/english/health/Women\%20and\%20Men_2015.pdf, Accessed: 2016-07-21.

Geostat (2016a). Population by municipalities for the beginning of the year (thousands). URL: http://www.geostat.ge/cms/site_images/_files/english/population/01\%20 Population\%20by\%20municipalities\%20for\%20the\%20beginning\%20of\%20the\%20yea r.xls, Accessed: 2016-07-21.

Geostat (2016b). Population under poverty threshold (registered poverty). URL: http://www.geostat.ge/index.php?action=page\&p_id=188\&lang=eng, Accessed: 201606-28.

Geostat (2016c). Subsistence minimum calculation methodology for working age male. URL: http://www.geostat.ge/cms/site_images/_files/english/methodology/Subsistenc e\%20Minimum\%20Calculation\%20Methodology\%20for\%20Working\%20Age\%20Male \%20ENG.pdf, Accessed: 2016-08-03.

Gertz, H. (2018). WDR-Dokuserie: Wer ist hier der Boss? Süddeutsche Zeitung, URL: https://www.sueddeutsche.de/medien/2.220/wdr-dokuserie-wer-ist-hier-der-boss1.3980620, Accessed: 2018-08-11.

Giger, N., Rosset, J., and Bernauer, J. (2012). The poor political representation of the poor in a comparative perspective. Representation, 48(1): 47-61.

Gilens, M., and Page, B. I. (2014). Testing theories of American politics: Elites, interest 
groups, and average citizens. Perspectives on Politics, 12(3): 564-581.

Greiner, B. (2015). Subject pool recruitment procedures: Organizing experiments with ORSEE. Journal of the Economic Science Association, 1(1): 114-125.

Greiner, L. (2013). Sozialerhebung: So leben Deutschlands Studenten. Spiegel Online, URL: http://www.spiegel.de/unispiegel/studium/sozialerhebung-so-leben-lieben -undarbeiten-studenten-a-907871.html, Accessed: 2015-07-28.

Gründler, K., and Köllner, S. (2017). Determinants of governmental redistribution: Income distribution, development levels, and the role of perceptions. Journal of Comparative Economics, 45(4): 930-962.

Guillaud, E., Olckers, M., and Zemmour, M. (2017). Four levers of redistribution: The impact of tax and transfer systems on inequality reduction. LIS working paper series (695).

Hagelüken, A. (2017). Deutschland ist so ungleich wie vor 100 Jahren. Süddeutsche Zeitung, URL: https://www.sueddeutsche.de/wirtschaft/einkommensverteilungdeutschland-ist-so-ungleich-wie-vor-jahren-1.3791457, Accessed: 2018-08-02.

Hensher, D. A., and Greene, W. H. (2001). The mixed logit model: The state of practice and warnings for the unwary. Institute of Transport Studies.

Hinz, P. (2010). Soziale Kosten: Süchtige kosten die Gesellschaft 60 Milliarden Euro. Frankfurter Allgemeine Zeitung, URL: http://www.faz.net/aktuell/wirtschaft/ wirtschaftspolitik/soziale-kosten-suechtige-kosten-die-gesellschaft-60-milliarden-euro11039184.html, Accessed: 2018-04-04.

Hoffman, E., McCabe, K., and Smith, V. L. (1996). Social distance and other-regarding behavior in dictator games. American Economic Review, 86(3): 653-660.

Hole, A. R. (2007). Estimating mixed logit models using maximum simulated likelihood. The Stata Journal, 7(3): 388-401.

Inglehart, R., C. Haerpfer, A. Moreno, C. Welzel, K. Kizilova, J. Diez-Medrano, M. Lagos, P. Norris, E. Ponarin, and B. Puranen et al. (eds.) (2012). 2010-2012 World Values Survey. URL: http://www.worldvaluessurvey.org/WVSDocumentation WV6.jsp, Accessed: 2018-06-25.

International Labour Organization (ILO) (2012). Social protection floors recommendation. URL:http://www.social--protection.org/gimi/gess/Ressource PDF.do?ressource.ressource Id=31088, Accessed: 2016-05-18.

Iriberri, N., and Rey-Biel, P. (2011). The role of role uncertainty in modified dictator games. Experimental Economics, 14(2): 160-180.

Jann, B. (2008). The Blinder-Oaxaca decomposition for linear regression models. The Stata Journal, 8(4): 453-479.

Jiang, T., Potters, J., and Funaki, Y. (2016). Eye-tracking social preferences. Journal of Behavioral Decision Making, 29 (2-3): 157-168.

Jost, J. T. (2006). The end of the end of ideology. American Psychologist, 61(7): 651-670.

Jost, J. T., Banaji, M. R., and Nosek, B. A. (2004). A decade of system justification theory: Accumulated evidence of conscious and unconscious bolstering of the status quo. Political Psychology, 25(6): 881-919.

Jung, M., Smeets, P., Stoop, J., and Vosgerau, J. (2018). Does money make you bad? Five replications of Piff et al.'s (2012) traffic-law violation field studies. Unpublished 
manuscript.

Kivikangas, J. M., Lönnqvist, J. E., and Ravaja, N. (2017). Relationship of moral foundations to political liberalism-conservatism and left-right orientation in a Finnish representative sample. Social Psychology, 48: 246-251.

Konow, J. (2000). Fair shares: Accountability and cognitive dissonance in allocation decisions. American Economic Review, 90(4): 1072-1091.

Konow, J. (2001). Fair and square: The four sides of distributive justice. Journal of Economic Behavior \& Organization, 46(2): 137-164.

Konow, J. (2010). Mixed feelings: Theories of and evidence on giving. Journal of Public Economics, 94(3): 279-297.

Korndörfer, M., Egloff, B., and Schmukle, S. C. (2015). A large scale test of the effect of social class on prosocial behavior. PloS ONE, 10(7): e0133193.

Küppers, C. (2018). ARD-Doku „Ungleichland“: Zerstören Super-Reiche unsere Gesellschaft? Bild, URL: https://www.bild.de/geld/wirtschaft/reich/reiche-und maechtige-doku-55629862.bild.html, Accessed: 2018-08-11.

Van Lanschot (2015). Vermogen Nederland: Dutch Wealth Report 2015. https://media.vanlanschot.nl/media/pdfs/Vermogend-Nederland-2015.pdf, Accessed: 2017-09-05.

Lee-Ross, D. (2015). Personality characteristics of the self-employed: A comparison using the World Values Survey data set. Journal of Management Development, 34(9): 10941112.

van Leeuwen, F., and Park, J. H. (2009). Perceptions of social dangers, moral foundations, and political orientation. Personality and Individual Differences, 47(3): 169-173.

List, J. A. (2011). The market for charitable giving. Journal of Economic Perspectives, 25(2): $157-180$.

Marinić, J. (2018). Es stinkt mir, wie derzeit verteilt wird. Die Tageszeitung, URL: http://www.taz.de/!5501474/, Accessed: 2018-7-05.

Mayeda, A. (2017). Raising taxes on the rich won't necessarily curb growth, IMF says. Bloomberg, URL: https://www.bloomberg.com/news/articles/2017-10-11/raising-taxeson-rich-won-t-necessarily-curb-growth-imf-says, Accessed: 2017-11-13.

McFadden, D. (1974). Conditional logit analysis of qualitative choice behavior. In P. Zarembka (Ed.), Frontiers in Econometrics, New York: Academic Press: 105-142.

Miller, D. (1999). Principles of social justice. Cambridge: Harvard University Press.

Mueller, A. (2012). In the public eye: Norms of distributive justice and sharing behavior under asymmetric information: Evidence from rural Malawi. Job Market Paper, Harvard University.

Niehues, J. (2018). Ungleichheit und Umverteilung in Europa. Institut der Deutschen Wirtschaft, URL: https://www.iwkoeln.de/presse/interaktive-grafiken/beitrag/judith niehues-ungleichheit-und-umverteilung-in-europa.html, Accessed: 2018-08-06.

Nilsson, A., and Erlandsson, A. (2015). The Moral Foundations taxonomy: Structural validity and relation to political ideology in Sweden. Personality and Individual Differences, 76: 28-32.

Norton, M. I., and Ariely, D. (2011). Building a better America: One wealth quintile at a time. Perspectives on Psychological Science, 6(1): 9-12. 
Oaxaca, R. (1973). Male-female wage differentials in urban labor markets. International Economic Review, 14(3): 693-709.

OECD (2008). Growing unequal? Income distribution and poverty in OECD countries. OECD Publishing, Paris, URL: https://doi.org/10.1787/9789264044197-en, Accessed: 2018-08-09.

OECD (2011). Divided we stand: Why inequality keeps rising. OECD Publishing, Paris, URL: http://dx.doi.org/10.1787/9789264119536-en, Accessed: 2018-08-09.

OECD (2013). OECD framework for statistics on the distribution of household income, consumption and wealth. URL: www.oecd.org/statisties/302013041e.pdf, Accessed: 2016-05-25.

OECD (2015). In it together: Why less inequality benefits all. OECD Publishing, Paris, URL: http://dx.doi.org/10.1787/9789264235120-en, Accessed: 2018-08-09.

OECD (2018a). Dataset: Income distribution and poverty (US). URL: https://stats.oecd.org/index.aspx?queryid=66670\#, Accessed: 2018-09-07.

OECD (2018b). Dataset: Social Expenditure: Aggregated data. URL: https://stats.oecd. org/Index.aspx?DataSetCode=SOCX_AGG\#, Accessed: 2018-06-04.

OECD (2018c). OECD tax policy studies: The role and design of net wealth taxes in the OECD: Summary. URL: http://www.oecd.org/tax/tax-policy/role-and-design-of-netwealth-taxes-in-the-OECD-summary.pdf, Accessed: 2018-06-06.

Okun, A. M. (1975). Equality and efficiency: The big tradeoff. Washington, D.C.: The Brookings Institution.

Piff, P. K., Kraus, M. W., Côté, S., Cheng, B. H., and Keltner, D. (2010). Having less, giving more: The influence of social class on prosocial behavior. Journal of Personality and Social Psychology, 99(5): 771-784.

Piketty, T. (1995). Social mobility and redistributive politics. Quarterly Journal of Economics, 110(3): 551-584.

Piketty, T. (2014). Capital in the twenty-first century. Cambridge Massachusetts: The Belknap Press of Harvard University Press.

Piketty, T., and Saez, E. (2003). Income inequality in the United States, 1913-1998. Quarterly Journal of Economics, 118(1): 1-41.

Piketty, T., and Saez, E. (2013). A theory of optimal inheritance taxation. Econometrica, 81(5): 1851-1886.

Rawls, J. (1971). A theory of justice. Cambridge: Harvard University Press.

Rosset, J., Giger, N., and Bernauer, J. (2013). More money, fewer problems? Cross-level effects of economic deprivation on political representation. West European Politics, 36(4): 817-835.

Ruffle, B. J. (1998). More is better, but fair is fair: Tipping in dictator and ultimatum games. Games and Economic Behavior, 23(2): 247-265.

Saez, E., and Stantcheva, S. (2016). Generalized social marginal welfare weights for optimal tax theory. American Economic Review, 106(1): 24-45.

Saez, E., and Zucman, G. (2016). Wealth inequality in the United States since 1913: Evidence from capitalized income tax data. Quarterly Journal of Economics, 131(2): 519-578.

Sajaia, Z. (2007). FASTGINI: Stata module to calculate Gini coefficient with jackknife 
standard errors. Statistical Software Components S456814, Boston College, Department of Economics.

Schildberg-Hörisch, H. (2010). Is the veil of ignorance only a concept about risk? An experiment. Journal of Public Economics, 94(11): 1062-1066.

Schwettmann, L. (2012). Competing allocation principles: Time for compromise? Theory and Decision, 73(3): 357-380.

Shue, H. (1996). Basic rights: Subsistence, affluence, and US foreign policy. Princeton: Princeton University Press.

Siebel, M. (2017). To each according to his needs: Measuring need-based justice. FOR 2104 Working Paper (2017-14).

Smeets, P., Bauer, R., and Gneezy, U. (2015). Giving behavior of millionaires. Proceedings of the National Academy of Sciences, 112 (34): 10641-10644.

Smeets, P., Norton, M., Whillans, A. and Bekkers, R. (2018). Time use and happiness of millionaires. Unpublished manuscript.

Smith, A. (1976). The wealth of nations. R.H. Campbell and A.S. Skinner and W.B. Todd (eds.): Oxford: Clarendon Press.

Smith, V. L. (1976). Experimental economics: Induced value theory. American Economic Review, 66(2): 274-279.

Sozialgesetzbuch (SGB) Zwölftes Buch (XII): Sozialhilfe (2003). URL: https://www.gesetze- im-internet.de/sgb_12/SGB_12.pdf, Accessed: 2018-08-13.

Statistisches Bundesamt (2012a). Wirtschaftsrechnungen: Einkommens- und Verbrauchsstichprobe: Einkommensverteilung in Deutschland 2008. Fachserie 15, Heft 6.

Statistisches Bundesamt (2012b). Wirtschaftsrechnungen: Leben in Europa (EU-SILC): Einkommen und Lebensbedingungen in Deutschland und der Europäischen Union 2010. Fachserie 15, Reihe 3.

Steffen, T. (2017). SPD plant Reichensteuer ab 250.000 Euro. Zeit Online, URL: http://www.zeit.de/politik/deutschland/2017-06/wahlprogramm-spd-reichensteuermartin-schulz, Accessed: 2017-11-13.

Stellinga, M., de Koning, P. (2017). De ongelijkheid in Nederland is en 25 jaar gegroeid. NRC Handelsblad, URL: https://www.nrc.nl/nieuws/2017/12/11/zorgen -over-wie-nietkan-meedoen-a1584583, Accessed: 2018-08-02.

Stewart Jr., W. H., and Roth, P. L. (2001). Risk propensity differences between entrepreneurs and managers: A meta-analytic review. Journal of Applied Psychology, 86(1): $145-153$.

Train, K. E. (2009). Discrete choice methods with simulation. New York: Cambridge University Press.

Traub, S., Bauer, A. M., Springhorn, N., Siebel, M., and Weiß, A. R. (2017). On the measurement of need-based justice. FOR 2104 Working Paper (2017-12).

van Uffelen, X. (2014). Een akkoord over vermogensbelasting moet niet ingewikkeld zijn. De Volkskrant, URL: https://www.volkskrant.nl/opinie/een-akkoord -oververmogensbelasting-moet-niet-ingewikkeld-zijn a3782747/, Accessed: 2017-11-13.

UNICEF Georgia and University of York (2010). How do Georgian children and their families cope with the impact of the financial crisis? URL: 
http://www.unicef.org/socialpolicy/files/Georgian_Families_and_Their_Children_Cope _w_Financial_Crisis.pdf, Accessed: 2014-12-01.

United Nations (2014). Population median age (years). URL: http://data.un.org/Data.aspx?q=age\&d=WHO\&f=MEASURE_CODE\%3aWHS9_88, Accessed: 2016-07-21.

Universität zu Köln (2016). 2014/2015 Zahlen | Daten | Fakten. URL: http://verwaltung.uni-koeln.de/stabsstelle01/content/e64074/e131765/ZDF_2014 _2015_V3.pdf, Accessed: 2016-03-22.

Washington Post (2013). Full transcript: President Obama's December 4 remarks on the economy. URL: https://www.washingtonpost.com/politics/running-transcript president-obamas-december-4-remarks-on-the-economy/2013/12/04/7cec31ba-5cff11e3-be07-006c776266ed_story.html?noredirect=on\&utm_term=.89547e1b93ec, Accessed: 2018-08-09.

Weiss, A. R., Bauer, A. M., and Traub, S. (2017). Needs as reference points: When marginal gains to the poor do not matter. Unpublished working paper.

Werner, G.W. (2018). Einkommen für alle: Bedingungsloses Grundeinkommen: Die Zeit ist reif. Köln: Kiepenheuer and Witsch.

Worldbank (2016). Education statistics: Core indicators. URL: http://databank.worldbank.org/data/reports.aspx?source=Education-Statistics:-coreindicators\&preview=off\#, Accessed: 2016-06-28.

Zeit Online (2015). Was kostet mein Studium? URL: http://ranking.zeit.de/lebenshaltungskosten/\#!/compare, Accessed: 2015-07-28. 



\section{Valorization addendum}

In Chapter II-IV, I showed that concerns for basic needs satisfaction are an important consideration in the distribution of incomes across different incentive structures and subject pools. By disentangling the motive from other established motives related to caring about the incomes of relatively poorer people in a society - maximin and generosity - I have established concerns for basic needs satisfaction as a distinct distributional motive. I further showed that subjects are willing to sacrifice some of their own income, efficiency, and utility in terms of envy in order to satisfy additional basic needs.

In Chapter II, I showed that in choices in which concerns for basic needs satisfaction and maximin predict the same allocation, basic needs satisfaction is another important driver next to maximin. This suggests that the prevalence of maximin would be overestimated if basic needs satisfaction was ignored as a behavioral motive. Results of Chapter III revealed that subjects (also) care - as proposed in the theoretical formulation of the motive in Chapter II - for the sum of unfulfilled needs. Finally, a heterogeneity analysis revealed that women care more strongly for the fulfillment of basic needs, while there is no relation of the motive to age or income. Chapter IV indicated that under a minimal strategic incentive to ensure the survival of the receiver in the game, the prevalence of behavior in line with concerns for basic needs satisfaction increases substantially and even otherwise selfish subjects satisfy the receiver's needs. Additional analyses suggest that the salience of group survival might have triggered dictators' desire to fulfill receivers' needs which is consistent with the notion that human beings are predisposed to act in accordance with the motive in situations in which it is evolutionarily important.

My findings of Chapter II to IV of this thesis can be useful both for academic purposes as well as for public policy. With respect to academia, my results can inform a normative theory of needs-based justice. The formulation of such a theory that is informed by research on individual distributional motives is, for example, aspired by the DFG research group "FOR2104: Needs-based justice and distributional procedures". ${ }^{177}$ For public policy, the knowledge about people's concerns for the fulfillment of basic needs as opposed to other distributional motives related to caring about poorer persons in society can be informative for the design and acceptance of social security systems. As elaborated on in Chapter VI, in discussions about the optimal design of redistributive policies, people with different motives for redistribution are likely not only to hold different positions, but also to discuss about different things. Understanding people's distributional motivations can thus help to structure the political debate and inform policy makers about the optimal design of redistributive policies, especially those targeted at the poorest members of society, and by this help create acceptance of these policies.

It should, however, be kept in mind that it is not advisable to directly apply my findings to public policy. Before this can be done, much more research on the motive of

177 Original title in German „Bedarfsgerechtigkeit und Verteilungsprozeduren“. 
basic needs satisfaction is necessary. This includes, for example, the question whether the application of the motive is unconditional or depends on the recipients characteristics such as individual responsibility, or on characteristics of the preference holder such as her gender, age, and income (as examined in Chapter III), or her cultural background, the (subjective) probability of becoming a recipient herself, and the features of the social security system in the country she lives in. As becomes clear, the findings of this thesis are just a first step towards understanding the importance of basic needs satisfaction as an individual concern for the distribution of incomes in a society.

In Chapter V, I showed that differences in the importance of hard work for success in life between the wealthy and people from the general population partly explains differences in attitudes towards redistribution. Millionaires believe that hard work is crucial for determining earnings and are therefore less willing to redistribute those earnings. These findings are important for academia, since they show that it is crucial to investigate (re-)distributional attitudes, preferences, and beliefs of those groups in society with a disproportionate policy impact, as they might differ from those of the general population. Scholars should thus consider these groups regularly as subjects for their empirical research. With respect to the relevance for public policy, especially for state redistribution, knowledge about what drives support for redistribution of the wealthy is indispensable. If policy makers want to fight rising inequality by increasing state redistribution from the rich to the poor, they can tackle the beliefs of the wealthy about what drives inequalities in society. Provided that the rich assign too much responsibility to individual effort, one way of increasing their willingness to redistribute is to raise awareness that differences in earnings are to a large part determined by luck. One possibility could be, for example, to provide them with information about actual social mobility or equality of opportunities in their society. This could increment their support for redistribution as expressed, for example, in increased tax honesty. If the low importance attached to luck is - as suggested by my results - driven by a desire to develop a narrative in order to maintain a positive self-image, millionaires might, however, be reluctant to give up this belief. Correcting possibly false beliefs that lead to certain revealed preferences is further ethically less problematic than directly intervening in people's preferences and trying to manipulate their likes and dislikes.

In the current times of digitalization and automatization, wealth is created by a decreasing number of people, as an increasing number of jobs and operations can be carried out by machines. In light of this, mechanisms to redistribute this wealth especially in order to ensure basic necessities - become more important. As a result, knowledge on people's (re-)distributive fairness concerns gains increasing significance in order to design redistributive policies that are viewed as fair and thereby promote social cohesion. 


\section{Curriculum Vitae}

Frauke obtained her bachelors degree in Economics at the University of Cologne in 2011, and her masters degree in International Economic Studies at Maastricht University in 2012, cum laude. She joined the Research Centre for Education and the Labour Market (ROA) at Maastricht University in September 2012 to start her $\mathrm{PhD}$ project on distributional motives. In 2015 she visited the University of California San Diego for a four month research stay. Since June 2018 Frauke works at the Institute for Philosophy at the University of Oldenburg. Frauke's research focuses on behavioral economics, needbased justice, moral decision making, (re-)distributive fairness attitudes, and individual reasoning processes. 



\section{ROA Dissertation Series}

1. Lex Borghans (1993), Educational Choice and Labour Market Information, Maastricht, Research Centre for Education and the Labour Market.

2. Frank Cörvers (1999), The Impact of Human Capital on International Competitiveness and Trade Performance of Manufacturing Sectors, Maastricht, Research Centre for Education and the Labour Market.

3. Ben Kriechel (2003), Heterogeneity Among Displaced Workers, Maastricht, Research Centre for Education and the Labour Market.

4. Arnaud Dupuy (2004), Assignment and Substitution in the Labour Market, Maastricht, Research Centre for Education and the Labour Market.

5. Wendy Smits (2005), The Quality of Apprenticeship Training, Conflicting Interests of Firms and Apprentices, Maastricht, Research Centre for Education and the Labour Market.

6. Judith Semeijn (2005), Academic Competences and Labour Market Entry: Studies Among Dutch Graduates, Maastricht, Research Centre for Education and the Labour Market.

7. Jasper van Loo (2005), Training, Labor Market Outcomes and Self-Management, Maastricht, Research Centre for Education and the Labour Market.

8. Christoph Meng (2005), Discipline-Specific or Academic? Acquisition, Role and Value of Higher Education Competencies, Maastricht, Research Centre for Education and the Labour Market.

9. Andreas Ammermüller (2007), Institutional Effects in the Production of Education: Evidence from European Schooling Systems, Maastricht, Research Centre for Education and the Labour Market.

10. Bart Golsteyn (2007), The Ability to Invest in Human Capital, Maastricht, Research Centre for Education and the Labour Market.

11. Raymond Montizaan (2010), Pension Rights, human capital development and wellbeing, Maastricht, Research Centre for Education and the Labour Market.

12. Annemarie Nelen (2012), Part-Time Employment and Human Capital Development, Maastricht, Research Centre for Education and the Labour Market.

13. Jan Sauermann (2013), Human Capital, Incentives, and Performance Out- comes, Maastricht, Research Centre for Education and the Labour Market

14. Harald Ulrich Pfeifer (2013), Empirical Investigations of Costs and Benefits of Vocational Education and Training, Maastricht, Research Centre for Education and the Labour Market.

15. Charlotte Büchner (2013), Social Background, Educational Attainment and Labor Market Integration: An Exploration of Underlying Processes and Dynamics, Maastricht, Research Centre for Education and the Labour Market.

16. Martin Humburg (2014), Skills and the Employability of University Graduates, Maastricht, Research Centre for Education and the Labour Market.

17. Jan Feld (2014), Making the Invisible Visible, Essays on Overconfidence, Discrimination and Peer Effects, Maastricht, Research Centre for Education and the 
Labour Market.

18. Olga Skriabikova (2014), Preferences, Institutions, and Economic Outcomes: an Empirical Investigation, Maastricht, Research Centre for Education and the Labour Market.

19. Gabriele Marconi (2015), Higher Education in the National and Global Economy, Maastricht, Research Centre for Education and the Labour Market.

20. Nicolas Salamanca Acosta (2015), Economic Preferences and Financial Risk-Taking, Maastricht, Research Centre for Education and the Labour Market.

21. Ahmed Elsayed Mohamed (2015), Essays on Working Hours, Maastricht, Research Centre for Education and the Labour Market.

22. Roxanne Amanda Korthals (2015), Tracking Students in Secondary Education, Consequences for Student Performance and Inequality, Maastricht, Research Centre for Education and the Labour Market.

23. Maria Zumbuehl (2015), Economic Preferences and Attitudes: Origins, Behavioral Impact, Stability and Measurement, Maastricht, Research Centre for Education and the Labour Market.

24. Anika Jansen (2016), Firms' incentives to provide apprenticeships - Studies on expected short- and long-term benefits, Maastricht, Research Centre for Education and the Labour Market.

25. Jos Maarten Arnold Frank Sanders (2016), Sustaining the employability of the low skilled worker: Development, mobility and work redesign, Maastricht, Research Centre for Education and the Labour Market.

26. Marion Collewet (2017), Working hours: preferences, well-being and productivity, Maastricht, Research Centre for Education and the Labour Market.

27. Tom Stolp (2018), Sorting in the Labor Market: The Role of Risk Preference and Stress, Maastricht, Research Centre for Education and the Labour Market.

28. Frauke Meyer (2019), Individual motives for (re-)distribution, Research Centre for Education and the Labour Market. 